\title{
Hidatidosis Hepática
}

RELATO OFICIAL

\section{$62^{\circ}$ CONGRESO URUGUAYO DE CIRUGÍA}

\section{Dr. Daniel González González}

Profesor Adjunto de Clínica Quirúrgica.

Clínica Quirúrgica 3. Hospital Maciel.

\section{Dr. Eduardo Olivera Pertusso}

Profesor Adjunto de Clínica Quirúrgica.

Clínica Quirúrgica 3. Hospital Maciel.

Profesor Agregado del Departamento de Anatomía.

Facultad de Medicina. Universidad de la República. 
Sociedad de Cirugía del Uruguay

Noviembre, 2011

Impreso en Montevideo-Uruguay

Pimesol S.A. Deposito Legal 357167

Montevideo Noviembre de 2011 


\section{Dedicatoria:}

A Carmen, Florencia y Santiago quienes con su apoyo permanente e incondicional han sabido comprender las horas restadas a la vida en común. A quienes con sus esfuerzos cotidianos hicieron posible mi formación, Hugo, Blanca y Ema.

A mis maestros de la Cirugía, Doctores Oscar Balboa, Martín Harretche, Luis Ruso y Gustavo Rodríguez.

Daniel

A mi madre por su incansable esfuerzo.

A Cecilia y Magui por su amor y por apoyarme en cada momento a pesar del tiempo que siempre les estoy debiendo.

A mi abuelo y tíos, cuyo ejemplo de vida me guiaron a este camino. A mis Profesores y amigos de la Cirugía por todo lo que han contribuido en mi formación.

Eduardo

\section{Agradecimientos}

Agradecemos a las autoridades del 62ํㅡㄹ Congreso Uruguayo de Cirugía, especialmente a su Presidente, Dr. Luis Ruso por habernos conferido el honor y responsabilidad de elaborar este Relato Oficial.

Al Doctores Oscar Balboa y Gustavo Rodríguez, quienes nos guiaron y analizaron críticamente este Relato.

A los Doctores Raúl Praderi y Fernando Mañe Garzón, por sus consejos y aporte de valioso material bibliográfico.

A las Licenciadas Cecilia Valenzuela y Beatriz Moreira por la corrección y búsqueda bibliográfica.

A los Doctores Elbio Gezuele y Ana Cuña, integrantes de la Cátedra de Parasitología, por la corrección de los capítulos vinculados a su especialidad y el aporte de valioso material.

AI Dr. Carlos Viscardi por su aporte de experiencia en screening ecográfico y material iconográfico.

Al Sr. Eduardo Miranda, dibujante.

A todos los colegas que en forma desinteresada han aportado al Relato. 


\section{HIDATIDOSIS HEPÁTICA}

\section{INTRODUCIÓN}

Me han solicitado que presente este trabajo, lo cual representa un honor y una responsabilidad. Dicha designación responde a la amistad y al cariño que me vincula al grupo humano responsable de su ejecución.

En toda actividad y en especial en la académica, la trasmisión y creación de conocimiento es un proceso que se va elaborando con la interacción de sus diferentes integrantes que aportan al crisol fermental del grupo, sus opiniones y experiencias, con lo cual vamos generando una verdad, que en la mayoría de los casos es transitoria, durando hasta que del crisol surja una nueva.

Esta dinámica excluye el individualismo, cada uno, aislado difícilmente obtiene grandes logros. Lo que yo soy capaz de trasmitir es la experiencia de un grupo humano que entre muchos otros temas se ha enfrentado al de la Hidatidosis Hepática, haciendo énfasis en lo que creo ha sido relevante.

Ésta historia, mi historia, es la de la Clínica Quirúrgica «F» en la que ingresé en 1965 como interno del profesor $\mathrm{H}$.Ardao,el cual a su vez era heredero de una tradición que nos lleva hasta el prof. Dr. A.Navarro. El profesor L.Praderi, lo sucede y es allí donde el profesor L.Ruso fue grado II al que luego encuentro en el Hospital Maciel, en la que fué Profesor, Raúl Praderi eminente cirujano hepato-bilio-pancreático que ha hecho importantes aportes al crisol. Es allí donde me designan Profesor Director de Clínica Quirúrgica, cargo que ocupa actualmente el Prof Luis Ruso

En esta escuela se van elaborando «verdades». De alguna manera debemos creer que esta «Puesta al Día» trasmite conocimientos y experiencias que se han ido desarrollando con el aporte invalorable de los más jóvenes que buscan caminos nuevos.

La Hidatidología en nuestro país es analizada profundamente en el capítulo de historia .Una de las figuras fundamentales es el Dr. Velarde Pérez Fontana al que conocí en 1960, en el Hospital Maciel, siendo Practicante Externo. Personalidad singular, rodeada de un rico anecdotario, fundó en 1934 los Archivos Internacionales de la Hidatidosis y en 1941 es miembro fundador de la Asociación Internacional de Hidatidología. Fue vicepresidente e importante promotor del Primer Congreso Mundial de Hidatidología que se desarrolló en Argel en 1951 y en especial del homenaje realizado al Profesor Felix Dévé, que invitado a Buenos Aires en1932 dió conferencias en Montevideo.

F. Dévé, que no era cirujano, R. Bourgeon, que concurrió al XXXVI Congreso Uruguayo de Cirugía y otros autores franceses, eran los nombres que siempre estaban presentes cuando se planteaban soluciones a problemas quirúrgicos. La pregunta que nos hacíamos era ¿Cómo, con la alta incidencia que la hidatidosis tiene en nuestro país, nosotros no aportamos nada? 
Aquí debemos mencionar al Profesor Dr. Roberto Perdomo, cirujano que claramente se identificaba por pensar la cirugía más allá de la técnica quirúrgica. Por esa época la quistostomía con resección de la adventicia emergente era la técnica más utilizada, pero frecuentemente se acompañaba de bilirragias persistentes. Surgió allí la problemática de los canalículos que quedaban abiertos y su solución por intermedio de su cateterización y la publicación del trabajo Coledocostomía transhepatoquística, que tuvo impacto en la literatura médica ${ }^{3}$.

Es también el Dr. R.Perdomo ${ }^{4}$, el que encabeza un equipo que promovió las salidas al interior del país para los estudios ecográficos de la población realizando más de 10.000 estudios, actividad en la que ha proseguido el Dr. Ciro Ferreira.

En este camino surge el trabajo del Dr. Carmelo Alvarez ${ }^{1}$ sobre el análisis de la fertilidad de los escólices que culmina en una Tesis.

En el ámbito de la técnica quirúrgica, se puede decir que nací, en la cirugía, con el libro de Larghero, Venturini y Broli ${ }^{2}$ bajo el brazo. Equinococosis Hidática del Abdomen se edito en 1962 y era la referencia obligada. En el capítulo de tratamiento quirúrgico, página 48, hay un esquema de las vías de abordaje, que en relación a la topografía, era prudente realizar. En esa época el hígado estaba fijo, no se movilizaba.

En 1973, presencié a J. L. Lortat Jacob realizar una hepatectomía derecha y para mí comenzó un cambio en la cirugía hepática, que se acentuó con todo el conocimiento que aportó la cirugía del transplante hepático. El hígado se movía completamente y hasta se podía realizar cirugía "ex vivo». Esto cambió radicalmente el manejo del órgano, eliminando muchas de las discusiones vinculadas a la vía de abordaje.

La aplicación clínica del conocimiento de la segmentación hepática, los clampeos vasculares selectivos, la nueva tecnología fueron aporatando elementos para realizar la cirugía hepática con más seguridad. En el caso de la hidatidosis, recordar siempre, que estamos operando una enfermedad benigna y que la cirugìa que realizamos debe apuntar a cero de mortalidad. No seducirnos con una técnica si ella no es segura para el paciente.

Por último,creo que la cirugía laparoscópica tendrá un lugar cada vez más importante en el armamentario quirúrgico. No se discuten los beneficios de los abordajes minimamente invasivos. La hemos utilizado en la resección de tumores y hapatectomías de segmentos o atípicas, pero no hemos tenido oportunidad de usarla en los casos comunes de hidatidosis.

\section{Referencias bibliográficas.}

1. Alvarez C, Perdomo R. Implicancias terapéuticas de la fertilidad del quiste hidático en las distrintas etapas evolutivas de la hidatidosis humana. Cir Uruguay. 1994;64:231.

2. Larghero P, Venturino W, Broli G. Equinococosis hidática del abdomen. Montevideo Delta. 1962.

3. Perdomo R, Morelli R, Carriquiry L, Chifflet J, Bergalli L. Cholédocostomie trans-hépatico kystique en cas de kyste hydatique ouvert dans les voies biliaires. Nouv Presse Med. 1977;6(9):747-49.

4. Perdomo R, Parada P, Alvarez C, Cattivelli D, Geninazzi H, Barragué AD, et al. Estudio epidemiológico de la hidatidosis. Detección precoz por ultrasonido en áreas de alto riesgo. Rev Med Uruguay. 1990;6:34-47.

5. Turnes A. La Hidatidosis como problema de salud pública. Una mirada histórica. Montevideo: Tradinco. 2009. 


\section{HIDATIDOSIS HEPÁTICA}

RELATO OFICIAL

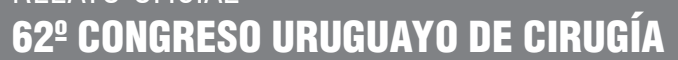

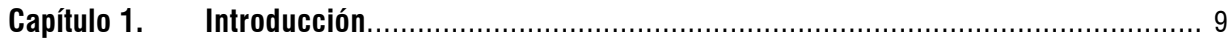

Capítulo 2. Historia de la hidatidosis y su lucha en Uruguay......................................... 13

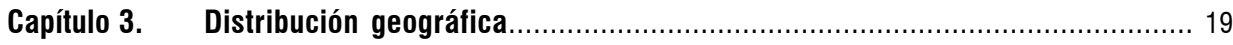

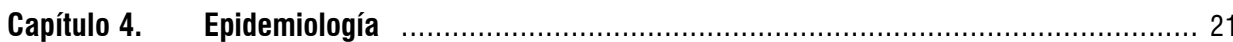

1. Prevalencia.

1.1 Prevalencia en humanos.

1.1.1 Uruguay.

1.1.1.1 Reportes clínicos.

1.1.1.2 Estudios imagenológicos.

1.1.1.3 Estudios inmunológicos.

1.1.2 América.

1.2 Prevalencia en perros.

1.3 Prevalencia en hospederos intermediarios.

2. Edad y sexo.

3. Topografía.

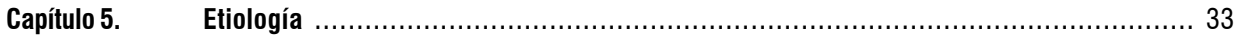

1. Helmintos.

1.1. Cestodos.

1.1.1 Género Echinococcus.

1.1.1.1 Echinococcus granulosus.

2. Ciclo evolutivo.

3. Anatomía patológica.

4. Fertilidad del quiste hidático en humanos.

Capítulo 6. Presentación clínica

1. Forma inaparente 0 asintomática (período de incubación).

2. Forma sintomática (período de estado y período de complicaciones).

Capítulo 7. Inmunodiagnóstico

Capítulo 8. Diagnóstico imagenológico

$1 . \quad$ Radiografía simple.

2. Radiografía contrastada.

3. Ecografía.

4. Tomografía computada.

5. Resonancia nuclear magnética.

6. Colangiopancreatografía endoscópica retrógrada.

Capítulo 9. Tratamiento médico

Capítulo 10. Tratamiento quirúrgico

1. Generalidades.

2. Principios básicos de la cirugía hidatídica.

2.1 Posición del paciente.

2.2 Incisión. 


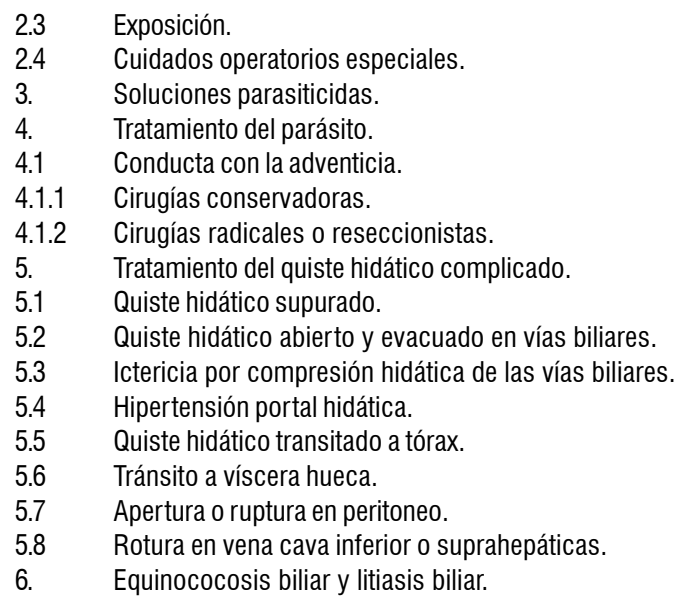

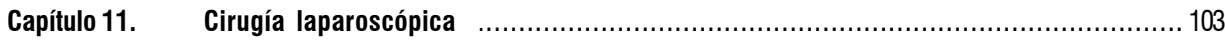

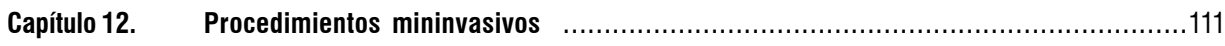

1. Punción, aspiración, inyección y reaspiración (PAIR).

2. Radiofrecuencia.

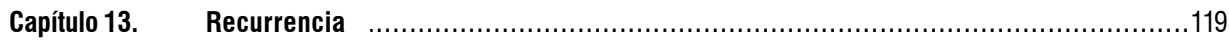

Capítulo 14. Repercusión social y económica de la enfermedad ............................................. 123

1. Impacto económico.

2. Impacto social.

3. Mortalidad

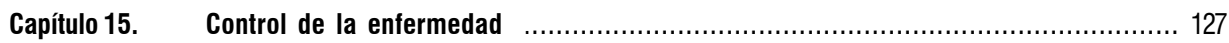

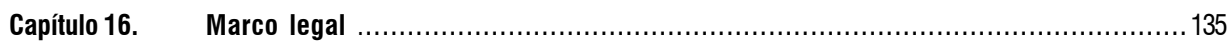




\section{CAPÍTULO 1}

\section{Introducción}

La República Oriental del Uruguay es un país ubicado en el cono sur de América, a 35 grados latitud sur y 55 grados longitud oeste. Limita al norte y noreste con la República Federativa del Brasil con la que posee una frontera terrestre de 800 kilómetros; al oeste con la República Argentina, separado por el Río Uruguay y por último al sur y este con el Río de la Plata y Océano Atlántico. Posee una superficie de $176.215 \mathrm{~km} 2$ y una población de 3.368 .595 habitantes según proyecciones del Instituto Nacional de Estadísticas para el año $2011^{1}$. De éstos, $3.171 .273(94,15 \%)$ viven en zonas urbanas y tan solo $197.322(5,85 \%)$ en áreas rurales ${ }^{2,3}$.

Su temperatura media anual es de 17,5 ㅇ $\mathrm{C}$, con una humedad relativa media anual que oscila entre 70 y $75 \%{ }^{4}$.

La actividad económica se ha sustentado en la producción agropecuaria y en especial la ganadera, aunque en las últimas décadas el peso de otros sectores de la economía se ha incrementado considerablemente. Los principales productos de exportación son la carne, lana y cuero, siendo la producción alimenticia su principal industria.

Según el Censo Agropecuario 2000, Uruguay posee el mayor porcentaje de su superficie dedicado a la ganadería (Tabla1), a pesar de la reducción de 9,9\% de las hectáreas dedicadas a dicha actividad en relación al censo $1990^{5}$ (Tabla 2) (Figura 1).

Las especies ganaderas más importantes son los bovinos y ovinos, con una existencia al año 2004 de 11.749 .000 y 8.656 .000 animales respectivamente ${ }^{5}$.

Tabla 1. Regiones agropecuarias de Uruguay. Año agrícola
\begin{tabular}{c|c|}
$1999 / 2000$. \\
\hline Regiones agropecuarias & $\%$ sobre la superficie total del país \\
\hline Ganaderas & 61,8 \\
\hline Agrícolas & 14,3 \\
\hline Arroceras & 10,5 \\
\hline Forestales & 5,8 \\
\hline Lecheras & 4,5 \\
\hline Con agricultura intensiva & 3,1 \\
\hline
\end{tabular}

Tomado del Anuario Estadístico Agropecuario $2010^{(5)}$

Tabla 2. Superficie de las regiones agropecuarias en $1990-2000$. Variación porcentual entre censos.

\begin{tabular}{|c|c|c|c|c|c|}
\hline \multicolumn{3}{|c|}{1990} & \multicolumn{3}{c|}{2000} \\
\hline $\begin{array}{c}\text { Regiones } \\
\text { agropecuarias }\end{array}$ & $\begin{array}{c}\text { Miles de } \\
\text { ha }\end{array}$ & $\%$ & $\begin{array}{c}\text { Miles de } \\
\text { ha }\end{array}$ & $\%$ & $\begin{array}{c}\text { Variación } \\
(\%)\end{array}$ \\
\hline Ganaderas & 11.268 & 71,3 & 10.150 & 61,8 & $-9,9$ \\
\hline Agrícolas & 2.764 & 17,5 & 2.343 & 14,3 & $-15,2$ \\
\hline \hline Arroceras & 699 & 4,4 & 1.732 & 10,5 & 147,8 \\
\hline Lecheras & 466 & 2,9 & 741 & 4,5 & 59 \\
\hline \hline $\begin{array}{c}\text { Con } \\
\text { agricultura } \\
\text { intensiva }\end{array}$ & 514 & 3,3 & 505 & 3,1 & $-1,8$ \\
\hline Forestales & 93 & 0,6 & 949 & 5,8 & 916,9 \\
\hline
\end{tabular}

Tomado del Anuario Estadístico Agropecuario $2010^{(5)}$

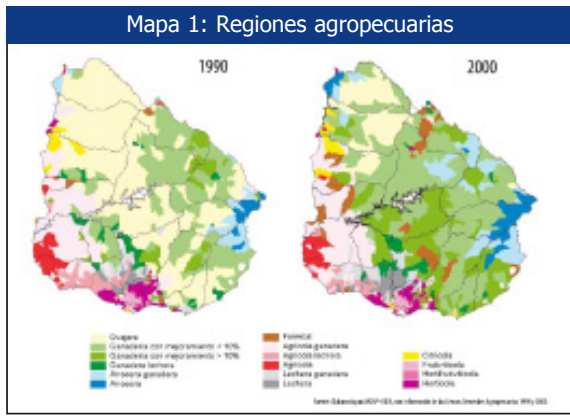

Figura 1.

Distribución de las regiones agropecuarias. Censos generales agropecuarios 1990-2000. (Tomado del Anuario Estadístico Agropecuario $\left.2010^{(5)}\right)$. 
INTRODUCCIÓN

Según cifras del año agrícola 2008-2009 existen en el país 51000 establecimientos dedicados a la ganadería ${ }^{5}$ (Tabla 3 ).

Tabla 3. Número de establecimientos de acuerdo al tipo de producción en Uruguay. Año agrícola $2008-2009$.

\begin{tabular}{|c|c|}
\hline Tipo de producción & Número de establecimientos \\
\hline Ganadera & 41.136 \\
\hline Agrícola y ganadera & 6.733 \\
\hline Lechera & 4.231 \\
\hline
\end{tabular}

La aproximación al conocimiento del número de perros - el principal huésped definitivo de la equinococosis hidatídica en nuestro país - se remonta a la década del 60 en que Purriel ${ }^{6}$ estimó una población de 700.000 animales, lo que representaba 1 cada 4 personas. Posteriormente Perdomo ${ }^{7}$ en 1990 sobre un total de 6027 entrevistas realizadas a personas de poblaciones de alto riesgo para la enfermedad, determinó que el 55\% poseía por lo menos un perro.

Sin embargo es en el año 2009 cuando se publicó una encuesta nacional realizada por la empresa Equipos Consultores, en la que sobre una muestra representativa del país se estimó una existencia de 1.130 .000 perros. De ellos, 640.000 (57\%) correspondieron al interior del país, en tanto 490.000 (43\%) a Montevideo. Es preciso destacar que en dicha estimación no se tuvo en cuenta los perros callejeros. En este sentido, $49 \%$ de las personas encuestadas refirieron percibir un mayor número de animales en la calle ${ }^{8}$.

Sobre la base de los aspectos señalados precedentemente, podemos decir que la confluencia de las características geográficas y climatológicas de nuestro país, la alta densidad demográfica de ovinos, así como de perros, junto a la ignorancia o irresponsabilidad del hombre, crean las condiciones adecuadas para el mantenimiento de la trasmisión cíclica del Echinococcus granulosus.

Schantz ${ }^{9}$ agrega que el hombre sustenta esta propagación al permitir, intencionalmente o por negligencia, que los perros domésticos se alimenten con las vísceras de ganado infectado, por lo que define la equinococosis hidatídica como una enfermedad "hecha por el hombre". En nuestro país Amorín ${ }^{10}$ califica esta conducta como delito ultraintencional.

Por lo tanto, esta enfermedad constituye un importante problema de Salud Pública, con graves repercusiones en la salud humana y animal, así como en la esfera socioeconómica, que afecta tanto a personas que habitan en zonas rurales, suburbanas y urbanas ${ }^{11}$.

Referencias bibliográficas.

1. Instituto Nacional de Estadística. Población total de ambos sexos proyectada según departamento de residencia habitual al 30 de junio de cada año. Período 1996 - 2025 [En línea]. Montevideo: INE. [Acceso 12 de junio de 2011]. URL: http://www.ine.gub.uy/socio-demograficos/proyecciones2008.asp\#total.

2. Instituto Nacional de Estadística. Población urbana de ambos sexos proyectada según departamento de residencia habitual al 30 de junio de cada año. Período 1996 - 2025 [En línea]. Montevideo: INE. [Acceso 12 de junio de 2011]. URL: http://www.ine.gub.uy/socio-demograficos/proyecciones2008.asp\#total

3. Instituto Nacional de Estadística. Población rural de ambos sexos proyectada según departamento de residencia habitual al 30 de junio de cada año. Período 1996 - 2025. [En línea]. Montevideo: INE. [Acceso 12 de junio de 2011]. URL: http://www.ine.gub.uy/socio-demograficos/proyecciones2008.asp\#total.

4. Dirección Nacional de Meteorología. Características climáticas [en línea]. Montevideo: Dirección Nacional de Meteorología. [Acceso 15 de junio de 2011]. URL: http://www.meteorologia.gub.uy/index.php/caracteristicas-climaticas.

5. Anuario Estadístico Agropecuario 2010. Estadísticas Agropecuarias. [En línea] Montevideo: Ministerio de Ganadería Agricultura y Pesca (Uruguay). [Acceso 24 de junio de 2011] .URL: http://www.mgap.gub.uy/ portal/hgxpp001.aspx?7,5,352,O,S,0,MNU;E;27;6;MNU;

6. Purriel P, Mendoza G, Decedo H. Hidatidosis en el Uruguay. Estudio epidemiológico (1962-1968). El Tórax. 1970;19(3):149-63. 
INTRODUCCIÓN

7. Perdomo R, Parada R, Alvarez C, Cattivelli D, Geninazzi H, Barragué AD et al. Estudio epidemiológico de hidatidosis. Detección precoz por ultrasonido en áreas de alto riesgo. Rev Med Urug. 1990;6:34-47.

8. Uruguay tiene más de un millón de perros. Zoonosis. 2009;1(1):10-3

9. Schantz P. Hidatidosis: magnitud de problema y perspectivas de control. Bol Of Sanit Panam. 1972;73(3):187-97.

10. Dar achuras a los perros: Médico de excepción lo califica como delito ultraintencional. Zoonosis. 2009;1 (1):22.

11. Turnes A. La hidatidosis como problema de salud pública. Una mirada histórica. Montevideo: Tradinco;2009. 


\section{CAPÍTULO 2}

\section{Historia de la hidatidosis y su lucha en el Uruguay}

Nuestro país cuenta con una amplia y muy rica historia en lo que a equinococosis hidatídica se refiere. Ya sea en lo referente a investigación, diagnóstico y tratamiento de la enfermedad, como así también, desde muy temprano en el siglo XX, la realización de planes de concientización y asistencia a nivel nacional de esta epidemia. Destacados médicos y otros profesionales de nuestro medio han sido referentes internacionales en este tema y aún hoy día a través de la Comisión Nacional Honoraria de Zoonosis, antes llamada Comisión Honoraria de Lucha Contra la Hidatidosis, se mantiene esa llama encendida de más de 100 años de historia.

La primera comunicación nacional sobre el tema es la Tesis de Doctorado presentada por Alberto Stirling en Nuestra Facultad de Medicina. En ella reunió 16 casos de quistes hidáticos del hígado y su tratamiento ${ }^{1}$.

En los inicios de la Revista Médica del Uruguay es posible encontrar numerosas publicaciones sobre equinococosis hidatídica. A fines del siglo XIX y en la primera década del siglo XX se destacaron los trabajos de los Doctores Enrique Pouey, J. H. Olivier, Luis P. Lenguas, Ricardo Mackinon, Pedro Duprat, Alfonso Lamas, Alfredo Navarro y Domingo Prat entre otros ${ }^{2-5}$.

La primera observación de un caso de quiste hidático en nuestro país la realizó Pedro Visca en 1884. Correspondió a un hombre de 40 años con un quiste hidático hepático. El paciente fue operado en Paris por Dieulafoy con buena evolución. Diez años más tarde Juan Francisco Canessa operó el primer paciente con hidatidosis en nuestro país ${ }^{6}$.

En 1889 Enrique Pouey presentó en la Sociedad de Medicina el caso de una paciente con una equinococosis múltiple peritoneal y hepática, producida por la rotura de un quiste abdominal desconocido para la paciente. En ese momento se realizó una intervención actuándose sobre los quistes peritoneales. En la exploración se diagnosticaron múltiples quistes hepáticos que no fueron tratados en dicha cirugía por lo prolongada de la misma. A partir de esta complicación - siembra peritoneal - estableció claramente el hecho de que una enfermedad benigna pueda adoptar las características evolutivas de una afección maligna ${ }^{2}$.

En 1902 presentó 7 casos de siembra hidatídica por rotura de quistes. Estableció la conveniencia de operar los quistes hidáticos luego de su diagnóstico. Afirmó que en el terreno profiláctico de la infección hidatídica está todo por hacer ${ }^{7}$.

En 1904 Berger, Médico Veterinario, formuló los principios básicos de la lucha contra la hidatidosis durante $\mathrm{el} 2^{\circ}$ Congreso Médico Latino-Americano.

- Fiscalización veterinaria de los mataderos;

- Limitar el número de perros a lo estrictamente necesario;

- Prohibición de alimentar los perros con achuras;

- Educar sobre los peligros de la enfermedad y su profilaxis.

Estos se habían aplicado con éxito en Islandia, donde se erradicó la enfermedad. Cien años después estos principios siguen vigentes, sólo se agregó el uso de antiparasitarios ${ }^{8}$.

En 1905 la Sociedad de Medicina de Montevideo apoyó con entusiasmo la idea de Pouey de iniciar el combate de la hidatidosis y junto a Luis Pedro Bottaro y Augusto Turenne formaron la primera Comisión de Lucha Contra la Hidatidosis en el país ${ }^{9,10}$.

En 1907 Oliver publicó un artículo sobre los quistes hidáticos del hígado y el síndrome colelitiásico. Afirmó que en general el desarrollo de la hidatidosis es de una sintomatología muy pobre y la presencia de un tumor redondeado, renitente e indolente es el primer y único síntoma de esta afección. En otros la sintomatología sugiere otras enfermedades, haciendo la descripción de aquellos casos que simulan una calculosis hepática. A esta la divide en 2 formas clínicas: 
1. Asociación de litiasis biliar y quiste hidático hepático, explicando la sintomatología por los propios cálculos.

2. Quistes hidáticos del hígado sin litiasis biliar, dividiéndolos a su vez en casos de quistes abiertos en vías biliares y no abiertos. En los primeros explica la fisiopatología y anatomía patológica de la complicación con conceptos que mantienen su vigencia hoy día. Cita como rara la presentación de síndrome colelitiásico sin rotura del quiste. Presentó 2 casos clínicos, uno personal y otro tratado por Lenguas, en los que encontraron un quiste hidático abscedado durante la operación ${ }^{3}$.

En 1908 Pedro Duprat realizó un estudio estadístico de los quistes hidáticos en el Uruguay ${ }^{4}$. Recolectó los datos del período 1901-1906 del Hospital de la Caridad, hoy Hospital Maciel, estimando que constituían la casi totalidad de enfermos del país ingresados por dicha patología. Agregó los datos de la Tesis inédita de Ricardo Mackinon qué analizó los casos del período 1896-1900, desestimando los años anteriores por no haber registros fehacientes. En esos 11 años encontaron 429 enfermos con quistes hidáticos, 105 en el período 1896-1900 y 324 entre 1901-1906. De los datos obtenidos se destaca:

Sexo masculino: $50,7 \%$ - Sexo femenino $49,3 \%$.

Adultos mayores de 15 años: $77,65 \%$ - Niños: $22,35 \%$.

El pico de edad se encontró entre los 20 y 30 años con el ascenso de la curva en la niñez.

Si bien constató un mayor número de casos entre 1901-1906, no encontró un aumento proporcional según el número de pacientes internados en ese período.

La topografía hepática fue predominante, correspondiendo al 76\%, seguida del pulmón y la pleura con un $9 \%$.

En 1913 Domingo Prat realizó la estadística de los años 1908-1912 ${ }^{5}$. Destacó un aumento significativo en el número de casos, 471. Esta cifra es una vez y media superior a la reportada por Duprat y cuadriplicó la serie de Mackinon. Esto lo llevó a plantear que la profilaxis de la enfermedad constituye un serio problema social, al que hay que prestar preferente atención, a fin de encontrar medios rápidos para evitar su avance progresivo.

Los datos en cuanto a incidencia por sexo, edad y topografía son similares a los hallados previamente. Los tratamientos habituales de la época eran la marsupialización para los quistes con bilis, hemorragia o supuración y la evacuación y cierre simple para los no complicados. La mortalidad por esta patología para sus pacientes era de $8 \%$.

En esta misma publicación expone el trabajo de Lamas y Lenguas sobre sintomatología y tratamiento. El signo más constante fue la tumefacción de crecimiento lento, lisa, regular, renitente, mate y móvil con los movimientos respiratorios. En un tercio de los casos encontró el frémito hidatídico. En referencia al dolor estableció que su aparición es tardía o es el agente causal para descubrir la enfermedad. El levantamiento del reborde costal se encuentra en un $25 \%$ de los casos, al igual que la urticaria. El tratamiento empleado fue la evacuación y cierre de los quistes siempre que no encuentren contraindicación. Con respecto a la marsupialización, si bien la consideraban un método seguro, no la recomendaban ya que el quiste está condenado a una larga supuración.

En la misma publicación dedicada a la equinococosis hidatídica, Pouey expuso sus resultados con la realización de la quistostomía mediatizada por tubo, llamándola en ese momento "Tunelización intraabdominal aplicada al tratamiento de los quistes hidáticos del abdomen" ${ }^{11}$. Encontró mejores resultados con respecto a la marsupialización y al cierre de la periquística - las cirugías más empleadas en la época - fundamentalmente cuando ésta era asiento de complicaciones evolutivas.

Dicha operación fue descrita por primera vez en 1904 por Llovet en el $2^{\circ}$ Congreso LatinoAmericano, quién publicó sus buenos resultados en $1913^{12}$.

En 1920 Gerardo Arrizabalaga dicta una Conferencia en la Facultad de Ciencias Médicas de Buenos Aires sobre el "Tratamiento de los Quistes del Hígado". Habló en primera instancia de las equinococosis múltiples, realizando claramente las definiciones de:

- Quistes primitivos por infestaciones múltiples, 
- Quistes secundarios por siembra e injerto y

- Quistes secundarios por metástasis.

Expuso su casuística de 51 quistes hidáticos hepáticos no complicados en que realizó quistectomía y cierre de la adventicia y fijación a la pared. Los resultados favorables fueron de $60 \%$. $25 \%$ mejoraron luego de una punción evacuadora del contenido intraquístico. Reoperó 15\% de los casos y les realizó una marsupialización. La mortalidad fue de 1 caso en 60 pacientes operados ${ }^{13}$.

El 20 de junio de 1934 el Ministerio de Salud Pública, a cargo del cirujano Eduardo Blanco Acevedo, creó por decreto el Centro de Estudio y Profilaxis de la Hidatidosis. Su actividad se centró en educación, epidemiología, investigación y experimentación. Se designó como Director del Centro a Velarde Pérez Fontana quien lo dirigió durante 30 años.

Pérez Fontana fue el editor de «Archivos Internacionales de la Hidatidosis» donde se publican trabajos internacionales y en diferentes idiomas, de los principales referentes en hidatidología del mundo. Son estos volúmenes aún hoy día libros de consulta obligatoria para quién se interesa en el tema. En el preámbulo del primer volumen el editor en 7 idiomas dice: «Los Archivos Internacionales de la Hidatidosis se propone reunir la documentación mundial referente a la enfermedad hidática. A pesar de los estudios realizados en el terreno de la patología de esta enfermedad, su profilaxis no ha sido aún planteada de una manera sistemática y definitiva. El intercambio científico reportará beneficios sobre todo a los países de América del Sur donde todavía queda mucho por hacer en materia de profilaxis.» 14

Es así que desde el Centro de Estudio y Profilaxis de la Hidatidosis, en 1937, Pérez Fontana envía el Proyecto de Ley de Profilaxia de la Hidatidosis al Ministro de Salud Mussio Fournier para que este lo eleve al Poder Ejecutivo ${ }^{15}$. En mayo de 1938 el Ministerio de Salud Pública envía un mensaje donde se declara peligro para la salud pública y la economía nacional la enfermedad hidatídica y se presentó el proyecto de ley correspondiente ${ }^{16}$. En 1939 se promulgó la Ley 9.852, que legitima al Centro de Estudio y Profilaxis, encargándole la coordinación de actividades de diversos organismos y entidades científicas para lograr una mayor efectividad en la lucha anti-hidática. ${ }^{17}$ Se establece así:

- Denuncia obligatoria de los casos de Hidatidosis humana y animal.

- Prohibición de alimentar los perros con achuras.

- Vigilancia de los mataderos.

- Limitación del número de perros.

- $\quad$ Obligación de los Maestros Rurales de por lo menos una vez al mes explicar a los alumnos sobre la prevención y los riesgos de la enfermedad.

Fue incansable la actividad de este notable Médico-Cirujano, fundador de la Asociación Internacional de Hidatidología, junto a representantes médicos y veterinarios de Uruguay, Argentina y Brasil, el 21 de Setiembre de 1941 en Colonia del Sacramento. De dicha asociación fue Presidente vitalicio.

Entre otros libros editó "Cachito y Rigoleto", texto escolar de enseñanza sobre los riesgos de la hidatidosis y la manera de evitarlos a través de la relación entre un niño y su perro ${ }^{18}$. Este fue traducido en varios idiomas y la Organización Panamericana de la Salud lo distribuyó en varios países.

Personalmente Pérez Fontana recorre todo el país dictando charlas informativas y tapizando las paredes de las diferentes estaciones de tren con carteles educativos, como lo disponía la ley por él propuesta. Participa en múltiples jornadas y congresos Nacionales e Internacionales, así como visita los principales centros del mundo en que se trataba el tema.

En 1947 se realizó en Durazno el 1er Congreso Internacional de Hidatidología bajo la presidencia de Domingo Prat.

En 1950 se realizó el Primer Congreso Uruguayo de Cirugía, presidido por Héctor Ardao. En 1953, durante el $4^{\circ}$ Congreso Uruguayo de Cirugía, el tema del Relato Oficial fue "Equinococosis Hepática - Tratamiento". El encargado del mismo fue Barsabás Ríos, jefe de cirugía del Hospital de 
Tacuarembó. El correlato sobre "Quiste hidático del hígado abierto en vías biliares”, correspondió Eduardo Calleri, jefe de cirugía del Hospital de Durazno 10,19,20.

En 1962 se publicó un libro fundamental en la cirugía abdominal del quiste hidático: "Equinococosis hidática del abdomen" de Larghero, Venturino y Broli. Posteriormente citado en la bibliografía mundial, aunque con las limitaciones de un libro en lengua española, dadas las dificultades para trascender a otros públicos científicos ${ }^{21}$.

En esos años la producción científica Nacional sobre el tema fue muy prolífica, cabe citar a Roberto Perdomo, cirujano investigador, cuyos trabajos sobre la desconexión quisto-biliar tuvieron un impacto a nivel Mundial ${ }^{22,23}$.

Por dicha época, desde el punto de vista Sanitario Nacional, se dieron grandes pasos en la lucha contra esta zoonosis. En diciembre de 1965 se aprobó la Ley 13.459: "Declárase plaga nacional la hidatidosis humana y animal y obligatoria la lucha para erradicarla en todo el territorio de la República." y se crea la Comisión Honoraria de Lucha contra la Hidatidosis, determinándose su integración y cometidos. Establece la obligatoriedad del pago de la patente de perro y se facilita la revisión y control sanitario de los canes y de los lugares destinados a la faena pública y domiciliaria. Esta Comisión tiene una integración pluri-ministerial, multi-institucional con participación además de sectores sociales y laborales ${ }^{24}$.

Se nombró como presidente a Pablo Purriel, quién con sus colaboradores realizó por entonces los primeros estudios epidemiológicos nacionales ${ }^{25}$.

Dicha comisión se modificó en los años 1990 por la Ley № 16.106 y en 2005 cuando pasó a denominarse Comisión Nacional Honoraria de Zoonosis por la Ley 17.930 26,27.

Finalmente destacamos la realización del XXIII Congreso Mundial de Hidatidología en la ciudad de Colonia del Sacramento, Uruguay, en diciembre de 2009. Allí se destacó la presentación del libro del Dr. Antonio Turnes: "La hidatidosis como problema de salud pública. Una mirada histórica" ${ }^{10}$.

Referencias bibliográficas.

1. Stirling A. Quistes hidáticos del hígado. Tesis del 8 de abril de 1897. Arch Int Hidatid. 1963;21 (1-2): 49-68.

2. Pouey E. Multiplicidad de quistes hidáticos en la cavidad abdominal. Rev Med Urug 1899; 2:187-8.

3. Oliver JH. Quistes hidáticos del hígado y síndrome colelitiásico. Rev Med Urug 1907; 10:115-27.

4. Duprat P. Los quistes hidáticos en el Uruguay. Rev Med Urug 1908;11: 305-24.

5. Prat D. Los quistes hidáticos en el Uruguay (1908 a 1912) Rev Med Urug 1913;16:467-537.

6. Buño W, Bollini-Folchi H. Tesis de Doctorado presentada a la Facultad de Medicina de Montevideo entre 1881 y 1902. Apartado de la «Revista histórica» Tomo LII- Año LXXIII. Nos. 154-156. A. Monteverde y Cía. S.A. Montevideo 1980. p.142-50.

7. Pouey E. Quistes hidáticos múltiples de abdomen. Rev Med Urug 1902; 5:362-64.

8. Berger P. $2^{\circ}$ Congreso Médico latino-Americano. Rev Med Urug 1904; 7:213

9. Sesión del 19 de junio de 1905. Rev Med Urug 1905;8;217-21.

10. Turnes A. La hidatidosis como problema de salud pública. Una mirada histórica. Tradinco. Montevideo. 2009.

11. Pouey E. Quistes hidáticos del abdomen, principalmente del hígado. Rev Med Urug 1913;16:540-46.

12. Llovet E. Consideraciones sobre diagnóstico y tratamiento de los quistes hidáticos. Rev Med Urug. 1913; 16:656-69.

13. Arrizabalaga G. Quistes hidáticos múltiples. Tratamiento de los quistes del hígado. Rev Med Urug. 1920; 23:243-59.

14. Pérez Fontana V. Prólogo. Arch Int Hidatid. 1934;1.

15. Pérez Fontana V. Centro de Estudios y Profilaxis de la Hidatidosis. Antecedentes y resoluciones. Arch Int Hidatid. 1937; 2(2):317-23.

16. Mensaje del Ministerio de Salud Pública. Arch Int Hidatid. 1938; 4(1-2):357-60.

17. Ley 9852. [En Línea]. [Acceso 1 de noviembre de 2011] URL: http://sip.parlamento.gub.uy/leyes/Acceso TextoLey.asp?Ley=09852\&Anchor $=$ 
HISTORIA DE LA HIDATIDOSIS Y SU LUCHA EN EL URUGUAY

18. Pérez Fontana V, Soto A. Cachito y Rigoleto, libro escolar. Impresora Uruguaya S. A. Montevideo. 1942.

19. Ríos B. Equinococosis hepática. Tratamiento. 4 Congreso Uruguayo de Cirugía. 1953. Imprenta García Morales-Mercant, Montevideo. pp. 149-200.

20. Calleri E. Quistes del hígado abiertos en vías biliares. 4 Congreso Uruguayo de Cirugía. 1953. Imprenta García Morales - Mercant, Montevideo. pp. 201-21.

21. Larghero P, Venturino W, Broli G. Equinococosis hidática del abdomen. Editorial Delta. Montevideo. 1962.

22. Perdomo R, Balboa O, Morelli R, Melognio S. Quistes hidáticos del hígado abiertos en las vías biliares. Desconexión quistobiliar por coledocostomía transhepaticoquística. Cir Uruguay. 1976;46(1):33-9.

23. Perdomo R, Morelli R, Carriquiry L, Chifflet J, Bergalli L. Cholédocostomie trans-hépatico kystiqueen cas de kyste hydatique ouvert dans les voies biliaires. Nouv Presse Med. 1977;6 (9):747-49.

24. Ley 13459. [En Línea]. [Acceso 1 de noviembre de 2011] URL: http://sip.parlamento.gub.uy/leyes/ Acceso TextoLey.asp? Ley $=13459 \&$ Anchor $=$

25. Purriel P, Schantz PM, Beovide H, Mendoza B. Hidatidosis en el Uruguay: comparación de los índices de morbilidad y mortalidad, 1962-1971. Bull World Health Organ. 1973;49:395-402.

26. Ley=16106. [En Línea]. [Acceso 1 de noviembre de 2011] URL: http://sip.parlamento.gub.uy/leyes/Acceso TextoLey.asp?Ley $=16106 \&$ Anchor $=$

27. Ley=17930 [En Línea]. [Acceso 1 de noviembre de 2011] URL: http://sip.parlamento.gub.uy/leyes/Acceso TextoLey.asp?Ley $=17930 \&$ Anchor $=$ 


\section{CAPÍTULO 3}

\section{Distribución geográfica}

La equinococosis hidatídica es una zoonosis cosmopolita presente en todos los continentes donde habita el hombre (Figura 1). A consecuencia de la carencia de información de algunos países es imposible tener un conocimiento cabal de su prevalencia. De todas formas, existe documentación que avala su existencia en más de 100 países ${ }^{1}$.

Figura 1.

Distribución geográfica del Echinococcus granulosus.

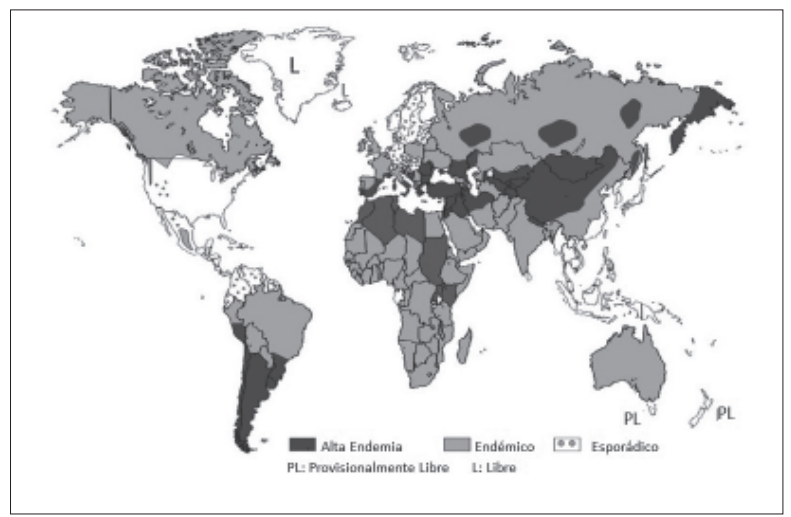

Su distribución es heterogénea, existiendo zonas hiperendémicas, entre ellas el norte de África, Eurasia, Australia y América del Sur.

Precisamente en Europa, existe un cinturón de alta prevalencia (1 a 8 / 100.000 habitantes) que se extiende desde la península Ibérica a los Balcanes, que incluye a Bulgaria, Córcega, sur de Francia, Italia, Grecia, Portugal, Rumania, Sicilia, España y Yugoslavia.

En China donde constituye un real problema de salud pública, la prevalencia oscila entre 2,1 y 42 / 100.000 habitantes de acuerdo a la región considerada ${ }^{2-4}$.

En países de Asia Central (Kazakhstan, Kyrgystan y Tadjidistan) se reportó en el año 2006 una incidencia anual de 13.20 y 27 casos por 100.000 habitantes respectivamente $^{5}$.

América Latina es reconocida como una región donde la enfermedad alcanza su más alta prevalencia, tanto en hombres como animales.

Predomina en los países del cono sur, lo que representa el 9\% del territorio del continente y la población de riesgo supera los 14 millones de personas ${ }^{6}$.

Diferente es la situación en el noroeste y centro de Europa, América Central y el sur de América del Norte donde se han reportado casos esporádicos.

Por otro lado existen islas donde la enfermedad ha sido erradica como es el caso de Islandia y Groenlandia. En tanto Nueva Zelanda, Tasmania y el sur de Chipre se han reportado casos esporádicos en animales domésticos ${ }^{7}$.

La razón de la alta prevalencia, la emergencia o reemergencia de la enfermedad se vincula a varios factores ${ }^{8-13}$ :

1. Alto porcentaje de perros infectados con Echinococcus granulosus. 
DISTRIBUCIÓN GEOGRÁFICA

2. Fácil acceso de los perros a vísceras provenientes de animales faenados e infectados con Equinococcus granulosus.

3. Carencia de lugares adecuados para la faena y destrucción de las vísceras infectadas.

4. Faenas clandestinas y ausencia de reglamentación y control de las mismas.

5. Convivencia de perros con otros animales en pequeñas fracciones de tierra.

6. Movimientos de animales no controlados dentro y entre los países.

7. La pobreza, vinculada especialmente a la imposibilidad de acceder a agua potable.

8. La ausencia de una educación sanitaria adecuada.

9. La inestabilidad económica de los países, que tiene estrecha vinculación con la pobreza y las restricciones en políticas de prevención y control.

Dos estudios de tipo caso control determinaron mediante el análisis multivariado, que los factores de riesgos de mayor importancia epidemiológica para la enfermedad son: faenar ovinos en el domicilio (OR 3,2), convivir con un elevado número de perros en los primeros años de vida $(\mathrm{OR} 2,6)$, antecedentes familiares de hidatidosis (OR 2,5). En tanto, beber agua potable constituye un factor protector (OR 0,1) ${ }^{14,15}$.

Referencias bibliográficas.

1. Eckert J, Schantz PM, Gasser RB, Torgerson PR, Bessonov AS, Movses-sian SO et al. Geographic distribution and prevalence. En: Eckert J, Gemmell MA, Meslin FX, Pawlowski ZS ed. WHO/OIE manual on echinococcosis in humans and animals: a public health problem of global concern. World Organisation for Animal Health, Paris, France; 2001, p. 100-42.

2. Wen H, Yang WG. Public health importance of cystic echinococcosis in China. Acta Trop. 1997;67(1):133-45.

3. Wang Q, Qiu J, Schantz P, He J, Ito A, Liu F. Investigation of risk factors for development of human hydatidosis among households raising livestock in Tibetan areas of western Sichuan province. Chin J Parasitol Parasit Dis. $2001 ; 19(2): 93-6$

4. Menghebat $L$, Jiang $L$, Chai J. A retrospective survey for surgical cases of cystic echinococcosis in the Xinjiang Uygur Autonomous Region, PRC (1951-90). En: Andersen FL, Chai J, Liu F editors. Compendium on cystic echinococcosis with special referencet to the Xinjiang Ugur Autonomous Region, the People's Republic of China. Provo, Utah: Brigham Young University Print Services;1993.p.135-45.

5. Torgerson PR, Oguljahan B, Muminov AE, Karaeva RR, Kuttubaev OT,_Aminjanov Met al. Present situation of cystic echinococcosis in central asia. Parasitol Int. 2006;55(Suppl):207-12.

6. Campano S. Plan de acción y estrategias regionales básicas para la eliminación de la hidatidosis humana en América del Sur. En: Organización Panamericana de la Salud. Informe del Proyecto Subregional Cono Sur de control y vigilancia de la hidatidosis. Argentina, Chile, Brasil y Uruguay. Primera reunión constitutiva. Montevideo: OPS; 2004. p. 52-7.

7. Eckert J, Deplazes P. Biological, epidemiological, and clinical aspects of echinococcosis, a zoonosis of increasing concern. Clin Microbiol Rev. 2004;17(1):107-35.

8. Todorov T, Boeva V. Human echinococcosis in Bulgaria: a comparative epidemiological analysis. Bull World Health Organ. 1999;77(2):110-8.

9. Battelli G, Mantovani A, Seimenis A. Cystic echinococcosis and Mediterranean Region: a long-lasting association. Parassitologia. 2002;44(1-2):43-57.

10. Shaikenov BS, Vaganov TF, Torgerson PR. Cystic echinococcosis in Kazakhstan: an emerging disease since independence from the Soviet Union. Parasitol Today. 1999;15(5):172-4.

11. Togerson P, Shaikenov B, Kuttybaev O. Cystic echinococcosis in Central Asia: new epidemic in Kazakhstan and Kyrgystan. En: Craig P, Pawlowski Z. Cestode zoononoses: echinococcosis and cysticercosis, and emergent and global problem. Amsterdan, The Netherlands: IOS Press; 2002. p. 99-105.

12. Togerson PR, Karaeva RR, Corkeri N, Abdyjaparov A, Kuttubaev OT. Human cystic echinococcosis in Kyrgystan: an epidemiological study. Acta Trop 2003;85(1):51-61.

13. Torgerson PR, Shaikenov B, Baitursinov KK, Abdybedova AM. The emerging epidemic of echinococcosis in Kazakhstan. Trans R Soc Trop Med Hyg. 2002;96(2):124-8.

14. Larrieu E, Del Carpio M, Costa M, Yadon Z. Risks factors for hidatidosis in children of Rio Negro Province. A study of cases and control. Ann Trop Med Parasitol. 2002;96:43-52.

15. Campos-Buenos A, López-Abente G, Andres-Cedrcadillo A. Risk factors for Echinococcus granulosus infection: a case-control study. Am J Trop Med Hyg. 2000;62(3):329-34. 


\section{CAPÍtULO 4}

\section{Epidemiología}

\section{PREVALENCIA.}

\subsection{PREVALENCIA EN HUMANOS.}

Tanto en Uruguay, Argentina y Chile, donde la equinococosis hidatídica es una enfermedad de notificación obligatoria, su prevalencia real se desconoce. La falta de conciencia o el desconocimiento del marco legal regulatorio, determinan un muy bajo nivel de notificación y consecuentemente un subregistro que no permite objetivar el problema en su real dimensión. Creemos que la solución es la aplicación de políticas de detección en poblaciones asintomáticas ya que a través de ellas se puede llegar a diagnosticar la enfermedad en su período preclínico.

Precisamente en referencia al último punto, Purriel ${ }^{1}$ en base a estudios necrópsicos realizados a personas sin sospecha clínica de enfermedad hidatídica, concluyó que esta zoonosis se comporta como un iceberg para hacer referencia al gran número de casos que no tienen expresión clínica (Figura 1).

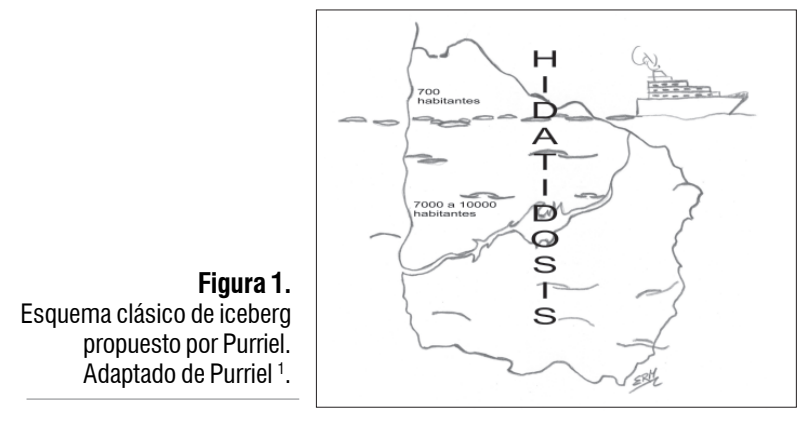

En el editorial de la revista Zoonosis de julio de 2011 se expresa que existe entre 7.000 y 10.000 uruguayos que están enfermos y no lo saben ${ }^{2}$.

El análisis de la evolución de las cifras publicadas permite observar la variabilidad de las mismas, así como la metodología utilizada para su obtención. Independientemente de lo anterior, en todos los casos se trata de tasas y porcentajes elevados.

A continuación abordaremos la realidad nacional y finalmente la situación regional.

\subsubsection{URUGUAY.}

\subsubsection{REPORTES CLINICOS.}

Fecunda es la producción científica con respecto al tema en nuestro país, existiendo trabajos referentes a nivel mundial.

En tal sentido, Purriel ${ }^{3}$ sobre una encuesta realizada en 98 centros asistenciales del país (67 del interior y 31 de Montevideo) en la que recabó datos de casos confirmados quirúrgicamente o con radiografía de tórax sugerente de equinococosis hidatídica, determinó una incidencia anual de 17,7 / 100.000 habitantes.

Al discriminar la procedencia de los pacientes, la tasa para la población rural fue de 123/ 100.000 habitantes en comparación al 10,1 / 100.000 habitantes para la población urbana y suburbana. 
El análisis de las cifras por departamentos evidenció la mayor tasa para Durazno con 84,33 / 100.000 habitantes y la menor Canelones con 9,75/100.000 habitantes ${ }^{1}$.

Años después y únicamente considerando el número de pacientes intervenidos quirúrgicamente en el departamento de Durazno, se estableció una prevalencia de 29 / 100.000 habitantes. Una encuesta realizada en la ciudad de Sarandí del Yí a 376 jóvenes que cursaban el primer ciclo de enseñanza secundaria, determinó una prevalencia de $0,53 \%$ considerando los antecedentes personales del grupo encuestado, en tanto cuando se tomó en cuenta los antecedentes familiares la cifra ascendió a 15,1\% ${ }^{4}$.

Con el transcurrir de los años y de la implementación de políticas de vigilancia y control de la enfermedad, la prevalencia de casos operados descendió de 20,7 / 100.000 habitantes en el año 1962 a 4,2 / 100.000 habitantes en el año $2004^{5,6}$.

\subsubsection{ESTUDIOS IMAGENOLOGICOS.}

La ecografía abdominal al igual que la radiografía de tórax, han demostrado ser herramientas fundamentales en la pesquisa de la enfermedad hidatídica. Cuando se utilizan en forma sistematizada sobre muestras representativas de la población, permiten obtener una información más real de la incidencia y prevalencia de la enfermedad, y de esta forma eliminar los sesgos que surgen de las series de casos clínicos aportados por centros asistenciales o de los estudios autópsicos.

La ecografía es el método que más utilidad presenta para este propósito. Se trata de un estudio no invasivo, eficiente y de alta accesibilidad en virtud de equipos portátiles ${ }^{7}$.

Perdomo ${ }^{8,9}$ sobre 6027 ecografías realizadas en 7 poblaciones rurales del interior del país (Caraguatá, Villa Ansina, Cerro Colorado, Capilla del Sauce, Aiguá, Garzón y Vergara), determinó que $1,5 \%$ de la población poseía imágenes quísticas hepáticas. De ellas el $93 \%$ fueron únicas, las restantes tenían 2 y 3 quistes. Predominaron en el lóbulo derecho, 69\%.

El valor predictivo positivo en base a los pacientes intervenidos quirúrgicamente fue de $89,13 \%$. Se estimó una prevalencia de hidatidosis hepática de 1,39\% en la población estudiada.

Con una muestra menor -376 ecografías-, Paolillo ${ }^{4}$ estableció una prevalencia global para la ciudad de Sarandí del Yí de 1,32\%, siendo para las poblaciones urbana y rural de 2,38 y 1,02\% respectivamente (Tabla 1).

\section{Tabla 1. Prevalencia de equinococosis hidatídica en la ciudad de Sarandí}

\section{del Yí según procedencia.}

\begin{tabular}{|c|c|c|c|c|}
\hline Procedencia & $\mathbf{N}^{\mathbf{0}}$ de jóvenes & Con $\mathbf{Q H}^{*}$ & Sin $\mathbf{Q H}^{*}$ & $\begin{array}{c}\text { Prevalencia } \\
(\mathbf{\%})\end{array}$ \\
\hline Total & 376 & 5 & 371 & 1,32 \\
\hline Rural & 84 & 2 & 82 & 2,38 \\
\hline Urbana & 292 & 3 & 289 & 1,02 \\
\hline
\end{tabular}

Cohen ${ }^{10}$ en el período 1991 - 1992 estudió 82,8\% de la población de La Paloma, población rural del departamento de Durazno. La prevalencia en portadores asintomáticos fue de 3,6\%.

Otro estudio llevado a cabo en poblaciones rurales del departamento de Florida durante el período mayo de 1993 y julio de 1994, determinó una prevalencia de 1,6\%. Es de remarcar que los 9515 participantes que tomaron parte del estudio concurrieron en forma voluntaria y fueron convocados a través de los medios de prensa locales ${ }^{11}$.

El screening realizado en el departamento de Río Negro en el período julio 2007 - julio 2009 determinó una prevalencia global de $0,72 \%$. Para Fray Bentos fue de $0,18 \%$ en tanto para el interior de $0,85 \%{ }^{12}$. 
Guisantes ${ }^{13}$ en su evaluación externa del plan estratégico para el control de la equinococosis en nuestro país en el período 2007 - 2009, comunicó tasas de 630 / 100.000 y 3.220 / 100.000 habitantes, para áreas de riesgo y muy alto riesgo respectivamente sobre un total de 56.814 ecografías realizadas. Es preocupante la tasa en niños que ascendió a $21 / 100.000$ habitantes, ya que significa que se mantienen las condiciones adecuadas para que esta zoonosis mantenga su vigencia en nuestro país.

En el informe sobre el Proyecto Subregional Cono Sur de Control y Vigilancia de la Hidatidosis del año 2009, se comunicó que en nuestro país se realizaron 70.000 ecografías como método de screening a nivel nacional en el período 2006 - 2009. Incluyó áreas rurales, poblados menores y áreas suburbanas. En la misma se determinó una prevalencia para quiste hidático hepático entre 1 y $2 \%{ }^{14}$. En el año 2011 con más de 100.000 ecografías realizadas, el porcentaje se mantiene ${ }^{2}$.

Es de destacar que en campañas de detección ecográfica de equinococosis hidatídica, se diagnosticaron una serie de incidentalomas, que según la serie de Perdomo ${ }^{8}$ ascendieron a $5 \%$. Dentro de ellos predominó la litiasis vesicular con $63 \%$, seguidos por otras entidades que se aprecian en la tabla 2.

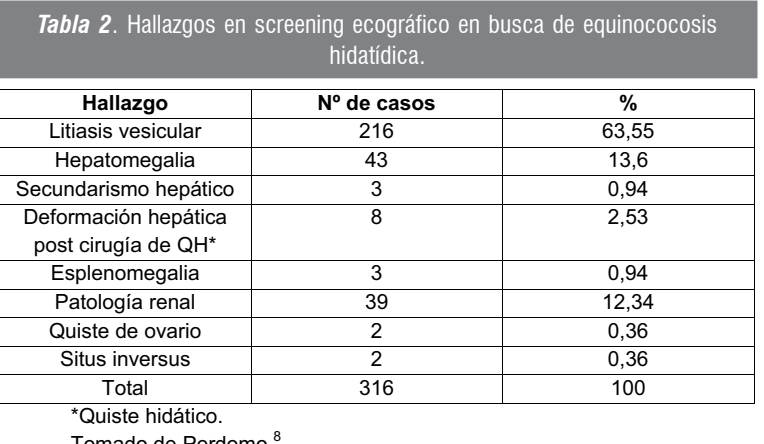

\subsubsection{ESTUDIOS INMUNOLOGICOS.}

El advenimiento de nuevas técnicas inmunológicas empleadas en la pesquisa de la enfermedad ha contribuido al diagnóstico en el período presintomático.

Bonifacino ${ }^{15}$ empleando la técnica de ELISA, estableció una seroprevalencia de 1,24\% sobre un total de 420 personas de zonas rurales de los departamentos de Paysandú, San José y Rivera.

\subsubsection{AMERICA.}

En Argentina la equinococosis hidatídica constituye la enfermedad zoonótica transmitida por helmintos de mayor prevalencia. Se estima que el $30 \%$ del territorio nacional es asiento del ciclo zoonótico doméstico de dicho parásito. Esta superficie coincide con las zonas de mayor producción pecuaria: Patagonia, Pampa Húmeda, Mesopotamia, Cuyo, zona central y altas montañas del Noroeste. Aquí residen 4.000 .000 personas, de las cuales $10 \%$ son niños menores de 5 años. Se estima que entre 2 y $5 \%$ de los escolares son portadores de la enfermedad hidatídica ${ }^{16}$.

Esta realidad se mantiene desde la década del 80 , cuando Frieder ${ }^{17,18}$ reportó una prevalencia para portadores asintomáticos en el rango etario de 7 a 13 años de 5,6\%.

En Chile, considerando el período 1961-1992, las tasas medias anuales de incidencia y prevalencia ascendieron a 4,4 y 4,5/ 100.000 habitantes, con una tasa de letalidad de $8,5 \%{ }^{19}$.

Otro estudio en el mismo país, teniendo en cuenta el período 1989 - 1994 y de acuerdo con el registro de enfermedades de notificación obligatoria del Ministerio de Salud, mostró una prevalencia de 2,3 / 100.000 habitantes, no habiendo diferencias significativas entre los diferentes años (Tabla 3) ${ }^{20}$. 


Tabla 3. Prevalencia de equinococosis hidatídica en Chile.
Período 1989 - 1994 .
\begin{tabular}{|c|c|}
\hline Año & $\begin{array}{c}\text { Prevalencia (casos / 100.000 } \\
\text { habitantes) }\end{array}$ \\
\hline 1989 & 2,6 \\
\hline 1990 & 1,9 \\
\hline 1991 & 2,0 \\
\hline 1992 & 2,6 \\
\hline 1993 & 2,6 \\
\hline 1994 & 2,4 \\
\hline
\end{tabular}

Sin embargo cuando se discrimina esta prevalencia por región, se comprueba una cifra muy elevada en la Decimoprimera Región con un valor de 52,5 / 100.000 habitantes.

Considerando el registro de notificación obligatoria de ese país, para el año 1990 la incidencia ascendió a 1,9 / 100.000 habitantes. En 2008 correspondió a 1,6 / 100.000 habitantes. Sin embargo al considerar los egresos hospitalarios la misma osciló entre 6,5 y 11,4 / 100.000 habitantes. Esta cifra aún fue mayor al utilizar estudios serológicos, alcanzando tasas de $540 / 100.000$ habitantes ${ }^{21-23}$. Esta variación tradujo el importante subregistro existente, lo que llevó que a partir del año 2000, a través de un decreto del Ministerio de Salud Pública, la misma sea de declaración obligatoria en forma diaria. A pesar de ello, de acuerdo al registro de los años 2000 - 2005 se estimó que esta subnotificación osciló entre 66 y $75 \%{ }^{22}$.

En el estado de Río Grande do Sul, Brasil, donde la enfermedad constituye un importante problema de salud pública, sucesivos estudios de detección serológica llevados a cabo en municipios fronterizos con Uruguay, reportaron una prevalencia de 8,3 / 1.000 habitantes en el año 1983, en tanto en 1999 oscilaron entre 8,82 y 89,44 / 100.000 habitantes $^{24,25}$.

En Perú, en los períodos 1980 - 1988 y 1988 - 1992 la prevalencia fue de 1,04 y 2,4 / 100.000 habitantes respectivamente ${ }^{26,27}$.

En Bolivia se reportó una prevalencia en poblaciones rurales de $39,8 \%$ mediante la pesquisa serológica con el método de ELISA, entre 3,8 y 4,8\% mediante estudio ecográfico y de 1,6\% cuando se utilizó la radiografía de tórax ${ }^{28}$.

\subsection{PREVALENCIA EN PERROS.}

\subsubsection{URUGUAY.}

En la década del 50, múltiples fueron las comunicaciones referidas a la prevalencia de la enfermedad en perros. Las mismas se realizaron sobre la base del estudio de muestras de materias fecales. Tanto el número de animales como las regiones del país estudiadas fueron diversos. Teniendo en cuenta esta variabilidad, las cifras reportadas oscilaron entre 21,9 y $45 \%{ }^{29}$.

En la década del 70, un estudio llevado a cabo por la Comisión Honoraria de Lucha Contra la Hidatidosis reveló, mediante la autopsia de 908 perros vagabundos de la zona urbana y suburbana de Montevideo, una prevalencia de infección por equinococosis hidatídica de $7,7 \%{ }^{30}$.

Sin embargo en la misma época, dos estudios comunicaron prevalencias que superaban a las del precedente trabajo. Los mismos se ejecutaron en zonas rurales ubicadas en diferentes regiones, una de ellas en el sur del país y otra en el centro. Purriel ${ }^{3}$ reportó una prevalencia de $39,3 \%$ de equinococosis hidatídica en 2600 perros del departamento de Flores, que fueron sometidos a purga con bromhidrato de arecolina. Por otro lado el estudio realizado en Rincón de la Bolsa, el valor fue de $42 \%{ }^{31}$.

Conti-Díaz ${ }^{32}$ sobre una muestra muy pequeña de 20 perros de la población rural de Palmares de Quebracho, Paysandú, tomó muestras de heces en búsqueda del parásito luego de la administración de bromhidrato de arecolina, resultando todas ellas negativas. 
En la década del ochenta el trabajo llevado a cabo por la filial Durazno de la Comisión Nacional de Lucha Contra la Hidatidosis, estableció para los años 1986, 1987 y 1989, una parasitación por Echinococcus granulosus en la población canina del departamento de $6,13 \%, 12 \%$ y $4,49 \%$ respectivamente ${ }^{4}$.

Posteriormente sobre un total de 158 perros de la ciudad de Sarandí del Yí que fueron llevados en forma voluntaria por sus propietarios, se determinó un prevalencia de $2,5 \%{ }^{4}$. Esta cifra, inferior a la precedente, seguramente tenga un sesgo, ya que la actitud del propietario de llevar su perro al control en forma voluntaria traduce la dedicación y cuidado de la salud de su mascota, a diferencia de quien no lo realizó y que probablemente indique un cuidado menos riguroso, y que involucre entre otros aspectos la alimentación.

Estudios posteriores llevados a cabo en perros de zonas rurales en los años 1991 y 1997 comunicaron cifras de $24,8 \%$ y $0,74 \%$ respectivamente ${ }^{10,33,34}$

En el año 1991, en la fase de diagnóstico realizado en el marco del programa nacional para la erradicación de la hidatidosis Ilevado adelante por la Comisión Honoraria de Lucha Contra la Hidatidosis, se comunicó una prevalencia de equinococosis hidatídicas de 10,7\% para perros del medio rural. Esta cifra descendió a $0,74 \%$ en la fase de consolidación del programa que tuvo lugar en el período $1997-2004^{35}$.

Hasta el momento la búsqueda del parásito se realizó mediante la administración de bromhidrato de arecolina, un alcaloide derivado de la nuez de areca. Las ventajas de su utilización son las siguientes: posibilidad de obtener resultados inmediatos, alta especificidad, generar un alto impacto en la población determinado por la observación de las tenias expulsadas por el animal.

Las desventajas atribuidas son las siguientes: sobre el animal, puede provocar reacciones indeseables, está contraindicado en perros añejos, hembras o con patologías particulares, posee entre 15 y $20 \%$ de resultados falsos negativos, lo que determina una baja sensibilidad. Por tal motivo exige la utilización de un método alternativo para determinar la prevalencia con mayor precisión. Es un método técnico dependiente, pudiendo generar riesgos biológicos en personas así como en el medio ambiente.

Es así que en nuestro medio se comenzó a utilizar el test de coproantígeno por captura ELISA con anticuerpo monoclonal EmA9. continuación.

Al igual que el anterior método, este presenta ventajas y desventajas que enumeraremos a

Ventajas: posee una alta sensibilidad y especificidad, menor riesgo para humanos y de contaminación ambiental, no existen limitaciones en su uso en cuanto a la categoría del animal, teniendo la posibilidad de realizar diagnóstico en el período prepatente y con bajas cargas parasitarias.

Desventaja: la necesidad en ciertas ocasiones de recurrir a otra técnica confirmatoria y de esta forma incrementar los costos.

En un estudio llevado a cabo en establecimientos rurales de nuestro país durante el período 2004 - 2005, se estudiaron 4266 perros. En la totalidad de los animales se empleó la técnica de bromhidrato de arecolina, en tanto a 3122 de ellos también se los estudió mediante la técnica de ELISA coproantígeno.

Con la primera técnica se obtuvo una prevalencia de Echinococcus granulosus de 0,4\%, en tanto que con la segunda se confirmaron los conceptos expuestos precedentemente y el porcentaje ascendió a $4,3 \%{ }^{36}$.

\subsubsection{ARGENTINA.}

En la Provincia de Río Negro, Argentina, la prevalencia descendió de 41,5\% a 2,3\% en el período 1980 - 1997, luego de la aplicación de un programa de control de la enfermedad ${ }^{37}$.

Experiencias similares ocurrieron en las Provincias de Tierra del Fuego y La Pampa donde las cifras comunicadas fueron de $2,5 \%$ y $8,33 \%{ }^{38,39}$. Por su parte en diferentes localidades de la Provincia de Córdoba las cifras oscilaron entre $9,15 \%$ y $13 \%{ }^{40,41}$. 
Descensos menos marcados se produjeron en Chubut, donde se pasó de $28,23 \%$ a 19,19\% en casi dos décadas. Cifras más elevadas se constataron en la provincia de Buenos Aires, donde ascendió a $22,4 \%$ en el año $1993^{37}$.

\subsubsection{BRASIL.}

En Río Grande do Sul la prevalencia en el año 1997 osciló entre 14\% y 50\%. Descendió a 9\% en un estudio realizado a perros vagabundos mediante la técnica de coproantígeno en el año $2000^{33}$.

\subsubsection{CHILE.}

Las cifras reportadas en este país varían de acuerdo a la región considerada. De esta forma, trabajos realizados en la década del 90 establecieron valores de 0,35\%, 0,7\%, 6,5\% y $11 \%$ para las regiones $\mathrm{XI}, \mathrm{X}$, VII y XII respectivamente ${ }^{42-45}$.

\subsubsection{PERU.}

Este país ha registrado valores bajos en Lima, 0,3\%. En las tierras altas centrales y altas del sur se elevaron a $12 \%$ y $31 \%$ respectivamente ${ }^{46}$.

\subsection{PREVALENCIA EN HOSPEDEROS INTERMEDIARIOS.}

La distribución del Echinococcus granulosus en distintos ámbitos ecológicos y localizaciones geográficas, demuestra la gran adaptabilidad del parásito a variadas condiciones ambientales. La especie ovina es el hospedero intermediario más apto, y el $97 \%$ de los 65 millones de ovinos existentes en América del Sur viven en las regiones endémicas de Argentina, Uruguay, Chile, Brasil y Perú ${ }^{16}$.

\subsubsection{URUGUAY.}

\subsubsection{OVINOS.}

De acuerdo a lo aseverado precedentemente, Purriel ${ }^{29}$, citando a Prevettoni comunicó una prevalencia total para la especie ovina de $59,3 \%$. De acuerdo a la categoría considerada, las cifras oscilaron entre $34,7 \%$ y $38,1 \%$ para corderos, entre $94,2 \%$ y $100 \%$ en ovejas y $93,9 \%$ a $98,6 \%$ para capones.

Los registros de faenas llevadas a cabo en la década del noventa determinaron una prevalencia de 44\%, 12,8\% y 8\% para los años 1990, 1996 y 1998 respectivamente. La discriminación de acuerdo a categorías en el año 1998, evidenció una infestación de 7,7\% para aquellos animales de 4 a 6 dientes y de $18 \%$ para los de 6 a 8 dientes ${ }^{47,48}$.

Finalmente en el año 2002 la cifra descendió a 3,85\% ${ }^{35}$.

\subsubsection{BOVINOS.}

Purriel ${ }^{29}$ cita cifras de investigaciones llevadas a cabo en diferentes centros de faena de la especie bovina de nuestro país. En 1929 se determinó específicamente la equinococosis hidatídica hepática en el frigorífico Artigas; Ios valores oscilaron entre 60,5 y $68,7 \%$ considerando novillos y vacas respectivamente. Posteriormente en el período 1947-1951 se reportó una prevalencia de hidatidosis visceral de 34\% en el frigorífico Swift. Por último, en el mayor período de investigación (1941-1953) que se realizó en dos mataderos del interior del país (Mercedes y Dolores) la cifra de infestación ascendió a $65,6 \%$.

Purriel ${ }^{29}$ mediante el estudio macroscópico (inspección visual y palpación) de las vísceras de animales faenados en el frigorífico Nacional en el período 1963-1965 reportó una prevalencia global de hidatidosis de $61,23 \%$. La distribución para las localizaciones hepática, pulmonar, esplénica, renal y cardíaca fue de $42,19 \%, 50,98 \%, 1,54 \%, 0,65 \%$ y $0,035 \%$ respectivamente.

Por su parte al evaluar la procedencia de los animales infectados, se determinó una distribución sumamente uniforme en todo el territorio nacional. Las cifras variaron entre 50,7 y $68,5 \%$ para los departamentos de Canelones y Flores respectivamente. No existieron diferencias al considerar los provenientes del norte y sur del Río Negro. 
Con el transcurso de los años y la implantación de programas de control de la enfermedad las cifras comenzaron a descender. Así lo evidenciaron una serie de comunicaciones. Comenzando en el año 1990 donde la cifra fue de $64,87 \%, 22,6 \%$ en 1996, 12,2\% en 2002 y alcanzó el 6,55\% en el año $2003^{35,49}$

\subsubsection{ARGENTINA.}

En Argentina, en el año 1996 la fiscalización realizada a 10.550 .624 bovinos y 571.595 ovinos, permitió identificar y decomisar 243.313 y 224.000 vísceras infectadas con quiste hidático en cada grupo respectivamente.

En este país se estima, que la prevalencia nacional global ascendería a: $12,5 \%$ en ovinos, $9,8 \%$ en porcinos, $7 \%$ en bovinos y $6 \%$ en caprinos ${ }^{16}$.

En concordancia con lo establecido anteriormente, se comprobó en la provincia de Río Negro, un descenso en la prevalencia de la enfermedad en ovinos faenados en mataderos. La cifra pasó del 61 a 18,3\% en el período 1980 - 1999 luego de la aplicación de programas de control ${ }^{50}$.

Bajo las mismas condiciones, se reportó en Tierra del Fuego en el año 1996 una muy baja prevalencia en ovinos. La misma fue de $1,2 \%{ }^{38}$. Aún menor fue en las Islas Malvinas, $0,47 \%{ }^{51}$.

\subsubsection{BRASIL.}

Es en el sur de este país, específicamente Río Grande do Sul, donde se han reportado la mayor prevalencia de la enfermedad. $\operatorname{cerdos}^{24,52}$

Las cifras oscilan entre 3 y $30,24 \%$ para ovinos, 18 y $25,52 \%$ para bovinos y $0,04 \%$ para

Finalmente en el año 2005 se diagnosticaron 119.445 bovinos infectados con equinococosis hidatídica y 24.300 y 560 ovinos y suinos respectivamente ${ }^{53}$.

\subsubsection{CHILE.}

Morales ${ }^{20}$ teniendo en cuenta el registro del Departamento de Higiene Ambiental del Ministerio de Salud, presentó cifras de prevalencia para el período 1989 - 1995 en diferentes especies animales. Las tasas promedios fueron los siguientes: bovinos 21,8 / 100 faenados; porcinos 2,5 / 100 faenados; ovinos 6,2 / 100 faenados; equinos 5,9 / 100 faenados; caprinos 7 / 100 faenados y camélidos 2 / 100 faenados (Tabla 4).

\section{Tabla 4.Prevalencia anual de hidatidosis en población ganadera.} $1989-1995$.

\begin{tabular}{|c|c|c|c|c|c|c|}
\hline Año & Bovinos & Porcinos & Ovinos & Equinos & Caprinos & Camélidos \\
\hline 1989 & 22,8 & 2,6 & 6,7 & 4,4 & 5,9 & 1,6 \\
\hline 1990 & 21,9 & 2,5 & 6,6 & 4,4 & 7,7 & 1,4 \\
\hline 1991 & 23,2 & 2,9 & 7,6 & 6 & 7,3 & 1,4 \\
\hline 1992 & 22 & 2,7 & 6,5 & 7,7 & 6,2 & 3 \\
\hline 1993 & 22,5 & 2,5 & 5,6 & 8,9 & 5,3 & 2,7 \\
\hline 1994 & 20,6 & 2,2 & 6 & 7,2 & 8,8 & 3,1 \\
\hline 1995 & 20,1 & 2 & 3,9 & 4,8 & 9,9 & - \\
\hline \multicolumn{7}{|r|}{ Tomado de Morales ${ }^{20}}$. \\
\end{tabular}

Es de remarcar que la prevalencia es variable de acuerdo a la región considerada. Teniendo en cuenta este aspecto se reportaron cifras de $1,3 \%, 4,4 \%, 10,4 \%$ y $90 \%$ en ovinos para las regiones XII, VII, XI y X respectivamente. Con respecto a bovinos y porcinos las cifras fueron de $13 \%$ y $4,2 \%$ para la VII región ${ }^{42-45,54}$. 


\subsubsection{PERU.}

Registros llevados a cabo en las tierras altas centrales y altas del sur comunicaron los siguientes valores: ovinos (28\% para las primeras y entre 13 y $50 \%$ para las segundas). Bovinos ( $50 \%$ y entre 16 y $69 \%$ respectivamente). Cerdos (2,8 y $9,1 \%$ respectivamente) ${ }^{27}$.

\section{EDAD Y SEXO}

Purriel ${ }^{29}$ comunicó 1607 casos de equinococosis hidatídica en el período 1962-1964. De ellos 56\% correspondió al sexo masculino, siendo el grupo etario más afectado el comprendido entre 20 y 50 años. Rango similar reportó Serra ${ }^{55}$ en Chile en el período 1989-1993, donde las edades comprendidas entre 15 y 54 años fueron las más afectadas. Sin embargo cuando se consideró únicamente a personas que fueron operadas en el período 1969 - 1971, la mayor incidencia correspondió a personas entre 60 y 64 años, con una tasa de 24,2 / 100.000 habitantes (3) (Tabla 5). Posteriormente Perdomo ${ }^{8}$ mediante estudios ecográficos determinó que la población con mayor prevalencia se ubicó en el rango de 50 y 79 años, siendo a su vez el sexo masculino el que presentó mayor riesgo relativo de infección hidatídica en todos los grupos etarios.

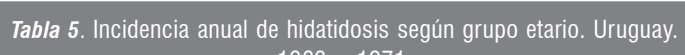
$1969-1971$.

\begin{tabular}{|l|l|}
\hline \multicolumn{1}{|c|}{ Grupo etario } & Casos / año / 100.000 habitantes \\
\hline $0-4$ & 3,7 \\
\hline $5-9$ & 14,1 \\
\hline $10-14$ & 15 \\
\hline $15-19$ & 14,7 \\
\hline $20-24$ & 19,6 \\
\hline $25-29$ & 15,6 \\
\hline $30-34$ & 13,2 \\
\hline $35-39$ & 16,7 \\
\hline $40-44$ & 16,9 \\
\hline $45-49$ & 18,3 \\
\hline $50-54$ & 16,4 \\
\hline $55-59$ & 23,6 \\
\hline $60-64$ & 24,2 \\
\hline $65-69$ & 22,7 \\
\hline $70-74$ & 20,3 \\
\hline $75+$ & 10,9 \\
\hline & \\
\hline
\end{tabular}

\section{TOPOGRAFIA}

Con respecto a la topografía, Purriel ${ }^{29}$ sobre en una serie de 1607 casos estableció la siguiente distribución: 45,4\% hepática, 34\% pulmonar, 14\% (otras localizaciones), 2,5\% (hígado - pulmón), 4,1\% (múltiples). Este predominio de la localización hepática lo vuelve a confirmar Purriel ${ }^{3}$ en este caso al tomar en cuenta pacientes que fueron intervenidos quirúrgicamente: $58 \%$ hepática, $42 \%$ pulmonar. Perdomo ${ }^{8}$ afirma que cuando se utilizan métodos de similar sensibilidad en la detección de enfermedad hidatídica, hepática y pulmonar (ecografía y radiografía de tórax) la relación es de 23 a 1 a favor de la localización hepática. Esta realidad también la confirmó Frieder ${ }^{17}$ en Argentina utilizando la misma metodología, aunque la relación en este caso fue de 10 a 1 . 
Este predomino de la localización hepática es confirmada por múltiples estudios, donde las cifras oscilaron entre 41 y $75 \%{ }^{28,56-59}$ (Figura 2).

El estudio de 409 autopsias comunicado por Purriel ${ }^{1}$ determinó la siguiente distribución topográfica: hepática 12, renal, peritoneal y pulmonar 1 respectivamente.

Considerando el número de casos incidentes más las readmisiones ocurridas en el período 1969 - 1971, se logró establecer en 1617 de 1755 casos la topografía de la equinococosis. De ellos $936(57,8 \%)$ fueron hepáticos, 591 (36,5\%) pulmonares, 49 en ambas localizaciones y 41 distribuidos en diferentes órganos ${ }^{3}$.

Larrieu ${ }^{60}$ en un análisis de 9970 casos de áreas endémicas de América del Sur, África, Europa y Australia determinó una relación hígado pulmón de 2,5 a 1. En tanto esta relación se elevó a cifras de 12 a 1 y 6 a 1 cuando estudió poblaciones de Uruguay y Argentina respectivamente.

Figura 2. Distribución topográfica del quiste hidático.

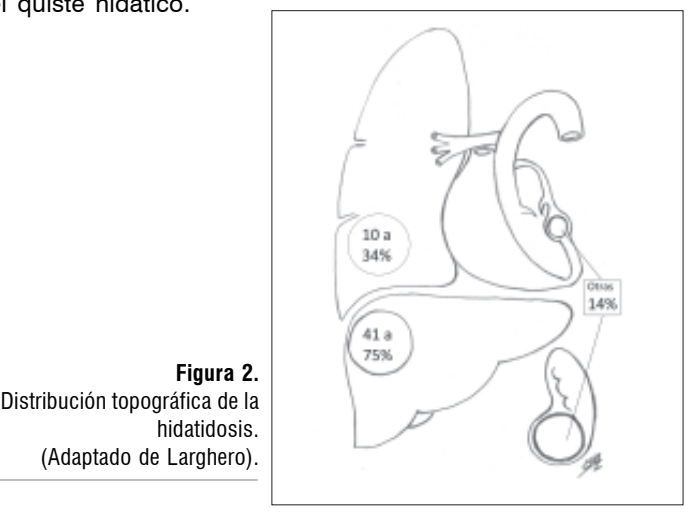

Referencias bibliográficas.

1. Purriel P, Mendoza G, Decedo H. Hidatidosis en el Uruguay. Estudio epidemiológico (1962-1968) El Tórax. 1970;19(3):149-62.

2. Esterilización quirúrgica y desparasitación de canes, ecografías en humanos y educación. Nuestros pilares. Zoonosis. 2011;(2):3.

3. Purriel P, Schantz PM, Beovide H, Mendoza B. Hidatidosis en el Uruguay: comparación de los índices de morbilidad y mortalidad, 1962-1971. Bol Of Sanit Panam. 1975;78(6):519-30.

4. Paolillo E, Botta B, Cohen H, Dibarboure L, Rodrlguez O, Antoniello L et al. Hidatidosis: un problema de atención primaria en salud. Rev Med Urug 1991;7:32-7.

5. Instituto Nacional de Estadística. Salud. Morbilidad. Enfermedades inmunoprevenibles, infecto-contagiosas y parasitarias. [En línea] Montevideo: INE;[2000?]. [Acceso 29 de julio de 2011]. URL: http://www.ine.gub.uy/ biblioteca/Variables\%20siglo\%20xx/Salud.PDF.

6. Turnes A. La hidatidosis como problema de salud pública. Una mirada histórica. Montevideo: Tradinco;2009. p.60.

7. Viscardi C. Diagnóstico ecográfico de hidatidosis. Zoonosis. 2009;(1):23.

8. Perdomo R, Parada R, Alvarez C, Cattivelli D, Geninazzi H Barragué A, et al. Estudio epidemiológico de hidatidosis. Detección precoz por ultrasonido en áreas de alto riesgo. Rev Méd Urug 1990;6:34-47.

9. Perdomo R, Alvarez C, Geninazzi H, Ferreira C, Monti J, Parada R, et al. Early diagnosis of hydatidosis by ultrasonography. Lancet. 1988;30:244.

10. Cohen H, Paolillo E, Bonifacino R, Botta B, Parada L, Cabrera P, et al. Human cystic echinococcosis in a uruguayan community: a sonographic serologic and epidemiologic study. Am J Trop Med Hyg. 1998; 59(4):620-7.

11. Carmona C, Perdomo R, Carbo A, Alvarez C, Monti J, Grauert R, et al. Risk factors associated with human cystic echinococcosis in Florida, Uruguay: Results of a mass screening study using ultrasound and serology. Am J Trop Med Hyg. 1998; 58(5):599-605.

12. Viscardi C, Roslik S. Pesquisamiento de quiste hidático mediante ecografías en el departamento de Río Negro, Uruguay. XXII Congreso Mundial de Hidatidología. Colonia del Sacramento, Uruguay. 2009;149

13. Guisantes JA. Evaluación externa del plan estratégico. Zoonosis. 2009;(1):44-6. 
14. Organización Panamericana de la Salud. Informe del Proyecto Subregional Cono Sur de Control y Vigilancia de la Hidatidosis Argentina, Brasil, Chile y Uruguay. Sexta Reunión. Colonia del Sacramento, Uruguay. 9 de diciembre de 2009. Colonia del Sacramento: OPS; 2010. p.17.

15. Bonifacino R, Malgor R, Barbeito R, Balleste R, Rodríguez MJ, Botto C, et al. Seroprevalence of Echinococcus granulosus infection in a Uruguayan rural human population. Trans R Soc Trop Med Hyg. 1991;85(6):769-72.

16. Echegoyen MC. Situación de los países. Argentina. En: Organización Panamericana de la Salud. Informe del Proyecto Subregional Cono Sur de Control y Vigilancia de la Hidatidosis Argentina, Brasil, Chile y Uruguay Primera Reunión Constitutiva Montevideo, Uruguay. Montevideo: OPS; 2004. p.28-30.

17. Frieder $B$, Larrieu $E$, Odriozzola $M$, Vargas $F$. Catastro ecográfico, serológico y radiológico en hidatidosis humana. Acta Gastroenterol Latinoam. 1985;15(4):199-211.

18. Frieder B, Larrieu E, Aguero A. Catastro ecográfico de hidatidosis en un área endémica, estudio comparativo con DD5. Rev Iber Parasitol. 1986;46:257-66.

19. Apt W, Pérez C, Galdamez E, Campano S, Veja F, Vargas D, et al. Equinococosis/hidatidosis en la VII Región de Chile: diagnóstico e intervención educativa. Rev Panam Salud Publica. 2000;7(1):8-16.

20. Morales M M, Luengo L J, Vásquez P J. Evolución de las tasas de morbilidad por hidatidosis en Chile desde 1989 a 1995. [En línea]. Avances en Ciencias Veterinarias 1998 [Acceso 31 de agosto de 2011];13(2):[2 p]. URL: http://www.revistas.uchile.cl/index.php/ACV/article/viewArticle/4810/4695.

21. Serra I, García V, Pizarro A, Luzoro A, Cavada G, López J. Un método universal para corregir la subnotificación en enfermedades transmisibles. Incidencia real de la hidatidosis humana en Chile, 1985-1994. Rev Med Chile. 1999;127(4):485-92.

22. González Ugas J. Situación de la echinococcosis quística en Chile. En: Organización Panamericana de la Salud. Tercera Reunión del Proyecto Subregional Cono Sur de Control y Vigilancia de la Hidatidosis Argentina, Brasil, Chile e Uruguay; 2006. Mayo 23-26; Porto Alegre, RS, Brasil. Río de Janeiro: OPS; 2006. p. 17-8.

23. Pavletic Brevis C. Situación de la equinococosis quística en Chile-2008. En: Organización Panamericana de la Salud. Informe del Proyecto Subregional Cono Sur de Control y Vigilancia de la Hidatidosis Argentina, Brasil, Chile y Uruguay. Sexta Reunión. Colonia del Sacramento, Uruguay. 9 de diciembre de 2009. Colonia del Sacramento: OPS; 2010. p.14-5.

24. Zancan Paz FA. Situación de la hidatidosis en Río Grande do Sul, Brasil. En: Organización Panamericana de la Salud. Informe del Proyecto Subregional Cono Sur de Control y Vigilancia de la Hidatidosis Argentina, Brasil, Chile y Uruguay Primera Reunión Constitutiva Montevideo, Uruguay. Montevideo: OPS; 2004. p.45-51.

25. Irabedra P, Salvatella R. El Proyecto Subregional Cono Sur de Control y Vigilancia de la Hidatidosis. Rev Peru Med Exp Salud Pública. 2010;27(4):598-603.

26. Náquira C, Bullón F, Balbín. Epidemiología de la Hidatidosis en el Perú. Anales del Seminario Nacional de Hidatidosis y Enfermedades de Transmisión Alimentaria. Ed. MINSA. Programa Nacional de Control de Zoonosis 1989.

27. Náquira C. Situación de la Hidatidosis en el Perú En: Reunión del grupo científico de trabajo sobre Hidatidosis. Montevideo Octubre 1994. Washington: OPS;1994. p 262-77.

28. Echinococosis quística en Bolivia. Hidatidosis en el municipio de Tupiza, Potosí. En: Organización Panamericana de la Salud. Informe del Proyecto Subregional Cono Sur de Control y Vigilancia de la Hidatidosis Argentina, Brasil, Chile y Uruguay. Sexta Reunión. Colonia del Sacramento, Uruguay. 9 de diciembre de 2009. Colonia del Sacramento: OPS; 2010. p.22-5.

29. Purriel P, Staehle J, Tórtora H, Prantl ML. Hidatidosis en el Uruguay. Radiografía de un problema. El Tórax. 1965;14(3):149-62.

30. Comisión Honoraria de Lucha Contra la Hidatidosis. Resultados de la encuesta helmintológica sobre mil canes de Montevideo y sus alrededores. Bol Trim Inform (Montevideo). 1971;3(3):4-5.

31. Importantes y peligrosas fuentes de infestación hidática en un suburbio de Montevideo: Rincón de la Bolsa. Hidatidosis. Bol Trim Inform (Montevideo). 1970;2:2.

32. Conti-Díaz I. Experiencia de docencia-investigación sobre enfermedades parasitarias en una población rural: Palmares de Quebracho, Paysandú, 1988 - 1898. Rev Med Urug 1990;6(2):103-9.

33. Cabrera, P. Presentación de la hidatidosis en la región sudamericana. [En línea] 2004. [Acceso 24 de enero de 2011] [aprox. 10p]. URL: http://www.panaftosa.org.br/hida/ hidatidosis-sudamer.doc.

34. Orlando DF. Evolution of the programme for the control of hydatidosis in Uruguay. Arch Int Hidatid. 1997;32:69-72.

35. Orlando DF. Situación de los países. Uruguay. En: Organización Panamericana de la Salud. Informe del Proyecto Subregional Cono Sur de Control y Vigilancia de la Hidatidosis Argentina, Brasil, Chile y Uruguay 2004. Montevideo: OPS; 2004. p. 39-42.

36. Elola S, Sakai H, Armúa T, Nonaka N, Oku Y, Irabedra P et al. Prevalencia de Echinococcus granulosus en Uruguay. Zoonosis 2009;1(1):35-6.

37. Larrieu E, Costa M, Cantoni G, Alvarez J, Jiménez N, Pérez A. Evaluación actividades de atención veterinaria. Rev San Hig. 1994;68:197-202. 
38. Zanini F, Bitsch A. Perspectivas de erradicación de la Hidatidosis en Tierra de Fuego, Argentina. Arch Int Hidatid. 1999;33:19-23.

39. Lamberti R, Calvo C, Pombar A, Gino L, Alvarez E, Aguado C et al. Hidatidosis en la provincia de La Pampa, Argentina, 1998. Bol Chil Parasitol. 1999;54(3-4):110-2.

40. González Peralta J, González G, González A, Sbaffo G, Bernardes A, Alacoba A et al. Echinococcosis canina en un sector del sur de las Sierras de Comechingones, Argentina. Rev Med Vet. 1996;77: 61-3.

41. González Peralta J, González G, Sbaffo A, Bessone A, Chassagnade M, Ugnial L, et al. Equinococosis canina en un sector del Departamento de Río Cuarto, Provincia de Córdoba, Argentina. Arch Med Vet. 1998; 30 (2):157-63.

42. Vargas D, Bonet R, Campano S, Chacón T, Vidal M. Evaluación epidemiológica de las técnicas de ELISA y electroinmunotransferencia en el diagnóstico de la hidatidosis ovina en la XI Región de Chile. Parasitol al Día. [En línea] 2001 [Acceso 28 de agosto de 2011]; 25(3-4): [aprox. 8p.]. URL: http://www.scielo.cl/scielo. php?script $=$ sci_arttext\&pid $=$ S0716-07202001000300004\&lng $=$ es\&nrm $=$ iso\&tlng $=e s$.

43. Campano Díaz S. Control de echinococcosis / hidatidosis en la X, XI y XII región de Chile. Arch Int Hidatid. 1997;32:64-9.

44. Campano Díaz S. Erradicación de hidatidosis/equinococcosis en la comuna Tierra de Fuego, XII Región de Magallanes y Antártica Chilena, Chile. Arch Int Hidatid. 1999;33:24-33.

45. Náquira C. Hydatidosis situation in Perú. En: Ruiz A, Schantz P, Arámbulo P, ed. Memorias de la Reunión del Grupo Científico sobre Avances en la Prevención, Control y Tratamiento de la Hidatidosis. Montevideo: OPS; 1994. p.218-29.

46. Chuquisana J, Chávez VA, Casas A.E. Determinación de Echinococcus granulosus en perros del Cono Norte de Lima. Rev Inv Vet Perú. 2000;11(2):126-31.

47. Cabrera P. Jornada de Capacitación para Maestros Coordinadores Departamentales CAPDER, MGAP Campaña de sensibilización sobre la importancia de la Salud Animal como patrimonio de los uruguayos. [En línea]. 2007. [Acceso 1o de setiembre de 2011]. [aprox. 5p.]. URL: www.cep.edu.uy/archivos/rural/ Hidatidosis.pdf.

48. Cabrera P, Irabedra P, Orlando D. Prevalencia de echinococcosis ovina nacional en establecimientos de faena. Arch Int Hidatid. 1999;33: 246-7.

49. Cabrera P, Irabedra P, Orlando D, Alvarez M, Elola S, Dos Santos C, et al. Diagnóstico de Prevalencia Nacional de metacestodes de Echinococcus granulosus en bovinos de playa de faena. En: Seminarios de Trabajos de Investigación. Departamento de Parasitología. Facultad de Veterinaria. Regional Norte. Salto, 28 de mayo de 2004.

50. Larrieu E, Costa MT, Cantoni G, Alvarez R, Cavagion L, Labanchi JL et al. Ovine Echinococcus granulosus transmission dynamics in the province of Río Negro, Argentina, 1980-1999. Vet Parasitol. 2001;98(4): 263-72.

51. Reickel MP, Baber DJ, Craig PS, Gasser RB. Cystic echinococcosis in the Falkland Islands. Prev Vet Med. 1996;27(3-4):115-23.

52. Salgueiro Nunes PC. Situación de la Hidatidosis en Brasil. En: Ruiz A, Schantz P, Arámbulo P, ed. Memorias de la Reunión del Grupo Científico sobre Avances en la Prevención, Control y Tratamiento de la Hidatidosis. Montevideo: OPS; 1994. p.164-88.

53. Elkhoury MR. Brasil: O Projeto Sub Regional Cone Sul e o Equinococose no Brasil» (en portugués). En: Organización Panamericana de la Salud. Informe del Proyecto Subregional Cono Sur de Control y Vigilancia de la Hidatidosis. Argentina, Brasil, Chile y Uruguay. Porto Alegre: OPS; 2006. p. 15-6.

54. Rycke PH. Equinococosis/hidatidosis en la VII Región de Chile: diagnóstico e intervención educativa. Rev Panam Salud Pública/Pan Am J Public Health. 2000;7(1):8-16.

55. Serra I, Araneda J, Araya C, Serra V. Análisis regional de la hidatidosis humana y animal en Chile, 1989-1993. Bol Chil Parasitol. 1996;5:3-12.

56. Sapunar J, Rappoport J Jr, Cumsille F. Quiste hidatídico hepático: características clínicas, factores pronósticos y resultados quirúrgicos. Parasitol Día. 1989;13(2):52-63.

57. Beggs I. The radiology of hydatid disease. AJR 1985;145(3):639-48.

58. Barquet N, Cayla JA, Corominas M, Bordas JM, Brau J, Trias E, et al. Hidatidosis en Cataluña. Estudio en pacientes menores de 20 años 1977-1985. Med Clin (Barc). 1989; 92 (4):121-8.

59. Latourrette Sapriza F. Equinococosis: retrospectiva de una enfermedad. Zoonosis. 2009;1:16-7

60. Larrieu EJ, Frider B. Human cystic echinococcosis: contributions to the natural history of the disease. Ann Trop Med Parasitol. 2001;95(7):679-87. 


\section{CAPÍTULO 5}

\section{Etiología}

La equinococosis hidática es una enfermedad parasitaria causada por un helminto de la familia Taeniidae, phyllum Platyhelminthes, clase Cestoidea.

\section{HELMINTOS.}

Los helmintos son animales invertebrados, de vida libre o parasitaria conocidos como gusanos. cilíndricos

Básicamente se distinguen los Platyhelminthes o gusanos aplanados, y los Nematoda o gusanos

Los Platyhelminthes, constituidos por trematodos y cestodos, se caracterizan por su simetría bilateral y ausencia de cavidad celómica. A excepción de algunas planarias, todos son parásitos.

\subsection{CESTODOS.}

Su aspecto morfológico les confiere el aspecto de cintas, motivo por el cual se los denomina tenias. Su tamaño es variable, no obstante su constitución anatómica es similar. Morfológicamente es posible reconocer tres segmentos: escólex o cabeza, cuello y estróbila.

El escólex o cabeza es la porción anterior del parásito. Su principal función es la de actuar como órgano de fijación, para lo cual puede presentar ventosas, botrias y ganchos. Las ventosas tienen un aspecto redondeado u oval y están provistas de una gruesa capa muscular. Habitualmente son cuatro. Las botrias, que generalmente se encuentran en número de dos, son hendiduras longitudinales. Los ganchos se disponen en uno o más círculos por delante de las ventosas en una zona retraible conocida como rostelo. del helminto.

El cuello delgado y relativamente indiferenciado posee la capacidad de formar todo el resto

El cuerpo recibe el nombre de estróbila o cadena. Está constituido por un número variable de proglótidas, elementos cuadrangulares dispuestos longitudinalmente uno tras otro.

Las proglótidas se originan en el cuello por un proceso de gemación asexuada conocido como la estrobilización. Las recién formadas están más cercanas al cuello y son más pequeñas. Es característico el desarrollo progresivo del aparato genital a medida que las mismas se alejan de la extremidad anterior, de modo que es posible distinguir proglótidas inmaduras, maduras y grávidas. La presencia de huevos constituye un rasgo distintivo de las últimas.

El tegumento de color blanco o grisáceo, está cubierto en toda su extensión por pequeñas elevaciones, denominados microtricos. Estos poseen una membrana constituida por macromoléculas de carbohidratos (glicocálix) cuya función es aumentar la superficie de absorción. La ausencia de aparato digestivo le confiere a la membrana especial importancia, ya que a través de ella se realiza el intercambio metabólico.

Debajo se identifican dos capas musculares.

Los sistemas nervioso y excretorio, rudimentarios pero eficientes, se extienden a lo largo de todo el cuerpo. El ganglio nervioso principal provisto de numerosas terminaciones sensitivas se ubica a nivel del escólex.

Son hermafroditas y cada proglótida presenta un sistema genital masculino. Este consta de un número variable de testículos, que por intermedio de vasos, conducto deferente y vesícula seminal, hacen llegar su contenido al órgano copulador o cirro. Al lado de éste se sitúa la vagina, que se comunica con el útero. Este puede almacenar gran cantidad de huevos y su aspecto morfológico constituye un elemento de gran valor para diferenciar las distintas especies. En el caso del Echinococcus 
granulosus lo caracteriza la presencia de divertículos bien desarrollados. El ovario morfológicamente semeja un riñón.

La fecundación habitualmente ocurre entre dos proglótidas que se adosan, no obstante pueden fecundarse a sí mismas ${ }^{1}$.

\subsubsection{Género Echinococcus.}

Cuatro son las especies del género Echinococcus (granulosus, multilocularis, oligarthus y vogeli) que se reconocen. En el cono sur de América únicamente la primera se ha identificado ${ }^{2}$.

Sus características morfológicas, biológicas y comportamiento epidemiológico son los elementos que se toman en cuenta para establecer los diferentes grupos.

Desde el punto de vista morfológico, estas se evidencian a nivel de las estróbilas, poro genital, ganchos rostelares, número de testículos y la forma del útero grávido. En el estadio larvario la ausencia o presencia de septos intraquísticos, su disposición y la ausencia de membranas que limitan su crecimiento. Así también las variaciones moleculares en la secuencia nucleotídica del segmento de 366 pares de bases, del gen mitocondrial citocromo oxidasa subunidad 1 del DNA (CO1) y en algunos pares de bases del segmento de 471 pares, del gen mitocondrial NADH dehidrogenasa (ND1), determinan rasgos característicos para cada una de las especies.

\subsubsection{Echinococcus granulosus.}

El ciclo del parásito reconoce 3 estadios: adulto, huevo y larva.

\section{FORMA ADULTA.}

Echinococcus granulosus es un parásito de naturaleza compleja cuya vida oscila entre 10 meses y 4 años.

Su fenotipo es el mismo en todos los ejemplares salvo las variaciones individuales propias de los seres vivos.

En forma general se puede establecer que en su estado adulto mide 4,8 $\pm 1,3 \mathrm{~mm}$ de longitud y $0,6 \mathrm{~mm}$ de ancho $^{3}$ (Foto 1 ).

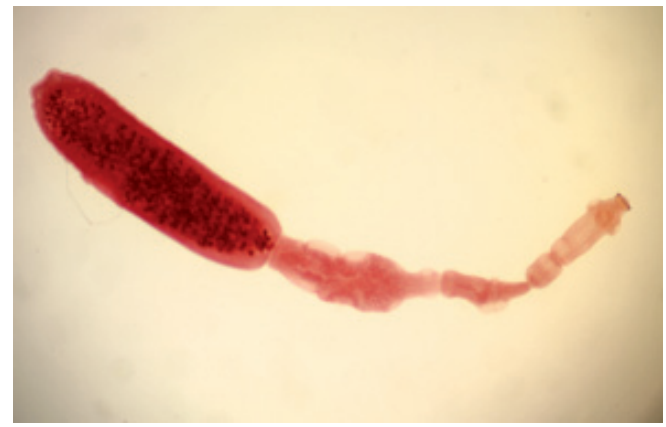

Foto 1.

Echinococcus granulosus. Adulto, Carmín Clorhídrico. (Cortesía de la Cátedra de Parasitología de la Facultad de Medicina de la Universidad de la República).

Su escólex consta de 4 ventosas que posibilitan la adherencia a las vellosidades intestinales y una doble corona de ganchos. Estas se disponen en forma concéntrica en un número que oscila entre 24 y 52, que contribuyen a la fijación del parásito. La longitud de los mismos varía entre 25 y 35 micras para los mayores y los más pequeños entre 22 y 27 micras. El cuello es corto y delgado, su longitud es de 0,25 mm.

La estróbila mide $2 \mathrm{~mm}$ de longitud, es decir que representa el $50 \%$ del parásito. Presenta 3 o 4 proglótidas. La última aloja el útero grávido conteniendo entre 100 a 800 huevos. El número de testículos oscilan entre 32 y $68^{4}$. Junto al primer testículo existe una glándula vitelógena y por delante de ésta un ovario bilobulado. El canal deferente es sinuoso y el saco del cirro es grande. 
Comienzan a producir huevos en un período de 34 a 53 días, estimándose que dicha capacidad se mantiene por un plazo que varía entre 100 días y 18 meses.

Esta especie se caracteriza por la gran diversidad genotípica originada por el proceso de adaptación del parásito al huésped intermediario.

Esta característica junto a uno o más caracteres de significado real o potencial para la epidemiología y el control de la equinococosis, determinan las cepas ${ }^{5}$.

Actualmente se reconocen 9 cepas que se identifican con números itálicos, muchas de ellas presentes en América del Sur ${ }^{6-8}$. Ellas son: oveja (G1), oveja de Tasmania (G2), búfalo (G3), caballo (G4), bovino (G5), camello (G6), cerdo (G7), ciervo (G8), león (G9).

La cepa G1 se distribuye fundamentalmente en América del Sur, Australia, África, Europa, Estados Unidos de Norteamérica, Nueva Zelanda, China y Oriente Medio. Son huéspedes intermediarios los ovinos, bovinos, cerdos, camellos, cabras y el hombre. Los huéspedes definitivos son cánidos (perro, dingo, chacal y lobo) y carnívoros (hiena y zorro).

La cepa G2 se encuentra en Tasmania y Argentina, siendo sus huéspedes intermediarios las ovejas y el hombre, los definitivos perros y zorros. definitivo.

La cepa G3 se ha identificado en Asia, siendo su huésped intermediario el búfalo y el perro el

La cepa G4 se distribuye en Europa, Oriente Medio y Sudáfrica. Son huéspedes intermediarios el caballo y otros equinos y el definitivo cánidos.

La cepa G5 se encuentra en Europa, América del Sur, Sudáfrica, India, Sri Lanka. Sus huéspedes intermediarios son los vacunos y el hombre y el definitivo cánidos.

Cepa G6 presente en Argentina, Oriente Medio, África y China. Su huésped intermediario son los camellos y cabras y definitivo cánidos (familiaris y lupus).

Cepa G7 presente en América del Sur y Europa. Su huésped intermediario es el cerdo y el definitivo el perro.

Cepa G8 que tiene a los ciervos y el hombre como huéspedes intermediarios y al perro y lobo como definitivos se distribuye en Eurasia y América del Norte.

Cepa G9 se encuentra en África, siendo los huéspedes intermediarios las cebras, ñus, jabalíes, búfalos y antílopes y el huésped definitivo el león ${ }^{4}$.

\section{b) HUEVOS.}

Los huevos constituyen la forma infectante del huésped intermediario. Estos resultan de la pérdida de la capa vitelina del embrióforo una vez que los últimos han tomado contacto con el medio exterior.

Su forma es ovoidea con un tamaño que oscila entre 35 y 38 micras. Estructuralmente se encuentran constituidos por el embrión hexacanto u oncoesfera (primer estado larval) cubierto por una cápsula radiada, gruesa, resistente y queratinizada. Morfológicamente son indistinguibles de los huevos de otras tenias.

De acuerdo a sus características biológicas es posible clasificar los ciclos de los cestodos. Las del Echinococcus granulosus pertenecen al orden Cyclophyllidea, caracterizado por contener un embrión hexacanto capaz de infectar un nuevo huésped al momento de la postura.

\section{c) METACESTODO.}

Constituye el segundo estado larval, caracterizado por su forma esférica, unilocular, siendo su contenido líquido (Figura 1). Estructuralmente consta de dos capas, una externa llamada membrana cuticular o laminar y otra interna, membrana germinativa o prolígera (Foto 2). 


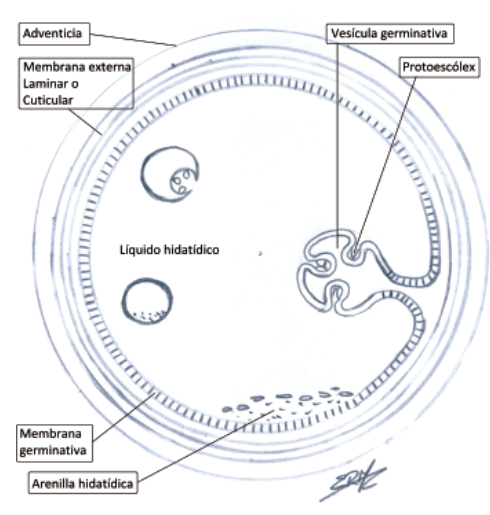

Foto 2.

Echinococcus granulosus. Membranas hidáticas (cuticular laminada), Hematoxilina Eosina.

(Cortesía de la Cátedra de Parasitología de la Facultad de Medicina de la Universidad de la República)
Figura 1.

Esquema de quiste hidático

La membrana cuticular desde el punto de vista macroscópico es lisa, opaca, de color blanco, a veces amarillento y elástica. Se la compara con la clara de huevo cocida. Mide 1 a $2 \mathrm{~mm}$ de espesor, es acelular, constituida por una serie de capas. Ultraestructuralmenente se compone de un complejo proteína - polisacáridos en el que se destacan, la glucosa, galactosa, N-acetilglucosamina, Nacetilgalactosamina, y mucinas ${ }^{9-12}$. Las proteínas representan el $33 \%$ de su peso seco. El aminoácido predominante es la treonina. Dentro de sus componentes inorgánicos las sales de calcio representan el $20 \%$.

Es de destacar que en nuestro país se realizaron trabajos pioneros en la determinación de la composición de esta membrana ${ }^{13}$.

En el año 2002 se identificó en nuestro país, la existencia de importantes cantidades de myo inositol hexaquifosfato asociado a calcio en forma de sal ${ }^{14-17}$. Representa aproximadamente el $15 \%$ del peso seco de la pared del quiste, encontrándose en forma de gránulos densos que alcanzan a medir decenas de nanómetros de diámetro. Su función en el parásito aún no ha sido claramente determinada. Se postula que puedan estar involucradas en la retención selectiva de calcio. El hexafosfato de inositol es un antioxidante que posee un efecto protector contra el cáncer de colon. Su presencia en la hidátide constituye una importante línea de investigación.

Esta capa con escasa permeabilidad, constituye una verdadera barrera inmunológica y microbiológica, siendo a través de ésta que el parásito realiza intercambios nutricionales ${ }^{18}$. A partir del tercer día del proceso de desarrollo del metacestodo, es posible observar tres tipos de vesículas (Vd, $\mathrm{Vg}, \mathrm{Vg} 2)$ que contribuirán al desarrollo final de las capas del parásito.

La prolígera cuyo espesor oscila entre 10 y 30 micras, se encuentra constituida por células mononucleares, proliferativas y pluripotenciales que dan origen al líquido hidatídico y vesículas prolígeras. Se encuentra adherida laxamente a la cuticular, pudiendo desprenderse de ésta a causa de traumatismos, pérdida de la vitalidad parasitaria o alteraciones químicas como las debidas al aumento de potasio.

En un período aproximado de seis meses, da inicio el desarrollo de las vesículas prolígeras. Al completarse alcanzan un diámetro entre 300 y 600 micras. La estructura de su membrana es igual a la de la prolígera, a la que se mantiene unida por un pedículo. A partir de su membrana se originan los protoescólices, en los que inicialmente se identifican las ventosas y luego los ganchos (Foto 3). Las proteínas, hidratos de carbono y lípidos constituyen el $62,5 \%, 19,8 \%$ y $13,6 \%$ respectivamente de su peso seco. Cada vesícula prolígera contiene entre 10 a 40 protoescólices. 
Foto 3.

Echinococcus granulosus . Arenilla hidática (protoescólices invaginados y evaginados), Examen en fresco.

(Cortesía de la Cátedra de Parasitología de la Facultad de Medicina de la Universidad de la República)

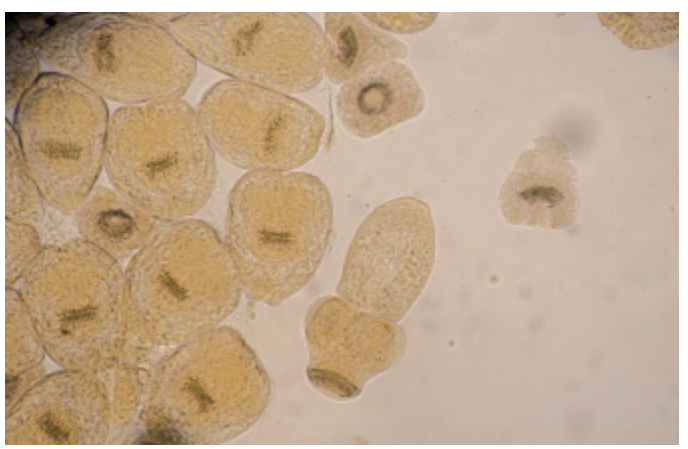

A diferencia de los huevos son muy sensibles al calor húmedo. Su exposición a una temperatura de 55 o C los destruye en 30 minutos. Igual efecto produce en pocos minutos el cloruro de sodio al $33 \%$, hipoclorito de sodio, bicloruro de mercurio al 1:1000 y formol al 1:100.

La composición del líquido hidático varía de acuerdo a la especie animal e individuo parasitado, así como a la localización y edad del parásito. Se caracteriza desde el punto de vista macroscópico por presentar un color claro (cristal de roca) en quistes no complicados.

Su densidad varía entre 1007 y 1012, en tanto el ph entre 6,7 y 7,9. Es rico su contenido proteico, oscilando los valores de albúmina entre 0,08 y 0,69 gramos por litro. Este importante contenido proteico es el responsable de la antigenicidad provocada por el parásito, determinante de las reacciones alérgicas en el huésped en situaciones de complicación del quiste. Fundamentalmente se trata de los antígenos 5 y B. El primero de ellos está presente en la capa prolígera e interior de los protoescólices, en tanto el segundo en la capa cuticular y superficie de los protoescólices.

Habitualmente la glucosa varía entre 0,08 y 0,40 gramo por litro, aunque en la topografía hepática puede alcanzar niveles de 0,5 y 1 gramo por litro. Los lípidos, proteínas y aminoácidos también han sido identificados, fundamentalmente leucina y tirosina.

La urea adquiere un valor de 0,47 gramos por litro, ácido úrico entre 0,003 y 0,03 gramos por litro, cloro 3,47 gramos por litro. La concentración de este último tiene una relación inversa con el contenido de albúmina. A esto debemos sumarle la presencia de las sales de: cloruro (4,5 a 6,5 gramos por litro), sulfato y fosfato de sodio. Otros componentes son $\mathrm{K}, \mathrm{Mg}, \mathrm{Cu}$, Fe.

Dentro de los componentes parasitarios los ganchos, escólices, vesículas prolígeras y elementos de descamación de la capa germinativa constituyen la arenilla hidática. Las vesículas prolígeras se originan en la capa germinativa, siendo los escólices producto de estas últimas. Los escólices cuando degeneran o mueren desprenden sus ganchos (Foto 4).

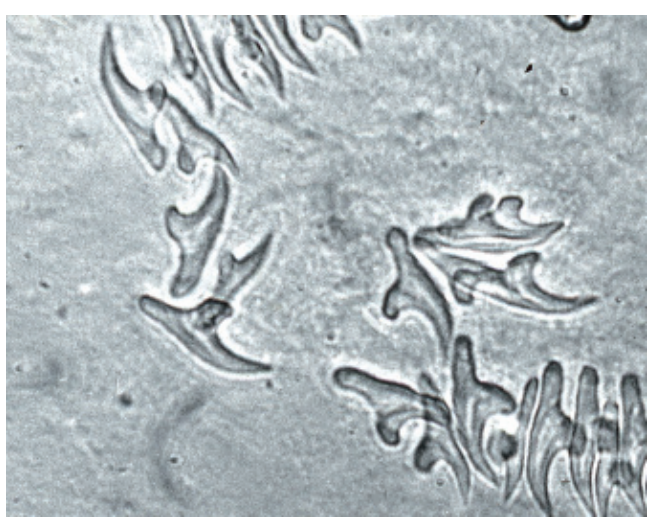

Foto 4.

Echinococcus granulosus. Ganchos.

(Cortesía de la Cátedra de Parasitología de la Facultad de Medicina de la Universidad de la República) 
Es preciso recordar que por cada centímetro cúbico de esta última existe un promedio de 400.000 escólices. Este aspecto adquiere real importancia al momento de la cirugía ya que la única forma de evitar la siembra por derramamiento del líquido hidatídico en el campo operatorio es su adecuada protección y esterilización del contenido.

La presión en un quiste hialino oscila entre 40 y 80 centímetros de agua. El tratamiento médico puede hacer descender estas cifras a valores de entre 35 y 45 centímetros de agua. Estas presiones superan las alcanzadas por la vía biliar y vía aérea, hecho que explica desde el punto fisiopatológico la comunicación generada con dichas estructuras al producirse la apertura del quiste.

\section{CICLO EVOLUTIVO.}

El ciclo biológico del parásito se cumple entre animales ungulados herbívoros (huéspedes intermediarios) y predadores caninos (huéspedes definitivos). Los huéspedes intermediarios ingieren huevos provenientes de los huéspedes definitivos, desarrollándose la segunda fase larval (metacestode). El ciclo se completa tras la ingestión por parte de los huéspedes definitivos de vísceras contaminadas de huéspedes intermediarios.

De acuerdo al tipo de animales en que este ocurra, se lo puede catalogar en doméstico o silvestre (Figura 2).

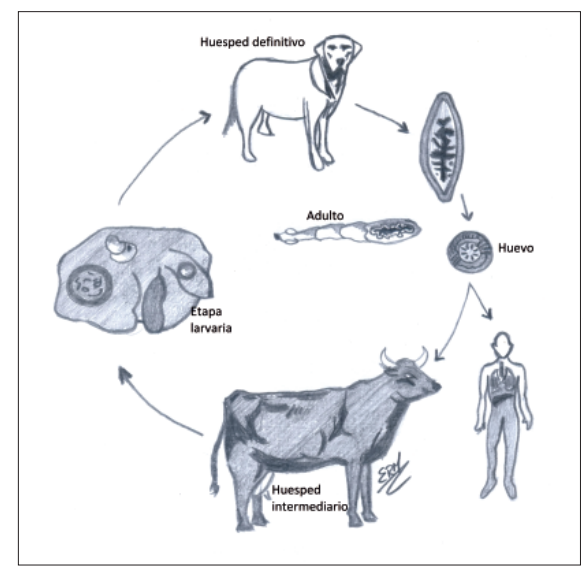

Figura 2.

Ciclo doméstico.

En el primero de ellos la fase adulta transcurre en el intestino del perro, en tanto la fase larvaria se desarrolla en forma de quiste en las vísceras del ganado bovino, ovino, porcino, caprino y ocasionalmente en el caballo, asno, gato y conejo.

Por su parte en el ciclo silvestre los predadores son carnívoros, entre ellos: el zorro, hiena, león. Su fase larvaria se desarrolla en ciervos, alces, renos, osos, liebres y ratas ${ }^{19}$.

El ser humano es huésped intermediario accidental, por tanto huésped terminal de la cadena epidemiológica sin implicancias para la transmisión.

Los huéspedes definitivos se infectan al ingerir los quistes hidatídicos localizados en vísceras de los huéspedes intermediarios.

Seis horas luego de la ingestión, se produce la liberación de los protoescólices determinada por la acción de la pepsina gástrica y la bilis al disolver la membrana quística. Los protoescólices se fijan a la mucosa intestinal a través de sus ventosas y ganchos. A partir de ellos se desarrollan las proglótidas, presentes a los 14, 18 y 21 días la primera, segunda y tercera respectivamente (Foto 5). A los 30 días se comienzan a formar los huevos en la última proglótida. Este desprendimiento ocurre entre 47 y 52 días, marcando el final del período de crecimiento del parásito. Su vida media es de 180 a 240 días, motivo por el cual es capaz de producir 2 o 3 partos y luego alcanzar el estado senil y finalmente ser eliminado junto a las heces del animal. 
Foto 5.

Echinococcus granulosus. Adulto en epitelio intestinal de perro, Hematoxilina Eosina.

(Cortesía de la Cátedra de Parasitología de la Facultad de Medicina de la Universidad de la República)

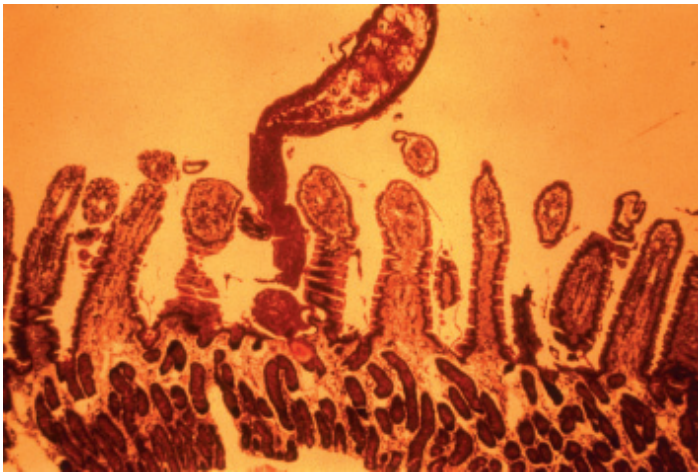

La presencia de tenias en el perro es capaz de determinar dos tipos de teniasis, aguda y crónica. La primera rápidamente letal, no constituye un real problema en la trasmisión de la enfermedad, ya que la tenia no logra el desarrollo suficiente para ser infectante. La crónica generalmente transcurre en forma asintomática o determina una enteritis leve y transitoria, a pesar de la existencia de una media de 1000 a 1500 tenias en los primeros $30 \mathrm{~cm}$ del intestino del perro. Se han llegado a identificar más de 20.000. Si tenemos en cuenta que cada una de ellas produce diariamente entre 34 y 58 huevos, es fácilmente objetivable el número total de huevos eliminados. En nuestro país, Tálice ${ }^{20}$ en 1937 llevó a cabo varios experimentos de infestación en perros con fines de investigación.

Los huevos eliminados junto a la materia fecal pueden quedar adheridos a los pelos, ano $u$ hocico del perro o ser esparcidos a largas distancias por intermedio de insectos (hasta 30.000 hectáreas) o el viento. Se ha comprobado que estos huevos pueden ser fértiles 4 meses luego de haber permanecido a una temperatura de menos $1^{\circ} \mathrm{C}$, o un año a temperaturas entre 4 y $15^{\circ} \mathrm{C}$ y ambientes húmedos. Igualmente su permanencia en aguas poco profundas o arena húmeda les permiten sobrevivir 3 semanas. Resisten a la exposición a etanol a concentraciones de 50, 70 y 95\% en períodos que oscilan entre 5 y 60 minutos. Los desinfectantes comerciales con acción sobre bacterias y virus no los afectan, siendo muy resistentes al formol, permanganato de potasio y lugol.

El comportamiento es diferente cuando son sometidos a desecación. Su destrucción se produce a los 4 días cuando son sometidos a una humedad ambiente de 25\%, 1 día cuando la misma es de $0 \%$ y 5 minutos a temperaturas entre 60 y $800^{\circ} \mathrm{C}$. Son poco resistentes a su permanencia en aguas profundas. La ebullición los destruye luego de 20 minutos. También son altamente sensibles al glutaraldehído a concentraciones de 5 y $10 \%$.

Los huéspedes intermediarios se infectan tras ingerir alimentos o agua contaminada con huevos eliminados por los carnívoros.

En el hombre y especialmente en niños, las características de sus hábitos de juego, particularmente aquellos que determinan el contacto de sus manos con el suelo y la compañía de perros parasitados, son factores determinantes de la enfermedad en este grupo etario.

En ovinos se ha determinado que ello ocurre luego de la ingestión entre 598 y 693 huevos, lo que permitirá el desarrollo de 2,1 y 6,03 quistes por infección ${ }^{21}$.

La acción de las enzimas proteolíticas del estómago e intestino permiten la liberación del embrión hexacanto que por medio de sus ganchos, liberación de secreciones y movimientos rítmicos del cuerpo atraviesa las criptas de las vellosidades del yeyuno íleon alcanzando así la luz de los capilares del sistema porta. De esta forma se distribuyen pasivamente hasta encontrar el primer filtro, el parénquima hepático, que de sortearlo alcanzarán otros órganos o tejidos (Figura 3).

A las tres horas de ingestión se reconocen los embriones hexacantos en el hígado. Adoptan la forma de una masa multinucleada de 30 a 36 micras rodeada de leucocitos a partir de la quinta. A las 6 horas mide 200 micras de diámetro, disminuyendo su tamaño a 30 o 40 micras al cuarto día, momento 


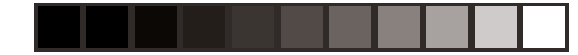

ETIOLOGÍA

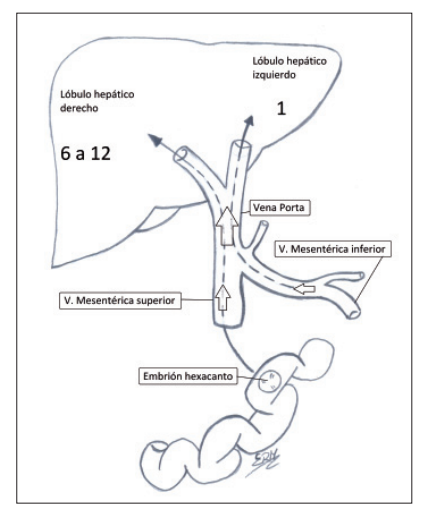

Figura 3.

Pasaje del embrión hexacanto desde el intestino al hígado. (Adaptado de Larghero)

en el que comienza a identificarse una vacuola central. Al séptimo día alcanza la forma y estructura definitiva. Su crecimiento es progresivo midiendo 1, 1,5 y 5 milímetros al segundo, tercer y quinto mes respectivamente. De ahí en más el mismo dependerá del potencial evolutivo del embrión hexacanto, del tejido en el que se aloja, de la edad y especie del animal parasitado.

La formación de vesículas prolígeras y escólices en el hombre ocurre en general tardíamente. Estas dependen del sufrimiento del parásito vinculadas a la limitación de su libre crecimiento, determinado por el parénquima en el cual asientan, envejecimiento del quiste e infección del espacio pericistoadventicial entre otros. Otro mecanismo defensivo en respuesta a dicha agresión es la vesiculización endógena, proceso por el cual los escólices dan origen a vesículas hijas y éstas a vesículas nietas (Foto 6 y 7).

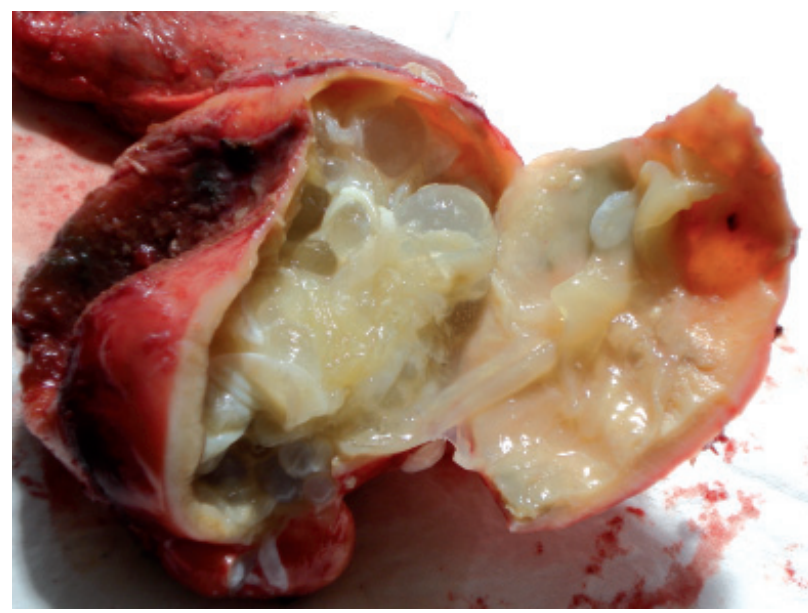

Foto 6.

Vesículas hijas en el interior de un quiste.

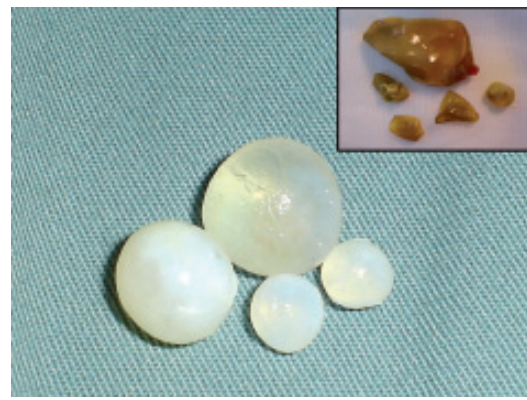

Foto 7.

Vesículas teñidas de bilis, denotan algún tipo de comunicación del quiste con la vía biliar. 
La vesiculización exógena es otra modalidad evolutiva aunque de menor frecuencia. Las vesículas hijas se pueden desarrollar entre la membrana germinativa y quitinosa, motivo por el cual se las denomina intraquitinosas o subgerminales. Otras lo hacen entre la quitinosa y la adventicia y se la conoce como extraquitinosas o subadventiciales. Se plantea que se originan de la transformación vesicular de los escólices o de islotes germinativos presentes en la membrana hidatídica. De esta forma crecen entre la capa germinativa y la adventicia.

Se estima que el desarrollo de los protoescólices dentro del quiste ocurre luego de 10 meses de la infección, aunque algunos de ellos permanecen estériles. Los protoescólices son los responsables de la siembra ante la rotura del quiste. Poseen la capacidad de vesiculización en su base, con desaparición de ganchos y ventosas y así dan origen a una nueva hidátida. Esta potencialidad regresiva de la porción basal de los protoescólices es muy importante desde el punto de vista biológico (Foto 8).

Foto 8.

Echinococcus granulosus. Vesiculización de protoescólice en cultivo. (Cortesía de la

Cátedra de Parasitología de la Facultad de Medicina de la Universidad de la República)

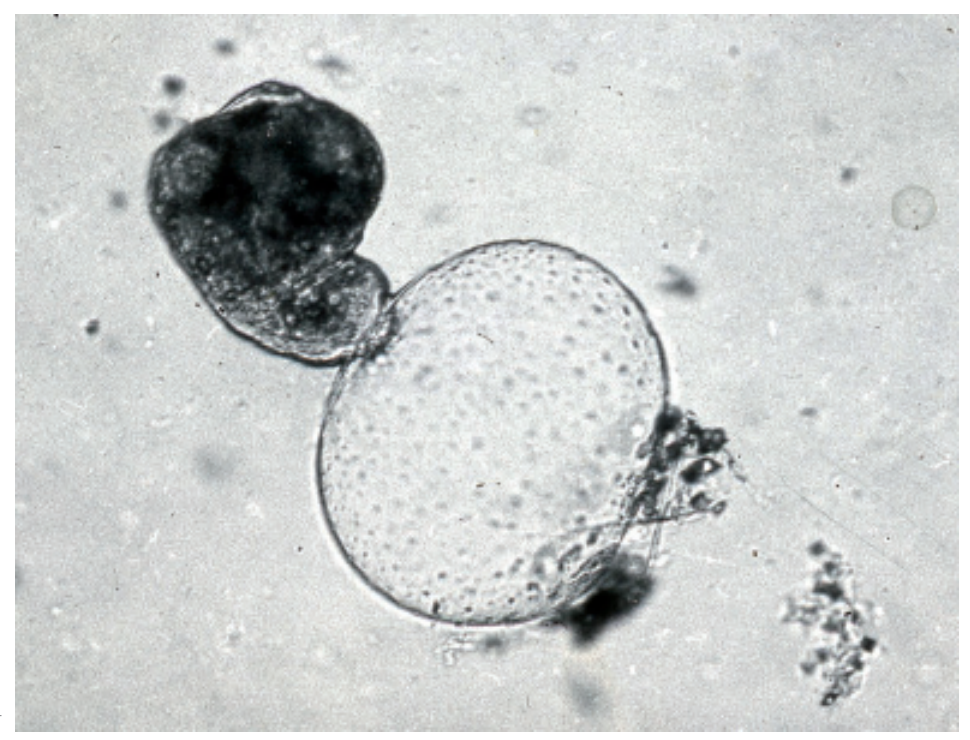

Se ha establecido que la fertilidad aumenta con la edad del animal, habiendo reportes que comunicaron una fertilidad de $4,5 \%$ de los quistes en animales de $4 / 6$ dientes, con una viabilidad del $36 \%{ }^{22}$.

En animales, la madurez se alcanza muy lentamente, estimándose un crecimiento de 1 milímetro por mes. En herbívoros puede sobrevivir durante toda la vida del animal y permanecer asintomático. En otros, la sintomatología es similar a la ocurrida en humanos.

Si bien se ha demostrado que la re infección en perros ocurre entre $5,2 \%$ y $6,7 \%$ a los 60 días y $18,6 \%$ y $21,3 \%$ a los 120 días del total de perros tratados con antihelmínticos, $50 \%$ de los mismos adquieren inmunidad natural luego de la sexta infestación ${ }^{23,24}$.

Una vez establecida la re infección, el perro inicia un nuevo ciclo de contaminación ambiental en un plazo aproximado de 7 semanas, momento en el cual comienza nuevamente a liberar huevos fértiles ${ }^{3}$.

La inmunidad adquirida también ha sido demostrada en ovinos en condiciones de permanencia de huevos en el medio ambiente. Como contrapartida, la desaparición de éstos últimos por un período de 6 a 12 meses determina el resurgimiento de la enfermedad ${ }^{23}$. 


\section{ANATOMIA PATOLOGICA}

La llegada del embrión hexacanto al tejido parasitado, induce una reacción local en el huésped que dará origen a la adventicia o periquística. Esta última junto a la segunda forma larval del Echinococus granulosus (metacestode), constituye el quiste hidático (Foto 9).

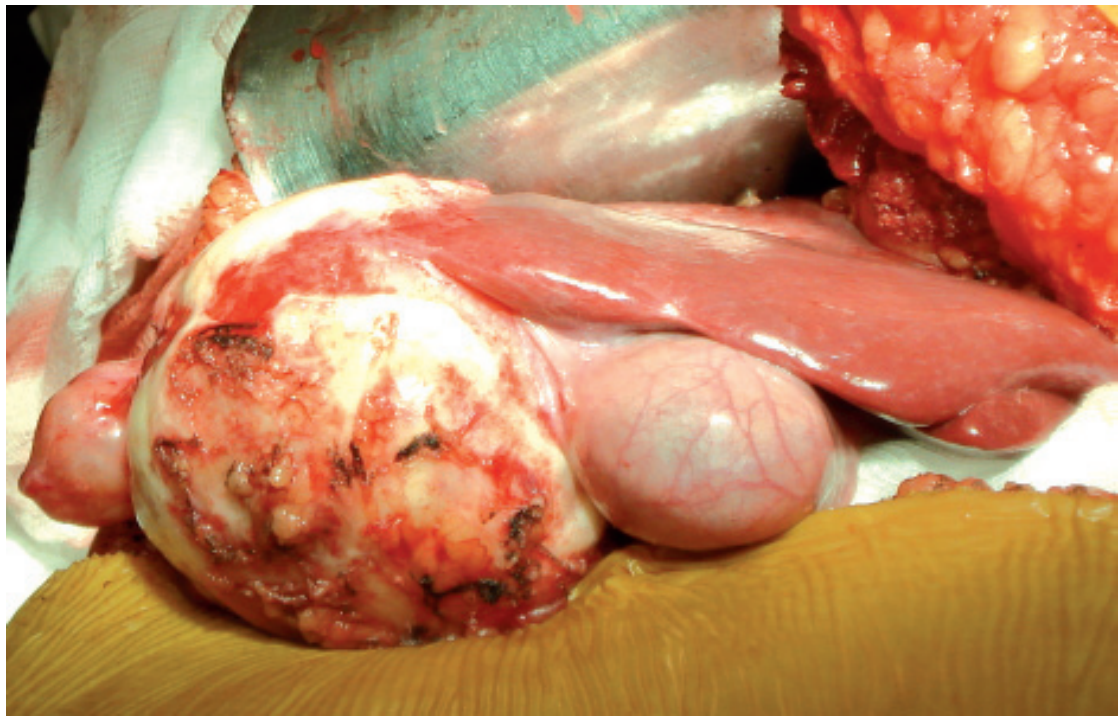

Foto 9. Quiste hidático hepático.

En esta sesión desarrollaremos los principales aspectos vinculados con la adventicia, ya que la descripción del metacestode fue realizada previamente.

En el hígado, a las 60 horas de producida la llegada del embrión hexacanto es posible distinguir tres zonas que se definen claramente entre el tercer y séptimo día. 1) La interna contacta con el parásito y la forman células epitelioides, eosinófilos y gigantes multinucleadas; 2) una zona media conjuntiva, fibroelástica con vasos de neoformación además de neutrófilos, linfocitos, plasmocitos y fibroblastos y 3) la zona externa o periférica donde se aprecia la citolisis de las células hepáticas e infiltración de polimorfonucleares.

Entre los 3 y 5 meses ha completado su desarrollo y se definen tres zonas: 1) una interna yuxtahidatídica epitelioide, gigantocelular, fibrosa, a veces hialinizada, conocida como herida esferoidal en la que es posible identificar conductos biliares y vasos sanguíneos obliterados parcial o totalmente; 2) una media formada por tejido de granulación con escasa fibrosis y 3) una periférica, fibrosa, que aumenta de espesor a consecuencia de la citolisis de nuevas células hepáticas infiltrada por linfocitos, eosinófilos y neutrófilos.

El crecimiento progresivo del quiste determina la degeneración hialina y caseosa de la adventicia, llegando en sus etapas más avanzadas a la degeneración calcárea. Debemos destacar que este proceso de degeneración no es homogéneo, por lo que es posible reconocer sectores en diferentes etapas evolutivas junto a otros que mantienen sus características habituales. Esta involución adquiere su grado máximo denominado pasta o masilla hidática caracterizada por la retracción del parásito y la adventicia en la que es posible reconocer las diferentes etapas de degeneración.

Las estructuras canaliculares del parénquima hepático son involucradas en este proceso. Los vasos son colapsados y finalmente trombosados. La horadación y pasaje de elementos parasitarios hacia la circulación solo es posible en el sistema venoso, ya que así lo permite la diferencia de presiones existente entre ambos. 
El compromiso y apertura de canalículos biliares son los responsables de la colerragia perivesicular e intraquística, pasaje de elementos hidáticos a las vías biliares e infección de la adventicia. Esta última de ser localizada no produce mayores alteraciones en el metacestode. De lo contrario se desarrollan los mecanismos defensivos ya tratados precedentemente, hasta alcanzar la desintegración del parásito y constituir el quiste hidatídico supurado. Aquí se mezclan los restos parasitarios con los productos de supuración de la adventicia. La infección determinada por bacterias anaerobias productoras de gas es la base del pioneumoperiquiste observado en estudios imagenológicos.

En el parénquima hepático dos hechos caracterizan la evolución de los quistes, especialmente los de localización intrahepática: atrofia del lóbulo parasitado e hipertrofia compensadora del indemne.

\section{FERTILIDAD DEL QUISTE HIDATICO EN HUMANOS}

En sus Tesis de Doctorado, Alvarez ${ }^{25}$ concluyó:

1. En cualquier etapa evolutiva del quiste pueden haber elementos fértiles, en menor proporción en el estado mastic y probablemente nula en los calcificados.

2. La fertilidad no guarda relación con el aspecto externo del quiste, dado por la reacción adventicial.

3. En los quistes hepáticos la presencia de bilis y supuración produce una aceleración en la muerte del parásito; pero en quistes con bilis y vesículas hijas enteras, pueden quedar protoescólices vitales dentro de las mismas.

4. El tamaño y la localización no son elementos confiables para prejuzgar la viabilidad del quiste.

5. Los quistes primitivos comienzan a ser fértiles posiblemente antes y seguramente al alcanzar el tamaño de 2 a $3 \mathrm{~cm}$.

6. Las vesículas hijas son fértiles desde un diámetro menor de $5 \mathrm{~mm}$.

Esta tesis constituye un valioso aporte a la práctica quirúrgica. Independientemente de su estado evolutivo, el cirujano debe considerar como fértil a todo quiste hidático y por tanto tomar las máximas precauciones para minimizar el riesgo de contaminación peritoneal.

\section{Bibliografía consultada.}

Atías A, Neghme A. Parasitología Clínica. Ed. Mediterráneo. Santiago de Chile. 2ª Reimpresión; 2001.

Osimani J. Parasitología Médica. Tomo II. Librería Médica Editorial. Montevideo; 1982.

Ivanissevich O, Rivas Cl. Equinococosis hidatídica. Buenos Aires; 1961.

Larghero P, Venturino W, Broli G. Equinococosis hidatídica del abdomen. Montevideo: Delta editorial. Montevideo; 1962.

Referencias bibliográficas.

1. Lymbery A. Combining data from morphological traits and genetic markers to determine transmission cycles in the tapeworn, Echinococcus granulosus. Parasitology. 1998;117(Pt.2):185-92.

2. Guarnera E. Hidatidosis humana, su impacto, diagnóstico, manejo y tratamiento. En: Organización Panamericana de la Salud. Informe del Proyecto Subregional Cono Sur de Control y Vigilancia de la Hidatidosis Argentina, Brasil, Chile y Uruguay Primera Reunión Constitutiva Montevideo, Uruguay. Montevideo: OPS; 2004 p.57-85.

3. Larrieu E, Belloto A, Arambulo III P, Tamayo H. Echinococcosis quística: epidemiología y control en América del Sur. Parasitol Latinoam. 2004;59(1-2):82-9.

4. Eckert J, Deplazes P. Biological, Epidemiological, and Clinical Aspects of Echinococcosis, a Zoonosis of Increasing Concern. Clin Microbiol Rev. 2004;17(1):107-35.

5. Thompson R, Lambery A. The nature, extent and significance of variation within the genus Echinococcus. Adv Parasitol. 1988;27:209-58. 
6. Eckert J, Thompson R. Intraespecific variation of Echinococcus granulosus and related species with emphasis on their infectivity to humans. Acta Trop. 1997;64(1-2):19-34.

7. Rosenzvit M, Zhang L, Kamenetzky L, Canoba SG, Guarnera EA, Mc Manus DP. Genetic variation and epidemiology of Echinococcus granulosus in Argentina. Parasitology. 1999;118(Pt.5): 523-30.

8. Thompson R, McManus D. Towards a toxonomic revision of the genus Echinococcus. Trends Parasitol 2002;18(10):452-7.

9. Casaravilla C, Díaz A. Studies on the structural mucins of the Echinococcus granulosus laminated layer. Mol Biochem Parasitol. 2010;174(2):132-6.

10. Díaz A, Fontana EC, Todeschini AR, Soulé S, González H, Casaravilla C, et al. The major surface carbohydrates of the Echinococcus granulosus cyst: mucin-type O-glycans decorated by novel galactose-based structures. Biochemistry. 2009;48(49):11678-91.

11. Freire T, Fernández C, Chalar C, Maizels RM, Alzari P, Osinaga E, et al. Characterization of a UDP$\mathrm{N}$-accetyl-D-galactosamine: polypeptide $\mathrm{N}$-acetylgalactosaminyltransferase with na unusual lectin domain from the platyhelminth parasite Echinococcus granulosus. Biochem J. 2004;382(Pt.2):501-10.

12. Khoo KH, Nieto A, Morris HR, Dell A. Structural characterization of the N-glycans from Echinococcus granulosus hydatid cyst membrane and protoscoleces. Mol Biochem Parasitol. 1997;86(2):237-48.

13. Lasalvia E, Hierro J, Calcagno M, Kork I. Estudio químico de la membrana hidatídica. El Tórax. 1965;14(3-4):196-201.

14. Irigoín F, Ferreira F, Fernández C, Sim RB, Díaz A. myo-Inositol hexakisphosphate is a major component of an extracellular structure in the parasitic cestode Echinococcus granulosus. Biochem J. 2002;362(Pt.2):297-304.

15. Irigoín F, Casaravilla C, Iborra F, Sim RB, Ferreira F, Díaz A. Unique precipitation and exocytosis of a calcium salt of myo-inositol hexakisphosphate in larval Echinococcus granulosus. J Cell Biochem. 2004;93(6):1272-81.

16. Díaz A, Casaravilla C, Irigoín F, Lin G, Previato JO, Ferreira F. Understanding the laminated layer of larval Echinococcus I: structure. Trends Parasitol. 2011;27(5):204-13.

17. Casaravilla C, Brearley C, Soulé S, Fontana C, Veiga N, Bessio MI, et al. Characterization of myoinositol hexakisphosphate deposits from larval Echinococcus granulosus. FEBS J. 2006;273(14):3192203.

18. Díaz A, Casaravilla C, Allen JE, Sim RB, Ferreira AM. Understanding the laminated layer of larval Echinococcus II: immunology. Trends Parasitol. 2011;27(6):264-73.

19. Schantz P, Collie C, Cruz Reyes A, Prezioso U. Sylvatic echinococcosis in Argentina. Tropenmed Parasitol. 1976; 27(1):70-8.

20. Tálice RV. Infestación experimental del perro con la tenia equinococo. Arch Urug Med Cir Espec. 1937;10:746-59.

21. Torgerson P, Williams D, Abosheada M. Modeelling the prevalence of echinococcus and taenia species in small rumiants of different ages in northern Jordan. Vet Parasitol. 1998;79(1):35-51.

22. Cabrera P, Harán G, Benavídez U, Valledor S, Perera G, Lloyd S, et al. Transmission dynamics of Echinococcus granulosus, Taenia hydatigena and Taenia Ovis in sheep in Uruguay. Int J Parasitol. 1995;25(7):807-13.

23. Cabrera P, Lloyd S, Haran G, Pineyro L, Parietti S, Gemmell M, et al. Control of Echinococcus granulosus in Uruguay: evaluation of different treatment intervals for dogs. Vet Parasitol. 2002;103(4):333-40.

24. Larrieu E, Costa M, Cantoni G, Labanchi JL, Bigatti R, Aquino A, et al. Rate of infection and of reinfection by Echinococcus granulosus in rural dogs of the Province of Rio Negro. Vet Parasitol. 2000; 87(4): 281-6.

25. Alvarez C. Aspectos evolutivos de la hidatidosis humana y correlación con su fertilidad [Tesis de Doctorado]. Montevideo: Facultad de Medicina, Universidad de la República;1989. 
CAPÍTULO 6

\section{Presentación clínica}

Diversos aspectos determinan que la presentación clínica de la hidatidosis hepática sea muy variable. Son factores determinantes la topografía, tamaño, estado evolutivo y relaciones que adquiere el quiste dentro del parénquima hepático. Circunscribiremos el desarrollo del tema a la hidatidosis hepática primaria, entendiendo por tal aquella que resulta del desarrollo de la hidátide en el hígado luego del implante del embrión hexacanto, previa ingestión de huevos viables. Por tanto no se tratará la hidatidosis secundaria, producto de la rotura - espontánea o traumática - de un quiste hidático fértil.

Sobre esta base y de acuerdo a la historia natural de la enfermedad es posible reconocer tres periodos: 1) asintomático, inaparente o de incubación en referencia al tiempo que transcurre desde la infestación hasta la aparición de los primeros síntomas, hecho que podrá durar varios años e incluso serlo en forma permanente ${ }^{1}$; 2) período de estado y finalmente 3 ) período de complicaciones. Precisamente éstos dos últimos constituyen la forma sintomática ${ }^{2,3}$.

\section{FORMA INAPARENTE O ASINTOMATICA (PERIODO DE INCUBACION).}

Este es debido a que en los primeros años del lento crecimiento del quiste hidático $-1 \mathrm{~cm}$ por año - no se producen alteraciones anatómicas ni funcionales en el hígado y órganos vecinos en virtud de la complacencia visceral y de la cavidad abdominal ${ }^{2,4}$.

Habitualmente se inicia en los primeros años de vida. Lizaso ${ }^{5}$ citando a Zerbino en relación a este aspecto expresaba: «el quiste hidático se ve con preferencia en la infancia y juventud» y agregaba «la equinococosis es una lesión fría que crece silenciosa durante un largo período de latencia, sobre todo en órganos profundos e indiferentes».

El conocimiento de este aspecto ha adquirido un enorme valor desde la perspectiva de la salud pública, ya que dentro de las diferentes estrategias para el control de la enfermedad se ha apelado a estudios poblacionales mediante ecografía abdominal y screening serológicos, siendo los escolares un grupo privilegiado en este aspecto ${ }^{6}$.

$30 \%{ }^{3,7}$.

Esto ha permitido establecer que en zonas endémicas la población asintomática supere el

El resultado inmediato de esta estrategia, donde aún no han aparecido las complicaciones se traduce en mejores respuestas terapéuticas, menor morbimortalidad, días de internación y secuelas ${ }^{2,8}$.

Menos frecuente es el hallazgo durante la exploración quirúrgica en un procedimiento sin vinculación con la enfermedad hidatídica - inhabitual en nuestros días - y finalmente constituir un incidentaloma - hallazgo imagenológio sin relación a la sintomatología o patología estudiada.

Nuestra realidad permite aseverar que los incidentalomas y las campañas de detección de portadores asintomáticos se han convertido en las formas más frecuentes de diagnóstico de la enfermedad hidatídica hepática.

A pesar de este cambio cualitativo en el diagnóstico de la enfermedad, no podemos dejar de reconocer aquellos casos en los cuales es el propio paciente, en otras el médico en el curso de un examen físico de rutina, quien palpa u observa una tumoración de hipocondrio derecho o epigastrio.

El examen minucioso permitirá valorar deformaciones en la base tóraco abdominal derecha u ocupación del hipocondrio derecho que se desplaza con los movimientos respiratorios. Producto del lento crecimiento del quiste, la medición de las bases de ambos hemitórax podrá evidenciar una mayor circunferencia a derecha, al igual que una mayor separación de los arcos costales derechos y un mayor relieve costal.

Los hallazgos de la palpación del hipocondrio derecho son variables. Es así que se puede objetivar una hepatomegalia difusa o nodular, cuya consistencia podrá ser desde normal a firme y dura. 
La hipertrofia compensadora del hígado izquierdo en quistes que ocupan el derecho, determinan su palpación en epigastrio y la disminución o abolición del espacio de Traube a la percusión.

La palpación de una tumoración redondeada que asciende y desciende con los movimientos respiratorios es producto de quistes emergentes de los segmentos inferiores.

El frémito hidatídico - sensación de vibración del contenido líquido al percutir el quiste - 9 debe ser buscado con precaución para evitar la ruptura traumática del mismo.

A modo de ejemplo de lo expresado anteriormente, exponemos los resultados del estudio epidemiológico de Perdomo ${ }^{10}$. Hubo un predomino de los casos asintomáticos y con un examen físico completamente normal (56\%), seguido por aquellos que presentaron hepatomegalia (34\%) y tumoración abdominal $(2,4 \%)$.

\section{FORIMA SINTOMATICA (PERIODO DE ESTADO Y PERIODO DE COMPLICACIONES)}

La presentación clínica a través de manifestaciones locales, regionales o generales, dependerá de la topografía, tamaño y estado del parásito y de las repercusiones y respuesta del huésped ante el parásito, entre otras. Su variabilidad determinará que en muchas oportunidades pase desapercibida en sus etapas iniciales ${ }^{11}$

Los síntomas y signos no son patognomónicos de la enfermedad, por lo que la presunción diagnóstica estará basada en la encuesta epidemiológica junto a una alta sospecha de la enfermedad. Claramente lo demostró Perdomo ${ }^{10}$ en su screening ecográfico de zonas endémicas de nuestro país, donde sobre 1615 personas que manifestaron sintomatología torácica o abdominal, únicamente se demostró la presencia de hidatidosis hepática en $1 \%$ de los casos.

Una de las formas de presentación corresponde al tipo dispéptico-tumoral, donde predominan las alteraciones funcionales del tránsito digestivo alto, acompañadas de sensación de pesadez en hipocondrio derecho. En la serie de González ${ }^{12}$ el motivo de consulta de 60,4\% de los pacientes fue molestias inespecíficas de hipocondrio derecho.

El hallazgo de una hepatomegalia regular o asimétrica a consecuencia de la hipertrofia compensadora, o una tumoración redondeada en hipocondrio derecho o epigastrio son elementos claves para orientar el diagnóstico clínico.

En cambio cuando asistimos a una complicación, la variabilidad de las manifestaciones estará determinada por el tipo de complicación a la que nos enfrentemos (Figura 1). En este sentido recurriremos a la división propuesta por diferentes autores y que utilizaremos para el desarrollo del tema (Tabla 1) ${ }^{2,3}$.

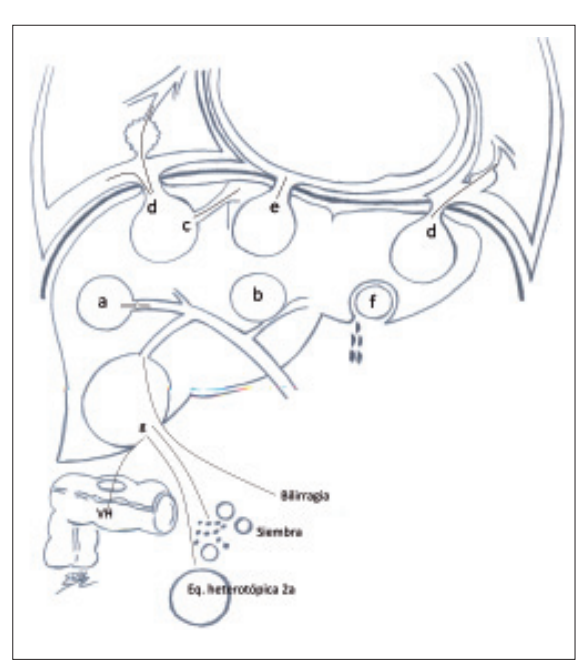

Figura 1.

a) apertura en vía biliar. b) compresión de vía biliar. c) apertura en vena cava inferior. d) tránsito hepatopleural o hepatobrónquico. e) tránsito hepatopericárdico. f) hemorragia por rotura de la adventicia. g) rotura en peritoneo, con posibilidad de fístula a víscera hueca, equinococosis heterotópica, siembra y bilirragia. (Adaptado de Larghero).

Tabla 1. Clasificación de las complicaciones de la equinococosis
hidatídica hepática.


1. Supuración. Determinada por la apertura y comunicación de canalículos biliares en el espacio comprendido entre la adventicia y membrana cuticular y la consecuente proliferación microbiana. Su frecuencia varía entre 10 al 30\%.

La presentación clínica es variable dependiendo del grado de infección, tipo de germen y estado inmunológico del paciente. Las principales manifestaciones son la fiebre y el dolor en hipocondrio derecho ${ }^{3,11,13-16}$.

Cuando el quiste se localiza en segmentos superiores hepáticos, el dolor puede irradiarse al hombro derecho y acompañarse de tos y dolor tipo puntada de lado por irritación frénica. Estos síntomas deben ser tenidos en cuenta ya que representan el inicio de otra complicación, el tránsito torácico.

En cambio cuando el quiste se ubica en segmentos inferiores, la irritación visceral que este produce determinará vómitos, náuseas y distensión abdominal.

Habitualmente este cuadro se acompaña de un síndrome de repercusión general producto de la infección crónica.

De acuerdo al tipo evolutivo la enfermedad se puede presentar con las características de una infección tórpida, dada por febrícula de días o semanas de evolución, asociada a dolor más o menos constante en hipocondrio derecho.

En ocasiones puede hacerlo como una infección aguda severa con fiebre en ganchos, compromiso del estado general y dolor agudo toracoabdominal derecho. Al síndrome de respuesta inflamatoria sistémica se puede asociar la falla multiorgánica constituyendo de esta manera una sepsis. El examen permite determinar una hepatomegalia dolorosa y en otras oportunidades la palpación exquisitamente dolorosa del quiste.

Finalmente puede hacerlo como un absceso hepático, donde el cuadro clínico es similar al anterior, aunque es menor el compromiso del estado general.

2. Apertura y evacuación en vías biliares. Producida por la compresión, adelgazamiento y perforación de canales biliares, determinada por el crecimiento de la hidátide y la consecuente evacuación del quiste en dichos conductos (Figura 2). Habitualmente ésta es parcial y ocurre en la vía biliar intrahepática ${ }^{17-21}$.

Figura 2.

Quiste hidático hepático abierto en vías biliares.

A) comunicación con pequeño canalículo biliar. B) evacuación parcial con pasaje de vesículas hijas.

C) evacuación total. (Adaptado de Larghero).

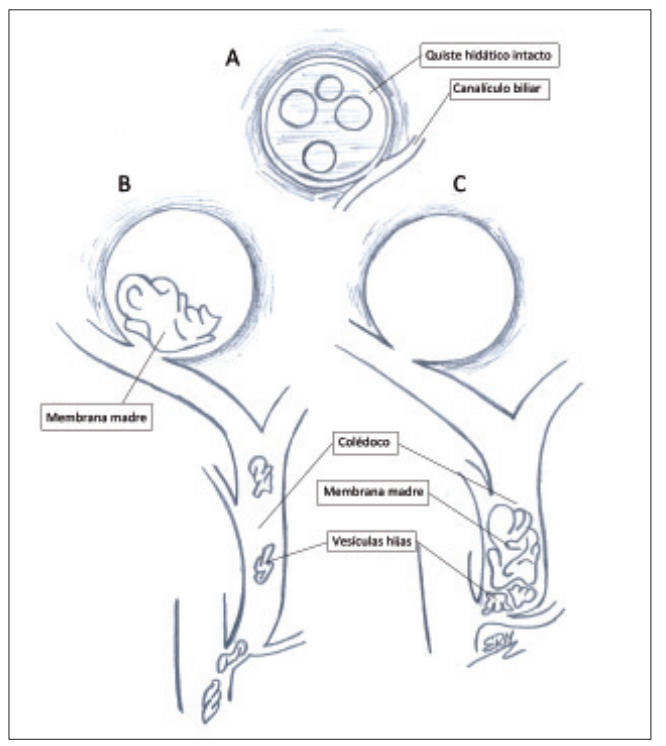


Es la segunda complicación en frecuencia, varía del 5 al $20 \%$.

En general los quistes que presentan estas complicaciones se ubican a derecha, aunque los ubicados en el segmento IV son los que provocan las lesiones más graves de la vía biliar al estar apoyados sobre el confluente biliar superior ${ }^{3,22}$.

La presentación clínica habitual está dada por la tríada de Murphy, conformando el síndrome coledociano: dolor en hipocondrio derecho, ictericia y fiebre ${ }^{3,11,23}$.

Dado que la obstrucción puede ser fugaz, intermitente o persistente, el cuadro clínico es variable. El o los gérmenes responsables del componente infeccioso son los que previamente infectaron el quiste, y la gravedad del cuadro toxiinfeccioso depende de ello y el grado de obstrucción biliar ${ }^{3}$.

Es así que la sintomatología puede ser solapada. Los episodios de dolor en hipocondrio derecho pueden simular un cólico vesicular y de esta forma llevar al planteo de una litiasis biliar ${ }^{24-26}$. En general los síntomas infecciosos pueden faltar o la fiebre ser intermitente y la subictericia ser la manifestación cutánea.

En otras oportunidades se presenta como una colangitis intermitente, con elementos infecciosos de intensidad intermedia y al examen una hepatomegalia que disminuye al remitir el cuadro obstructivo.

Finalmente el cuadro de mayor gravedad esta dado por la colangitis que se produce en forma brusca y grave, con intenso dolor en hipocondrio derecho, fiebre en ganchos con «chucho solemne» e ictericia en aumento franco, destacándose al examen una hepatomegalia dolorosa. La disfunción multiorgánica y el shock pueden acompañar el cuadro, por lo que el sostén de las funciones fisiológicas mayores requiere de una unidad de cuidados especiales ${ }^{3}$. En nuestro medio la colangitis aguda debida a la apertura y evacuación en vías biliares de un quiste hidático hepático corresponde a un 5 a $7,8 \%$ de las causas de colangitis, tal lo publicado por Estefan y colaboradores ${ }^{27}$. Destacan además que generalmente se presenta con claros elementos infecciosos.

Se debe tener presente un signo que puede acompañar la historia de esta complicación, la palpación de una vesícula distendida y dolorosa, ocupada por pus - piocolecisto hidatídico - o un líquido blanquecino constituyendo un mucocele vesicular hidatídico. En ocasiones puede determinar una pancreatitis o repercusión pancreática debido a la terminación común de la vía biliar y el conducto de Wirsung.

3. Compresiones de la vía biliar. Estas pueden ocurrir a nivel del hilio hepático o de sus ramas intraparenquimatosas. Depende de la ubicación del quiste, así como de su tamaño ${ }^{28}$. De acuerdo al conducto biliar comprometido, podrá manifestarse con cuadros colestáticos con o sin colangitis. Si el conducto biliar se encuentra involucrado en la adventicia, la evolución natural será la horadación de su pared y luego la evacuación del contenido del quiste en la vía biliar.

\section{Compresiones vasculares venosas e hipertensión portal. Determinadas por:}

a) compresión del pedículo portal, ya sea a nivel del hilio o de alguna de sus ramas intraparenquimatosas. La consecuencia es: 1) la hipertensión portal, 2) la atrofia del parénquima hepático tributario de la rama portal afectada y 3) la hipertrofia compensadora del parénquima no afectado.

b) compresión del pedículo suprahepático, produciendo una congestión venosa con anoxia que conduce a la cirrosis con hipertensión portal. Raramente se observa un síndrome de Budd-Chiari, el que requiere al menos la compresión de 2 venas suprahepáticas para ser sintomático, o un síndrome de vena cava inferior ${ }^{29}$.

Estos cuadros se pueden presentar con episodios de hematemesis a consecuencia de las várices esófagicas, ascitis, esplenomegalia, hepatomegalia irregular y circulación colateral.

5. Apertura en vena cava inferior o suprahepática. Es una complicación rara y en general mortal, determinada por quistes ubicados en sector postero-superior del hígado en relación con el confluente suprahepático-cava ${ }^{30}$ Las manifestaciones clínicas pueden ser variadas: (a) paciente con equinococosis pulmonar múltiple; (b) paciente con shock agudo y embolias pulmonares, seguido de recuperación; (c) reacción anafiláctica aguda, seguido de siembra hidatídica pulmonar; (d) cuadro infeccioso grave, hepatomegalia y sintomatología embólica; (e) cor pulmonar hidático o bilihemia. 
6. Complicaciones torácicas. Se produce como complicación de los quistes hidáticos superiores o del domo hepático, que en general han supurado o se han abierto en vía biliar ${ }^{31-35}$. Su frecuencia oscila entre un 5 a $9 \%{ }^{11}$. Debido a que algunos autores consideran la sínfisis pleurodiafragmática como un tránsito verdadero, la frecuencia de esta complicación puede llegar a un $30 \%{ }^{3}$. Desde el punto de vista clínico-patológico se considera que las complicaciones torácicas se pueden dividir en tránsito hepatopleural y tránsito hepatobrónquico.

a) Tránsito hepatopleural.

Los síntomas se pueden manifestar en forma brusca y grave o en forma más atenuada, incluso ser un hallazgo radiológico.

Inicialmente presenta una etapa hepatofrénica cuyo síntoma principal está dado por dolor. Su intensidad varía de acuerdo al grado de supuración del quiste. En ocasiones es de tipo pesadez, otras cólico y a veces intenso y continuo. También puede ser de tipo pleural, acompañado de tos, disnea y a veces expectoración hemoptoica. En casos de apertura previa en vías biliares, la ictericia puede estar presente. Se puede acompañar de un síndrome toxiinfeccioso, con fiebre y en ocasiones chuchos de frío.

La etapa torácica se manifiesta de forma variable. En algunos casos el cuadro corresponde al de un empiema hidatídico agudo con dolor torácico intenso, disnea, polipnea, cianosis y eventualmente shock. En otros la sintomatología es solapada, con menos dolor y sin elementos de insuficiencia ventilo respiratoria o shock. En el examen físico se constata un síndrome en menos determinado por la presencia de un derrame pleural.

Si la colección queda limitada a la cavidad pleural, constituye un tránsito hepatopleural cerrado. Se convertirá en un tránsito hepato - pleuro - bronquial si dicha colección se evacúa en el árbol bronquial. Su traducción clínica estará dada por: hemoptisis, hidatidoptisis, bilioptisis, vómica hidatídica, tos quintosa con disnea, aliento fétido, entre otros. Habitualmente este cuadro se acompaña de una importante repercusión general, fundamentalmente cuando asocia la comunicación y obstrucción de la vía biliar.

\section{b) Tránsito hepatobrónquico.}

Se pueden distinguir 3 etapas o períodos: hepatofrénica, torácica y la vómica hidatídica hepatopulmonar ${ }^{36-38}$ (Figura 3).

Figura 3.

Forma más típica del tránsito hepatobrónquico.

A) comunicación con vía biliar.

B) formación de caverna pulmonar. (Adaptado de Larghero).

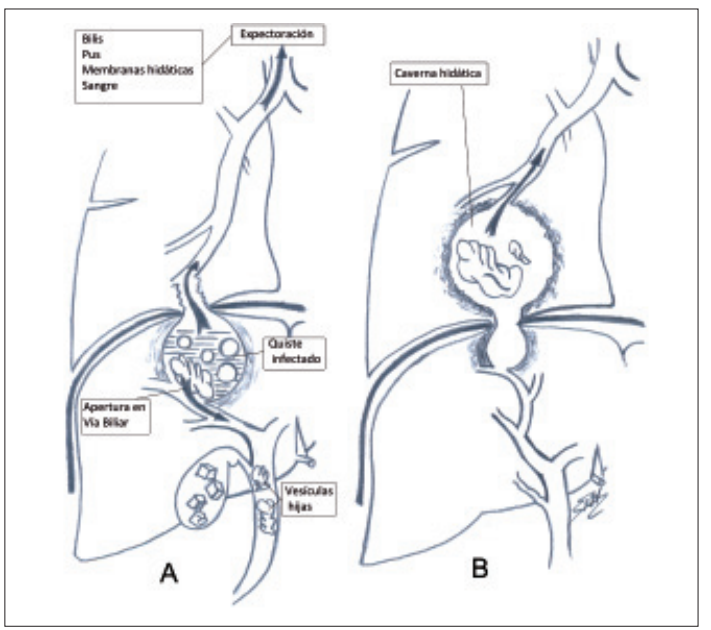

La etapa hepatofrénica o período preparatorio es similar a la del tránsito hepatopleural, donde el síntoma predominante es el dolor. Dura entre 15 y 60 días 
La etapa torácica o fase premonitoria (hepato pulmonar incompleta) precede a la vómica y se presenta con dolor torácico (generalmente intenso y de instalación aguda), tos, disnea, expectoración mucopurulenta, a veces hemoptoica. La halitosis y el síndrome toxiinfeccioso completan la presentación clínica.

La vómica hidatídica hepatopulmonar (hepato pulmonar completa) puede ser una hidatidoptisis, cuyo contenido es claro y límpido, tratándose de líquido hidatídico o la situación más habitual, que se trate de una vómica purulenta. La cantidad puede ser de unos pocos centímetros cúbicos a 2 litros de líquido fétido, en el que eventualmente se pueden reconocer vesículas hidáticas. Se acompaña de tos irritativa, disnea y opresión torácica. Hasta un $30 \%$ el quiste puede estar abierto en vía biliar, por lo que se puede reconocer bilis en la expectoración. Después de la vómica se vacía la cavidad pulmonar y pueden aparecer signos cavitarios como el soplo anfórico. La broncorrea resultante del establecimiento de una fístula hepatobronquial es patognomónica si en ella se reconoce bilis. Una intensa repercusión general y elementos toxiinfecciosos completan el cuadro.

7. Complicaciones peritoneales. Se produce por rotura del quiste o la adventicia hacia la cavidad peritoneal libre. Es propio de los quistes emergentes inferiores. Representa un 5-6\% de las complicaciones. De acuerdo a su forma de presentación clínica es posible reconocer tres formas: aguda, subaguda y crónica.

La forma aguda es la llamada peritonitis hidatídica, donde el síntoma principal esta dado por el dolor abdominal brusco e intenso, seguido de elementos de reacción vasovagal. Los antígenos del quiste pueden desencadenar una reacción anafiláctica intensa pudiendo llegar al shock. Es excepcional que se produzca solo la rotura de la adventicia y permanezca intacta la hidátide, migrando a través de la brecha y asentarse en la cavidad peritoneal como equinococosis peritoneal primitiva heterotópica.

La forma subaguda y crónica se caracteriza por exudación, involución o enquistamiento. El desarrollo de los implantes peritoneales producirá una equinococosis secundaria peritoneal.

8. Apertura en vísceras vecinas. Es una complicación rara que producirá la fístula de la cavidad quística con algún órgano del tubo digestivo, en general estómago, duodeno, ángulo derecho del colon y más raramente vesícula biliar. No hay síntomas específicos de esta complicación ${ }^{39-40}$.

9. Compresión de vísceras vecinas. En general los órganos comprometidos son esófago y estómago. La compresión del primero por un quiste ubicado en los segmentos II - III es responsable de la disfagia, en tanto cuando ocurre sobre el estómago, la plenitud precoz caracteriza el cuadro

10. Manifestaciones alérgicas y shock anafiláctico. Son debidas a la hipersensibilidad del paciente a los antígenos hidatídicos. Puede ir desde el rush cutáneo, crisis asmáticas o prurito a un cuadro grave de shock anafiláctico. En este último caso es posible reconocer: a) síntomas respiratorios: disnea, polipnea, tos con expectoración y broncoespasmo; b) síntomas circulatorios: shock; c) síntomas digestivos: nauseas, vómitos y diarrea; d) síntomas neurológicos: cefaleas, convulsiones y coma; e) síntomas cutáneos: rush, prurito.

\section{Bibliografía consultada.}

Larghero P, Venturino W, Broli G. Equinococosis hidatídica del abdomen. Montevideo: Delta editorial. Montevideo; 1962.

Venturino W, Silva C, Laviña R. Equinococosis hidatídica abdominal. En: Larre Borges U, Cazabán L, del Campo A. Patología quirúrgica. Aparato digestivo, hígado, vías biliares y páncreas. Montevideo: Librería Médica Editorial; 1982. p.153-89.

Arcos Pérez M. Semiología de hígado y vías biliares. 2a edición. Montevideo: Librería Médica Editorial; 1980.

Kremer A, Chicconi E, Moguillansky S. Hidatidosis. Clínica y diagnóstico. En: Findor J, Sapunar I. Enfermedades del hígado y las vías biliares. Buenos Aires: Librería Akadia Editorial; 1985. p. 545-66. 
Referencias bibliográficas.

1. Frieder B, Larrieu E, Odriozola M. Long term outcome of asymptomatic liver hydatidosis. J Hepatol. 1999; 30:228-31.

2. Guarnera E. Hidatidosis humana, su impacto, diagnóstico, manejo y tratamiento. En: Organización Panamericana de la Salud. Proyecto Subregional Cono Sur de Control y Vigilancia de la Hidatidosis. Argentina, Brasil, Chile y Uruguay. Primera Reunión Constitutiva. Montevideo:OPS; 2004.p.57-85.

3. Odriozola M, Pettinari R. Relato Oficial. Hidatidosis abdominal. 69 Congreso Argentino de Cirugía. Rev Arg Cir. 1998; (No. Extra):9-70.

4. Cosco Montaldo H. Quiste hidático de hígado a sintomatología mínima o nula. 4o Congreso Uruguayo de Cirugía; Montevideo; 195330 nov - 5 dic. Montevideo: Garcia Morales-Mercant; 1954. p.330-63.

5. Lizaso I, Benedictti JL. Rotura traumática del quiste hidático de hígado en el niño. Cir Uruguay. 1985;55(6):335-39.

6. Mercapide C, Del Carpio M, Salvitti J, Sustercic J, Panomarenko H, Uchiumi L, et al. Diagnóstico y tratamiento de la equinococcosis mediante ultrasonografía aplicada por médicos generalistas en población escolar. Río Negro, Argentina. Zoonosis. 2009;1:35-40.

7. Mac Pherson C, Romig T, Rees P. Portable ultrasound- scanner versus serology in screening for hydatid cysts in a nomadic population. Lancet. 1987; 2: 259-61.

8. Larrieu E, Frieder E, Del Carpio M, Salvitti JC, Mercapide C, Pereyra R, et al. Portadores asintomáticos de hidatidosis: epidemiología, diagnóstico y tratamiento. Rev Panam Salud Publica. 2000;8(4):250-56.

9. Diccionario de términos médicos. [En línea] [Acceso el 28 de octubre de 2011]. URL: http://www.iqb.es/ diccio/diccio1.htm.

10. Perdomo R, Parada R, Alvarez C, Cattivelli D, Geninazzi H, Barragué A, et al. Estudio epidemiológico de hidatidosis. Detección precoz por ultrasonido en áreas de alto riesgo. Rev Med Urug 1990;6(1):34-47.

11. Guidelines for treatment of cystic and alveolar echinococcosis in humans. WHO Informal Working Group on Echinococcosis. Bull World Health Organ. 1996;74(3):231-42.

12. González D, Vega A, Monti J, Torres M. Enfermedad hidatídica hepática. Experiencia de los últimos 13 años en Florida. Cir Uruguay. 1999;69(3-4):200-3.

13. Otero JP. Pio-neumo-quiste hidático del hígado (supurado). Bol Soc Cir Uruguay. 1950;21:93-105.

14. Otero JP. Pio-neumo-quiste hidático del hígado. Bol Soc Cir Uruguay. 1937;8:116-33.

15. Perdomo R, Geninazzi H, Santana C, López J, Castro D, Morelli R, et al. Abertura lateral de conductos biliares principales en la adventicia hidática. Cir Uruguay. 1984;54(2):84-97.

16. Porras Y. Complicaciones hepatobiliares de la hidatidosis. Cir Uruguay. 1973;43:441-89.

17. Anastasia H. Dos casos de quiste hidático del hígado abierto en las vías biliares. Bol Soc Cir Uruguay. 1933;4:185-98.

18. Lamas Pouey E. A propósito de un quiste hidático del hígado abierto en las vías biliares. Bol Soc Cir Uruguay. 1935; 6:16-9.

19. Maquieira G. Complicaciones biliares de la equinococosis hepática del niño. Cir Uruguay. 1975;45:424-6.

20. Prat D. Sobre algunas complicaciones del quiste hidático abierto en las vías biliares. Bol Soc Cir Uruguay. 1935; 6:85-106.

21. Risi F, Schiaffarino O. Complicaciones biliares de la hidatidosis hepática. 11을 Congreso Uruguayo de Cirugía; Montevideo;1960 4-7 dic. Montevideo: Rosgal-Hilario Rosillo, 1961. p.214-20.

22. Ruso L, Balboa O, Fernández R, Alvarez O, Díaz F, de Simone G. Destrucción del confluente biliar superior de causa hidatídica. Manejo quirúrgico. Cir Uruguay. 2005;75(3):150-54.

23. Calleri EM. Quistes hidáticos del hígado abiertos en vías biliares. 4ํㅡㅁongreso Uruguayo de Cirugía; Montevideo; 195330 nov - 5 dic. Montevideo: Garcia Morales-Mercant, 1954. p.201-21.

24. Morador JL. El cólico hepático de origen hidatídico. En: Blanco Acevedo E. Práctica quirúrgica: simposio sobre equinococosis. Montevideo:[s.n.];1947.p.295-316.

25. Chifflet A. La hidatidosis hepática es una afección hepato-biliar. Bol Soc Cir Uruguay. 1948;19:23-38.

26. Prat D. Sobre cólico hepático seudo litiásico o cólico hepático hidatídico. Bol Soc Cir Uruguay. 1945;16:453-62.

27. Estefan A, Bagnulo H, Carriquiry L, Cassinelli D, Pomi J, Torterolo E, Silva C. Colangitis aguda séptica. Cir Uruguay 1982;52:24-73.

28. Praderi R, Gómez Fossati C, Praderi L. Ictericia por compresión hidática de las vías biliares. Cir. Uruguay. 1973;43:506-9.

29. Piacenza G, Mesa G, Casinelli D. Compresión de la vena cava inferior por quiste hidático de hígado. Cir Uruguay, 1974;44:24-8. 
30. Castiglioni Alonso H. Quiste hidático del hígado abierto en la vena cava inferior. En: Blanco Acevedo E. Práctica quirúrgica: simposio sobre equinococosis. Montevideo:[s.n.];1947.p.317-26.

31. Praderi L, Cassinelli D. Tránsitos hepatotorácicos de origen hidatídico. Cir Uruguay. 1970;40(2):140-57.

32. Armand Ugon V, Tomalino D. Tránsitos hidáticos hepatotorácicos. Consideraciones sobre 40 casos personales. El Tórax. 1958;7:188-209.

33. Delbene R. Complicaciones torácicas de quistes hidáticos del domo hepático. Cir Uruguay. 2003;73(3):339-43.

34. Galarraga J, Soto J, Di Leoni F, Tchekmedyian V, Lorenzelli J.A, Chifflet J. Complicaciones torácicas de la equinococosis. Cir Uruguay. 1994; 64(4):241-56.

35. Tomalino D. Complicaciones torácicas de la equinococosis hepática. El Tórax. 1962;11:85-118.

36. Soto Cordano J. Formas anátomo-clínicas. Cir Uruguay. 1994;64(4):242-45.

37. Anavitarte E, Arruti C, Torres, D. Quiste hidático hepático complicado con tránsito hepatobrónquico en un niño de10 años. Cir. Uruguay. 1974;44:21-4.

38. Piquinela JA, Purriel P. Quiste hidático del hígado abierto en los bronquios. Bol Soc Cir Uruguay. 1949;11:136-44.

39. Goller W. A propósito de un quiste hidático de hígado abierto en estómago. Bol Soc Cir Uruguay. 1963;34 (1-2):19-22.

40. Ríos Bruno, G., Gateño, N. Quiste hidático del hígado abierto en la vesícula biliar. Cir Uruguay. 1972; 42(3): 175-7. 


\section{CAPÍTULO 7}

\section{Inmunodiagnóstico}

El diagnóstico inmunológico es uno de los cuatro pilares sobre el cual asienta el diagnóstico de la equinococosis hidática. Adquiere real valor en el seguimiento de pacientes que han sido intervenidos quirúrgicamente o han recibido tratamiento médico, en estudios seroepidemiológicos de poblaciones en zonas endémicas o cuando se trata de establecer la etiología de una tumoración.

Requiere como condición indispensable la estimulación antigénica determinada por el contacto del líquido hidático con el sistema inmunológico del huésped. Ello únicamente es posible si se produce una alteración en la permeabilidad en la capa germinativa a consecuencia de una microfisura, rotura o complicación ${ }^{1}$. Esta situación es particularmente frecuente a nivel hepático, hecho que explica la positividad de los estudios en estas circunstancias, así como su negatividad ante quistes hialinos.

Las fuentes de antígenos utilizadas para el inmunodiagnóstico provienen del líquido hidático, extracto de protoescólices, membrana hidática y de la forma adulta. La inmunofluorescencia indirecta (IFI) utiliza preparados de protoescólices.

Cuando se utilizan las proteínas rEpC1 obtenida de protoescólices y la rEgcMDH de la forma adulta, la sensibilidad y especificidad para la inmunofluorescencia indirecta (IFI) es de 92 y $96 \%$ respectivamente, en tanto que para la inmunoadsorcion enzimática (ELISA) los valores son de 90 y $95 \%{ }^{2}$.

Debemos destacar que estas técnicas están en fase de investigación, por lo que al momento actual los mejores resultados se obtienen con el empleo de líquido hidático ${ }^{3}$. Precisamente en éste, se encuentran los principales antígenos utilizados para establecer el inmunodiagnóstico: 5 y B ${ }^{4}$.

El antígeno 5 (termolábil), lipoproteína de alta masa molecular (400 kDa), es sintetizado como cadena polipéptidica simple que a través de puentes de disulfuro generan subunidades de 22 y $38 \mathrm{kDa}$ y éstas, unidades mayores de 57 y $67 \mathrm{kDa}{ }^{5,6}$.

La técnica de doble difusión 5 (DD5) identifica anticuerpos contra el antígeno 5 del líquido hidático. En pacientes que han recibido tratamiento médico o quirúrgico se estima que el período necesario para la negativización de la prueba es de 24 meses.

El antígeno B (termoestable) al que se atribuye la participación en la evasión de la respuesta inmunitaria del huésped ${ }^{7}$, es una lipoproteína con masa molecular de $120 \mathrm{kDa}$, que se constituye de monómeros de $8 \mathrm{kDa}$, siendo las subunidades Ag8/1 y Ag8/2 las de mayor utilidad en el inmunodiagnóstico ${ }^{8-13}$. Es más específico que el antígeno 5 ya que presenta reacciones cruzadas únicamente con el Echinococcus multilocularis ${ }^{4}$.

Se han desarrollado numerosas técnicas tratando de lograr una mejor sensibilidad, especificidad y valor predictivo. La eficacia de las mismas depende de una serie de factores: origen, pureza y calidad del extracto antigénico utilizado ${ }^{14,15}$, panel de sueros seleccionados (sueros de pacientes confirmados o no quirúrgicamente, subclase de las inmunoglobulinas) ${ }^{16}$, órgano afectado y número de quistes ${ }^{17}$. La detección de anticuerpos específicos de la clase lgG o lgE son los de mayor rendimiento por lo que las técnicas que la utilizan son las recomendadas ${ }^{18}$.

Ninguna de las pruebas es satisfactoria individualmente y es recomendable utilizar dos o más ensayos. Uno sensible pero poco específico como la hemaglutinación indirecta (HAl) o inmunoadsorción enzimática (ELISA) y la doble difusión 5 (DD5) como confirmación. Tienen una elevada especificidad cuando existe arco 5 (cercana al $98 \%$ ), pero su sensibilidad no supera el $60 \%$. De este modo una reacción negativa no descarta el diagnóstico. Las reacciones cruzadas con otros parásitos son escasas.

La doble difusión 5 (DD5) y la inmunoelectroforesis (IEF) son las técnicas de confirmación por excelencia dado su alta especificidad. Si bien el resultado con la técnica de IEF puede obtenerse en un día a diferencia de los 4 días para la doble difusión 5 , requiere como condición indispensable una cantidad de antígeno suficiente y experiencia del personal encargado de su identificación. En 


\section{INMUNODIAGNÓSTICO}

nuestro país, Yarzábal ${ }^{19}$ en 1971 recomendaba la utilización de la inmunoelectroforesis (IEF) asociada a una o dos técnicas confirmatorias.

La sensibilidad y especificidad de las diferentes técnicas son claramente diferentes cuando se consideran por un lado personas portadoras de equinococosis hidatídica sintomática y por otro las asintomáticas.

Diversos estudios en pacientes sintomáticos y operados de quiste hidático determinaron una sensibilidad que osciló entre $80 \%$ para la hemaglutinación indirecta (HAI), $82 \%$ para la inmunoelectroforesis (IEF), entre 82 y $88 \%$ para la doble difusión 5 (DD5), entre 88 y $96 \%$ para la inmunoadsorción enzimática (ELISA) y $92 \%$ para la inmunofluorescencia indirecta (IFI). La especificidad osciló entre el 95\% para la hemaglutinación indirecta y 100\% para la doble difusión 5 (DD5) ${ }^{20-26}$.

Estos resultados surgen de considerar títulos superiores de 1/20 para la inmunoadsorción enzimática (ELISA), 1/256 para la hemaglutinación indirecta (HAI) y 1/100 para la inmunofluorescencia indirecta (IFI).

La técnica de inmunoblot cuando utiliza antígenos del líquido hidático de ovinos presenta una sensibilidad que oscila entre 88 y $95 \%$ y una especificidad entre 95 y $100 \%{ }^{27}$. Con líquido hidático proveniente de bovinos la sensibilidad establecida es de $80 \%$ y la especificidad de $100 \%{ }^{28}$.

Miranda ${ }^{29}$ no encontró diferencias estadísticamente significativas en un estudio comparativo entre el empleo de líquido hidático ovino y caprino con la técnica de inmunoblot para la detección de enfermedad hidática en humanos. Reportó una sensibilidad de 91,4\%, especificidad de 95,4\%, valor predictivo positivo de 95,5\% y valor predictivo negativo de 91,2\% para el antígeno ovino.

En tanto para el caprino la sensibilidad fue de $92,9 \%$, la especificidad de $100 \%$, el valor predictivo positivo de $100 \%$ y el valor predictivo negativo de $92,9 \%$. Estos resultados permiten recomendar ambos antígenos para el diagnóstico inmunológico de la equinococosis hidática.

Larrieu ${ }^{30}$ comunicó su experiencia en la aplicación de las técnicas de doble difusión 5 (DD5) e inmunoadsorción enzimática (ELISA) en poblaciones asintomáticas portadoras de equinococosis hidática, utilizando como patrón oro estudios imagenológicos (TAC, ecografía, radiografía).

Tomando en cuenta títulos iguales o superiores a $8 \mathrm{DE}$ (desviación estándar) para la técnica de ELISA, la sensibilidad y especificidad correspondió a 63 y 97,05\% en tanto que para la de doble difusión 5 (DD5) 31 y 100\% respectivamente. Desviaciones estándar menores para la técnica de ELISA, determinaron valores de sensibilidad mayores y especificidad menores en relación a 8 DE (Tabla 1).

Tabla 1. Sensibilidad y especificidad de la prueba ELISA de acuerdo a diferentes
desviaciones estándar en portadores asintomáticos.
\begin{tabular}{|c|c|c|}
\hline Técnica & Sensibilidad (\%) & Especificad (\%) \\
\hline ELISA mayor 1 DE & 84 & 60 \\
\hline ELISA mayor 5 DE & 74 & 84 \\
\hline ELISA mayor 8 DE & 63 & 97 \\
\hline
\end{tabular}

Tomado de Larrieu ${ }^{30}$.

Títulos iguales o superiores a 8 en poblaciones asintomáticas establecen $85 \%$ de probabilidad de presentar una equinococosis hidatídica. Desciende a $56 \%$ cuando los valores oscilan entre 5 y 8 . Un título igual o superior a 8 se considera como valor de corte en poblaciones asintomáticas, siendo altamente probable su existencia con un valor de 5 o superior en pacientes sintomáticos.

Este menor porcentaje de positividad en relación a la población sintomática, no llama la atención si tomamos en cuenta la base fisiopatológica al inicio referida.

En nuestro país se llevó a cabo el proyecto ELISA, que consistió en el diagnóstico de prevalencia de quiste hidático en niños preescolares y escolares a nivel de centros poblados rurales con menos de 1000 habitantes. El mismo se efectivizó mediante la técnica serológica ELISA en sangre y como confirmatorio se realizó el estudio en suero con técnica de doble difusión 5 (DD5). 
Sobre un total de 39948 niños estudiados en el período comprendido entre los años 1991 2003, se detectaron 20 casos mediante ambas técnicas ${ }^{31}$ (Tabla 2).

\begin{tabular}{|c|c|c|c|c|}
\hline Departamento & $\begin{array}{l}\text { Centros } \\
\text { poblados }\end{array}$ & Niños & ELISA & DD5 \\
\hline Artigas & 20 & 730 & 13 & 0 \\
\hline Canelones & 22 & 7.501 & 85 & 0 \\
\hline Cerro Largo & 30 & 774 & 10 & 2 \\
\hline Colonia & 18 & 1.658 & 40 & 0 \\
\hline Durazno & 24 & 1.553 & 66 & 1 \\
\hline Flores & 4 & 240 & 2 & 0 \\
\hline Florida & 20 & 1.098 & 26 & 2 \\
\hline Lavalleja & 17 & 1.158 & 82 & 1 \\
\hline Maldonado & 13 & 680 & 21 & 4 \\
\hline Montevideo & & 8.601 & 140 & 0 \\
\hline Paysandú & 28 & 1.584 & 49 & 1 \\
\hline Río Negro & 35 & 1.377 & 34 & 4 \\
\hline Rivera & 28 & 757 & 6 & 0 \\
\hline Rocha & 19 & 1.566 & 50 & 0 \\
\hline Salto & 50 & 2.707 & 49 & 0 \\
\hline San José & 23 & 1.456 & 33 & 1 \\
\hline Soriano & 15 & 1.401 & 20 & 0 \\
\hline Tacuarembó & 73 & 3.104 & 46 & 3 \\
\hline Treinta y Tres & 16 & 2.006 & 50 & 0 \\
\hline Total & 455 & 39.948 & 822 & 20 \\
\hline
\end{tabular}

Tomado de la Comisión Honoraria de la Lucha Contra la Hidatidosis ${ }^{38}$.

Referencias bibliográficas.

1. Larrieu E. Bases biológicas y epidemiológicas para el control de la hidatidosis-equinococosis. Vet Argentina. 1991;54:612-21.

2. Li J, Zhang W-B, Wilson M, Ito A, McManus DP. A novel recombinant antigen for immunodiagnosis of human cystic echinococcosis. J Infect Dis. 2003;188(12):1951-60.

3. Carmena D, Benito A, Eraso E. Avances recientes en el inmunodiagnóstico de la hidatidosis humana. Enferm Infecc Microbiol Clin. 2007;25(4):263-9.

4. Siracusano A, Vuitton D. Immunology and immunopathology of Echinococcus granulosus and Echinococcus multilocularis infection. Arch Int Hidat. 1997;32:132-5.

5. Lightowlers M, Liu D, Haralambous A, Rickard MD. Subunit composition and specificity of the major cyst fluid antigens of Echinococcus granulosus. Mol Biochem Parasitol. 1989;37(2):171-82.

6. Lorenzo C, Salinas G, Brugnini A, Wernstedt C, Hellman U, González Sapienza G. Echinococcus granulosus antigen 5 is closely related to proteases of the trypsin family. Biochem J. 2003;369(Pt.1):191-8.

7. Riganò R, Profumo E, Bruschi F, Carulli G, Azzara A, loppolo S, et al. Modulation of human immune response by Echinococcus granulosus antigen $B$ and its posible role in evading host defensas. Infect Immun. 2001;69(1):288-96.

8. Oriol R, William J, Pérez-Esandi M, Oriol C. Purification of lipoprotein antigens of Echinococcus granulosus from sheep hydatid fluid. Am J Trop Med Hyg. 1971;20(4):569-74.

9. Oriol C, Oriol R. Physicochemical properties of a lipoprotein antigen of Echinococcus granulosus. Am J Trop Med Hyg. 1975;24(1):96-100.

10. González G, Nieto A, Fernández C, Orn A, Wernstedt C, Hellman U. Two different 8 kDa monomers are involved in the oligomeric organization of the native Echinococcus granulosus antigen B. Parasite Immunol. 1996;18(12):587-96.

11. Frosch $P$, Hartmann M, Mühlschleger F, Frosch $M$. Sequence heterogenity of the echinococcal antigen $B$. Mol Biochem Parasitol. 1994;64(1):171-5. 
12. Fernández V, Ferreira H, Fernández $\mathrm{C}$, Zaha $\mathrm{A}$, Nieto $A$. Molecular characterization of a novel $8 \mathrm{kDa}$ subunit of Echinococcus granulosus antigen B. Mol Biochem Parasitol. 1996(2);77:247-50.

13. Rott MB, Fernández V, Farias S, Ceni J, Ferreira HB, Haag KL et al. Comparative analysis of two differente subunits of antigen $\mathrm{B}$ from Echinococcus granulosus: gene sequences, expression in Escherichia coli and serological evaluation. Acta Trop. 2000;75(3):331-40.

14. Poretti D, Felleisen E, Grimm F, Pfister M, Teuscher F, Zuercher C, et al. Differential immunodiagnosis between cystic hydatid disease and other cross-reactive pathologies. Am J Trop Med Hyg. 1999;60(2):193-8.

15. Virginio VG, Hernández A, Rott MB, Monteiro KM, Zandonai AF, Nieto A, et al. A set of recombinant antigens from Echinococcus granulosus with potencial for use in the immunodiagnosis of human cystic hydatid disease. Clin Exp Immunol. 2003;132(2):309-15.

16. Gottstein B. Molecular and immunological diagnosis of echinococcosis. Clin Microbiol Rev. 1992;5(3):248-61.

17. Orduña A, Zarzosa P, Abad R, Bratos MA, Sainz M, Gutiérrez P, et al. Influence of factors related to cysts in the sensitivity of six serological tests for diagnosis of human hydatid disease. Arch Int Hidatid. 1997;32:280-6.

18. Ramzy R, Helmy H, El Zayyat E, Rifaat M, Andel Hameed D, Abdel-Baki M. An enzyme-linked immunosorbent assay for detection of IgG1 antibodies specific to human cystic echinococcosis in Egypt. Trop Med Int Health. 1999;4(9):616-20.

19. Yarzábal LA, Capron A. Aportes de la inmunoelectroforesis al diagnóstico inmunológico de la hidatidosis. El Tórax. 1971;20(3):168-74.

20. Coltorti E, Varela-Díaz V. Detection of antibodies against Echinococcus granulosus arc 5 antigens by doublé diffusion test. Trans R Soc Trop Med Hyg 1978;72(3):226-9.

21. Zamorano C, Contreras M, Sánchez A, Bahamondes M, Sandoval L. Estudio seroepidemiológico de la hidatidosis y triquinosis humana mediante la reacción de hemaglutinación indirecta en la comuna de San Juan de la Costa, Chile, 1990-1991. Bol Chil Parasitol. 1991;46(3-4):82-4.

22. Coltorti E, Fernández E, Guarnera E, Lago J, Iriarte J. Field evaluation of an enzyme immunoassay for detection of asymptomatic patients in a hydatid control program. Am J Trop Med Hyg. 1988;38(3):603-7.

23. Coltorti E. Standardization and evaluation of an enzyme immunoassay as a screening test for the seroepidemiology of human hydatidosis. Am J Trop Med Hyg. 1986;35(5):1000-5.

24. Shambesh M, Craig P, Gusbi A, Wen H. Immunoblot evaluation of the 100 and $130 \mathrm{Kda}$ antigens in camel hydatid cyst fluid for the serodiagnosis of human cyst echinococcosis in Libya. Trans R Soc Trop Med Hyg. 1995;89(3):276-9.

25. Arienti $\mathrm{H}$, Guignard S, Rinakldi D, Elbarcha O. Comparison of two serologic methods for the diagnosis of hydatidosis. Rev Panam Salud Publica. 1997;1(5):376-80

26. Lorca M, Escalante H, Garcia A, Denegri M, Sierra P, Silva M. Estandarización y evaluación de una técnica de ELISA para el diagnóstico de hidatidosis humana. Parasitol Día. 1991;15(3-4):74-8.

27. Gómez de la Torre Prettell JC. Valor diagnóstico de inmunoblot con líquido hidatídico humano, frente a antígeno ovino y bovino. Rev Mex Patol Clin. 2004; 51(2): 75-89.

28. Verástegui M, Moro P, Guevara A, Rodríguez T, Miranda E, Gilman RH. Enzyme-linked immunoelectrotransfer blot test for diagnosis of human hydatid disease. J Clin Microbiol. 1992; 30(6):1557-61

29. Miranda E, Velarde F, Somocurcio J, Ayala E. Evaluación de dos pruebas de inmunoblot con antígeno hidatídico de caprino y ovino para el diagnóstico de equinococosis humana. Rev Peru Med Exp Salud Publica. 2010;27(2):209-14.

30. Larrieu E, Dapcich C, Guarnera E, Coltorti E, Bianchi C, Moguilansky A. Evaluación de ELISA y DD5 en el diagnóstico de la hidatidosis humana en población asintomática. Rev San Hig Publ. 1994;68:393-8.

31. Proyecto ELISA. Comisión Honoraria de Lucha Contra la Hidatidosis [En línea].[Acceso 20 de octubre de 2006]. URL:http://www.hidatidosis.org. 


\section{CAPÍTULO 8}

\section{Diagnóstico imagenológico}

\section{Radiografía simple}

Amplio es el arsenal imagenológico para el diagnóstico de la equinococosis hidatídica hepática. El avance tecnológico ha relegado a la radiología simple a la valoración pleuropulmonar en estudios poblacionales ${ }^{1}$.

Sin embargo es necesario tener presente algunos aspectos que pueden constituir hallazgos en radiografías de abdomen o en enfoques del sector hepato diafragmático en las radiografías de tórax. El desplazamiento o deformación de órganos vecinos traducen su comportamiento como masa ocupante de espacio.

Las calcificaciones, especialmente aquellas en forma de anillo o redondeadas (Foto 1) al igual que la «línea arciforme» (línea fina con espesor entre 0,5 y 1,5 mm, de límites netos y redondeada) constituyen signos patognomónicos que traducen la presencia de la adventicia ${ }^{2}$.

Foto 1:

Radiografía simple de abdomen. Imagen de quiste hidático calcificado.

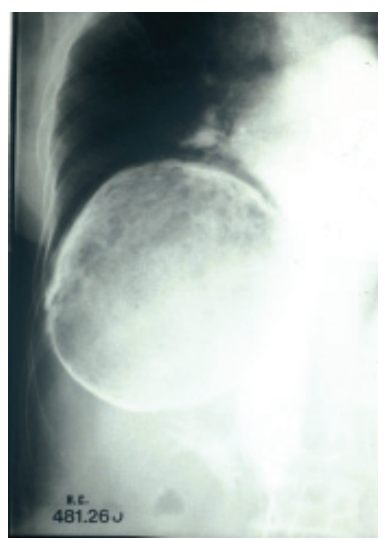

Se debe tener presente que existen otras entidades que pueden simular un quiste hidático. Calcificaciones de la glándula suprarrenal derecha, de un quiste simple complicado y oblito han sido reportadas en la literatura ${ }^{3-5}$ (Foto 2 y 3).

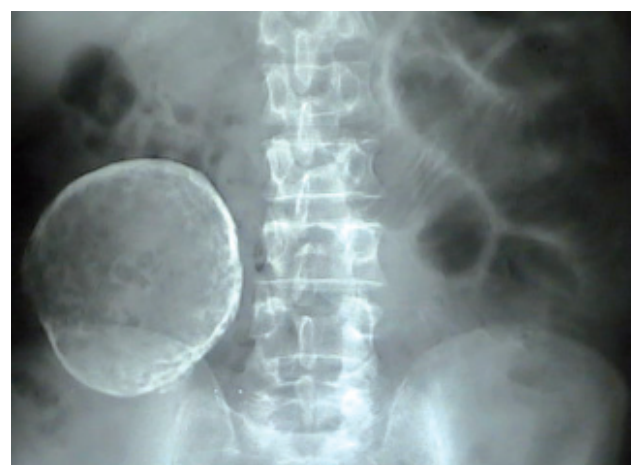

Foto 2:

Radiografía simple de abdomen. Imagen calcificada de flanco derecho (oblito).

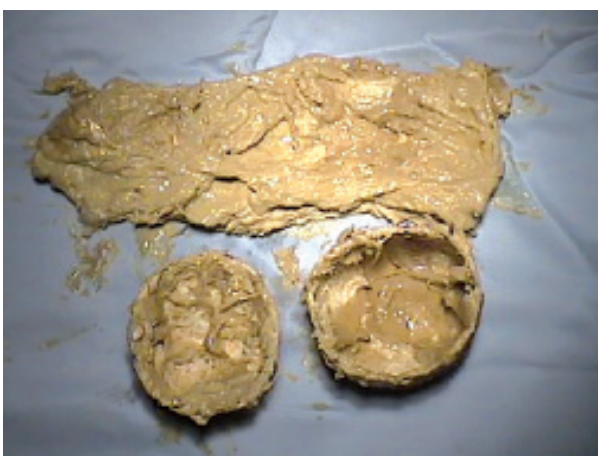

Foto 3: Pieza quirúrgica conteniendo una compresa. 
El algoritmo sugerido por Larghero comenzaba por una radioscopia del tórax a través de la cual valoraba ambos diafragmas (Foto 4) y sus movimientos, continuaba con una radiografía tóracoabdominal panorámica y una penetrada de hígado y diafragma y finalmente enfoques oblicuos y con diferente penetración de acuerdo al caso considerado.

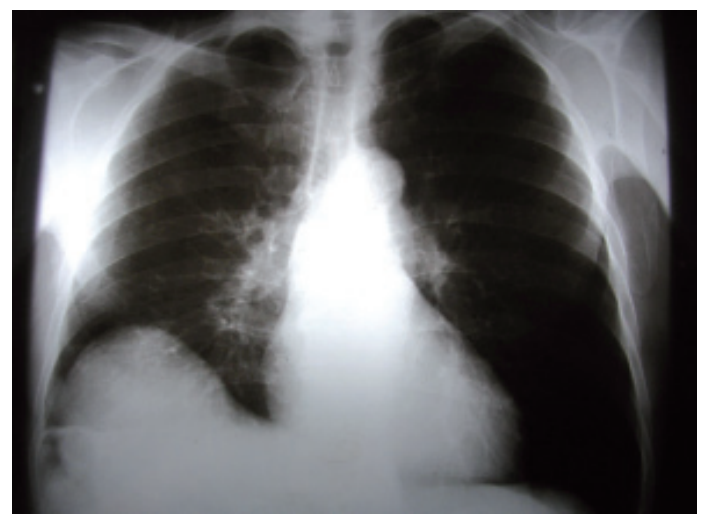

Foto 4:

Elevación y deformación del hemidiafragma derecho.

Múltiples son los signos radiológicos torácicos, por lo que atenta debe ser la valoración de aquellas imágenes sobre el parénquima pulmonar, la pleura o la cúpula diafragmática, ya que pueden ser la traducción imagenológica de un tránsito torácico.

Larghero al referirse al tránsito hepatobrónquico expresaba: «En el estudio radiológico encontramos un levantamiento hemidiafragmático total o parcial, más o menos inmóvil, que traduce la existencia expansiva del quiste y, además, en la base pulmonar una serie de modificaciones (sombras difusas, imágenes nodulares y lineales, cavernas, etc.) que ocupan una región que se extiende desde el hemidiafragma levantado hasta el hilio».

Otras imágenes que merecen especial atención son el derrame pleural producto de la irritación generada por quistes supurados de los segmentos hepáticos superiores, el nivel hidroaéreo en el pioneumoquiste, el signo del camalote (membrana flotante) o la imagen de pompas de jabón (vesículas hijas flotando).

\section{Radiografía contrastada.}

El esófago gastro duodeno o el colon por enema, actualmente no tienen indicación primaria en el estudio de la equinococosis hidatídica hepática. Sin embargo es necesario conocer que pueden objetivar en situaciones especiales fístulas con el aparato digestivo ${ }^{2}$. (Foto 5).

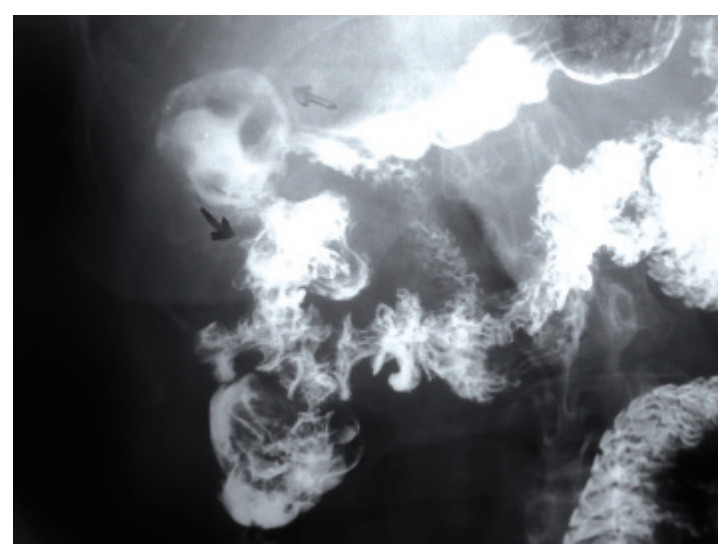

Foto 5:

En Esófago-gastro-duodeno se ve fístula Duodeno-quisto-cólica (Cortesía Dr. J. Zeballos) 
Como hechos a destacar, cabe recordar el signo del «halo opaco periquístico» descripto por Larghero, también denominado «halo cálcico» por Pratt, «signo del arco» por Cosco Montaldo o «línea arciforme» por Mogullansky, todos ellos obtenidos mediante colecistografía.

La arteriografía, esplenoportografía y cavo-suprahepatografía en tanto estudios invasivos y no exentos de riesgos se limitan a situaciones muy precisas - grandes quistes y recidivas con la finalidad de definir la táctica quirúrgica ante el planteo de una cirugía resectiva - habiendo quedado relegadas por la angio tomografía o angio resonancia nuclear magnética dada la calidad de imagen lograda a través de la reconstrucción tridimensional ${ }^{2,6,7}$.

\section{Ecografía.}

El advenimiento de la ecografía a partir de la década del 70 , ha determinado un cambio cualitativo en el estudio inicial de la patología hepática ${ }^{8}$. En la actualidad constituye el estudio imagenológico por excelencia en relación a la equinococosis hidatídica hepática. Su utilidad y validez ha sido ampliamente demostrada en múltiples estudios, tanto como herramienta de diagnóstico, screening poblacional, seguimiento de pacientes en los que se ha realizado tratamiento no quirúrgico o como instrumento de investigación para poder comprender la evolución de la hidátide a lo largo de los años ${ }^{2,9-17}$

Su sensibilidad y especificidad para el diagnóstico de equinococosis hepática se estima en 100 y $98,5 \%$ respectivamente, con un valor global de la prueba del $98,9 \%{ }^{10,18}$. Estas cifras descienden cuando la técnica se aplica en áreas no endémicas, oscilando la sensibilidad entre 93 y $98 \%$ y la especificidad entre 88 y $90 \%{ }^{19}$. En zonas endémicas su utilización como método para el diagnóstico de casos asintomáticos ha constituido una herramienta fundamental en el control de la enfermedad. Precisamente en ellas el entrenamiento de médicos generales para la detección de lesiones hepáticas, ha demostrado su real valor en campañas de screening ${ }^{10}$. En la Provincia de Río Negro, Argentina, en el período 2000 - 2007 se efectuaron 8 cursos teórico práctico al que asistieron 160 médicos generales y residentes de medicina, los que fueron capacitados en epidemiología y control de hidatidosis, diagnóstico ecográfico y su aplicación en encuestas de campo y tratamiento con albendazol y/o punción. En dicho período efectuaron 16975 ecografías, habiéndose diagnosticado 75 casos de hidatidosis ${ }^{20}$.

La ecografía como método diagnóstico permite reconocer ciertas imágenes consideradas patognomónicas de la enfermedad ${ }^{8,21}$. Estos signos son:

a) Lesión anecoica univesicular, redonda u ovalada, con una pared clara y bien definida (membrana laminar) o el signo de la doble línea (membrana laminar y periquística).

b) Contenido de pequeños ecos densos que se mueven al cambio de posición (signo del nevado: corresponde a las vesículas prolígeras de la arenilla hidatídica).

c) Quiste multivesicular o multiseptado con la apariencia de rueda de carro.

d) Quiste unilocular con vesículas hijas en su interior, pudiendo presentar la imagen de panal de abeja.

e) Quiste con la presencia de la membrana flotando en su interior.

Estos signos han sido la base para establecer diversas clasificaciones, la mayoría modificaciones de la propuesta por Gharbi en $1981^{5,11,22-26}$. De acuerdo a los hallazgos morfológicos y estructurales, Gharbi ${ }^{5}$ considera 5 patrones ecográficos (Esquema 1). Los mismos se relacionan con el estado evolutivo del parásito, hecho de especial relevancia a la hora de decidir la conducta terapéutica. La clasificación es la siguiente:

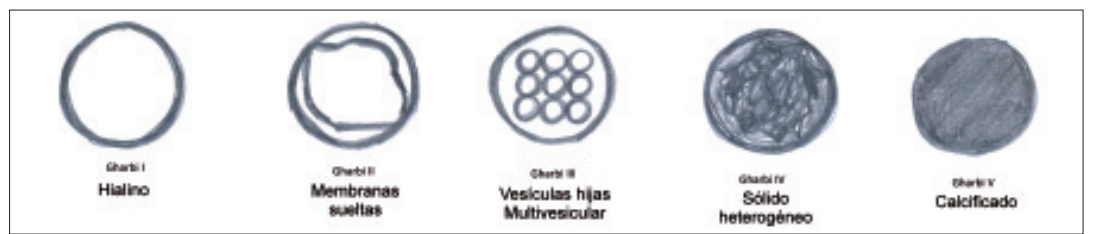

Esquema 1: Clasificación de Gharbi sobre los hallazgos ecográficos en la equinococosis hidatídica hepática. 
I. Colección líquida pura: Este tipo se caracteriza por una imagen anecoica con marcado realce de los ecos de la pared posterior. Se trata de una colección líquida, redondeada y con los bordes bien definidos. Su pared puede variar de espesor, siendo su engrosamiento un signo de hidatidosis por lo que su pesquisa debe realizarse en forma sistemática. El diagnóstico diferencial es con el quiste simple hepático. (Foto 6)

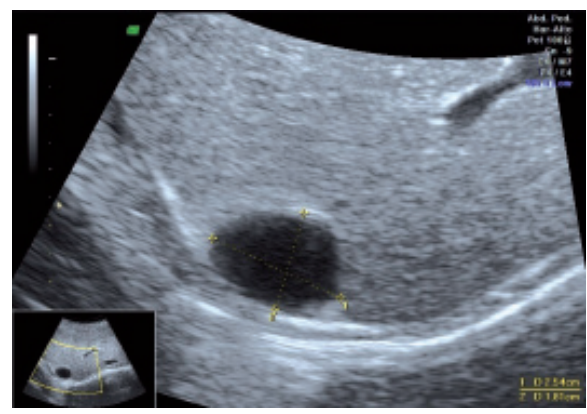

Foto 6:

Ecografía hepática. Quiste hidático hepático: Gharbi I

(Cortesía Dr. C. Viscardi )

II. Colección líquida con pared dividida: Es menos redondeada, pero mantiene una pared bien definida con hundimientos en ciertas zonas. La pared separada de la adventicia da el aspecto de «membrana flotante», la que se identifica dentro del quiste constituyendo un signo patognomónico de hidatidosis. (Foto 7)

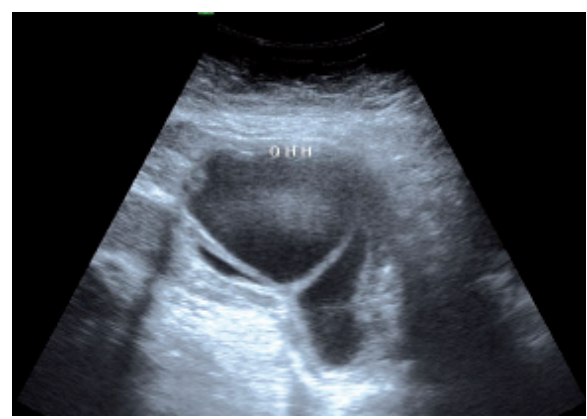

Foto 7:

Ecografía hepática. Quiste hidático hepático: Gharbi II (Cortesía Dr. C. Viscardi)

III. Colección líquida con septos: Se mantiene un contorno de pared bien definido, pero la colección es dividida por septos, más o menos gruesos o completos. Dichos tabiques determinan formas ovales o redondeadas, y en los casos más típicos le otorgan el aspecto patognomónico de «rueda de carro» o «panal de abeja» determinada por vesículas hijas. (Foto 8)

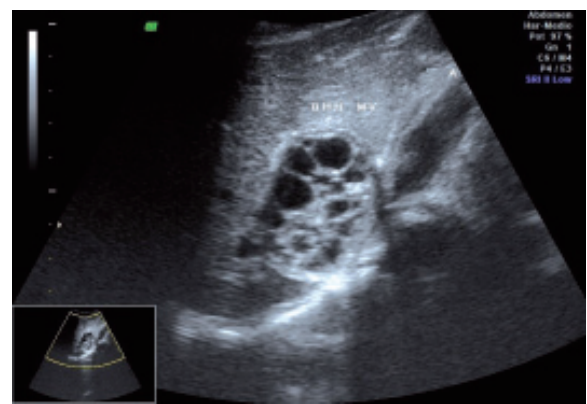

Foto 8:

Ecografía hepática. Quiste hidático hepático: Gharbi III (Cortesía Dr. C. Viscardi)

IV. Patrón de ecos heterogéneo: Este tipo de quiste aparece como una masa más o menos redondeada con un patrón ecográfico y un contorno irregular. Se reconocen 3 patrones: (Foto 9) 
Foto 9:

Ecografía hepática. Quiste hidático hepático: Gharbi IV (Cortesía Dr. C. Viscardi)

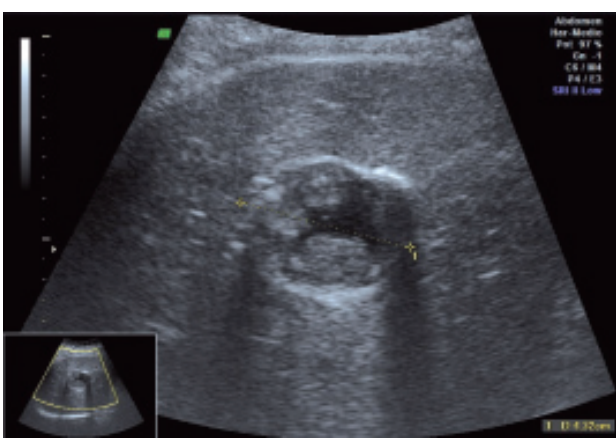

a. Hipoecoico con escasos ecos irregulares, traducción de la infección de un quiste multilocular.

b. Hiperecoica sólida, sin cono de sombra posterior.

c. Patrón mixto intermedio, donde las áreas hiperecoicas se agrupan en nódulos entre las áreas hipoecoicas.

V. Paredes gruesas calcificadas: Se trata de una formación irregularmente redondeada con contorno hiperecogénico que determina cono de sombra posterior. Este último se puede apreciar en su totalidad en quistes pequeños, en tanto cuando se trata de grandes quistes solo es posible identificar la pared más próxima al transductor, la que adopta la forma de un grueso arco con concavidad posterior. (Foto 10)

Foto 10:

Ecografía hepática. Quiste hidático hepático: Gharbi V (Cortesía Dr. C. Viscardi)

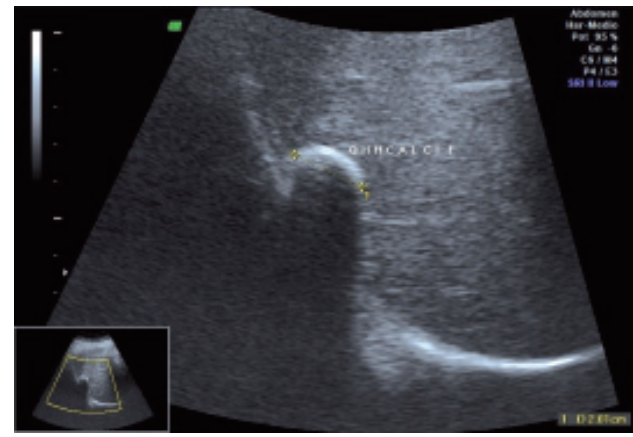

En 1995 médicos e investigadores de diferentes partes del mundo constituyeron el WHO Informal Working Group on Echinococcosis (WHO-IWGE), habiendo representado a nuestro país en dicha ocasión Roberto Perdomo. El propósito fue estandarizar la clasificación ultrasonográfica de las imágenes de quistes hidáticos, alcanzándose un acuerdo en Turquía en el año $2001^{8}$. La misma se sustenta en los siguientes preceptos:

1) Fácil uso.

2) Adaptarse a los actuales conocimientos de los mecanismos fisiopatológicos del crecimiento de los quistes.

3) Reflejar la historia natural de los quistes, así como poder brindar un seguimiento a los pacientes después de un tratamiento médico y las observaciones recogidas durante las encuestas de detección de masas

Dicha clasificación (WHO classification) considera 3 grupos: 1) Activos, en el que los quistes son fértiles; 2) Transicional, los quistes comienzan a degenerar, pero generalmente contienen protoescólices viables; 3) Inactivos, son quistes degenerados, parcial o totalmente calcificados, con baja probabilidad de fertilidad. 


\section{Quistes activos:}

- Lesiones Quísticas (CL), en las que no existen signos patognomónicos equinococosis, pudiendo tratarse de un quiste simple.

- Equinococosis Quística tipo 1 (CE1), corresponde al tipo I de Gharbi.

- Equinococosis Quística tipo 2 (CE2), corresponde al tipo III de Gharbi. En este grupo se distinguen las siguientes categorías: a) multivesicular o multiseptado en forma parcial, b) tabicación total (rueda de carro) y c) presencia de vesículas hijas (tipo roseta o en panal de abeja).

\section{Quistes transicionales:}

- Equinococosis Quística tipo 3 (CE3), corresponde al tipo II de Gharbi. Se puede presentar bajo dos formas: a) con la membrana flotante o «signo del lirio de agua», o b) como un quiste con vesículas hijas, alguna de ellas degeneradas las que determinan áreas ecoicas, que en conjunto conforman una masa compleja.

\section{Quistes inactivos:}

- Equinococosis Quística tipo 4 (CE4), corresponde al tipo IV de Gharbi. Se presentan como: a) una masa heterogénea hipoecoica, sin vesículas hijas o b) como el signo de «pelota de lana» que traduce la existencia de membranas degeneradas.

- Equinococosis Quística tipo 5 (CE5), corresponde al tipo V de Gharbi.

Además de su importancia en el diagnóstico de equinococosis hidática hepática, la ecografía es capaz evaluar la topografía del parásito tomando como referencia la segmentación portal descrita por Couinaud ${ }^{27}$. La aplicación del ecodoppler permite establecer las relaciones del parásito con los principales pedículos vasculares hepáticos. (Foto 11)

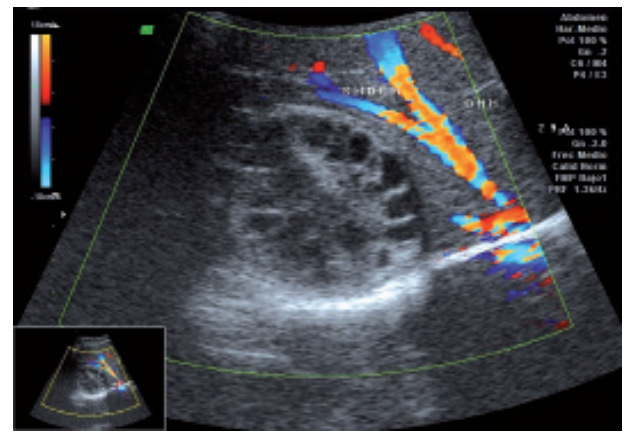

Foto 11:

Ecodoppler mostrando la relación de la vena suprahepática derecha con el quiste hidático (Cortesía Dr. C. Viscardi)

Sin duda otro valioso aporte de la ecografía lo constituye su empleo en el intraoperatorio, habiéndose transformado en este sentido en una herramienta imprescindible en la cirugía hepática moderna ${ }^{28}$. Permite evaluar el quiste y su relación con las estructuras vasculares, principalmente para topografiar los sectores de adventicia peligrosa en caso de emprender una quistoadventicectomía total. De acuerdo a la experiencia de Torterolo ${ }^{29}$ el mayor valor de su aplicación en cirugía hepática estuvo referido a la cirugía de la hidatidosis.

Como ya lo desarrolláramos en el capítulo de epidemiología no menos importante es su valor como método de screening poblacional.

Finalmente destacamos la importancia que ha adquirido en el conocimiento evolutivo de la enfermedad y el seguimiento de pacientes asintomáticos que recibieron tratamiento médico o simplemente hubo una abstención terapéutica. Así lo confirman las experiencias en la Provincia de Río Negro, Argentina donde se controló por más de 14 años a $67 \%$ de los portadores asintomáticos de hidatidosis hepática, y se evidenció que entre 54 a $71 \%$ de los portadores asintomáticos tratados con albendazol mostraron cambios sugerentes de pérdida de vitalidad del parasito en el seguimiento ecográfico ${ }^{16,17}$. Experiencia similar aportó Mercapide ${ }^{20}$ donde realizó el seguimiento de pacientes que 
habían recibido tratamiento médico y en los que hubo una abstención terapéutica a los 30 días, 2 meses, luego trimestralmente hasta completar el año y finalmente en forma anual, en busca de cambios cuanti y cualititvos, llevando muchos de ellos más de 10 años de control al momento actual. Los resultados evidenciaron que $22 \%$ de los pacientes que no recibieron tratamiento, los quistes involucionaron completamente, $17,9 \%$ presentaron cambios positivos, $28,2 \%$ se mantuvieron sin cambios y $5,1 \%$ pasaron a tipo III de la clasificación ecográfica y $28,2 \%$ presentaron cambios evolutivos negativos por lo que debieron ingresar a otros protocolos de tratamiento. En referencia a los casos que recibieron tratamiento con benzimidazólicos, $8 \%$ involucionó completamente, $68 \%$ mostraron cambios positivos, $4 \%$ sin cambios, $16 \%$ pasaron de tipo I o II al III y $4 \%$ presentó cambios evolutivos negativos, por lo cual recibieron nuevamente albendazol.

\section{Tomografía computada.}

Si bien la ecografía permite realizar el diagnóstico etiológico, topográfico y estadio evolutivo de la equinococosis hidatídica hepática así como establecer sus relaciones, la tomografía computada (TC) define estos aspectos con mayor precisión, siendo imprescindible al momento de planificar la cirugía.

Precisamente su mayor sensibilidad la convierten en un complemento ineludible especialmente cuando no se ha podido determinar con claridad la naturaleza de las imágenes hepáticas como puede ocurrir con algunos quistes tipo CE4 y CE5, o ante la positividad en estudios serológicos específicos para hidatidosis en los que la valoración previa mediante ecografía no ha permitido evidenciar imágenes subjetivas de la enfermedad ${ }^{21,30}$. Constituye una herramienta útil en la valoración de la respuesta al tratamiento médico, a lo que debe sumarse el valor que significa poder analizar las imágenes de forma objetiva, aspecto crucial para definir la táctica quirúrgica ${ }^{2}$.

Las imágenes que brinda son comparables a las definidas en la clasificación ecográfica de Gharbi, siendo patognomónicas la calcificación de la pared, tabiques internos, decolamientos de la membrana laminar y vesículas hijas ${ }^{21,31}$ (Fotos 12, 13, 14, 15, 16 y 17). Estas han sido la base para las diversas clasificaciones tomográficas ${ }^{32,33}$.

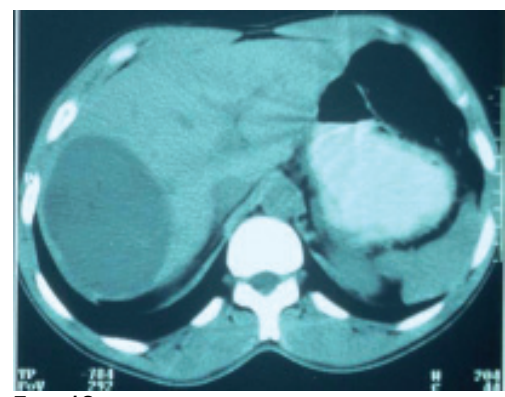

Foto 12: TC. Quiste hidático hialino.

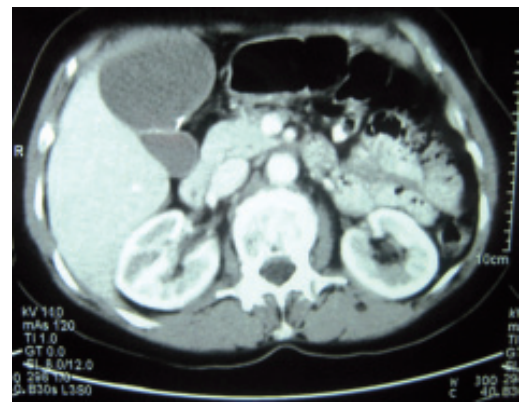

Foto 14: TC. Quiste hidático mastic en intimo contacto con la vesícula biliar. Se observa una calcificación en la pared del quiste próxima a la vesícula.

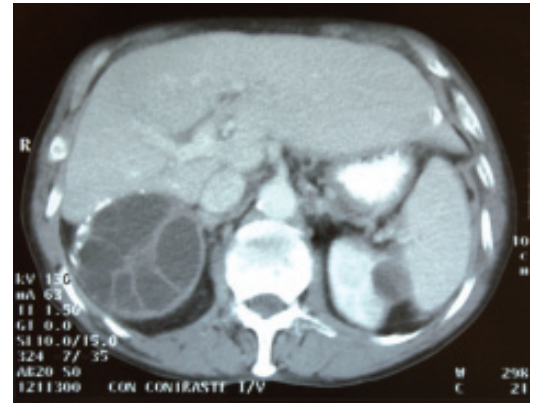

Foto 13: TC. Quiste hidático multivesicular. Se observan calcificaciones en su pared.

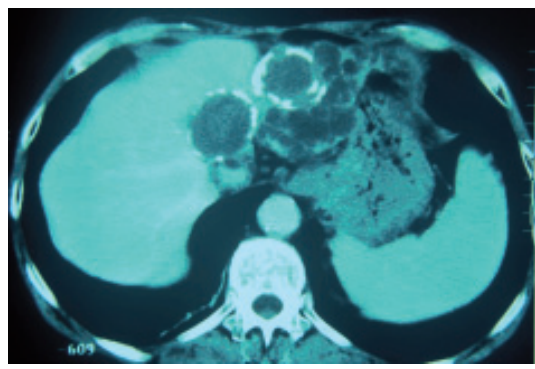

Foto 15: TC. Se observan 2 quistes hidáticos calcificados con zonas hipodensas centrales. 


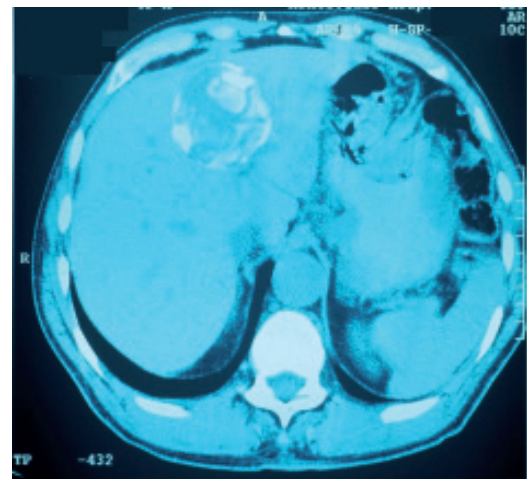

Foto 16:

TC. Quiste hidático calcificado, en su sector central presenta zonas hipodensas.

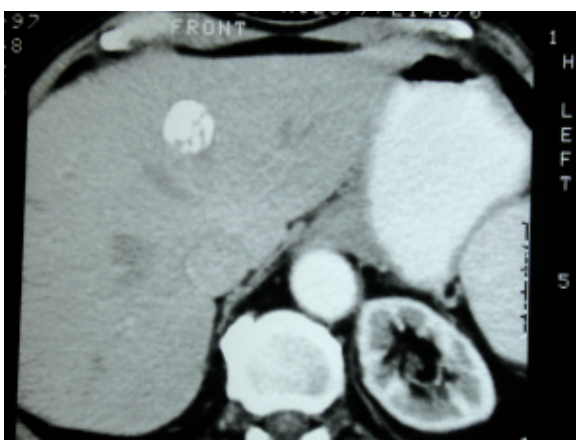

Foto 17:

TC. Quiste hidático totalmente calcificado.

Representa el estudio imagenológico de elección para el diagnóstico del quiste hidático infectado ${ }^{31}$. Se presentan como masas pobremente definidas, que ante la administración de contraste intravenoso adoptan la imagen típica de un anillo de alta atenuación que traduce la infección perilesional. Adquiere real importancia en la valoración de quistes transitados a tórax o a vísceras vecinas. Es muy específica para determinar la presencia de aire o un nivel líquido dentro de la cavidad (Foto 18). En referencia al tránsito hepato-torácico, permite evaluar el componente torácico. La presencia de una cavidad con nivel líquido que se llena de contraste luego de su administración por vía oral caracteriza la fístula quisto-gastroduodenal ${ }^{31}$ (Foto 19). Por su parte tiene una sensibilidad de $77 \%$ para el diagnóstico de la apertura del quiste en vía biliar, siendo los signos característicos la presencia de material atravesando la pared del quiste hacia el árbol biliar y de vesículas hijas en el sector terminal del hepato colédoco ${ }^{31}$.

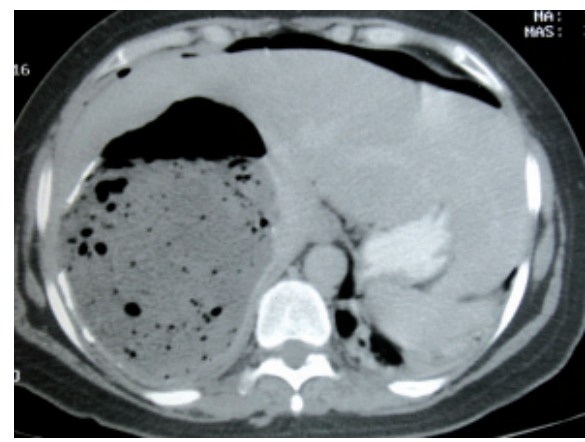

Foto 18:

TC. Quiste hidático supurado. Se observa un nivel hidroaéreo, múltiples burbujas de gas y la presencia de calcificaciones en su pared.

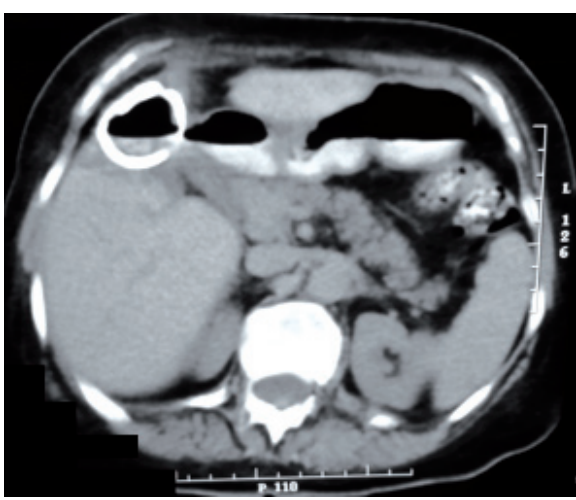

Foto 19:

TC. Fístula quisto-duodenal (Cortesía Dr. J. Zeballos)

Las nuevas generaciones de tomógrafos multicorte con 32 ó 64 detectores han mejorado la resolución de las imágenes. Permiten a través de reconstrucciones y del empleo de angio TC valorar el árbol vascular y sus relaciones con el quiste, hecho que ya destacáramos de especial relevancia en la planificación del procedimiento quirúrgico ${ }^{7}$ (Fotos 20a, 20b y 20c). 


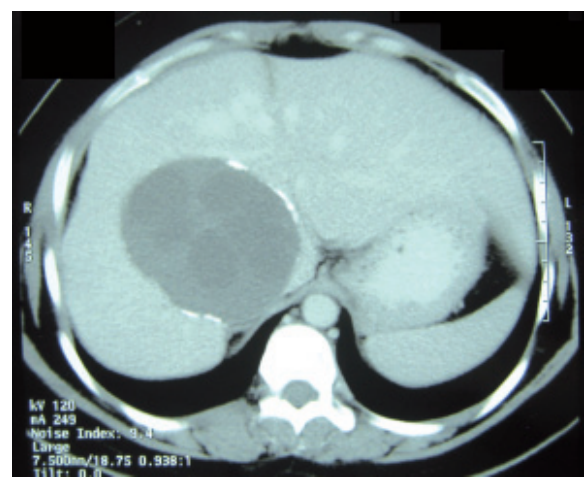

Foto 20a:

TC. Paciente con quiste hidático hepático en intima relación a confluente suprahepático cavo.

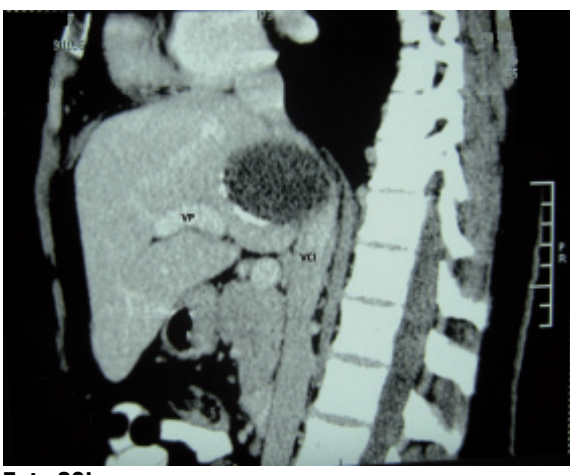

Foto 20b:

Corte sagital de TC. En el mismo paciente donde se observa la relación del quiste con la vena cava inferior $(\mathrm{VCl})$ y la vena porta (VP)

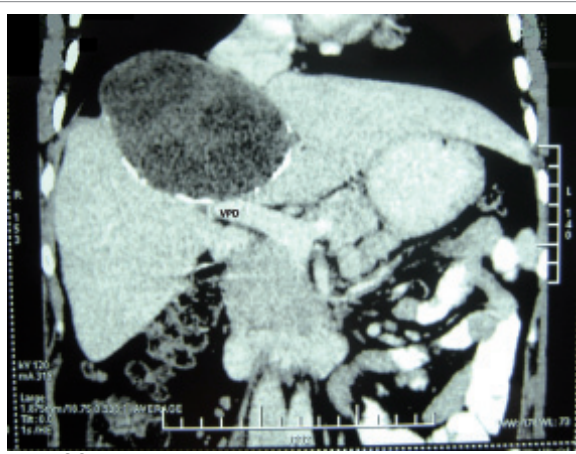

Foto 20c:

Corte coronal de TC donde se observa la relación del quiste con la rama derecha de la vena porta (VPD)

\section{Resonancia nuclear magnética.}

La resonancia nuclear magnética (RNM) a través de imágenes de alta calidad y claridad, tiene la ventaja de realizar cortes imagenológicos en varios planos, con una mejor definición que la TC en tejidos blandos sin la necesidad de irradiar al paciente ${ }^{34}$.

Es el examen por excelencia a la hora de definir el diagnóstico entre un quiste hialino y un quiste simple. La identificación de un anillo o borde de baja intensidad de señal en las imágenes T2 y T1 ponderado caracteriza la membrana del parásito ${ }^{2,33}$ (Fotos 21a y 21b).

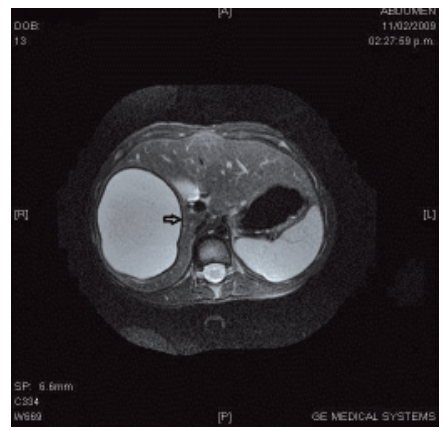

\section{Foto 21a:}

RNM. Quiste hialino donde se identifica el anillo o borde de baja intensidad de señal (flecha) en las imágenes en T2, que caracteriza la membrana del parásito
Foto 21b

RNM. El mismo paciente en un corte coronal.

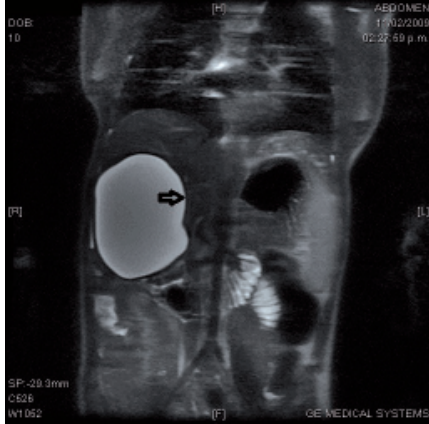


En el mismo sentido, es más eficaz que la TC en la valoración de complicaciones, especialmente en quistes infectados o fistulizados en el árbol biliar. También es un buen estudio para evaluar el quiste en sus relaciones con el diafragma y en casos de tránsito a tórax como vemos en las fotos 22a, 22b y 22c. Sin embargo no es la mejor opción para caracterizar las formas sólidas o pseudotumorales de la hidatidosis ${ }^{31}$.
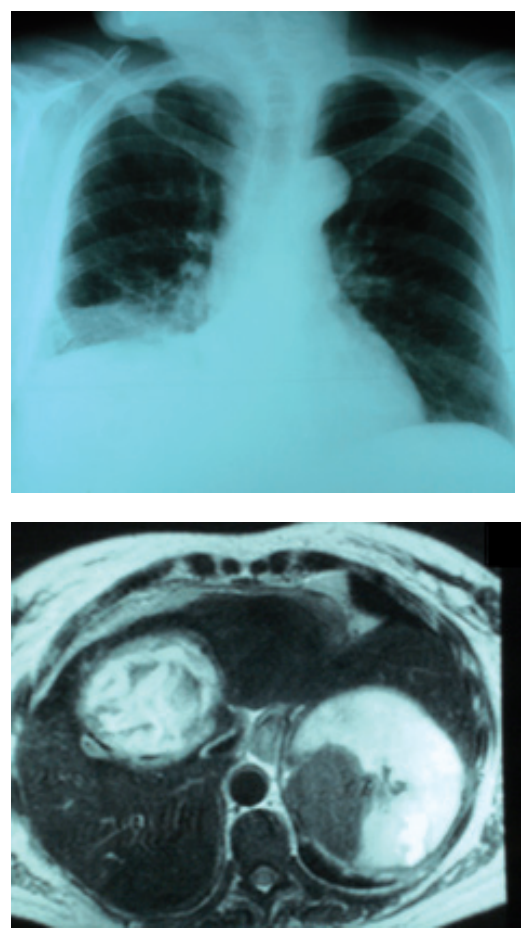

Foto 22a:

Rx de tórax, frente. Se ve elevación del diafragma derecho e imagen de condensación en base de pulmón derecho.

La colangiorresonancia nuclear magnética es un estudio no invasivo de alta sensibilidad y especificidad al momento de valorar complicaciones biliares, especialmente la fistulización y obstrucción por evacuación del contenido hidatídico en la vía biliar ${ }^{2}$ (Foto 23a y 23b). Adquiere gran relevancia a la hora de planificar la cirugía ya que permite definir las relaciones de los quistes, fundamentalmente los centrales que son los que se vinculan estrechamente con los canales biliares principales.

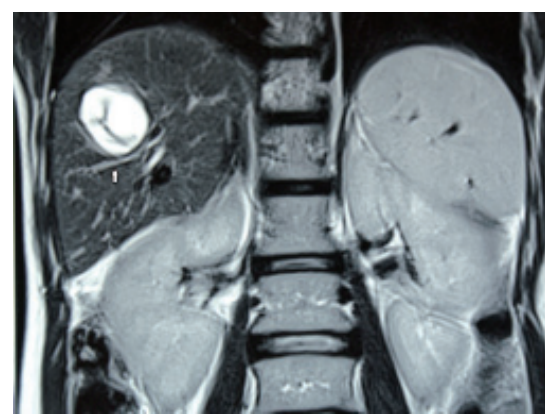

Foto 23a:

RNM. Corte coronal. Quiste hidático en segmento VII-

VIII apoyado sobre elementos de pedículo Glissoniano (flecha).

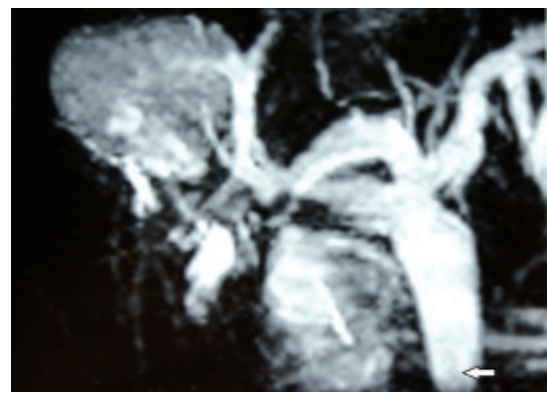

\section{Foto 23b:}

ColangioRNM. Vemos la relación del quiste con la vía biliar intrahepática. Hay una dilatación de la vía biliar intra y extra hepática. En el colédoco hay imágenes de falta de relleno correspondientes a vesículas hijas (flecha). 


\section{Colangiopancreatografía endoscópica retrógrada.}

Este estudio invasivo es un método eficaz en cuanto a detección y manejo del compromiso biliar en la hidatidosis hepática ${ }^{35}$. Por ello constituye un importante recurso diagnóstico y terapéutico. Desde el punto de vista diagnóstico nos permite evaluar la relación del quiste con la vía biliar, la dilatación de la misma, la presencia de vesículas hijas o fragmentos de membrana en el interior de la vía biliar, presencia de estenosis biliar por compresión y la presencia de una fístula entre el quiste y la vía biliar. Estaría indicado en pacientes con ictericia colestásica, en que se plantea la posibilidad de degravitar la vía biliar en el mismo momento mediante una papilotomía endoscópica y extracción de vesículas hijas o restos hidáticos ${ }^{35}$. Desde el punto de vista diagnóstico exclusivo ha quedado relegada a un segundo lugar por la colangio RNM, ya que no está exenta de complicaciones.

\section{Bibliografía consultada.}

Larghero P, Venturino W, Broli G. Equinococosis hidatídica del abdomen. Montevideo: Delta Eitorial. Montevideo; 1962.

Kremer A, Chicconi E, Moguillansky S. Hidatidosis. Clínica y diagnóstico. En: Findor J, Sapunar I. Enfermedades del hígado y las vías biliares. Buenos Aires: Librería Akadia Editorial; 1985. p. 545-66.

\section{Referencias bibliográficas.}

1. Galarraga J, Soto J, Di Leoni F, Tchekmedyian V, Lorenzelli J, Chifflet J. Complicaciones torácicas de la equinococosis. Cir Uruguay. 1994; 64: 241-56.

2. Odriozola M, Pettinari R. Relato Oficial. Hidatidosis abdominal. 69 Congreso Argentino de Cirugía. Rev Arg Cir. 1998;(No. Extra):9-70.

3. Moussi A, Jarboui S, Sayari Md S, Jerraya H, Morched Abdesselem M, Zaouche A. Right adrenal cyst mimicking a hydatid cyst of the liver. J Chir (Paris). 2007. 144(6):536-7.

4. Plard L, Guedin P, Le Pennec V, Chiche L. Kystes hépatiques dits « kystes biliaires du foie ». Journal de Chirurgie Viscérale. 2008(145);3:217-19.

5. López Penza P, Segura D, González D, Ruso L. Est-ce que les corps étrangers intraabdominaux peuvent simuler un kyste hydatique? Journal Chirurgie Viscérale. 2011;148(4 No. Spécial 1):41.

6. Davidenko N, Tiscornia E, Silva E, Davidenko A. La cavo-suprahepaticografía en el quiste hidático de los segmentos superiores del hígado. Cir Uruguay. 1980; 50 (3): 219-24.

7. Sahani D, Mehta A, Blake M, Prasad S, Harris G, Saini S. Preoperative Hepatic Vascular Evaluation with CT and MR Angiography: Implications for Surgery. Radiographics. 2004;24(5):1367-80.

8. WHO Informal Working Group. 2003. International classification of ultrasound images in cystic echinococcosis for application in clinical and field epidemiological settings. Acta Tropica. 2003; 85:253-61.

9. Gharbi H, Hassine W, Brauner M, Dupuch K. Ultrasound examination of the hydatic liver. Radiology. 1981;139(2):459-63.

10. Del Carpio M, Moguilansky S, Costa M, Panomarenko H, Bianchi G, Bendersky S, et al. Diagnosis of human hidatidosis. Predictive value of a rural ultrasonographic survey in an apparently healthy population. Medicina. 2000; 60: 466-68.

11. Perdomo R, Parada R, Alvarez C, Cattivelli D, Geninazzi H Barragué A, et al. Estudio epidemiológico de hidatidosis. Detección precoz por ultrasonido en áreas de alto riesgo. Rev Med Urug. 1990;6(1):34-47.

12. Perdomo R, Alvarez C, Geninazzi H, Ferreira C, Monti J, Parada R, et al. Early diagnosis of hydatidosis by ultrasonography. Lancet. 1988;1(8579):244.

13. Carmona C, Perdomo A, Carbo A, Alvarez C, Monti J, Grauert R, et al. Risk factors associated with human cystic echinococcosis in Florida, Uruguay: Results of a mass screening study using ultrasound and serology. Am J Trop Med Hyg. 1998;58(5):599-605.

14. Paolillo E, Botta B, Cohen H, Dibarboure L, Rodríguez O, Antoniello L, et al. Hidatidosis: un problema de atención primaria en salud. Rev Med Urug. 1991;7(1):32-7.

15. Cohen H, Paolillo E, Bonifacino R, Botta B, Parada L, Cabrera P, et al. Human cyst echinococcosis in a Uruguayan community: a sonographic, serologic and epidemiologic study. Am J Trop Med Hyg. 1998;59(4):620-27. 
16. Larrieu E, Frider B, Del Carpio M, Salvitti J, Mercapide C, Pereyra R, et al. Portadores asintomáticos de hidatidosis: epidemiología, diagnóstico y tratamiento. Rev Panam Salud Publica. 2000;8(4):250-56.

17. Frieder B, Larrieu E. Treatment of liver hidatidosis: How to treat an asymptomatic carrier? World $\mathrm{J}$ Gastroenterol. 2010;16(33):4123-29.

18. Frieder B, Ledesma C. Odriozola M, Larrieu E. Especificidad de la ecografía en el diagnóstico precoz de la hidatidosis hemana. Acta Gastroenterol Lat Amer. 1992;20:13-5.

19. Galindo F, Sanchez A. Hidatidosis hepática. En: Galindo F, editor. Cirugía digestiva. [En línea]. 2009 [Acceso 28 de octubre de 2011]:1-16. Disponible en: URL:http//www.sacd.org.ar/ enciclopedia.htm.

20. Mercapide C, Del Carpio M, Salvitti J, Sustercic J, Panomarenko H, Uchiumi L, et al. Diagnóstico y tratamiento de la equinococcosis mediante ultrasonografía aplicada por médicos generalistas en población escolar. Río Negro, Argentina. Zoonosis. 2009;1:35-40.

21. Pawlowski Z, Eckert J, Vuitton DA, Ammann RW, Kern P, Craig PS, et al. Echinococcosis in humans: clinical aspects, diagnosis and treatment. In: Eckert J, Gemmell MA, Meslin FX, Pawlowski Z, editors. WHO/OIE Manual on echinococcosis in humans and animals: a public health problem of global concern. Paris: 2001. p.20-48.

22. Canelo S, Gatica A. Hidatidosis hepática: nuestra experiencia más allá de la clasificación de Gharby. Rev Arg de Ultrasonido. 2007;6(1):23-7.

23. Beggs I. The radiological appearances of hydatid disease of the liver. Clin Radiol. 1983;34:555-63.

24. Caremani M, Benci A, Maestrini R, Accorsi A, Caremani D, Lapini L. Ultrasound imaging in cystic echinococcosis. Proposal of a new sonographic classification. Acta Trop. 1997;67;91-105.

25. Lewall D, McCorkell S. Hepatic Echinococcal cysts: sonographic appearence and classification. Radiology. 1985;155(3):773-75.

26. Shambesh M, Craig P, Macpherson C, Rogan M, Gusby A, Echtuish E. An extensive ultrasound and serologic study to investigate the prevalence of human cystic Echinococcosis in Northern Libya. Am J Trop Med Hyg. 1999;60(3):462-68.

27. Couinaud C. Le foie. Études anatomiques et chirurgicales. Paris: Masson; 1957.

28. Anatomía quirúrgica del hígado. En: Casanova D, Figueras J, Pardo F, editores. Cirugía hepática. Madrid: Arán; 2004. p. 25-42.

29. Torterolo E, Kaitazoff $P$, Fernández W. La ecografía intraoperatoria en cirugía hepática. Cir Uruguay. 1994;64:52-55.

30. Filippou D, Tselepis D, Filippou G, Papadopoulos V. Advances in liver echinococcosis: diagnosis and treatment. Clin Gastroenterol Hepatol. 2007;5(2): 152-59.

31. Pedrosa I, Saiz A, Arrazola J, Ferreiros J, Pedroza C. Hydatid disease: Radiologic and pathologic features and complications Radiographics. 2000;20: 795-817.

32. Polat P, Kantarci M, Alper F, Suma S, Bedel M, Okur A. Hydatid disease from head to toe. Radiographics. 2003;23:475-94.

33. Von Sinner W. New diagnostic signs in hydatid disease; radiography, ultrasound, CT and MRI correlated to pathology. Eur J Radiol. 1991;12:150-59.

34. Morris D, Buckley J, Gregson R, Worthington B. Magnetic resonance imaging in hydatid disease. 1987;38:141-44.

35. Goumas K, Poulou A, Dandakis D, Tyrmpas I, Georgouli A, Sgourakis G, et al. Role of endoscopic intervention in biliary complications of hepatic hydatid cyst disease. Scand J Gastroenterol. 2007;42:1113-9. 


\section{CAPÍTULO 9}

\section{Tratamiento médico}

El tratamiento médico es una alternativa y un coadyuvante a la cirugía y a los procedimientos invasivos mínimos, que en los últimos años ha logrado nuevas perspectivas en el tratamiento de la equinococosis hidática ${ }^{1}$.

Sus indicaciones son múltiples:

1. Es el tratamiento de elección en pacientes inoperables por su condición general o el riesgo vital que supone la cirugía vinculada a la localización del o los quistes.

2. Constituye una opción válida ante la negativa de la persona a la cirugía.

3. En la hidatidosis primitiva múltiple o multivisceral.

En estas tres indicaciones, es condición indispensable que los quistes no superen los 7 centímetros de diámetro, posean una pared delgada, sean hialinos y no estén complicados con infección o apertura en vía biliar o aérea ${ }^{2}$.

4. Previo a la cirugía con el objetivo de minimizar el riesgo de una equinococosis hidatídica secundaria determinada por la contaminación durante el acto quirúrgico.

Aktan ${ }^{3}$ en un estudio prospectivo no randomizado, comparó un grupo de 29 pacientes portadores de 35 quistes hidáticos hepáticos que recibió albendazol por un período de 3 semanas previos a la cirugía y otro de 41 pacientes con 54 quistes hidáticos hepáticos que no recibió tratamiento preoperatorio. En el primer grupo $42,8 \%$ de los quistes fueron no viables al momento de la cirugía en relación a 20,3\% para el segundo.

Stankovic ${ }^{4}$ en un ensayo clínico aleatorizado, randomizó 30 pacientes portadores de quistes hidáticos hepáticos que recibieron albendazol previo a la cirugía y un grupo control de 30 pacientes que no lo recibió. Encontró diferencias estadísticamente significativas a favor del primero en relación a la viabilidad de los protoescólices.

Gil-Grande ${ }^{5}$ en un trabajo prospectivo, controlado y aleatorizado estudio la viabilidad del quiste luego del tratamiento con albendazol mediante el estudio de la pieza quirúrgica. Comparó 3 grupos: A) grupo control $(n=18)$, B) tratados con albendazol 1 mes previo a la cirugía $(n=19)$ y C) tratados con albendazol 3 meses previo a la cirugía $(n=19)$.

Determinó que $50 \%, 72 \%$ y $94 \%$ no fueron viables en los grupos A, B y C respectivamente, siendo esta diferencia estadísticamente significativa $(p<0,015)$.

Concluye que el tratamiento con albendazol a dosis de $10 \mathrm{mg} / \mathrm{kg}$ por día en un período de 3 meses constituye una alternativa válida para el tratamiento del quiste hidático hepático no complicado.

Su empleo en población pediátrica también ha sido informado. Dopchiz ${ }^{6}$ en una revisión de 44 casos de niños con diagnóstico de quiste hidático en Buenos Aires, informó que el $52 \%$ de los niños operados recibieron tratamiento previo con albendazol, al igual que 2 niños cuyo único tratamiento fue médico.

5. En los casos complicados con apertura en vía biliar o vía aérea, rotura del quiste o infección, la cirugía se encuentra formalmente indicada El albendazol debe ser administrado en el postoperatorio por 90 días sin intervalo a dosis de $10 \mathrm{mg} / \mathrm{kg} /$ día. Se debe asociar ranitidina $150 \mathrm{mg}$ vía oral cada 12 horas $^{7}$.

6. Cuando se plantea la realización de la punción, aspiración, inyección y reaspiración (PAIR).

7. En las localizaciones óseas, cerebral, cardíaca y las siembras. 
Dentro de las opciones que se disponen, el fármaco de primera elección es el albendazol. Su metabolito activo, sulfóxido de albendazol, alcanza concentraciones óptimas en sangre e intraquísticas 24 horas de comenzada su administración. La concentración intraquística es 15 a 40 veces superiores a las que logra el mebendazol ${ }^{8,9}$. Inhibe la captación de glucosa y la polimerización de las proteínas del citoesqueleto del parásito. Su acción se objetiva en la disminución de la tensión intraquística, inactivación de los protoescólices y en la alteración de la integridad de las membranas quísticas.

Franchi ${ }^{10}$ comparó la eficacia del tratamiento entre albendazol y mebendazol, encontrando una diferencia estadísticamente significativa a favor del primero. Los cambios regresivos se constataron en $82 \%$ de los casos tratados con albendazol y $56 \%$ con mebendazol.

Se recomienda una dosis de 10 a $15 \mathrm{mg} / \mathrm{kg} /$ día en tres dosis junto a las comidas para lograr una mejor absorción. En pacientes que van a ser sometidos a cirugía se comienza un mes antes y luego se continúa por dos meses, teniendo un descanso de 15 días entre el primer y segundo mes. En el resto de las situaciones se debe realizar por un período de 3 meses como mínimo.

Este tratamiento está contraindicado en pacientes portadores de hepatopatía moderada y severa, leucopenia, epilepsia, mujeres embarazadas, lactancia, hipersensibilidad a la droga y en quistes calcificados.

Si bien los efectos secundarios son leves y raramente requieren la suspensión del tratamiento, es necesario un seguimiento estricto con hemograma y funcional y enzimograma hepático cada 15 días el primer mes y luego mensualmente ${ }^{11}$. Concretamente la elevación de la TGP, TGO, fostasa alcalina y la neutropenia traducen la toxicidad hepatocítica y medular respectivamente y son indicación de disminuir a la mitad la dosis de albendazol y asociarle praziquantel $40 \mathrm{mg} / \mathrm{kg} / \mathrm{día}$ o suspenderlo y remplazarlo por praziquantel solo.

La evaluación de la efectividad del tratamiento se realiza mediante controles clínicos, determinando la evolución de la sintomatología. Imagenológico semestralmente durante los dos primeros años y luego anual hasta completar los 5 años. Finalmente controles serológicos.

Cuatro son las respuestas posibles.

1. Curación, donde el quiste desaparece.

2. Mejoría, cuando se verifica una disminución del tamaño igual o superior al $25 \%$, aumento de la densidad por TAC, engrosamiento de la pared vesicular, desaparición de las vesículas hijas y el comienzo de la calcificación ${ }^{12}$.

3. Sin cambios, en la que la disminución de tamaño es menor al $25 \%$ o no se constatan cambios morfológicos.

4. Mala respuesta, cuando el quiste aumenta de tamaño o aparecen nuevos quistes.

El mebendazol que por mucho tiempo fue el tratamiento de elección tiene el inconveniente de poseer una muy baja absorción intestinal. La dosis indicada es de 40 a $50 \mathrm{mg} / \mathrm{kg} /$ día por un período de tres a seis meses.

Los resultados del tratamiento han sido comunicados en diversos trabajos. La remisión completa ocurrió entre 10 y $30 \%$ de los pacientes sintomáticos tratados con benzimidazólicos, entre 50 y $70 \%$ se produjo la reducción significativa del tamaño del quiste, en tanto entre 20 y $30 \%$ no se observó cambios morfológicos en los mismos $5,8,13-16$.

Las recaídas oscilaron entre 14 y $25 \%$, sin embargo $90 \%$ respondieron a una nueva serie ${ }^{17}$. En la casuística de Demirbileck ${ }^{18}$ en una población pediátrica las recidivas fueron menores a $6 \%$.

Este tratamiento ha demostrado su efectividad en poblaciones asintomáticas ${ }^{19}$.

Su aplicación en 15 portadores asintomáticos en la Provincia de Río Negro, Argentina, presentó $69 \%$ de respuestas favorables al tratamiento con albendazol ${ }^{20}$. Años más tarde, en la misma Provincia se comunicaron resultados estadísticamente significativos favorables al tratamiento con albendazol en relación a un grupo control sin tratamiento, en una población de niños asintomáticos luego de 4 años 
de seguimiento ${ }^{21}$. Larrieu ${ }^{22}$ afirmó que la indicación de cirugía como tratamiento de primera elección en portadores asintomáticos jóvenes se reduce a $7 \%$.

En la República Argentina la norma técnica y el manual de procedimiento para el control de la hidatidosis del Ministerio de Salud de la Nación, establece que para los quistes tipo lb (hialinos de 3 a $7 \mathrm{~cm}$ ), II (desprendimiento de la membrana de 1 a $7 \mathrm{~cm}$ ) y III (con vesículas hijas hasta $7 \mathrm{~cm}$ ) en portadores asintomáticos debe indicarse el tratamiento con albendazol a dosis de $10 \mathrm{mg} / \mathrm{kg} / \mathrm{día}$ en cuatro ciclos de 30 días. Debe asociarse ranitidina, $150 \mathrm{mg}$ vía oral cada 12 horas u omeprazol $20 \mathrm{mg}$ día ${ }^{7,23}$.

A pesar de ello aún no está claramente establecido cual es la mejor opción terapéutica para la población asintomática ${ }^{24}$.

\section{Bibliografía consultada.}

Da Rosa W, Calegari L. Tratamiento médico de la enfermedad hidatídica. [En línea]. Montevideo: OPS. [Acceso 19 de setiembre de 2011]. URL: http://www.infecto.edu.uy/espanol/guiatrat/guiapara/ qhidatico.htm.

\section{Referencias bibliográficas.}

1. Saimot AG. Medical treatment of liver hydatidosis. World J Surg. 2001;25(1):15-20.

2. Teggi A, Lastilla MG, De Rosa F. Therapy of human hydatid disease with mebendazole and albendazole. Antimicrob Agents Chemother. 1993;37(8):1679-84.

3. Aktan AO, Yalin R. Preoperative albendazole treatment for liver hidatid disease decreases the viability of the cyst. Eur J Gastroenterol Hepatol. 1996;8(9):877-9.

4. Stankovic N, Ignjatovic M, Noziæ D, Hajdukovic Z. Liver hydatid disease: morphological changes of protoscoleces after albendazole therapy. Vojnosanit Pregl. 2005;62(3):175-9.

5. Gil-Grande LA, Rodriguez-Caabeiro F, Prieto JG, Sánchez-Ruano JJ, Brasa C, Aguilar L, et al. Randomised controlled trial of efficacy of albendazole in intra-abdominal hydatid disease. Lancet. 1993;342(8882):1269-72.

6. Dopchiz MC, Elissondo MC, Andresiuk MV, Maiorini E, Gutiérrez AM, Muzulin PM, et al. Pediatric hidatidosis in the south east of the Buenos Aires province, Argentina. Rev Arg Microbiol. 2009;41(2):105-11.

7. Norma técnica y manual de procedimientos para el control de la hidatidosis en la República Argentina. [En línea]. Buenos Aires: Ministerio de Salud de la Nación; 2009. [Acceso 19 de setiembre de 2011]. URL: http://publicaciones.ops.org.ar/publicaciones/

8. Horton RJ. Albendazole in treatment of human cystic echinococcosis: 12 years of experience. Acta Trop. 1997;64(1-2):79-93.

9. Capan M, Keltner S, Thalhammer F, Winkler S, Jäger W, Zeitlinger M, et al. Intra-cystic drug concentration of albendazole sulphoxide in patients with Echinococcus granulosus cysts. Am J Trop MedHyg. 2009;81(4):712-3.

10. Franchi C, Di Vico B, Teggi A. Long-term evaluation of patients with hydatidosis treated with benzimidazole carbamates. Clin Infect Dis. 1999;29(2):304-9.

11. Guidelines for treatment of cystic and alveolar echinococcosis.Informal Working Group on Echinococcosis. Bull World Health Organ. 1996;74(3):231-42.

12. Caremani M, Benci A, Maestrini R, Accorsi A, Caremani D, Lapini L. Ultrasound imaging in cystic echinococcosis. Proposal of a new sonographic classification. Acta Trop. 1997;67(1-2):91-105.

13. Ammann RW, Eckert J. Cestodes: Echinococcus. Gastroenterol Clin North Am. 1996;25(3):655-89.

14. Davis A, Pawlowski Z, Dixon H. Multicentre clinical trials of benzimidazole-carbamates in human echinococcosis. Bull World Health Organ. 1986;64(3):383-8.

15. Nahmias J, Goldsmith R, Soibelman M. Three to 7 years follow up after albendazol treatment of 68 patients with cystic echinococcosis. Ann Trop Med Parasitol. 1994;88(3):295-304.

16. Kapan S, Turhan AN, Kalayci MU, Alis H, Aygun E. Albendazole is not effective for primary treatment of hepatic hydatid cysts. J Gastrointest Surg. 2008;12(5):867-71.

17. Todorov T, Georgiev P, Handjiev S, Vutova K. Potentials of benzimidazole compounds in treatment of human echinococcosis. Arch. int. Hidatid. 1997; 32:164-7. 
18. Demirbilek S, Sander S, Atayurt HF, Aydin G. Hydatid disease of the liver in childhood: the success of medical therapy and surgical alternatives. Pediatr Surg Int. 2001;17(5-6):373-7.

19. Smego RA Jr, Sebanego P. Treatment options for hepatic cystic echinococcosis. Int J Infect Dis. 2005;9(2):69-76.

20. Salvitti J, Mercapide C, Pereyra R, Odriozola M, Del Carpio M, Larrieu E. Treatment with albendazole of asymptomatic hydatic carriers. Arch Inter Hid. 1999;33:205-6.

21. Larrieu E, Del Carpio M, Salvitti JC, Mercapide C, Sustersic J, Panomarenko H, et al. Ultrasonographic diagnosis and medical treatment of human cystic echinococcosis in asymptomatic school age carriers: 5 years of follow-up. Acta Trop. 2004;91(1):5-13.

22. Larrieu E, Belloto A, Arambulo III P, Tamayo H. Echinococcosis quística: epidemiología y control en América del Sur. Parasitol Latinoam. 2004;59: 82-9.

23. Mercapide C, Del Carpio M, Salvitti J, Sustercic J, Panomarenko H, Uchiumi L, et al. Diagnóstico y tratamiento de la equinococosis mediante la ultrasonografía aplicada por médicos generalistas en población escolar. Zoonosis. 2009;1:37-42.

24. Frider B, Larrieu E. Treatment of liver hydatidosis: How to treat an asymptomatic carrier?. World J Gastroenterol. 2010;16(33):4123-9. 


\section{CAPÍTULO 10}

\section{Tratamiento quirúrgico del quiste hidático hepático}

\section{Generalidades}

«...la cirugía de la equinococosis hepática enfrenta al cirujano con problemas muy diversos, en muchos casos de difícil solución y que obligan a agotar los recursos en cuanto a táctica y técnica, para lograr el resultado buscado y evitar los accidentes, complicaciones y secuelas, que aún gravan pesadamente los resultados terapéuticos» ${ }^{1}$.

Siguiendo los preceptos de Larghero, la cirugía debe estar dirigida a los 3 componentes fundamentales del quiste: 1- El parásito; 2- La adventicia y 3- Las lesiones de los tejidos, órganos o serosas donde él se aloja. Para ello es necesario cumplir los siguientes objetivos: ${ }^{2}$

1. Extirpación total del parásito.

2. Evitar la contaminación con la consiguiente siembra de elementos fértiles y recidiva.

3. Meticulosa eliminación de todos los restos de membrana hidática

4. Impedir la persistencia de la cavidad residual: suprimiéndola, reduciéndola o resecándola.

5. Tratar la patología biliar asociada si existe, cerrando o facilitando el cierre de las comunicaciones bilioquísticas.

6. Tratar las complicaciones extrahepáticas.

7. Tratar otros quistes abdominales.

8. Reducir la hemorragia intraoperatoria.

9. Reintegro precoz a la sociedad.

10. Reducir el costo.

Dada la variabilidad de presentación, así como las características del paciente en particular, debemos considerar diferentes aspectos para encarar la terapéutica adecuada: edad y estado general del paciente, tamaño, localización, número y estado evolutivo del quiste, estado del parénquima circundante, estado inmunológico, experiencia del equipo quirúrgico y nivel de complejidad de la institución para el control y manejo peroperatorio ${ }^{2}$.

Múltiples procedimientos se han descrito en más de 100 años de cirugía de la hidatidosis, desde la simple punción y evacuación a las cirugías de resección hepática. Esto hace que sin lugar a dudas la cirugía de la hidatidosis hepática sea la que presenta los mayores desafíos tácticos y técnicos de las diferentes topografías del parásito a nivel abdominal. Debemos tener presente los diferentes procedimientos en uso para poder aplicarlos a cada caso en particular y en forma elástica según los hallazgos operatorios y el desarrollo de la cirugía. Por otra parte, como expresan la mayoría de los especialistas en el tema, el procedimiento ideal es la supresión total del parásito con la extirpación de la adventicia, hecho no siempre posible sin aumentar en forma importante los riesgos operatorios en esta enfermedad de presentación variable debido a las diversas complicaciones y su natural evolución 2. Entre una punción-evacuación y una resección hepática hay un conjunto de cirugías intermedias, con buenos resultados, baja morbimortalidad y postoperatorios breves.

\section{Principios básicos de la cirugía hidatídica.}

Son los mismos que se utilizan en la cirugía de resección hepática, sumados los cuidados propios de la cirugía de la enfermedad hidatídica. 


\subsection{Posición del paciente.}

En decúbito dorsal, con los miembros inferiores vendados con algodón laminado y venda elástica, para evitar pérdidas de temperatura y trombosis venosas de estos territorios. El tórax derecho se puede elevar unos $25^{\circ}$ a $30^{\circ}$. Con la ayuda de la bolsa neumática de un esfingomanómetro, colocada longitudinalmente, podemos elevar el reborde durante la cirugía que al desinsuflarlo facilita el cierre parietal $^{3,4}$.

\subsection{Incisión.}

Debe permitir una correcta exposición hepática y seguridad para el manejo del quiste y los pedículos vasculares, al mismo tiempo permitir la exploración y eventual acción sobre las vías biliares. Dependerá de la localización, número de quistes, tamaño, extensión a más de un lóbulo, estado evolutivo del quiste y sus complicaciones (supuración, apertura a vía biliar o tórax o a vísceras vecinas) y la presencia de lesiones asociadas ${ }^{2}$.

- Incisión subcostal: es una de las más utilizadas por la posibilidad de ampliarse a izquierda como una «boca de horno», o hacia el esternón, «incisión estrellada». Permite una adecuada exploración hepática y con la liberación de los ligamentos suspensorio y triangular la completa movilización hepática. La incisión en «boca de horno» completada con una mediana subxifoidea, tipo «Mercedes Benz», permite una adecuada exposición cuando es necesario disecar la vena cava y suprahepáticas ${ }^{3-5}$.

- Incisión transversa bilateral de Pean más prolongada en hipocondrio derecho. Tiene las mismas consideraciones que la anterior, pudiendo ampliarse por la línea media hacia el esternón.

- Transversa arciforme que parte por encima de la punta de la 11 a costilla, dirigida hacia la línea media con una suave curva a concavidad superior, utilizada por Cendán ${ }^{1}$. Ampliable a izquierda o hacia el $10^{\circ}$ espacio intercostal.

- Incisión mediana puede ser utilizada en quistes del lóbulo izquierdo 2 .

- Incisión torácica con frenotomía: para el tratamiento de los quistes posteriores o del domo en casos de estar transitados a tórax. Tienen el inconveniente de no permitirnos manejar la vía biliar, eventualidad necesaria cuando hay una apertura concomitante a vía biliar, posible en hasta un $30 \%$ de los casos. Tampoco nos permite el control del pedículo hepático ni la cava infrahepática, necesarios para un adecuado tratamiento de la adventicia. A esta incisión se la combina con un abordaje abdominal separado para el tratamiento del polo biliar ${ }^{2}$.

- Toracofrenolaparotomía: En casos de tránsitos a tórax está incisión nos permite una excelente exposición, pero dada su alta morbilidad no se utiliza frecuentemente y se prefieren las incisiones separadas.

- Las incisiones lumbares ante quistes hepáticos posteriores han quedado en desuso en la actualidad.

Debido a los avances de la cirugía hepática y el manejo anestésico perioperatorio podemos realizar una incisión abdominal amplia, con mejor exposición y adecuados clampeos vasculares que permiten cirugías radicales en un ambiente seguro para el paciente ${ }^{3,4}$.

\subsection{Exposición.}

En nuestro medio utilizamos la valva diseñada por Rafael García Capurro, que permite levantar el reborde condrocostal ${ }^{3}$ y exponer ampliamente el piso supramesocólico del abdomen (Foto 1).

Exploración y exposición de la emergente del quiste, descartando otra topografía. En quistes anteriores, del borde hepático, que no presenten relaciones vasculares de jerarquía por su topografía, la exposición de los pedículos vasculares hepáticos dependerá de la táctica a realizar (Foto 2). 
Foto 1.

Exposición del campo operatorio utilizando valva de García Capurro.

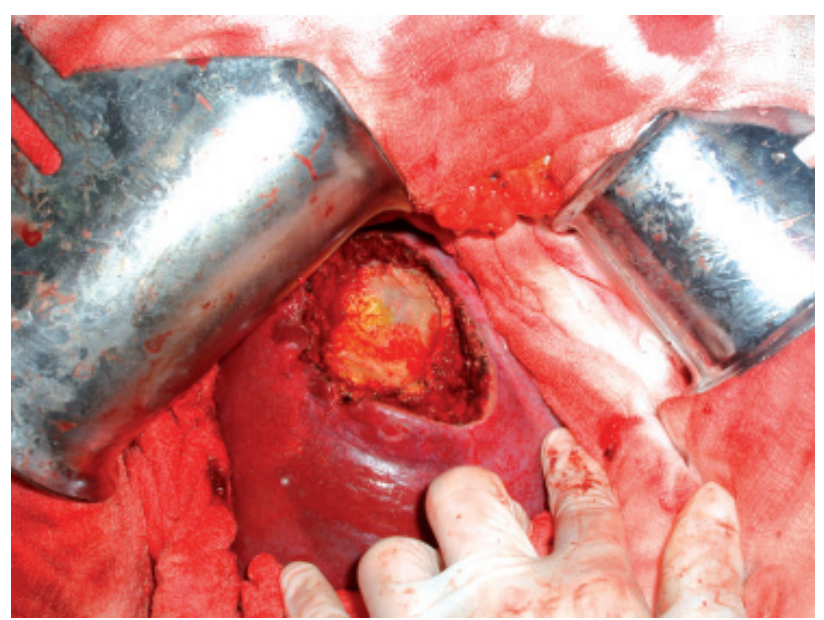

Foto 2.

Exposición de la adventicia emergente (AE).

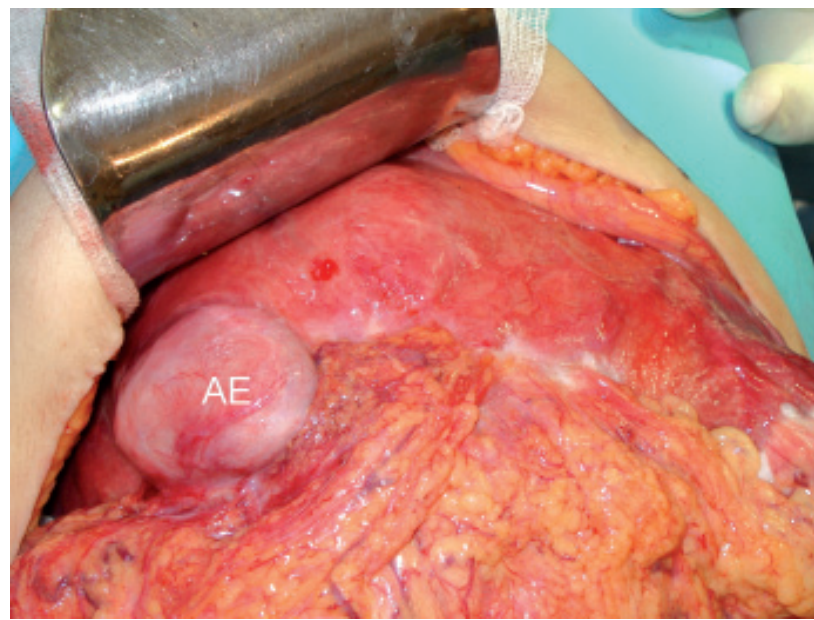

El siguiente tiempo consiste en la movilización hepática para exponer adecuadamente la zona emergente del quiste y controlar los pedículos vasculares. Esto se logra mediante la sección de los ligamentos redondo, suspensorio, triangular izquierdo, triangular derecho y coronario, maniobras tendientes a exponer la vena cava suprahepática. Movilización del duodeno para exponer la vena cava infrahepática. Sección del epiplón menor y pasaje a través del hiato de Winslow de una cinta hilera o sonda Nelaton para controlar el pedículo hepático mediante la realización de la maniobra de Pringle.

La exposición vascular que permita el control selectivo y la exteriorización de la masa hepática tiene riesgos de lesiones graves de por sí, son procedimientos de enorme magnitud, por lo que deben ser realizados en centros de experiencia por cirujanos entrenados y estrictamente protocolizados ${ }^{5}$. Para esto, a las maniobras anteriormente descritas para la movilización hepática se suma la ligadura de la vena diafragmática inferior izquierda y la derecha, sección del peritoneo precava derecho y el tracto fibroso que une el lóbulo derecho al Spiegel por detrás de la cava que nos permite exponerla en toda su porción retrohepática. Se ligan incluso la vena suprarrenal derecha y eventualmente alguna vena retrohepática accesoria para evitar su lesión. Quedan expuestas y controladas la vena cava inferior con posibilidades de control infra y suprahepático y las venas suprahepática derecha e izquierda. A nivel del pedículo hepático se puede realizar el control independiente del lóbulo izquierdo y derecho ${ }^{3}$, también maniobras quirúrgicas de gran envergadura y con altísimo riesgo si hay algún tipo de lesión. 
La utilización de ecografía intraoperatoria ${ }^{3}$ es hoy día una herramienta muy importante, ya que al ubicar los pedículos vasculares nos da más seguridad de evitar su lesión con el consiguiente sangrado, sobre todo cuando se emprende una cirugía radical. Permite tomar decisiones tácticas según los hallazgos en el intra-operatorio. Torterolo ${ }^{6}$ en una comunicación preliminar sobre la ecografía intraoperatoria encontró que el mayor valor de su experiencia está dado por los hallazgos en cirugía hepática de la hidatidosis. Encontró variaciones importantes del calibre vascular y las relaciones.

\subsection{Cuidados operatorios especiales.}

Siempre hay que cumplir con los pasos fundamentales dirigidos a evitar la contaminación por el líquido hidático a pesar de lo fácil que pueda resultar la cirugía y la experiencia del cirujano ${ }^{5}$. Se debe tener meticulosa precaución para evitar la contaminación por el líquido del parásito, pero también hay que considerar aspectos técnicos en relación al parasiticida, ya que todos los utilizados presentan efecto deletéreo.

\section{Soluciones parasiticidas.}

3.1 Suero clorurado hipertónico:(SCH) Distintos parasiticidas se han utilizado a lo largo del tiempo, pero las ventajas que ha mostrado el cloruro de sodio hipertónico al $33 \%$ y la prueba del tiempo hacen que este sea el de elección. Basado en los experimentos de Pérez Fontana, quién lo presentó en 1952 y lo publicó en 1953, el SCH es posteriormente utilizado por muchos colegas en diferentes partes del mundo ${ }^{7}$. En sus trabajos experimentales sobre la acción del SCH encontró que los escólices estallan y se desintegran con su uso, siendo más ventajoso que el formol por ser menos irritante. Puede quedar dentro de las cavidades para que continúe su acción, penetra en las áreas anfractuosas creando verdaderas corrientes de drenaje osmótico. Hay que evitar el contacto con el peritoneo por la hipernatremia que produce al absorberse por esta vía. Es el parasiticida de primera elección por la mayoría de los cirujanos ${ }^{5,8}$. Fue utilizado en casi el $50 \%$ de los 6834 casos tratados en la serie de Hidalgo ${ }^{9}$. Si bien Belghiti ${ }^{10}$ ha comunicado casos de colangitis esclerosante cáustica al entrar en la vía biliar, esto no se ha reportado en otras series con fístulas biliares ${ }^{11,12}$.

En caso de derrame de suero hipertónico en el peritoneo se debe forzar la diuresis en forma inmediata con suero glucosado al $5 \%$ y diuréticos. Con ello se elimina el cloruro de sodio absorbido en exceso y evita la obstrucción de los túbulos renales por una hemoglobinuria ${ }^{13}$. El empleo de una cuidadosa técnica quirúrgica pone a cubierto de esta peligrosa complicación ${ }^{7,8}$.

3.2 Formol: Durante años se usó la solución de formol al 2\%. Si bien mata instantáneamente al parásito, es tóxico, penetra menos en los tejidos, coagula, fija exudados y restos parasitarios ${ }^{13}$. Actualmente en desuso por las estenosis y fibrosis papilar que produce en casos de comunicaciones con la vía biliar. Muertes fueron descriptas por su utilización ${ }^{14}$.

3.3 Alcohol al 95\%: es el utilizado en los procedimientos de PAIR cuando no hay comunicación con la vía biliar. En estos casos optan por el $\mathrm{SCH}^{5}$.

Otros parasiticidas utilizados han sido el Cetrimide al $1 \%$, nitrato de plata al $0,5 \%$ y agua oxigenada, con los cuales existe poca experiencia en nuestro medio. Fernández ${ }^{15}$ utilizó agua oxigenada 10 volúmenes en animales de experimentación, siendo sus resultados superiores al del SCH y formol al $2 \%$ y $10 \%$. Desaconsejan el formol por su elevada mortalidad y lesiones que produce. No encuentran explicación a la mortalidad producida por el $\mathrm{SCH}^{15}$.

\section{Tratamiento del parásito.}

1. Una vez expuesta la cara emergente del parasito se procede a realizar un meticuloso aislamiento del sitio quirúrgico. La pared se protege cubriendo con campos doble. A nivel del peritoneo se coloca una primera capa de compresas secas, bloqueando todos los recesos peritoneales y serosas viscerales, con excepción de la zona a puncionar.

2. Se protege la zona a puncionar con compresas embebidas en cloruro de sodio al $33 \%$, debidamente escurridas, ante una eventual filtración al realizar la maniobra ${ }^{7,8}$. Las compresas con 
suero hipertónico no deben colocarse en contacto directo con el peritoneo ni la superficie hepática ${ }^{8}$ (Foto 3).

Foto 3.

Protección de la zona de punción con compresas embebidas en suero hipertónico.

(Cortesia Dr. F. González)

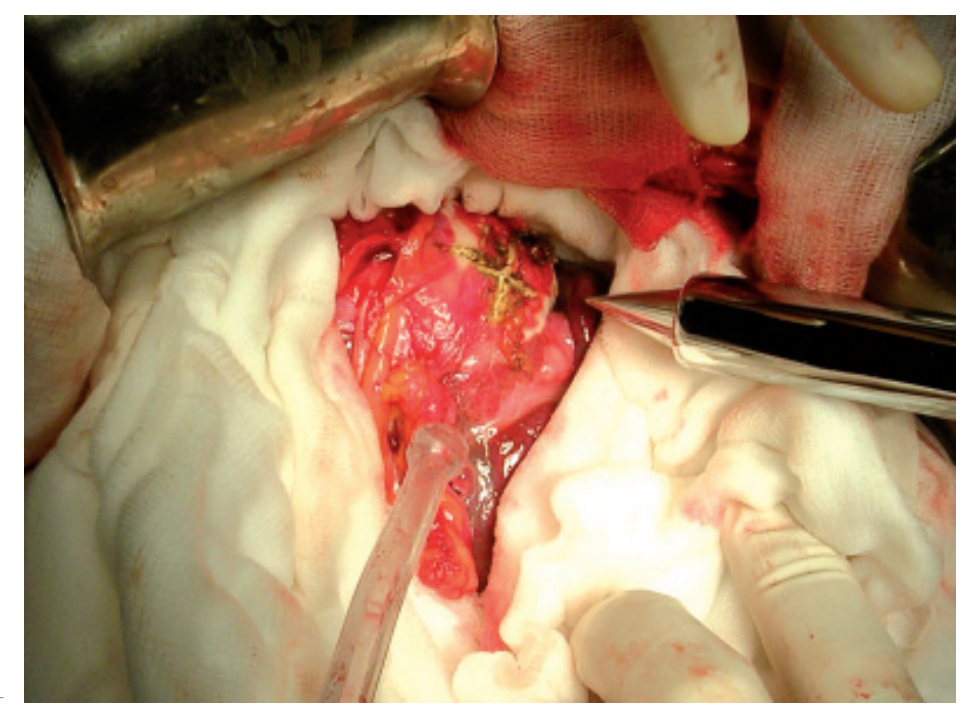

3. La punción se debe realizar en la adventicia emergente que es avascular.

4. La punción se realiza con un sistema en «T» con un tubo de Kehr, el cual permite la evacuación en forma lenta y a la vez inyectar la solución escolicida para ir sustituyendo en forma segura, controlada y paulatina el contenido hidático por el suero clorurado hipertónico, no siendo necesaria la sustitución completa para lograr la esterilización ${ }^{8}$ (Foto 4). Una rápida descompresión de un quiste hialino realizada con el aspirador de Finocchietto puede producir lesiones de las trabéculas hepáticas con un consiguiente exudado intracavitario en el postoperatorio. Este procedimiento con aguja gruesa no es posible con los quistes multivesiculares dado que se obstruye rápidamente la aguja.

Foto 4.

Punción del quiste con sistema en T, utilizando un tubo de Kehr. (Cortesia Dr. F. González)

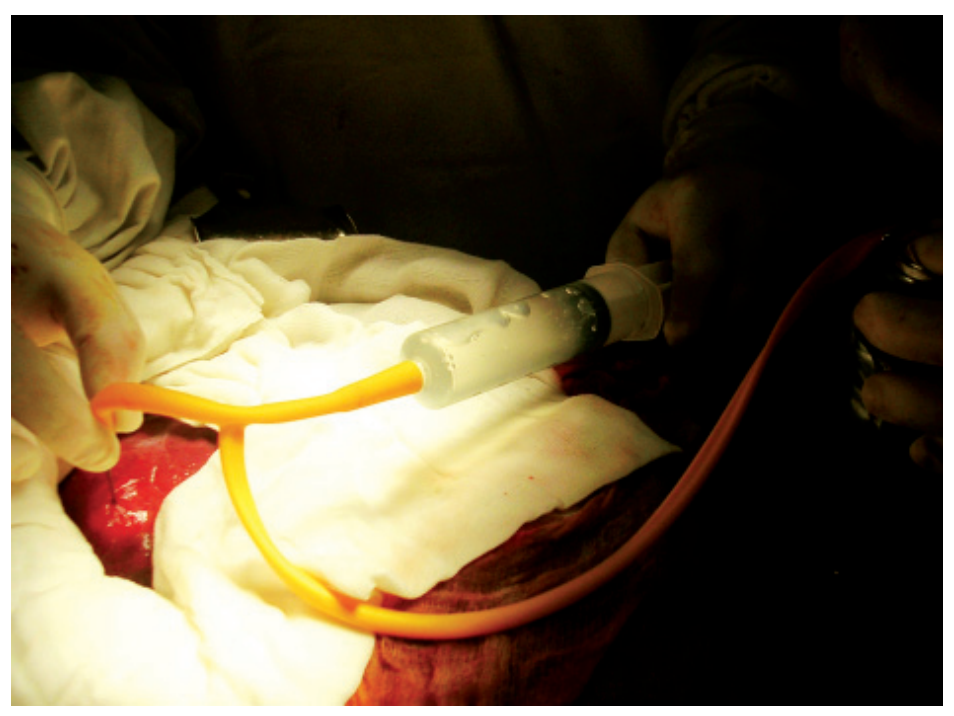


5. El líquido parasiticida se deja actuar 10 a 15 minutos ${ }^{1,2}$.

6. Durante todo este procedimiento un ayudante está con un aspirador en forma permanente sobre la zona de punción, para evitar un derrame inadvertido. Se debe disponer siempre de un aspirador potente ${ }^{13}$ y otro alternativo por si falla uno en el momento crítico. En nuestro medio se utiliza el aspirador de Finochietto, el cuál es muy potente, conectado con una gruesa manguera al trocar de punción.

7. Una vez evacuado el líquido parasiticida se procede a la extracción de la membrana. Se realiza una amplia incisión en la adventicia emergente, traccionando esta en forma vertical con 2 pinzas de Allis o similares. Esto evita el derramamiento del contenido y permite exponer la cavidad (Foto 5). Se localiza la membrana y extrae con una pinza de Foerster o con una cuchara ${ }^{1,2}$. Se extrae la membrana hacia un recipiente adecuado, el cual debe estar próximo.

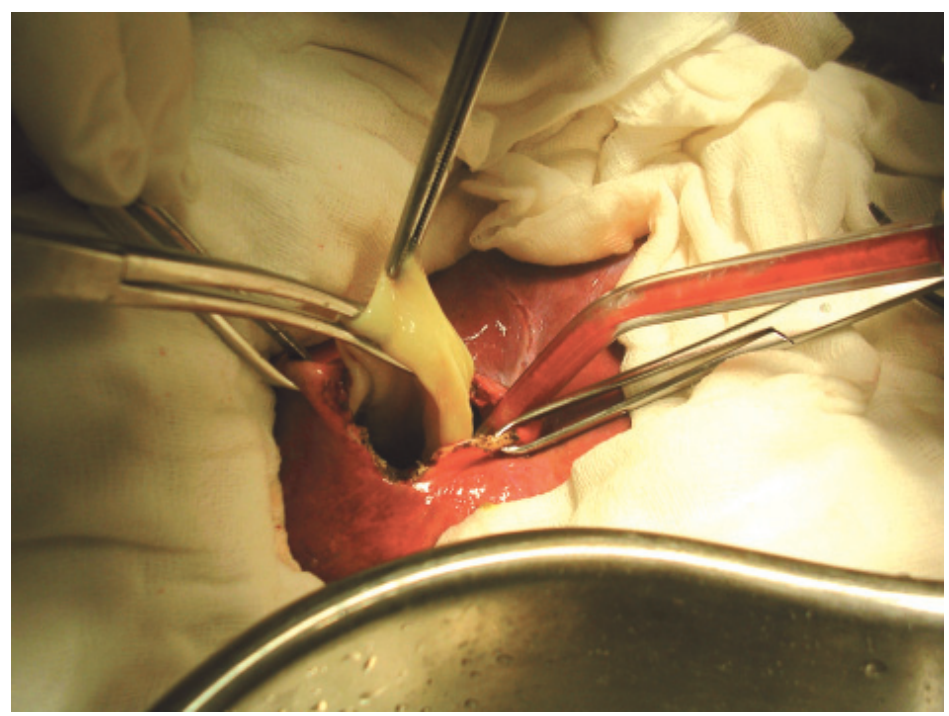

Foto 5.

Extracción de la membrana

hidática.

(Cortesia Dr. F. González)

8. Retirada la membrana se realiza la limpieza dentro del quiste, mediante un hisopado de la cavidad con solución parasiticida, barriendo restos parasitarios ${ }^{2}$. Se puede realizar con gasas embebidas en solución parasiticida que luego se dejan en la cavidad del quiste durante 15 minutos con solución de $\mathrm{NaCl}$ al $33 \%$.

9. Posteriormente se realiza una nueva inspección ocular de la cavidad, para lo cual se puede colocar un espéculo vaginal (maniobra de Arce) o pequeñas valvas. Beguiristain ${ }^{16}$ comunicó su experiencia con una técnica original, la exploración endoscópica (quistoscopía). La utilizó tanto en el intraoperatorio como en el postoperatorio, a través del trayecto del drenaje de una quistostomía. Si hay restos se procede al hisopado de la cavidad con una gasa montada hasta que quede completamente limpia.

10. Completado lo anterior se procede al cambio de guantes de todo el equipo y se desecha el instrumental usado en las maniobras precedentes. Se retiran todas las compresas y campos. Se procede a una reexploración para descartar otros quistes o lesiones asociadas.

El «parto» de la hidátide, procedimiento utilizado habitualmente en el tratamiento de la equinococosis pulmonar, no se recomienda a nivel hepático ya que se considerada peligroso por el riesgo de rotura ${ }^{2}$. 
En los quistes multivesiculares y con degeneración gelatinosa la técnica operatoria se modifica de acuerdo a las características físicas del contenido (Figuras 1,2,3).

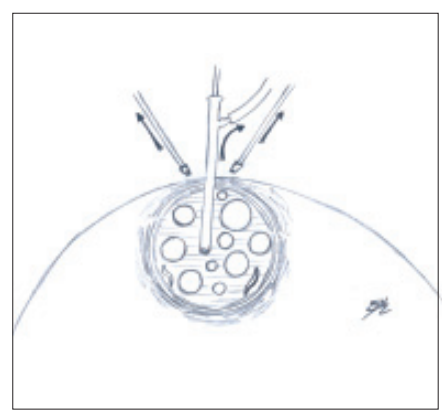

Figura 1.

Punción de quiste multivesicular con trocar de Ochsner conectado a aspirador de Finochietto. (Adaptado de Larghero).

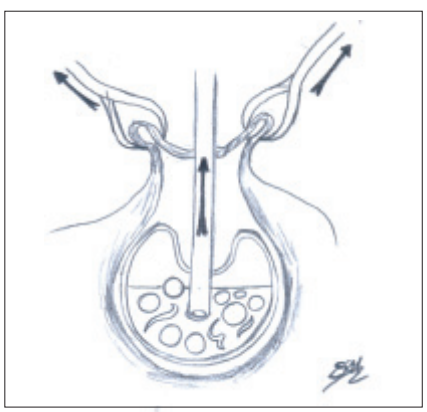

Figura 2.

Con quiste que pierde tensión se deben tomar los bordes con pinzas de Allis. (Adaptado de Larghero).

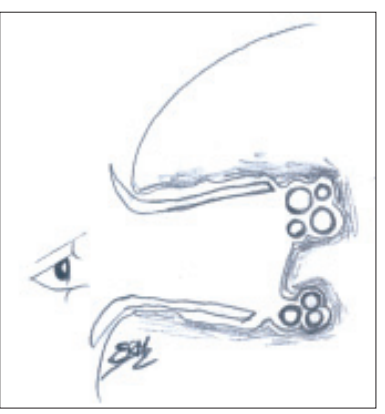

Figura 3.

Maniobra de Arce con valvas o espéculo para la exploración de la cavidad hidática. (Adaptado de Larghero).

1.La punción se realiza con el trocar de Ochsner conectado al aspirador de Finochietto (Foto 6).

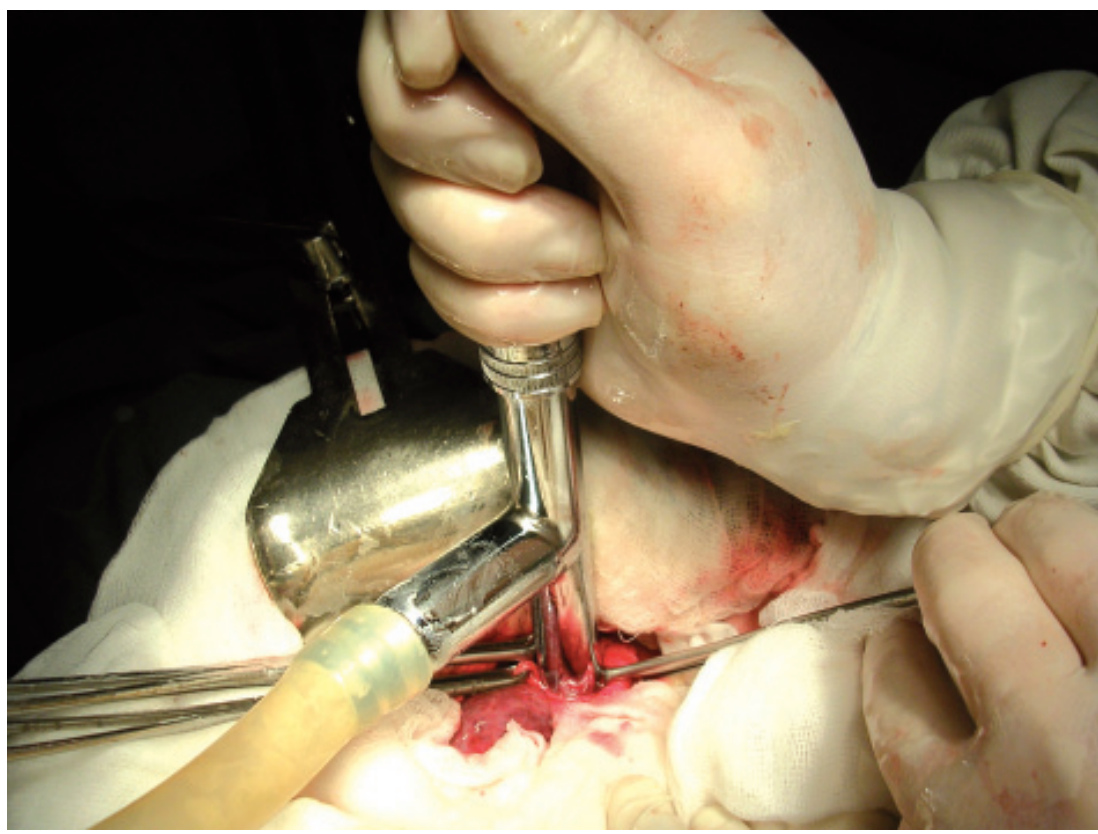

Foto 6. Punción con trocar de Ochsner. (Cortesia Dr. F. González)

2. Cuando la adventicia pierde tensión se la toma con 2 pinzas Allis y se tracciona en forma vertical para evitar el derrame de contenido, sobre todo al retirar el aspirador.

3. Se realiza la esterilización de la cavidad con solución escolicida y posteriormente la inspección de la cavidad (Foto 7). 


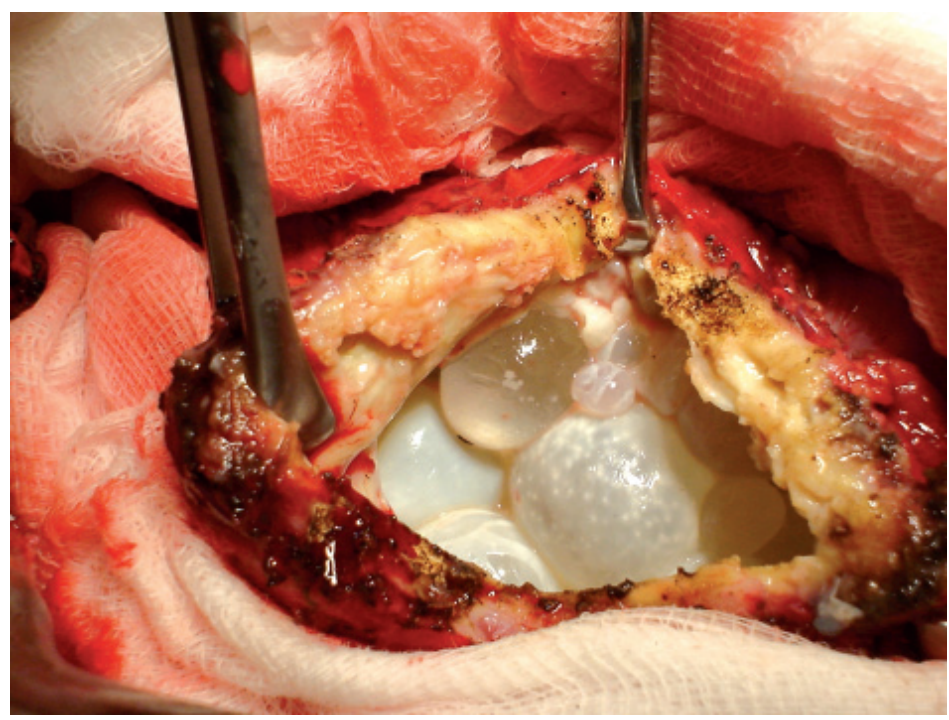

Foto 7.

Inspección de la cavidad donde se ven múltiples vesículas hijas.

4. En casos que no se pueda evacuar el contenido con el aspirador se debe extraer el contenido con una cuchara o cucharón y posteriormente se inyecta el escolicida o se colocan compresas embebidas en suero clorurado hipertónico.

5. En los quistes infectados el procedimiento de esterilización es el mismo, ya que no se descarta la presencia de vesículas hijas fértiles.

\subsection{Conducta con la adventicia.}

En caso de parásito hialino la adventicia es delgada y los canalículos y vasos tienen mínimas lesiones que son reversibles. Estos son los quistes qué se ven frecuentemente en niños. Torterolo ${ }^{17}$ en una serie de 71 pacientes adultos encuentra que su frecuencia es menos del $4 \%$, similar a lo comunicado por Coiro en Paysandú ${ }^{18}$. Lo único necesario para tratar este tipo de quiste es la evacuación aséptica de la hidátide y colocar el escolicida en la cavidad.

La gran mayoría de los pacientes adultos presentan un parásito envejecido y que ha sufrido. Esto lleva a que la adventicia también acompañe a estos cambios evolutivos, conduciendo a un espesamiento, fibrosis, calcificación, apertura de canales biliares por horadación, necrosis y exfoliación con desprendimiento espontáneo. Constituye una enfermedad en sí misma, la «enfermedad adventicia» como la denomina Larghero. Esta avanza progresivamente y explica las complicaciones de los quistes hacia la periferia, como rupturas o migraciones. Requiere un tratamiento especial, destacando que se puede encontrar en diferentes etapas evolutivas al igual que el parásito. Por lo que tratada la hidátide y puesto a cubierto el enfermo de la infestación parasitaria es necesario resolver la cavidad adventicial. Con ello se evitan complicaciones y secuelas como: bilirragia, hemorragia, supuración, secuestro, fistulización y cavidad residual ${ }^{19}$. Estas ocurren fundamentalmente en quistes con paredes fibrosas y calcificadas que mantienen la cavidad ${ }^{1}$.

Como ya expresáramos, el procedimiento ideal incluye la extirpación de la adventicia. Con ello se incrementan los riesgos operatorios, particularmente la hemorragia. Por tal motivo existen un conjunto de cirugías intermedias. La elección del procedimiento debe adaptarse al paciente, al momento y condiciones, con el objetivo de optimizar los resultados, especialmente los relacionados con la morbimortalidad. 
TRATAMIENTO QUIRÚRGICO DEL QUISTE HIDÁTICO HEPÁTICO

Las cirugías se clasifican en dos grandes grupos: conservadoras y radicales o reseccionistas.

\subsubsection{Cirugías conservadoras.}

4.1.1.1. Cierre primario o procedimiento de Posadas, (Thorton 1883, Posadas 1895). Se realiza la aspiración de la hidátide, desinfección y posteriormente el cierre hermético de la adventicia y abandono, dejando una cavidad residual (Figura 4A). Está indicada en quistes hialinos con adventicia fina y plegable. Esta situación se ve en niños, por lo cual es el procedimiento de elección ${ }^{13,20,21}$. Está contraindicada si hay bilirragia o si la adventicia es gruesa o está calcificada ${ }^{17}$. La fijación a la pared no se realiza por dolor, colapso incompleto y cicatrización demorada ${ }^{1}$.

4.1.1.2 Quistostomía. Se realiza en forma indirecta mediante la colocación en la cavidad adventicial de tubos de drenaje ${ }^{22}$ (Figura $4 B_{1}$ ). Está indicado en todos los casos en que se prevea un proceso de obliteración de la cavidad dificultoso por: supuración, hemorragia importante por rotura de vasos adventiciales o bilirragia; permite de esta manera manejar la secreción intracavitaria. También se puede indicar de necesidad si no se puede resecar la adventicia, en caso de adventicias fibrosas y calcáreas que no se colapsan y mantiene por largo tiempo un contenido hidroaéreo que expone a complicaciones. Para Torres ${ }^{5}$ este permite solucionar problemas difíciles y graves de la equinococosis hepática, es rápida, poco agresiva, pero en ocasiones difícil de manejar e indicar. En la serie de Florida, sobre 131 pacientes, la quistostomía fue el procedimiento más utilizado, realizándose a 115 pacientes $(76 \%)^{23}$. Encontraron una morbilidad menor a los procedimientos radicales (34\% vs. $62 \%$ ), menor estadía postoperatoria (7,9 días vs. 13,2 días), con un alta definitiva similar. No hicieron una evaluación a largo plazo, tuvieron una mortalidad del $1 \%$ y solo realizaron 10 procedimientos radicales, $5,26 \%$ del total. En tanto Coiro ${ }^{18}$ en Paysandú con una serie de 53 pacientes realizó la quistostomía en el $57 \%$ de los casos, encontrando mayor morbilidad, reingresos y tiempo de estadía hospitalaria que en los casos de cirugía radical.

La quistostomía directa o marsupialización no se realiza actualmente por su alta morbilidad y mortalidad (Figura $4 B_{2}$ ).

El drenaje interno mediante una quistoyeyunoanastomosis sobre asa en Y de Roux, fue aconsejada para quistes centrales, con comunicación biliar y que podían tener secuestros de adventicia 2,24-26. Autores nacionales con larga trayectoria en el tratamiento de esta enfermedad no incluyen dentro de sus casuísticas este procedimiento ${ }^{13}$. En la serie de Hidalgo ${ }^{9}$, sobre 6834 pacientes, se realizó en $3 \%$ de los casos.

4.1.1.3 Procedimiento de Mabit. Consiste en la resección de la adventicia emergente y abandono del saco adventicial abierto en peritoneo (Figura 4C). Cuando no se reseca la adventicia se denomina procedimiento de Roussel, actualmente en desuso.

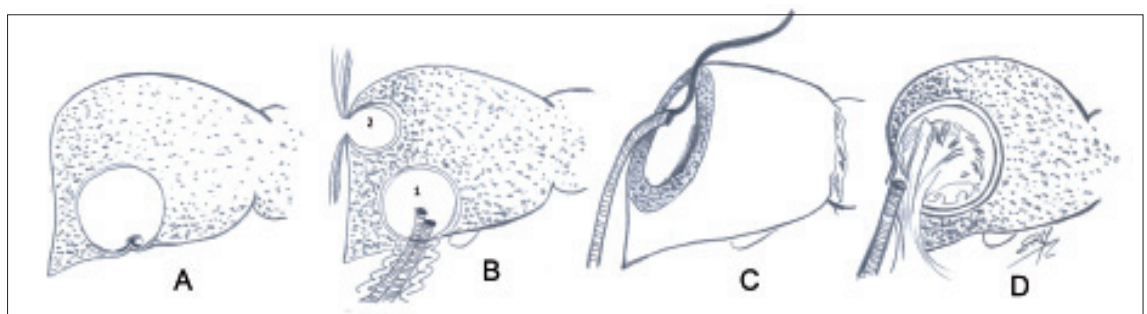

Figura 4. Técnicas conservadoras de la adventicia. A) cierre y abandono (Posadas). B ${ }_{1}$ ) Quistostomía sobre tubo. B Marsupilización. C) Quistectomía de la adventicia emergente (Mabit). D) Epiploplastia. (Adaptado de Praderi).

Sobre el borde de resección se realiza un surget en corona para evitar sangrado y bilirragia. La exposición de la cavidad al peritoneo disminuye la formación de colecciones intracavitarias (Foto 8). El procedimiento se puede completar con la epiploplastia intracavitaria ${ }^{5}$. 

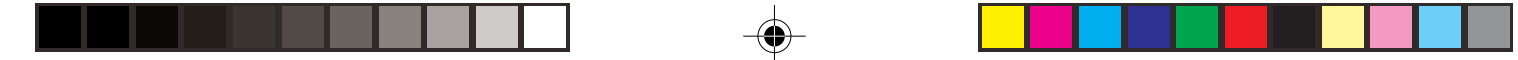

TRATAMIENTO QUIRÚRGICO DEL QUISTE HIDÁTICO HEPÁTICO

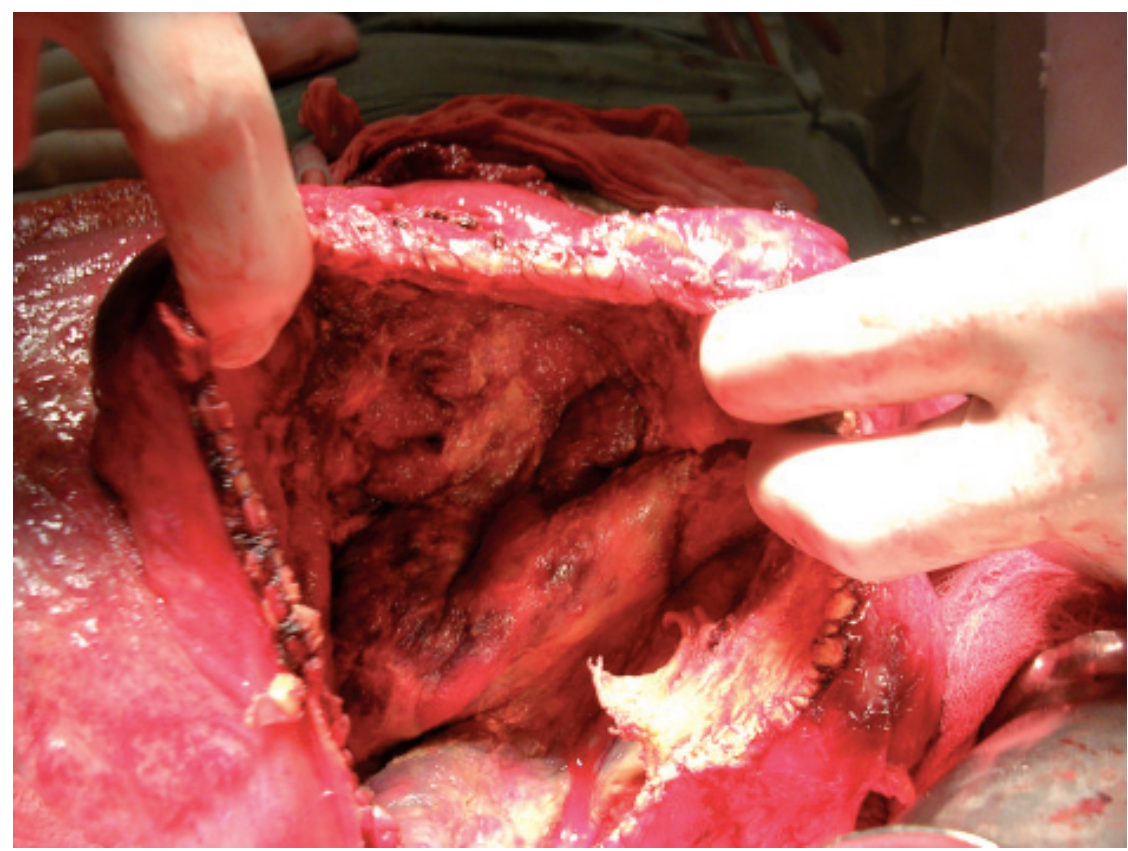

Foto 8.

Quiste central gigante con adventicia peligrosa, se optó por técnica de Mabit. (Cortesia Dr. F. González)

Su mortalidad es menor en relación a las técnicas radicales, ya que el ambiente vascular que rodea la adventicia incrementa los riesgos de sangrado y bilirragia. Como contrapartida se deja una cavidad residual, especialmente cuando las paredes son rígidas y calcificadas. En esta situación no se recomienda conservar la adventicia.

Perdomo ${ }^{27}$ estableció los aspectos técnicos necesarios para lograr buenos resultados mediante una cirugía conservadora. Ellos son: 1) dejar una cavidad adventicial ampliamente abierta; 2) realizar la desconexión quisto-biliar para evitar la retención y combatir la infección; 3) evitar dejar tubos de drenaje intracavitarios - solamente indicados en quistes supurados; y 4) antibioticoterapia.

En la serie de Hidalgo ${ }^{9}$, la cirugía conservadora representó el 65,6\% del total. De ellas 64\% correspondieron al procedimiento de Mabit En la serie de Moumen ${ }^{28}$ sobre quistes del domo hepático, representó el $87 \%$ de los procedimientos. Larghero la recomienda en quistes univesiculares hialinos o con vesículas hijas, con adventicias de poca estructura y situados en el borde hepático.

Se ha extendido la denominación de la técnica descrita por Mabit a los casos que se reseca parte de la adventicia intraglandular, llamándole procedimiento de Mabit ampliado ${ }^{2}$. Nos referiremos a ella en los procedimientos reseccionistas.

4.1.1.4 La epiploplastia intracavitaria. Es la colocación de epiplón pediculizado, o con la simple rotación dentro de la cavidad (Figura 4D). Fue preconizada en nuestro medio por Del Campo ${ }^{2,29}$. Praderi la utiliza en los casos que la cavidad del quiste bilobula el hígado (Foto 9). Sobre la epiploplastia se plantea que 1) evita el vacio de la cavidad residual, 2) anula por acción mecánica la trasudación capilar y absorbe los líquidos generados y 3 ) ocluye pequeñas fugas biliares ${ }^{19}$. Dziri ${ }^{30}$ en un estudio prospectivo multicéntrico y aleatorizado comunicó resultados estadísticamente significativos a favor de la omentoplastia para prevenir abscesos intracavitarios. 


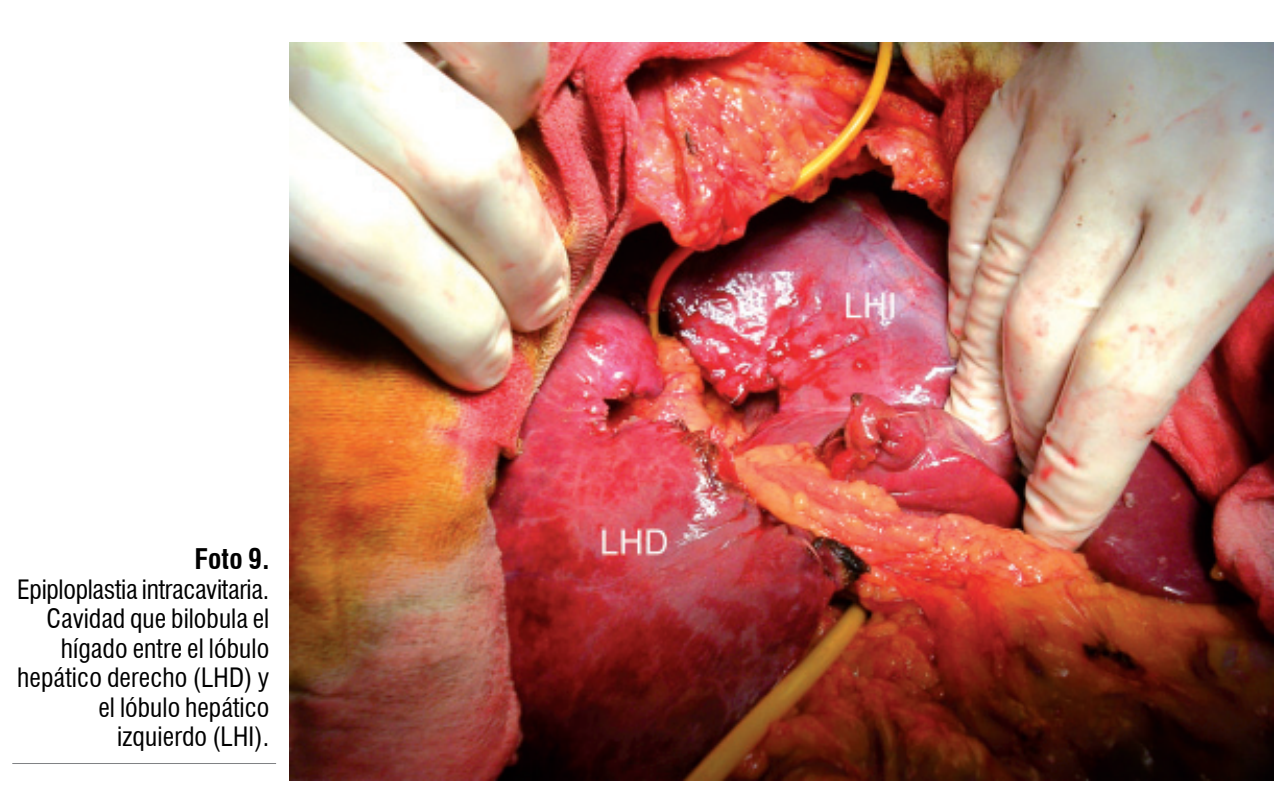

\subsubsection{Cirugías radicales o reseccionistas.}

La resección de la adventicia, o adventicectomía tiene como finalidad evitar la cavidad residual así como la enfermedad adventicial en el postoperatorio. De esta manera se logra reducir la morbilidad y acortar el postoperatorio ${ }^{13,19,31-37}$.

Es crucial evitar lesiones del pedículo glissoniano (rama portal o biliar) así como lesiones suprahepático cava. Emprender esta cirugía requiere un control vascular, sobre todo en casos de quistes con relaciones vasculares peligrosas. Según Porras ${ }^{13}$ para la realización de esta cirugía existen 3 planos por donde se puede avanzar:

- intra-adventicial, separa las capas más internas fibrosadas y calcificadas del tejido conjuntivo adventicial más periférico. Es el plano donde se puede realizar la exocleación de Magnusson (Figura 5). No siempre está bien delimitado este plano. Cendán ${ }^{1}$ asevera que cuanto más fibrosa y calcificada la adventicia más interesa eliminarla y más fácil resulta su extirpación.

Figura 5.

Curetaje de zonas calcificadas de la adventicia

(Magnusson). (Adaptado de Larghero).

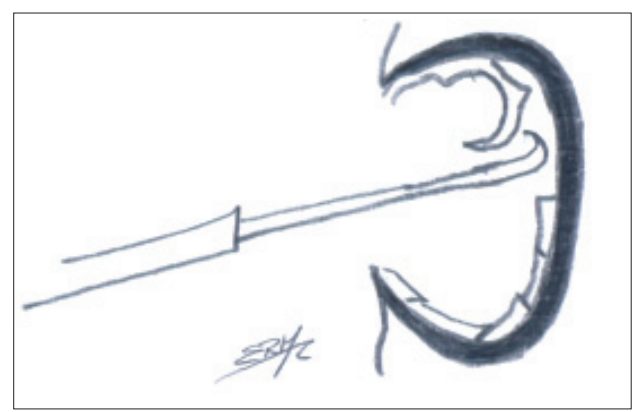

- Hepato-adventicial, es el más utilizado y generalmente está bien delimitado. No es avascular. Se realiza una disección roma y se van ligando los vasos que la atraviesan,y haciendo el cierre o ligadura de los pequeños canalículos biliares. Es el utilizado por Praderi. 
- Intra hepática, preferido por Porras ${ }^{13}$. Se avanza por el parénquima vecino al quiste hidático mediante digitoclasia o Kellyclasia, individualizando y ligando los pedículos por separado. Esta ligadura es más segura por realizarse en una zona donde la anatomía está conservada. Lesurtel ${ }^{38}$ en un estudio prospectivo randomizado sobre 100 casos en que comparó distintos tipos de técnicas de transección hepática (Kellyclasia o digitoclasia, bisturí armónico, sellador de vasos, bisturí eléctrico monopolar irrigado con agua, encontró que la técnica de Kellyclasia o digitoclasia están asociadas a la transección más rápida, con menor sangrado y son las que tienen mejor relación costo-efectividad, pero debieron realizar un clampeo vascular más prolongados por el mayor sangrado, en tanto que con las otras técnicas su empleo fue mínimo.

Para minimizar la hemorragia durante su realización es posible recurrir a diversas maniobras:

- Disección roma, manteniéndose contra la adventicia y evitando desgarrar el parénquima utilizando el dedo o la tijera roma por divulsión. Principalmente en adventicias gruesas y fibrosas o calcificadas.

- Se ligan los vasos y conductos que se van individualizando ${ }^{19}$.

- Los sangrados que se producen en general son venosos, por lo que el control de pedículos vasculares es fundamental para la realización de hemostasis. En casos de gruesos troncos venosos se utiliza sutura de 5-0 a 7-0, ayudados con magnificación. Se prefiere la realización de clampeos intermitentes al clampeo continuo para disminuir el daño hepático por isquemia ${ }^{19}$.

- La extirpación de la adventicia exige un equipo entrenado en este tipo de cirugías para disminuir la morbi-mortalidad ${ }^{3,39}$. Así concluyen dos trabajos realizados en el interior de nuestro país, donde se destaca la necesidad de capacitar cirujanos en cirugía hepática o crear centros regionales en el interior del país que permitan llevar adelante este tipo de procedimiento ${ }^{18,23}$. Ramia ${ }^{40}$ considera lógico el traslado de los pacientes a unidades de referencia para el tratamiento con técnicas radicales.

4.1.2.1 Adventicectomía parcial, subtotal o Mabit ampliado. Se reseca menos del $80 \%$ de la adventicia del parásito. Según Porras ${ }^{13}$ se deben considerar 3 sectores quirúrgicos de la adventicia: 1) la extravisceral o emergente, 2) la intravisceral sin riesgos y 3) la intravisceral peligrosa que es la profunda, donde se relaciona con los elementos vasculo-biliares (Figura 6). La adventicectomía parcial incluye la adventicia extravisceral y parcialmente la intravisceral, dejando la intravisceral peligrosa. Esta no causa mayor problema en el postoperatorio. Es una de las cirugías más realizadas, asociadas a epiploplastia y drenajes enfrentados a la cavidad ${ }^{2,41,42}$. Es una puesta a plano del quiste, y es indicado principalmente en los quistes emergentes. El abandono de adventicia en el sector profundo hepático, donde adquiere relaciones peligrosas, no ofrece mayores problemas y pone a cubierto de los riesgos de extirpación en zonas peligrosas (Figura 7A').

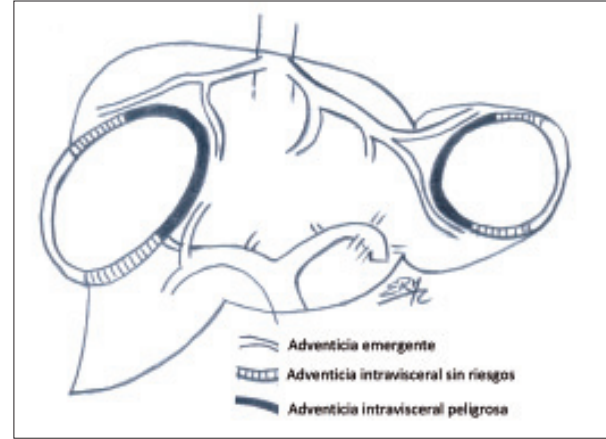

Figura 6

Zonas quirúrgicas de la adventicia. Las relaciones anatómicas de la adventicia intravisceral presenta zonas en íntimas relaciones vásculo biliares (peligrosas) que deben ser preservadas. (Adaptado de Larghero).

4.1.2.2 Quistectomía abierta total o procedimiento de Vigneron-Pozzi. Una vez evacuado el quiste y ampliada la brecha adventicial, se introduce la mano y se realiza una suave tensión, que permite establecer con más claridad la relación parénquima-adventicia. Llegado al punto de relaciones 
vasculares importantes y, eventualmente, guiado por ecografía intraoperatoria se puede dejar un medallón de adventicia (adventicia peligrosa) (Foto 10). Para considerarla radical se debe extirpar más del $80 \%$ (Figura $7 A^{\prime \prime}$ ). Su realización evita la enfermedad de la adventicia ${ }^{5}$. Posteriormente a la adventicectomía se debe revisar cuidadosamente la hemostasis y la bilistasis. En ocasiones se puede realizar una epiploplastia. Se deja un drenaje enfrentado por la posibilidad de bilirragia o para evitar la formación de una colección hemática.

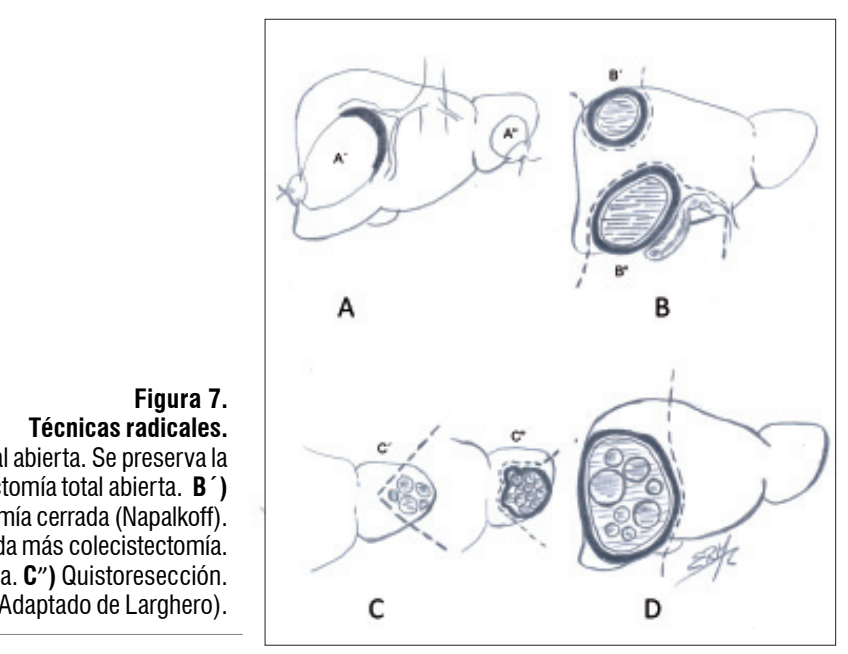

A') Quistectomía subtotal abierta. Se preserva la adventicia peligrosa. A") Quistectomía total abierta. B

Quistectomía cerrada (Napalkoff)

B") Quistectomía cerrada más colecistectomía.

C') Hepatectomía atípica. C") Quistoresección. D) Hepatectomía. (Adaptado de Larghero)

Foto 10.

Quistectomía abierta con

medallón de adventicia (Ad)

sobre pedículo hepático y

vena cava inferior. Se

observa el pedículo hepático

$(\mathrm{PH})$, vena cava inferior

(VCl), lóbulo hepático

izquierdo (LHI) y lóbulo

hepático derecho (LHD).

Diafragma (D).

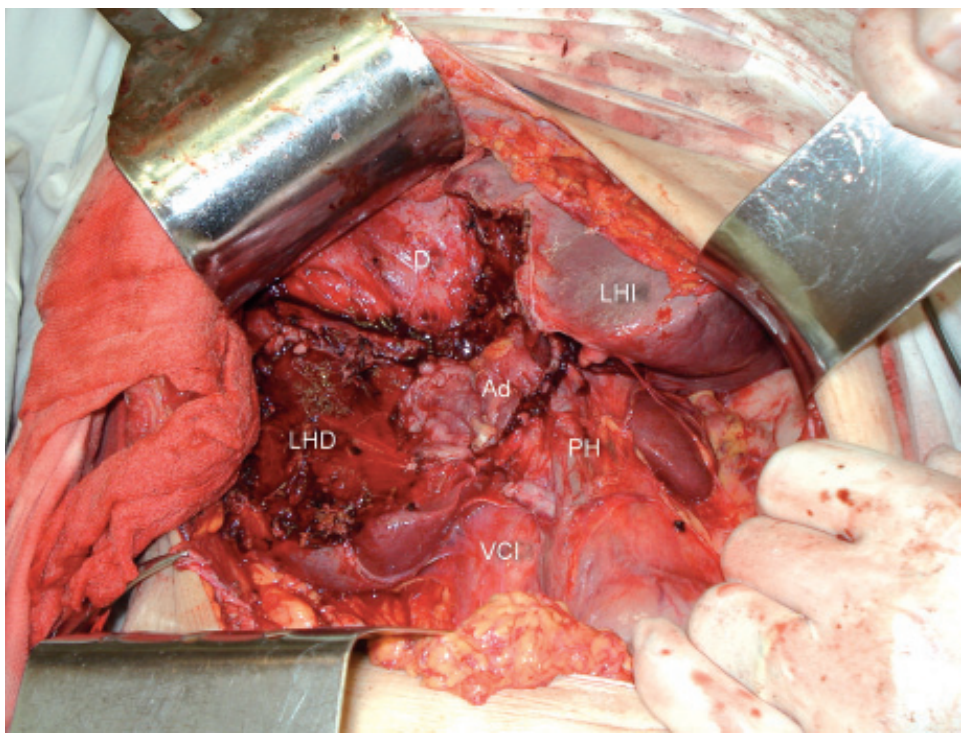

Torterolo ${ }^{17}$ insiste en que la morbimortalidad debe ser evaluada en un plazo de 10 años dado que es dentro de este lapso que se ven las complicaciones de la enfermedad adventicial, presentando una serie de 37 pacientes sin mortalidad y con una internación más corta y menos mórbida. Similares resultados en cuanto a morbilidad encuentra años después con una serie de 121 pacientes y una mortalidad de $2,4 \%{ }^{19}$. Delgado comunica una morbilidad de $46 \%$, sin tener que realizar reintervenciones, y una mortalidad de $5,1 \%$ en una serie de 39 pacientes ${ }^{39}$. 
El uso de ecografía intraoperatoria es considerado muy importante en esta técnica ya que aporta precisión topográfica continua para permitir y facilitar la resección. Presenta una mejor definición y la relación precisa con los pedículos hepáticos ${ }^{3,5}$. Permite detener la resección en caso de relación intima con un grueso elemento vascular.

4.1.2.3 Quistectomía cerrada, en block o a lo Napalkoff. Es la extirpación del quiste sin evacuación previa, una resección en bloque (Figura 7B) (Fotos 11,12). Estaría indicado en quistes emergentes y alejados del hilio hepático o del confluente cavo-suprahepático, pero lo principal a tener en cuenta es que haya bajo riesgo de que se rompa el quiste. Se requiere para su realización un conocimiento de su topografía, las relaciones vasculobiliares y sobretodo una gruesa adventicia fibrosada y calcificada para evitar la rotura en las maniobras ${ }^{13}$. Si no se cumplen dichas condiciones es preferible realizar la evacuación primero y a continuación la adventicectomía total o subtotal. Se diseca por el plano periadventicial o mejor aún entre la capa externa recuperable de la adventicia y la interna avascular e irrecuperable ${ }^{2}$. Este no es un plano continuo, por lo que en ocasiones se producen sangrados. Finalmente se logra que el parásito salga integro dentro de la adventicia.
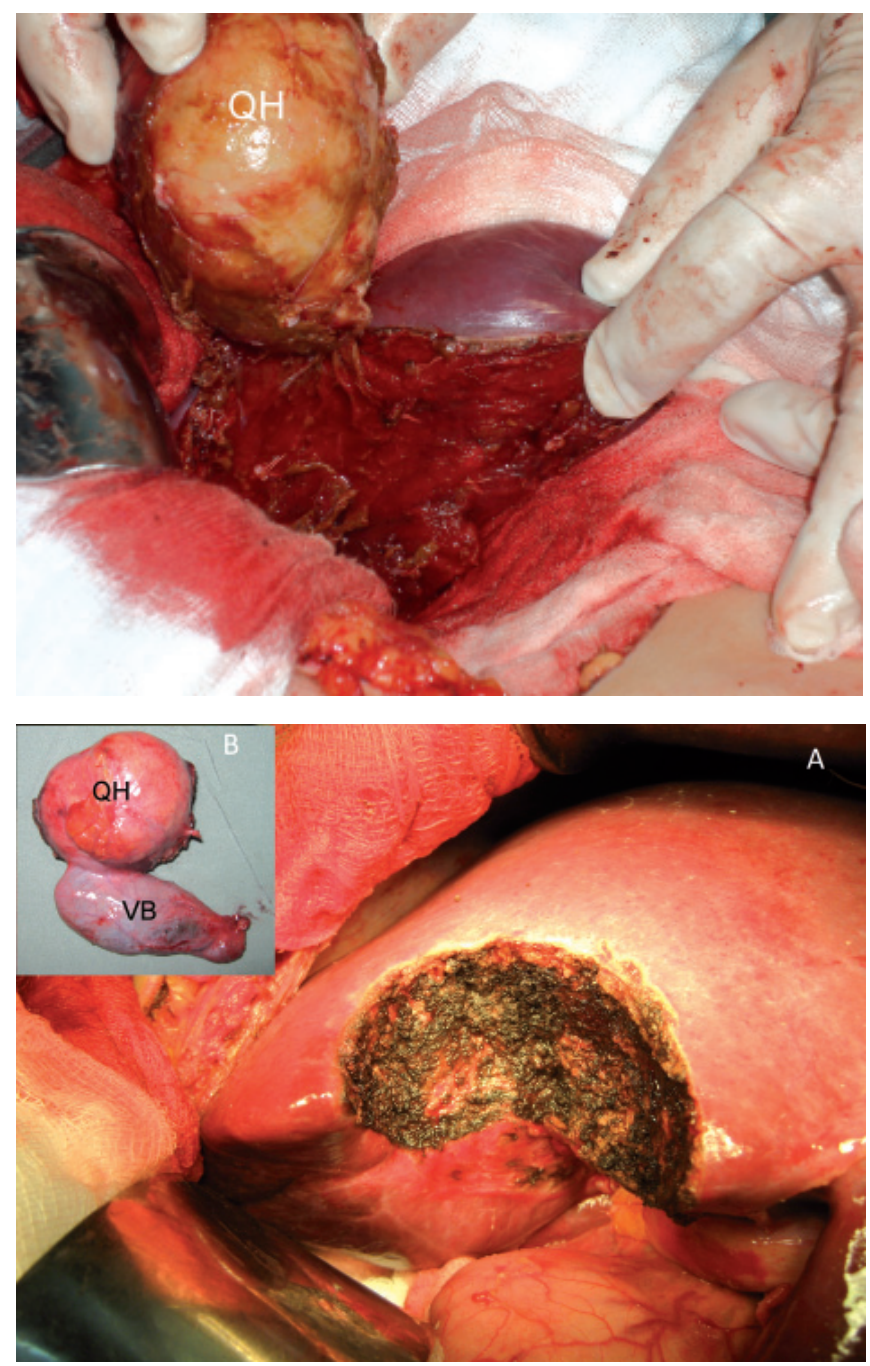

Foto 11.

Quistectomía cerrada

(Napalkoff). Quiste hidático (QH).
Foto 12

Quistectomía cerrada más colecistectomía. A) Transección hepática. B) Pieza de resección. Quiste hidático $(\mathrm{QH})$ más vesícula biliar (VB). 
4.1.2.4 - Quistoresección. Similar a la quistectomía (Figura 7C). Consiste en la resección cerrada del quiste utilizando los planos de disección anatómica cisurales del hígado, incluye un fragmento de parénquima simulando una resección atípica. Se evita dejar un sector de hígado devascularizado.

4.1.2.5 - Resecciones hepáticas. Discutido ampliamente a lo largo de los años, manejando el concepto de que es una enfermedad benigna y se debe conservar la mayor cantidad de masa hepática normal posible ${ }^{43}$ (Figura 7D). Cendán ${ }^{1}$ expresaba que sus indicaciones fluctúan entre el deseo del cirujano de practicar resecciones seguras y sin secuelas, y el temor de practicar una operación excesiva. En tanto Porras ${ }^{13}$ citando a Parodi dice que «su indicación surge del balance entre lo que se va a dejar luego de una quistostomía y los riesgos de una quistectomía de atrofia y necrosis parenquimatosa. Las hepatectomías regladas tratan lesiones irreversibles viscerales y son de menor riesgo que las quistectomías".

4.1.2.5.1 - Resecciones atípicas son quistectomías o adventicectomías en las que el plano de resección pasa por parénquima hepático laminado por el crecimiento del parásito, con el fin de eliminar el parénquima enfermo o atrófico. Podemos incluir aquí también a la quistorresección.

4.1.2.5.2 - Resecciones típicas, están indicadas en ${ }^{1,13}$ :

o grandes quistes con adventicias muy alteradas y destrucción casi total de uno o varios segmentos;

- equinococosis múltiple confluente;

- las cavidades residuales con repercusión biliar más o menos importantes, con ectasia y angiocolitis. Procesos en que la fibrosis y las alteraciones biliares llevan al fracaso de las exéresis locales y operaciones de drenaje.

- Las formas micropoliquísticas, infiltrantes y exógenas, que tienen una evolución y una malignidad semejante a la equinococosis alveolar.

Torterolo ${ }^{19}$ en una serie de 121 enfermos realizó 14 hepatectomías y 16 bisegmentectomias. Las hepatectomías fueron en quistes que sustituían la casi totalidad de un lóbulo o el resto del parénquima estaba atrófico. La resección del parénquima obedeció a razones vasculares y se evitó dejar parénquima irrecuperable del punto de vista funcional.

Para Odriozola ${ }^{2}$ su indicación es muy precisa: quistes con grave compromiso biliar, formas múltiples y en pacientes con reiteradas operaciones previas e importantes lesiones parenquimatosas. Los grandes quistes lobares y las recidivas podrían ser indicación de esta técnica radical.

Las lobectomías son excepcionales para el tratamiento de esta enfermedad. Las más utilizadas son: la lobectomía derecha o izquierda, la resección de los segmentos V-VI, la del segmento IV y la de los segmentos II-III ${ }^{13}$.

4.1.2.6. Adventicectomía diferida o secundaria: puede ser indicada en pacientes que tienen complicaciones de un procedimiento conservador previo o en aquellos en que debió realizarse un procedimiento conservador de necesidad ante graves complicaciones surgidas en el intraoperatorio. Generalmente es una cavidad residual complicada con supuración crónica, aunque puede hacerse invasora comprimiendo, involucrando y ulcerando estructuras vecinas, presentando comunicación biliar frecuentemente. La adventicectomía secundaria es el procedimiento indicado para curar al paciente ${ }^{44}$.

4.1.2.7. Trasplante hepático: Las causas que pueden llevar al mismo son: la cirrosis biliar secundaria, colangitis esclerosante por formol al $2 \%$, síndrome de Budd Chiari, hipertensión portal severa ${ }^{2,45}$.

\section{Tratamiento del quiste hidático complicado.}

\subsection{Quiste hidático supurado.}

El tratamiento se encara según la forma de presentación clínica, ya que se presenta en forma variable. Fundamentalmente en relación a la entidad del cuadro infeccioso y la repercusión general del paciente. En la sepsis es imprescindible un adecuado soporte de los sistemas fisiológicos. Los gérmenes aislados más frecuentemente son Enterobacter, Pseudomonas y E. Coli y hacia ellos debe estar dirigida 
la antibioticoterapia. El objetivo quirúrgico primario es la evacuación completa del contenido y el drenaje adecuado, por lo que la punción percutánea y drenaje, o la quistostomía mediatizada por un drenaje, tendrían indicación ${ }^{2}$. Según Larghero se debe evacuar el contenido y esterilizar la cavidad con solución escolicida, posteriormente se inspecciona la cavidad y si hay adventicia calcificada se realiza la exfoliación. Porras ${ }^{13}$ agrega el tratamiento de las lesiones biliares si está indicado. En la serie de Prousalidis ${ }^{46}$ sobre 77 pacientes realizó adventicectomía parcial con cierre y drenaje en el 89,6\% de los casos y tratamiento radical en los restantes. Su morbilidad fue de $19 \%$ y la mortalidad 2,6\%.

\subsection{Quiste hidático abierto y evacuado en vías biliares.}

La comunicación bilioquística es común en los quistes hidáticos hepáticos ${ }^{47}$. Hay lesión de la pared de los conductos biliares que forman parte de la adventicia. Estos canales conservan permeable su luz y favorecen la infección de la hidátide debido a que el espacio intercisto-adventicial está casi siempre en contacto con canalículos biliares. La infección trae como consecuencia la ruptura de la hidátide y su evacuación, hecho que en general es parcial en la vía biliar intrahepática, provocando una obstrucción biliar e ictericia ${ }^{48,49}$. La lesión es tanto más grave cuanto más cerca del confluente biliar sea, los quistes ubicados en el segmento IV se apoyan sobre el confluente biliar y producen lesiones de muy difícil manejo ${ }^{43,50}$. La comunicación bilioquística se puede apreciar después de la evacuación del parásito, en forma intraoperatoria, o en el postoperatorio manifestándose como una bilirragia ${ }^{51}$. La gravedad del cuadro dependerá del grado de obstrucción biliar y del proceso infeccioso.

El tratamiento de este tipo de complicaciones requiere un abordaje que permita manejar la vía biliar principal y el quiste. Desde punto de vista quirúrgico consiste en:

(1) Resolver el quiste, tratando la cavidad y descomprimiendo la vía biliar. El contenido se trata en forma habitual mediante aspiración. En pacientes sépticos y de urgencia, la resección de la adventicia no se debe extender, realizando una adecuada limpieza de la cavidad con extracción de zonas calcificadas.

(2) La exploración de la vía biliar principal, realizando la extracción de los restos hidáticos (Fotos 13,14) y dejándola adecuadamente drenada con un tubo de Kehr (tratamiento bipolar preconizado por Sasse) o realizar derivaciones bilio-digestiva (tratamiento tripolar). Se realiza en forma sistemática la colecistectomía dado que pueden haber restos hidáticos en su interior. Según Marella ${ }^{52}$ la coledocostomía como operación única es incompleta en la mayoría de los casos.

(3) Se deben ubicar el o los orificios fistulosos. Los pequeños se cierran. Los de mayor calibre se deben tratar, procediendo a desconectar la comunicación quisto-biliar o a intubarlos. Debe ser siempre reparado en primera instancia por medio de la intubación y/o desconexión ${ }^{50,53}$.

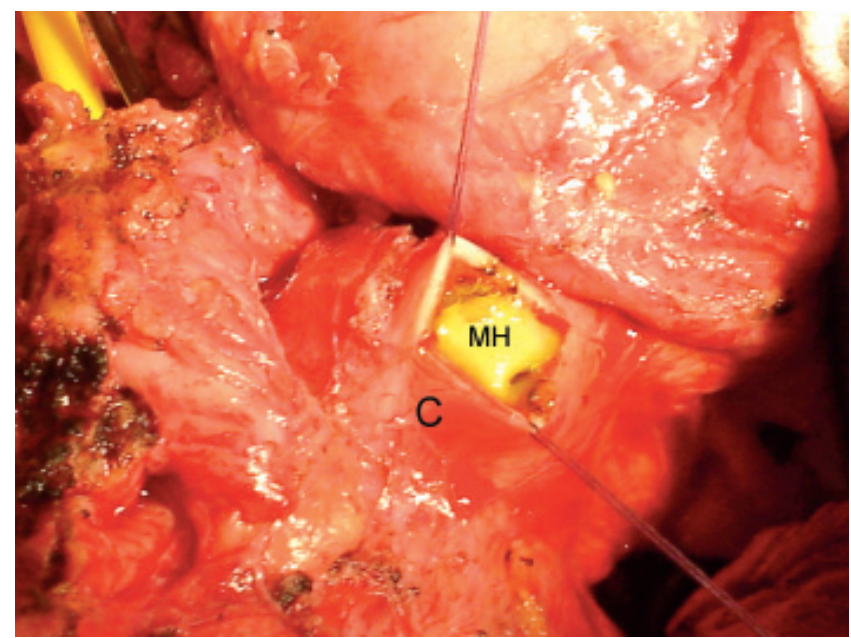

Foto 13.

Apertura del colédoco $(\mathrm{C})$ y visualización de membrana hidática (MH). (Cortesia Dr. F. González) 
Foto 14

Extracción de membrana hidática (MH) del colédoco (C). (Cortesia Dr. F. González)

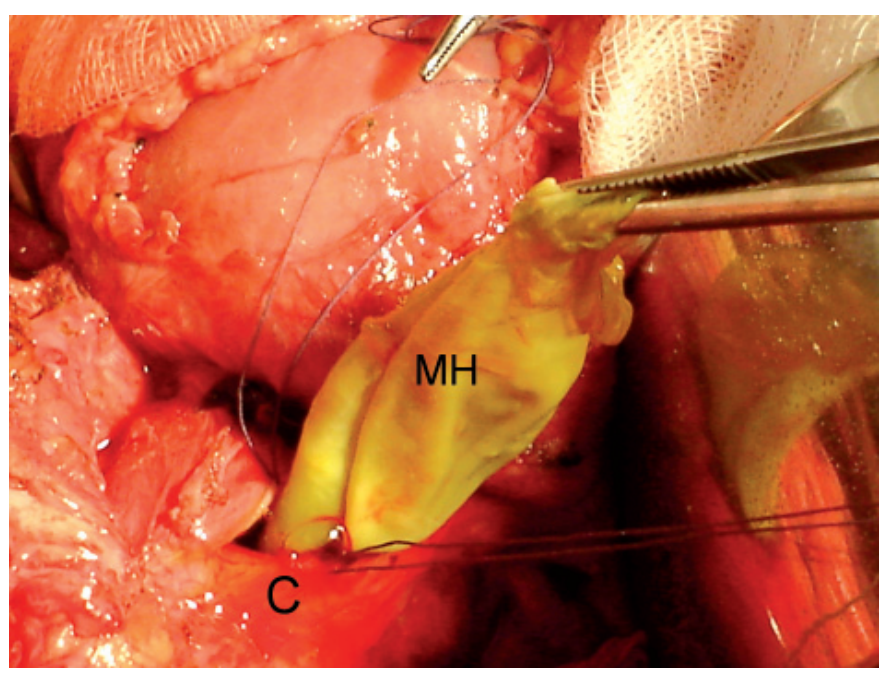

La colangiografía intraoperatoria es obligatoria con clampeo del colédoco distal. Permite evaluar la vía biliar intrahepática, el tamaño y localización de la fístula, así como su número.

Diversos procedimientos se han ideado para las fístulas quistobiliares:

- Para Larghero la evacuación del quiste y el drenaje de la cavidad, asociado al tratamiento de la vía biliar principal con su drenaje (drenaje bipolar) son suficientes (Figura $8 A$ ). En casos de lesiones laterales de gruesos conductos biliares o a nivel del hilio es insuficiente este proceder debido al riesgo de estenosis secundaria como complicación evolutiva ${ }^{54}$.

- Kehr saca un tubo de drenaje coledociano a través de la cavidad quística, efectuando una coledocostomía transquística.

- En nuestro medio Porras ${ }^{13}$ deja un drenaje coledociano transquístico o trans-hepatoquisto-coledociano (Figura 8B) (Foto 15). Realiza la coledocotomía para extraer restos parasitarios y pasa un tubo hacia la comunicación biliar en el quiste, y luego lo saca transhepático. Finalmente deja un tubo de drenaje enfrentado a la cavidad en forma de quistostomía. Las ventajas de este método son las siguientes: 1- evita los inconvenientes del Kehr, la obstrucción del cabo superior del colédoco y la permanencia de una coledocostomía en un ambiente inflamatorio; 2- la cámara parasitaria se cierra con la comunicación permeable, manteniendo así un drenaje interno natural de los canales biliares; y 3-el drenaje coledociano transquístico evita la bilirragia por el tubo de quistostomía, manteniendo una vía biliar tutorizada y expedita.

A) drenaje bipolar. B) procedimiento de Porras (drenaje coledociano transquístico). (Adaptado de Praderi).

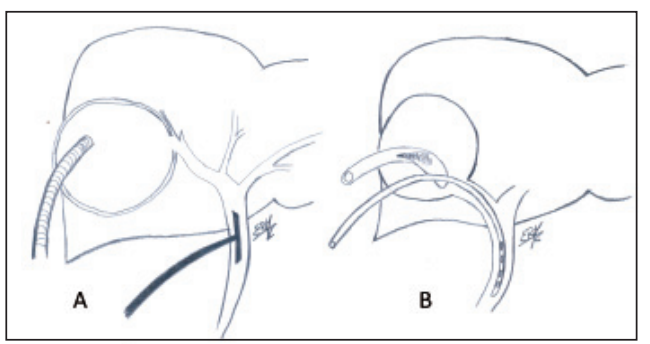

- Perdomo ${ }^{55,56}$ describió la técnica de desconexión quisto-biliar, para lo cual coloca un tubo de Kehr con una rama corta en el colédoco y otra en el hepático izquierdo. La rama larga sale por el hepático derecho a través de un corto trayecto transhepático, subadven- 


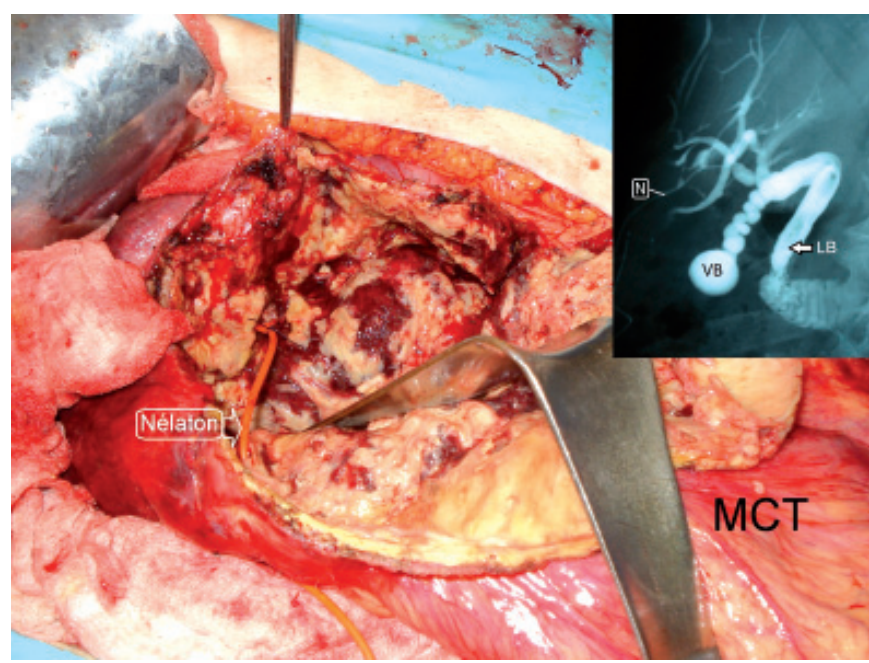

Foto 15.

Quiste hidático centro hepático gigante, adherido al mesocolon transverso (MCT). Drenaje coledociano transcístico (Porras). Colangiografía a través de la sonda Nélaton (N) que evidencia litiasis biliar (LB). Vesícula biliar (VB).
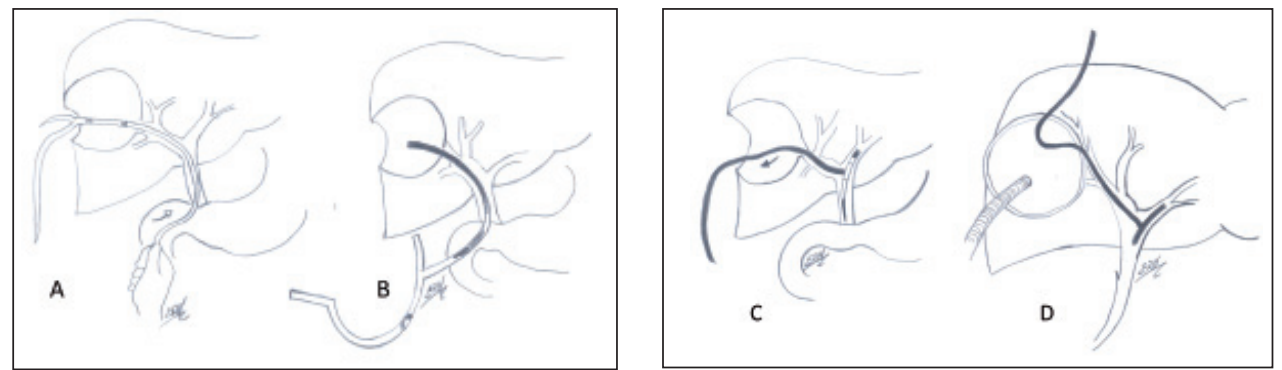

Figura 9.

Técnica de la desconexión quistobiliar de Perdomo. A) pasaje de sonda Nélaton por coledocostomía. B) tracción a contraremolque del Kehr. C) posicionamiento del Kehr en el confluente biliar, una rama queda hacia el hepático izquierdo y la otra en el colédoco. D) trayecto transhepático de salida del Kehr. (Adaptado de Perdomo ${ }^{56}$ ).

ticial, para evitar pasar por la cavidad residual. Para ello realiza una coledocostomía, limpieza de la vía biliar y posteriormente pasa a su través un explorador o sonda de Nélaton, la cual sale por el orificio en el quiste. Se trae a contra remolque el Kehr y lo posiciona en el confluente biliar superior (Figura 9). No coloca drenaje en la cavidad residual sistemáticamente, sino que lo utiliza cuando la cavidad está supurada ${ }^{27,54}$.

Este mecanismo permite una exclusión de la cavidad quística mediante su desconexión de la vía biliar, al formar un trayecto biológico por fuera del quiste. La cavidad quística en estas condiciones tendrá su evolución independiente de la vía biliar ${ }^{56,57}$. Permite resolver el problema de la fístula bilio-quística cuando se realiza un tratamiento conservador de la adventicia ${ }^{58}$.

\section{La desconexión se hace efectiva en 2 etapas:}

1. Inmediata, mecánica, mediante el ajuste de la fístula quistobiliar y de su canal de salida en torno al Kehr. El pasaje de líquidos es en ambos sentidos.

2. Mediata, la reacción granulomatosa peri Kehr genera un mecanismo biológico de exclusión.

Esto no se debe hacer si el canal biliar fistulizado en el quiste drena un importante sector proximal de hígado, es el caso de una abertura lateral de los conductos biliares principales en la adventicia hidática, la cual debe ser tratada como una herida de la vía biliar ${ }^{57}$. Para ello Perdomo ${ }^{50}$ comunicó diversas variantes de la técnica (Figura 10) (Foto 16). 


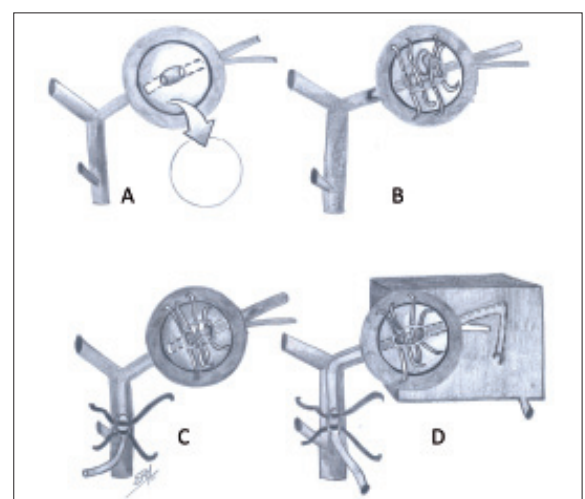

Figura 10.

Técnicas de desconexión quistobiliar en casos de lesión lateral de grueso canalículo biliar. A) lesión lateral. B) Se coloca un Kehr en el orificio. C) se coloca un drenaje por coledocostomía translesional. D) drenaje en setón por colecostomía translesional y transhepático. (Modificado de Perdomo ${ }^{50}$ ).

Foto 16.

Desconexión quistobiliar. Drenaje de Kehr (K2) en canal biliar con lesión lateral en la cavidad quística

(CQ). Drenaje de Kehr (K1) en colédoco (C). En ángulo superior derecho, esquema representativo de la situación.

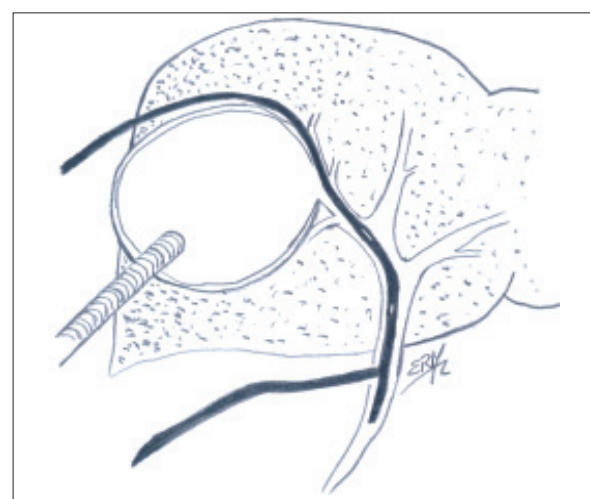

Figura 11. Técnica de Pomi y Pignata. (Adaptado de Praderi)

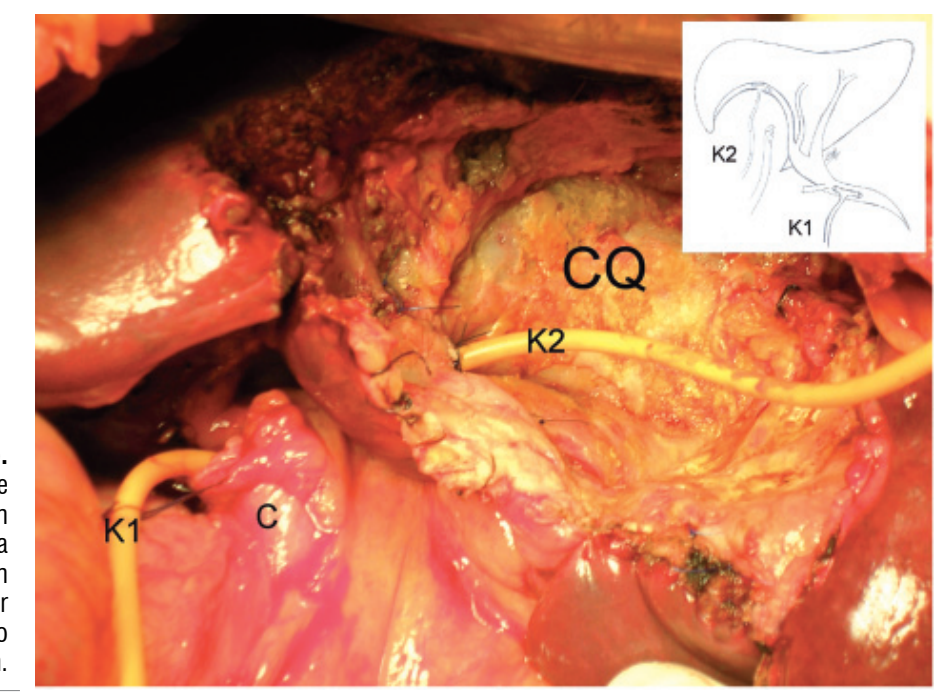

- Pomi y Pignata, en caso de encontrar una lesión lateral de un grueso canal biliar, colocan un tubo transhepático tangente a la cavidad, saliendo por el extremo periférico del canal fenestrado en el quiste (Figura 11). Es la coledocostomía transhepática yuxta quística. Se pretende que dicho conducto mantenga su diámetro lateral luego de cicatrizado ydrene los segmentos vecinos, tratando de evitar las alteraciones parenquimatosas por lafalta de drenaje. Otras opciones son la colocación de un tubo de Kehr en la lesión, o la colocación de una sonda multifenestrada transcoledociana y pasada por el conducto biliar lesionado hacia el sector proximal del mismo ${ }^{50,57}$.

\section{Esfintero-papilotomía endoscópica.}

La colangiografía endoscópica retrógrada además de ser un estudio diagnóstico en estos pacientes, puede ser un recurso útil en el tratamiento al realizar la descompresión de la vía biliar principal con una amplia esfinterotomía y extraer restos hidáticos. Odriozola ${ }^{2}$ lo plantea como primera indicación en pacientes que cursan una colangitis dada la baja morbi-mortalidad del método, permitiendo contemporizar al paciente para un tratamiento quirúrgico definitivo en diferido. También juega un papel importante en las complicaciones biliares del postoperatorio ${ }^{59}$. La descompresión biliar endoscópica 
ha demostrado ser eficaz en el tratamiento de las fístulas biliares que se desarrollan después del tratamiento quirúrgico de los quistes hidatídicos hepáticos. Los informes de casos y series pequeñas sugieren que la esfinterotomía endoscópica, con o sin stent biliar, es una solución eficaz, segura y ahorradora de tiempo y, probablemente, costo-efectiva, que facilita el cierre de las fístulas ${ }^{60}$.

Como método novedoso para el tratamiento de la bilirragia persistente postoperatoria en pacientes operados por una equinococosis hidatídica abierta y evacuada y en los cuales se les realizó un drenaje bipolar, Beguiristain ${ }^{16}$ plantea la colocación de un drenaje a través de la coledocostomía con técnica de Mazzariello y sacarlo en sedal a través del trayecto del drenaje de la quistostomía guiado por coledocoscopía.

\subsection{Ictericia por compresión hidática de las vías biliares.}

En casos de ictericia por compresión extrínseca de la vía biliar se encuentra un hepatocolédoco fino y la simple quistostomía trata la compresión. En estos pacientes no debe abrirse el colédoco ${ }^{61}$.

El problema se plantea en los casos que asocia compresión de la vena porta. Es un hecho muy poco frecuente para Porras ${ }^{13}$ y de muy difícil solución. Plantean una serie de dificultades como son la compresión de la vena porta con la consiguiente hipertensión portal y por otro lado la importante distorsión anatómica de las estructuras del pedículo hepático, hechos que dificultan enormemente la cirugía. Son ictericias de curso progresivo, que pueden confundirse con ictericias neoplásicas, difiriendo en forma significativa con la apertura y evacuación en vía biliar del parásito. La topografía de los quistes, cuando son primitivos hepáticos, están en el segmento I o en el IV en su sector anterior y emergiendo por la cara inferior. Otras posibilidades son por siembra hidática en el sector subhepático o raros quistes pancreáticos o pediculares. La arteria hepática en general escapa a la compresión por sus características anatómicas, manteniendo el trofismo hepático. La congestión venosa por la hipertensión portal aumenta considerablemente el riesgo de sangrado en la cirugía. También aumenta la posibilidad de lesión de vía biliar al estar esta laminada y no contar con una referencia anatómica adecuada ${ }^{61}$. Como tratamiento se plantea la evacuación y esterilización del quiste con el consiguiente drenaje. La evolución dependerá de las lesiones determinadas por el quiste y su evolución posterior. Es decir si retroceden los elementos de hipertensión portal y no continúa la estenosis biliar por autonomía evolutiva de la lesión por incorporación de la vía biliar a la adventicia.

\subsection{Hipertensión portal hidática.}

El obstáculo a la circulación portal puede ser pre, intra o posthepático. Pero el hecho capital es determinar la reversibilidad de las lesiones, dado por la presencia de fibrosis o trombosis. Puede tratarse de un síndrome de Budd Chiari por compresión del confluente suprahepático cava, solo o asociado a trombosis portal o compresión portal ${ }^{62}$. La estenosis biliar asociada puede llevar a cirrosis portal hidática. Esto se ve en pacientes multioperados, con hígados atróficos. En los casos que el factor dominante es la compresión, el tratamiento del quiste mejora al paciente ${ }^{63}$. Aunque hay casos en que las lesiones orgánicas fibróticas o trombóticas llevan a una hipertensión portal severa, en general son pacientes multioperados por quiste hidático que pueden terminar en el trasplante hepático ${ }^{45}$. mecanismos:

Según Maquieira, citado por Porras ${ }^{13}$, se produce por uno o varios de los siguientes

1. Compresión o trombosis de las venas suprahepáticas o sus ramas

2. Compresión o trombosis de la vena porta o sus ramas

3. Por compresión del lecho vascular y el parénquima por la presencia del quiste hidático como masa

4. Por atrofia y fibrosis hepática secundaria a trastornos vasculares, biliares, infecciosos e inmunológicos

5. Por obstrucción completa y prolongada del colédoco

En aquellos casos donde la compresión portal o suprahepática es el factor determinante, el tratamiento del quiste conduce hacia la mejoría de la circulación vascular hepática, ya sea en forma inmediata o progresiva, fundamentalmente cuando se forman nuevas vías derivativas portales. Se debe 
insistir con el tratamiento médico. Si hay trombosis portal se inician anticoagulantes, se debe tratar la hipertensión portal, insuficiencia hepatocítica, infección biliar y alteraciones de la crasis si existen ${ }^{13}$. En casos severos en que no retrocede la sintomatología se plantea el trasplante hepático ${ }^{2,45}$.

\subsection{Quiste hidático transitado a tórax.}

Si bien es una entidad poco frecuente - $3,9 \%$ de los casos de hidatidosis hepática en la serie de Praderi ${ }^{64}$-, constituye el principal desafío de la cirugía hidática, donde el criterio y la experiencia juegan un papel crucial ${ }^{2}$. En el adecuado manejo de estos pacientes es cuando se pone en evidencia el trabajo del equipo multidisciplinario. Es necesario contar con cuidados intensivos, equipo de nutrición, fisioterapeutas especializados en el aparato respiratorio y una activa participación e involucramiento de todos los integrantes del equipo asistencial. A pesar de todo, el tratamiento del quiste hidático transitado a tórax es esencialmente quirúrgico ${ }^{65}$.

El procedimiento quirúrgico ideal es el que resuelve la lesión torácica y el quiste hepático en una sola cirugía, hecho no siempre posible, dado que la oportunidad operatoria dependerá de la gravedad en que se manifiesta el cuadro, al igual que el tratamiento a realizar ${ }^{66}$. También debemos considerar la variabilidad en la forma de presentación así como las diversas clasificaciones ${ }^{67,68}$, hechos que nos han llevado al punto en que no se puede plantear un algoritmo terapéutico específico.

Como lo expresara Lorenzelli ${ }^{66}$ nos enfrentamos a 2 tipos de pacientes:

1. Pacientes graves $y / 0$ con mal terreno, en que se deben realizar procedimientos de salvataje. Operación en 2 etapas ${ }^{67}$, una primer cirugía en agudo para mejorar al paciente, y otra posterior que será la que resuelva toda la patología.

2. Pacientes con buen estado general, en los cuales es posible la cirugía de elección.

En todos los casos se debe evitar la inundación bronquial durante la anestesia y los cambios de posición del paciente. Para ello es fundamental el uso de la sonda de intubación bronquial selectiva, colocándola de preferencia con guía de fibrobroncoscopía, para evitar la contaminación e inundación contralateral ${ }^{66}$.

Abordaje. La elección del mismo es fundamental, ya que se debe tratar una patología que asienta en 2 cavidades y cuyas paredes son diferentes.

- Toraco-freno-laparotomía. Esta incisión permite un excelente campo de exposición ${ }^{69}$, pero tiene una morbilidad alta, sobre todo si no se tiene experiencia en su realización ${ }^{70}$.

- Toracotomía posterolateral derecha en $7^{\circ}$ u $8^{\circ}$ espacio intercostal, habitualmente no se necesita invadir el abdomen para realizar una tóraco freno laparotomía ${ }^{67}$. Se complementa

Foto 17.

Tránsito hepatotorácico. Abordaje por toracotomía posterolateral derecha. Se observa el quiste hidático $(\mathrm{QH})$ transitando al tórax.

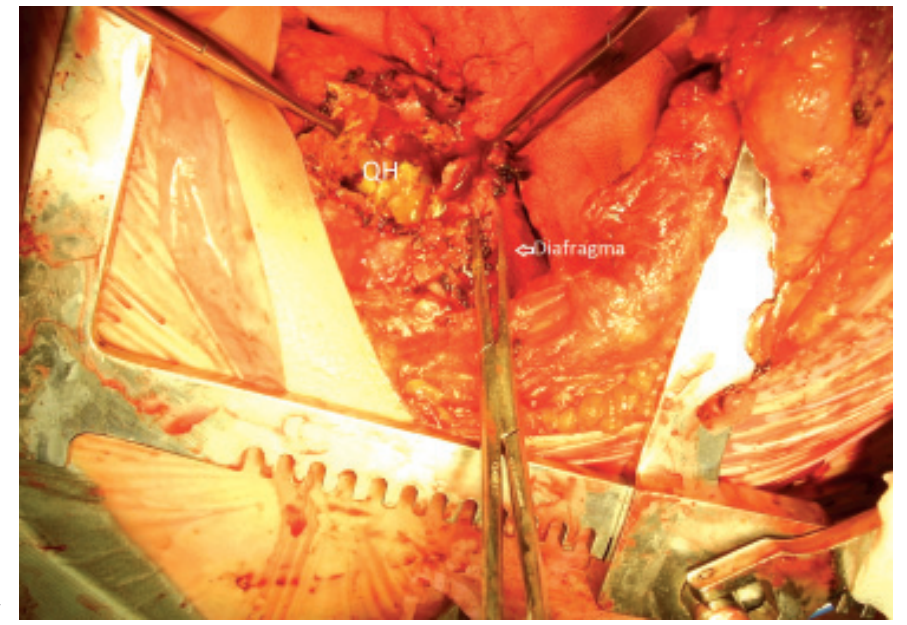




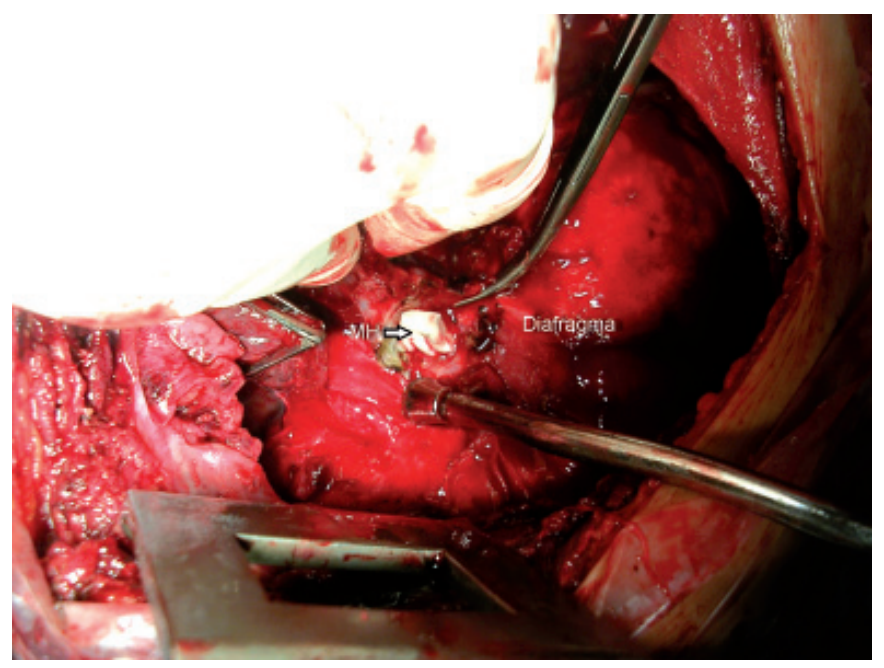

Foto 18.

Tránsito hepatotorácico. Abordaje por toracotomía posterolateral derecha. Se observa membrana hidática $(\mathrm{MH})$ transitando al tórax.

con una frenotomía sobre diafragma sano próximo a la zona del tránsito y cuidando de respetar la inervación diafragmática. Permite una muy buena exposición en quistes posteriores o del domo, sobre todo en casos de estar transitados a tórax (Fotos 17,18). No permite manejar la vía biliar, eventualidad necesaria cuando hay una apertura concomitante a vía biliar, posible hasta en un $30 \%$ de los casos. Tampoco permite el control del pedículo hepático ni la cava infrahepática, necesarios para un adecuado tratamiento de la adventicia. A esta incisión se la combina con un abordaje abdominal separado para el tratamiento del polo biliar.

- Incisión subcostal, ampliada a izquierda en «boca de horno». Permite una buena exposición hepática, y con su movilización se puede acceder a quistes posteriores. Se puede tratar el quiste, la vía biliar y el diafragma, aunque tiene el inconveniente de no poder evaluar y tratar adecuadamente las lesiones pleuropulmonares. Manterola ${ }^{71}$ y Gómez ${ }^{68}$ recomiendan este abordaje, pero la mayoría de los pacientes que intervinieron eran portadores de quistes en la etapa hepatofrénica, es decir sin lesiones pleuro-pulmonares.

- La incisión combinada torácica y subcostal derecha es la que nos presenta un buen abordaje en los casos más complejos. Permitiendo manejar el pulmón y pleura por la toracotomía, así como el hígado y la vía biliar por el abordaje abdominal.

En la etapa aguda actuamos sobre el sector que asienta la complicación, con cirugías simples, sin intentar solucionar en forma definitiva la enfermedad ${ }^{66}$.

- Si hay claros elementos de supuración hepática o apertura en vías biliares corresponde la evacuación del quiste y el drenaje de la vía biliar.

- Si predomina el síndrome de supuración pulmonar, con vómica purulenta, membranosa y biliosa, se debe resolver la caverna pulmonar. Se explora el orificio diafragmático y se aspira el contenido del quiste por esta vía, pudiendo ampliar el orificio para un mejor manejo.

- En casos de derrame pleural está indicado el drenaje pleural.

En la etapa crónica se realiza el tratamiento de todas las lesiones. Es decir el tratamiento integral de la enfermedad que comprende ${ }^{66}$ :

- Tratamiento del quiste,

- Tratamiento de la brecha diafragmática o cuello del tránsito,

- Tratamiento de lesiones pleuro-pulmonares, 
- Tratamiento de la vía biliar cuando está comprometida.

\section{La etapa crónica corresponde a 3 variedades principales:}

1) quistes hidáticos del hígado primitivamente abiertos en bronquios o pleura con sintomatología poco ruidosa;

2) tránsitos ya operados en etapa aguda y que requieren el complemento del tratamiento;

3) tránsito que se produce después de la evacuación de un quiste por continuación del proceso de necrosis y supuración de la adventicia y del diafragma, tránsito «ex vacuo».

El tratamiento se puede dividir en:

\subsubsection{Tránsito hepato pleural.}

- $\quad$ Presentan un derrame pleural con pus y restos hidatídicos. El tratamiento es la colocación de un drenaje pleural como primera etapa del tratamiento. En caso de encontrar bilis en el líquido se debe plantear la apertura a vía biliar, constituyendo un cole-pio-neumotórax. En estos casos se debe drenar la vía biliar en el mismo acto para evitar la fístula biliopleuro-cutánea ${ }^{66}$. En pacientes muy graves se plantea la realización de una papilotomía endoscópica con evacuación de la vía biliar por medio de una colangio pancreatografía endoscópica retrógrada.

- $\quad$ Posteriormente el tratamiento definitivo. A nivel pulmonar se debe ser lo más conservador posible, evitando las resecciones. El tratamiento transfrénico de la hidatidosis hepática tiene el problema de la adventicectomía, la cual si es por vía torácica exclusiva no se domina el pedículo hepático y se expone a riesgo de sangrados ${ }^{2}$. La desconexión se realiza al cerrar la brecha diafragmática, previo drenaje de la cavidad por vía abdominal. Se debe liberar el diafragma en forma extensa y resecar la zona de la brecha, posteriormente se repara en un plano con puntos separados ${ }^{66}$. En caso de haber apertura a vía biliar es obligatorio el abordaje abdominal para la resolución de ésta y del quiste.

\subsubsection{Tránsito hepato pulmonar incompleto.}

Se procede igual sobre el quiste. A nivel pleuro-pulmonar puede ser necesario realizar una decorticación pleural y resecciones económicas de parénquima. Sin dejar sectores patológicos de parénquima que dan origen a complicaciones posteriores. De constatar la pleura parietal engrosada, con elementos de siembra secundaria, se debe realizar la pleurectomía previa desinfección con agua oxigenada como escolicida, en la pleura visceral se realiza una decorticación ${ }^{66}$.

\subsubsection{Tránsito hepato pulmonar completo.}

El primer paso quirúrgico debe estar orientado a evacuar el quiste y la vía biliar. En caso de pacientes muy graves se puede indicar en primera instancia la papilotomía endoscópica. El abordaje quirúrgico inicial es por vía abdominal para tratar el quiste y la vía biliar. El tratamiento definitivo de la fístula, brecha diafragmática y lesión pulmonar requiere de una segunda cirugía por vía torácica. Se plantea también el tratamiento en un solo tiempo mediante toraco-freno-laparotomía o por 2 incisiones separadas, aunque no es recomendable esta gran cirugía en pacientes tan graves ${ }^{2}$. En cuanto a los tránsitos hepatobrónquicos, mantenidos o recidivantes, su reaparición es consecuencia casi siempre de una hipertensión biliar por obstrucción del colédoco con membranas o cálculos.

\subsection{Tránsito a víscera hueca.}

Es una complicación rara, en la cual los quistes de cara inferior presentan adherencias inflamatorias a la pared de la víscera. El tratamiento consiste en separar el quiste del órgano comprometido, realizar el tratamiento del quiste y actuar sobre la víscera comprometida ${ }^{2,72,73}$. Suiffet ${ }^{74}$ recomendaba drenar el quiste y no actuar sobre la víscera comprometida.

\subsection{Apertura o ruptura en peritoneo.}

Puede ser un cuadro grave en casos de ruptura brusca que origine una reacción anafiláctica 75. También puede haber derrame de pus, bilis o sangre. Genera además un implante peritoneal que 


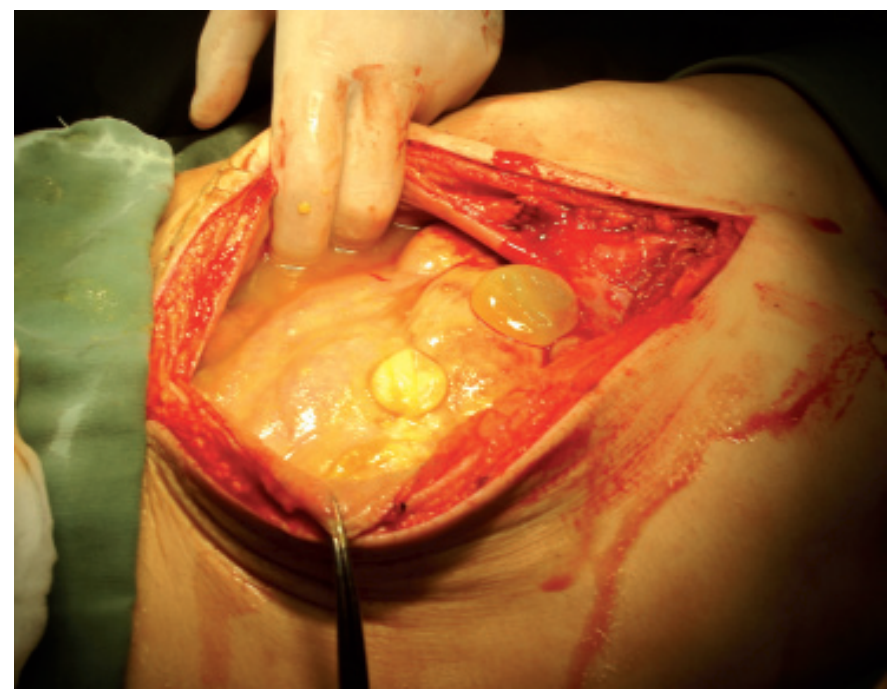

Foto 19.

Equinococosis hidática peritoneal secundaria masiva. Se observan vesículas hijas libres en cavidad peritoneal.

puede adoptar una forma subaguda o crónica ${ }^{2}$. El principal problema que plantea es la siembra hidática peritoneal masiva, o equinococosis peritoneal secundaria, de muy mal pronóstico (Foto 19). crónicas por otra.

Las complicaciones peritoneales se pueden dividir en agudas por una parte y subagudas y

Formas agudas. Ellas son la ruptura aguda y la equinococosis peritoneal primitiva heterotópica.

La rotura traumática con peritonitis hidatídica aguda es una complicación más frecuente en niños que en adultos, debido a las características anatómicas del niño, en que el hígado es más abdominal que en el adulto, así como un mayor porcentaje de quistes hialinos $(>70 \%)^{76}$. Se rompen principalmente los anteriores y voluminosos, en general vinculados a un traumatismo en la región. Además de reacción peritoneal pueden dar un cuadro de shock anafiláctico por los antígenos del parásito en contacto con el peritoneo. El contenido peritoneal estará dado por líquido hidatídico, exudado peritoneal y eventualmente sangre y bilis. El tratamiento consiste en cirugía de urgencia, se buscará y extraerá la membrana y vesículas hijas si las hubiera, posteriormente un adecuado lavado de la cavidad peritoneal con suero fisiológico. No se debe usar suero hipertónico por la absorción de cloruro de sodio en el peritoneo que causa trastornos hidroelectrolíticos severos ${ }^{76}$. Se procede posteriormente al tratamiento de la cavidad hidatídica en forma habitual. El tratamiento médico consiste en la reposición hidroelectrolítica, antibiótico debido a la sobreinfección, albendazol 10mg/kg/día y eventualmente corticoides.

La equinococosis peritoneal primitiva heterotópica es consecuencia de la rotura de la adventicia de un quiste hidático con la hidátide sana que pasa al peritoneo. La adventicia puede dar complicaciones, como ser el sangrado o en el fondo de la cavidad presentar una bilirragia, con el consiguiente hemoperitoneo o coleperitoneo respectivamente. El tratamiento consiste en extraer la hidátide en forma íntegra y a nivel de la adventicia en el hígado actuar según los hallazgos, tendiendo a resecar la adventicia en forma total.

Forma subaguda y crónica. Su tratamiento escapa a los objetivos de este trabajo. Pasaremos a enumerarlas según Chifflet ${ }^{77}$ :

Forma subaguda. Es la peritonitis hidática subaguda, en la que la rotura pasa desapercibida y luego de 24 a 48 horas aparece la ascitis.

La forma crónica corresponde a peritonitis plástica, peritonitis enquistante, hidatidosis peritoneal miliar y la hidatidosis peritoneal secundaria. 


\subsection{Rotura en vena cava inferior o suprahepáticas.}

1. Es muy poco frecuente y se puede manifestar como una complicación letal. En otros casos produce la siembra hematógena pulmonar masiva. Para su tratamiento se realiza una movilización hepática completa y una amplia exposición de la cava suprahepática, exposición de cava infrahepática para su eventual clampeo. La cara posterior del hígado permite la exploración y el vaciamiento del quiste y la sutura de la comunicación venosa a la cavidad hidática ${ }^{78}$.

\section{Equinococosis biliar y litiasis biliar.}

La asociación de equinococosis hidática y litiasis biliar es variable y va de un $16,3 \%$ a un $33,6 \%{ }^{13}$. Esta puede tener 3 explicaciones según Porras ${ }^{13}$ :

1. Litiasis biliar coincidiendo con una equinococosis hidatídica debido a la alta frecuencia de la misma en nuestro medio.

2. Litiasis parahidatídica, favorecida por la presencia del quiste hidático. El quiste hidático provoca estasis e infección biliar. El núcleo de estos cálculos no está formado por elementos hidatídicos. Litiasis biliar genuina.

3. Litiasis biliar hidática, poco frecuente y en general intraadventicial o coledociana. Debido a la precipitación de bilirrubinato de calcio y colesterol sobre restos hidáticos y vesículas hijas, trozos de adventicia calcificada e infectada o restos de quitinosa pueden actuar como cálculos o ser núcleo de formación.

\section{Las complicaciones de la cirugía.}

En caso de realizar resecciones hepáticas o grandes quistectomías pueden haber complicaciones intraoperatorias o postoperatorias inmediatas.La complicación intraoperatoria más grave es la hemorragia. Esta se puede manejar de forma adecuada al tener un amplio dominio vascular del pedículo hepático y de la cava infra y suprahepática ${ }^{19}$. En la serie de Hidalgo ${ }^{9}$ se produjo en un $1,38 \%$. Otra complicación intraoperatoria importante es la rotura del quiste con derrame de líquido hidático. En agudo puede desencadenar una reacción anafiláctica y en la evolución es consecuencia de recidivas. Porras ${ }^{13}$ encuentra un $6,2 \%$ de siembras operatorias. Otro elemento a tener en cuenta en el intraoperatorio es cuando se drena un quiste a través de la adventicia de otro. En este caso es necesario asegurarse de no lesionar un pedículo portal que transcurra por el tabique. Su lesión provoca hemorragia y bilirragia.

En el postoperatorio las complicaciones dependerán del procedimiento realizado, siendo los más frecuentes la fístula biliar $13,7 \%$ y la infección de la cavidad 7,6\% ${ }^{9}$. Esta última en caso de procedimientos conservadores.

La cavidad residual hidática presenta múltiples complicaciones inmediatas y tardías. El secuestro intraquístico, debido al desprendimiento postquirúrgico de la adventicia, necrosis y supuración posterior. Su extracción cura al enfermo en forma inmediata ${ }^{44}$.

Las quistostomías tienen tendencia a infectarse, por lo que los drenajes deben ser lavados en forma periódica para evitar que se tapen. El éxito de esta cirugía depende del buen manejo y cuidado de los drenajes ${ }^{13}$. Se pueden cambiar una vez formado el trayecto por otro más delgado. Por los drenajes quísticos aparecen a veces otras vesículas y fragmentos adventiciales que pasaron desapercibidos en la cirugía. En su serie Torterolo ${ }^{17}$ encontró para la quistostomía las siguientes complicaciones: supuración de la cavidad residual 32\%, bilirragia de alto gasto $15 \%$ y de bajo gasto $85 \%$. En tanto que para los que realizó una quistectomía encuentra 1 absceso subfrénico $(2,7 \%)$ y 2 hematomas en el lecho (5,4\%). En una serie más grande de tratamiento radical de la adventicia encuentra un $12 \%$ de complicaciones abdominales en 121 pacientes, siendo la bilirragia y las colecciones las más frecuentes ${ }^{19}$.

Por su parte Balik ${ }^{79}$ en una serie retrospectiva concluye que la quistostomía tiene una mayor incidencia de infección en la cavidad residual $(29,5 \%)$ y fístula biliar $(8,2 \%)$, en comparación con la 
epiploplastia, la quistectomía y la segmentectomía. Es también la cirugía con mayor internación postoperatoria, 16 días cuando no se infecta y 28 días si se infecta.

Bülbüller ${ }^{80}$ en una serie de 63 pacientes en que realizó procedimientos conservadores, principalmente quistectomía parcial con drenaje, epiploplastia o cierre de la cavidad, comunicó una morbilidad del $19 \%$ sin mortalidad.

En caso de fístula biliar persistente hay que tener en cuenta una posible hipertensión biliar mantenida por obstáculo coledociano o papilar, ya sea restos hidáticos, litiasis o papilitis.

La colangiografía endoscópica retrógrado y papilotomía ha demostrado ser efectiva para el tratamiento de las fístulas biliares postoperatorias ${ }^{81,82}$.

En algunos pacientes operados de quiste hidático pueden presentar estenosis de la vía biliar, con distorsiones anatómicas y cavidades secuelares, es la llamada estenosis biliar posthidática ${ }^{83}$ (Fotos 20a, 20b, 20c). Mientras más próxima al confluente sea la estenosis, o en casos de afectación bilateral por quistes hidáticos múltiples, más grave es el pronóstico. Los pacientes desembocan lenta y progresivamente hacia 3 formas clínico-evolutivas de gravedad: 1-episodios de colangitis; 2- cirrosis biliar con insuficiencia hepatocítica; y 3- hipertensión portal. Perdomo ${ }^{83}$ plantea la prevención de dichas lesiones estenóticas mediante la identificación y adecuado tratamiento de lesiones biliares durante la primer cirugía por quiste hidático. Los tratamientos una vez establecida la estenosis y/o las complicaciones evolutivas son más difíciles y de mayor morbilidad, tal el caso de un drenaje transparietohepático con dilatación y calibrado de la estenosis ${ }^{55}$.

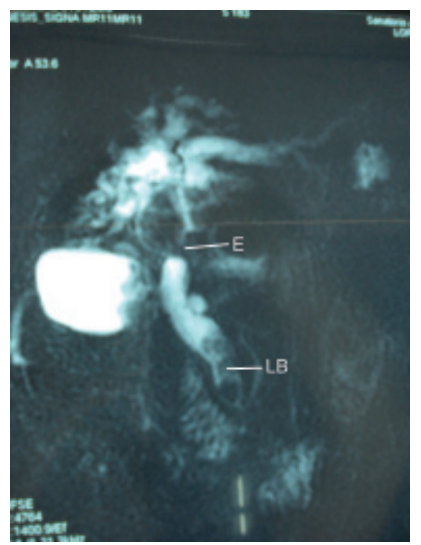

Foto 20a.

RNM. Secuela postquirúrgica de quiste hidático hepático. Dilatación del hepocolédoco con litiasis (LB) en su interior y estenosis (E) del confluente biliar superior.

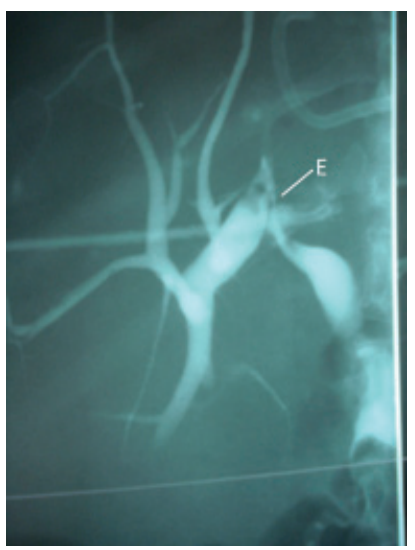

Foto 20b.

Colangiografía que muestra estenosis $(\mathrm{E})$ del confluente biliar superior.

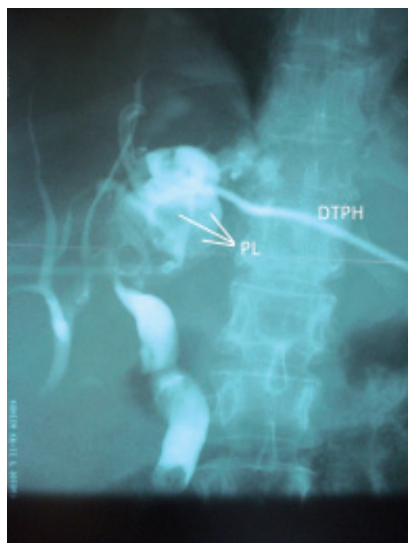

Foto 20c.

Drenaje transparietohepático (DTPH). Dilatación del hepático izquierdo con panlitiasis $(\mathrm{PL})$.

\section{Bibliografía consultada.}

Larghero P, Venturino W, Broli G. Equinococosis hidatídica del abdomen. Montevideo: Delta editorial. Montevideo; 1962.

Praderi R. Hidatidosis. Tratamiento quirúrgico. En: Findor J, Sapunar I. Enfermedades del hígado y las vías biliares. Buenos Aires: Librería Akadia Editorial; 1985. p.567-82. 
TRATAMIENTO QUIRÚRGICO DEL QUISTE HIDÁTICO HEPÁTICO

\section{Referencias bibliográficas.}

1. Cendán J. Estado actual de la cirugía en la hidatidosis hepática. Arch Int Hidatidosis. 1971;25:97-124.

2. Odriozola M, Pettinari R. Relato Oficial. Hidatidosis abdominal. 69 Congreso Argentino de Cirugía. Rev Arg Cir. 1998;(No. Extra):9-70.

3. Torterolo E, Silva C, Cidade L, Czarnevicz D, Leites A, Vergara M, et al. Consideraciones técnico tácticas de la cirugía hepática. Cir Uruguay. 1994; 64:116-24.

4. Perrier J, Secondo G, Harguindeguy M, Czarnevicz D, Cidade L, Leites A, et al. Evaluación pre, intra y postoperatoria en la cirugía hepática. Simposio. Cir Uruguay. 2002;72(2):181-221.

5. Torres M. Tratamiento del quiste hidático hepático. Estado Actual. Cir Uruguay. 2002;72(2):98-123.

6. Torterolo E, Kaitazoff P, Fernández W. La ecografía intraoperatoria en cirugía hepática. Comunicación preliminar. Cir Uruguay. 1994;64:52-5.

7. Pérez Fontana V. El formol y el cloruro de sodio en el tratamiento del quiste hidático. Arch Int Hidat. 1961;30:315-21.

8. Ruso Martínez L. Suero hipertónico e hipernatremia en hidatidosis hepática. Cir Esp. 2010;88(1):61-4.

9. Hidalgo M, Barquet N. Hidatidosis hepática. Estudio de una serie de 7435 casos. Rev Esp Enf Ap Digest. 1987;71(2):103-09.

10. Belghiti J, Benhamou J, Houry S, Grenier P, Huguier M, Fekete F. Caustic sclerosing colangitis. A complication of the surgical treatment of hydatid disease of the liver. Arch Surg. 1986;121:1162-5.

11. Zaouche A, Haouet K, Jouini M, Hchaichi A, Dziri Ch. Management of liver hydatid cysts with a large biliocystic fistula: Multicenter retrospective study. World J Surgery. 2001;25:28-39.

12. Safioleas M, Misiakos E, Kouvaraki M, Stamatakos M, Manti C, Felekouras E. Hydatid disease of the liver. A continuing surgical problem. Arch Surg. 2006;141:1101-8.

13. Porras Y. Complicaciones hepatobiliares de la hidatidosis. Cir Uruguay. 1973;43 (6):441-89.

14. Hankins JR. Management of complicated hepatic hydatid cyst. Ann Surg. 1963;158:1020-34.

15. Fernández G, Bianchi G, Palacios G, Piazze A, Keuchkerian S. Efecto de distintos parasiticidas sobre la vía biliar. Cir Uruguay. 1988;58(1):41-4.

16. Beguiristain $A$, Estefan $A$. Exploración endoscópica de la cavidad hidática hepática. Comunicación preliminar. Cir Uruguay. 1995;65:32-4.

17. Torterolo E, Perrier J, Aizen B, Piacenza G, Castiglioni J, Piñeyro A, et al. Estudio comparativo del tratamiento de la hidatidosis hepática por quistectomía. Hidatidectomía y adventicectomía total y procedimientos conservadores. Cir Uruguay. 1990;60(1-2-3):51-6.

18. Coiro M, Deleón G. Tratamiento de la hidatidosis hepática en Paysandú. Diagnóstico de situación. Cir Uruguay. 1999;69:82-7.

19. Torterolo E, Vergara M, Covic V, Leites A, Aizen B, Czarnevicz D, et al. Tratamiento radical de la hidatidosis hepática. Cir Uruguay. 1994;64:56-65.

20. Perdomo R, Ferreira C, Chiesa A, Alvarez C. Forma multivesicular y migración de los quistes hidáticos del hígado. Cir Uruguay. 1988;58(2-3): 61-71.

21. Maquieira G. Complicaciones biliares de la equinococosis hepática del niño. Cir Uruguay. 1975; 45 (5): 424-26.

22. Engin O, Calik B, Yilmaz M, Temiz E, Karagulle I. Cirugía conservadora en Hidatidosis. Problemas. Rev. Chil Cir. 2010; 62(2):114-18.

23. González D, Vega A, Monti J, Torres M. Enfermedad hidatídica hepática. Experiencia en los últimos 13 años en Florida. Cir Uruguay. 1999;69(3-4): 200-03.

24. Sahin M, Koksal H, Yilmaz H, Cakir M. Surgical treatment of h epatic hydatid cyst: cysto-jejunostomy by stapling. Bratisl Lek Listy. 2010;111(6):349-50.

25. Brezean I, Catrina E, Aldoescu S, Rahimi M, Manescu D, Veranu I, et al. The main utility of transanastomosis external drainage in the hydatid liver cysts treatment by peri-cystic-jejunostomy. Chirurgia (Bucur). 2005;100(5):457-9.

26. Apablaza Pedreros S, Burmeister Lorenzen R, Benavides C; Gacitua H, Nara F. Tratamiento quirúrgico del quiste hidatídico hepático. Rev Chil Cir. 1992;44(4):424-7.

27. Perdomo R, Ferreira $\mathrm{C}$, Alvarez C. Operación radical versus conservadora en algunos quistes hidáticos hepáticos. Conducta con la adventicia. Cir Uruguay. 1996;66:192-97.

28. Moumen M, el Fares F. Hydatid cysts of the hepatic dome. Apropos of 124 cases Chirurgie. 1991;117(10):848-53. 
29. Del Campo J. Quistes hidáticos calcificados del hígado. Bol Soc Cir Uruguay.1950:143-53.

30. Dziri C, Paquet JC, Hay JM, Fingerhut A, Msika S, Zeitoun G, et al. Omentoplasty in the prevention of deep abdominal complications after surgery for hydatid disease of the liver: a multicenter, prospective, randomized trial. French Associations for Surgical Research. J Am Coll Surg. 1999;188(3):281-9.

31. Chautems R, Bühler L, Gold B, Giostra E, Poletti P, Chilcott M, et al. Surgical management and long-term outcome of complicated liver hydatid cyst caused by echinococcus granulosus. Surgery. 2005;137:312-16.

32. Yüksel O, Akyürek N, Sahin T, Salman B, Azili C, Bostanci H Efficacy of radical surgery in preventing early local recurrence and cavity-related complications in hydatic liver disease.J Gastrointest Surg. 2008;12(3): 483-9.

33. Gollackner B, Längle F, Auer H, Maier A, Mittlböck M, Agstner I, et al. Radical surgical therapy of abdominal cystic hydatid disease: factors of recurrence. World J Surg. 2000; 24: 717-21.

34. Botrugno I, Gruttadauria S, Li Petri S, Cintorino D, Spada M, Di Francesco F, et al. Complex hydatid cysts of the liver: a single center's evolving approach to surgical treatment. Am Surg. 2010;76(9):1011-5.

35. Priego P, Nuño J, López Hervás P, López Buenadicha A, Peromingo R, Díe J, et al Hepatic hydatidosis. Radical vs. conservative surgery: 22 years of experience. Rev Esp Enferm Dig. 2008;100(2):82-5.

36. Seoane A, Sardón G, Sánchez O, Tanoue P. Quiste hidatídico hepático: tendencia actual al tratamiento quirúrgico radical Rev Arg Cir. 2000;78(6):249-55.

37. Mingo M, Fernández P. Tratamiento de la hidatidosis hepática en un hospital zonal del noroeste del Chubut. Rev Arg Cir. 2010;98(5-6): 111-16.

38. Lesurtel M, Selzner M, Petrowsky H, McCormack L, Clavien PA. How Should Transection of the Liver Be Performed? A Prospective Randomized Study in 100 Consecutive Patients: Comparing Four Different Transection Strategies. Ann Surg. 2005;242(6):814-22.

39. Delgado B. Tratamiento de la hidatidosis hepática por cirugía radical. Cir Uruguay. 1991;61:25-8.

40. Ramia Angel JM, Figueras Felip J. Hidatidosis hepática: ¿qué cirugía debemos realizar? Cir Esp. 2010; 88(1):1-2.

41. Akcan A, Sozuer E, Akyildiz H, Ozturk A, Atalay A, Yilmaz Z. Predisposing factors and surgical outcome of complicated liver hydatid cysts. World J Gastroenterol. 2010;16(24):3040-8.

42. Losada Morales H, Burgos San Juan L, Silva Abarca J, Muñoz Castro C. Experience with the surgical treatment of hepatic hydatidosis: case series with follow-up. World J Gastroenterol. 2010;16(26):3305-9.

43. Ruso L, Balboa O, Fernández R, Alvarez O, Díaz F, de Simone G. Destrucción del confluente biliar superior de causa hidática. Manejo quirúrgico. Cir Uruguay. 2005;75 (3):150-54.

44. Davezac V, Delgado B, Salisbury S, Folle E. Hidatidosis hepática. Enfermedad por persistencia de la cámara parasitaria. Cir Uruguay. 1991;61:44-7.

45. Moreno González E. Papel del trasplante de hígado en el tratamiento de la hidatidosis hepática. Rev Esp Enf Ap Digest. 1989; 76:1-3.

46. Prousalidis J, Kosmidis C, Anthimidis G, Fachantidis E, Harlaftis N, Aletras H. Forty-four years experience (1963-2006) in the management of primarily infected hydatid cyst of the liver. HPB. 2008;10:18-24.

47. Marella M. Conductas operatorias en el quiste hidatídico de hígado abierto en vías biliares. Cir Uruguay. 1967; 37(1-2):100-06.

48. Anastasia, H. Dos casos de quiste hidático del hígado abierto en las vías biliares. Bol Soc Cir Uruguay. 1933;4:185-98.

49. Lamas Pouey E. A propósito de un quiste hidático del hígado abierto en las vías biliares. Bol Soc Cir Uruguay. 1935; 6:16-9.

50. Perdomo R, Alvarez C, Monti J, Ferreira C, Chiesa A, Carbó A, et al. Principles of the surgical approach in human liver cystic echinococcosis. Acta Tropica. 1997;64:109-22.

51. Calleri EM. Quistes hidáticos del hígado abiertos en vías biliares. 4o Congreso Uruguayo de Cirugía; Montevideo; 195330 nov - 5 dic. Montevideo: Garcia Morales-Mercant, 1954. p.201-21.

52. Marella M. Diagnóstico y tratamiento de las complicaciones biliares de la hidatidosis. Cir Uruguay. 1973; 43(6):498-505.

53. Moreno González E, Herrera Cabrera V, González Pinto I, Hidalgo Pascual M. La ruptura intrabiliar como complicación de la hidatidosis hepática. Rev Arg Cir. 1994;67(3-4):65-9.

54. Perdomo R, Alvarez C, Tiscornia E, Zubiaurre L, Geninazzi H. Estenosis biliares posthidáticas. Formas anatomorradiológicas y tratamiento. Cir Uruguay. 1993; 63:158-64. 
55. Perdomo R, Balboa O, Morelli R, Melognio S. Quistes hidáticos del hígado abiertos en las vías biliares. Desconexión quistobiliar por coledocostomía transhepaticoquística. Cir Uruguay. 1976;46(1):33-9.

56. Perdomo R, Morelli R, Carriquiry L, Chifflet J, Bergalli L. Cholédocostomie trans-hépatico kystique en cas de kyste hydatique ouvert dans les voies biliaires. Nouv Presse Med. 1977;6(9):747-49.

57. Perdomo R, Geninazzi H, Santana C, López J, Castro D, Morelli R, et al. Abertura lateral de conductos biliares principales en la adventicia hidática: su tratamiento por desconexión quisto-biliar. Cir. Uruguay. 1984;54(2):84-97.

58. Medarhri J, El Ounani M, Echarrab M, Louchi A, Alami F, Amraoui M, et al. Les Kystes hydatiques du foie rompus dans les voies biliaires. A propos de 88 cas. Medecine du Maghreb. 2001;86:45-8.

59. Chautems R, Bühler L, Gold B, Giostra E, Poletti P, Chilcott M, et al. Surgical management and long-term outcome of complicated liver hydatid cyst caused by echinococcus granulosus. Surgery. 2005;137:312-16.

60. Goumas K, Poulou A, Dandakis D, Tyrmpas I, Georgouli A, Sgourakis G, ET al. Role of endoscopic intervention in biliary complications of hepatic hydatid cyst disease. Scand J Gastroenterol. 2007;42(9):1113-9.

61. Praderi R, Gómez Fossati C, Praderi L. Ictericia por compresión hidática de las vías biliares. Cir Uruguay. 1973;43(6):506-9.

62. Delgado B, Perrier J, Rissi L. Síndrome de Budd Chiari por hidatidosis hepática del segmento VIII tratado por quistectomía con buena evolución. Primera observación nacional. Cir. Uruguay. 1991;61(1-2): 48-50.

63. Stork G, Mañanes G, Echeverría M, Cabo A, Santiago R. Síndrome de hipertensión portal secundario a quiste hidatídico hepático. Rev Arg Cir. 2006;90;(5-6):181-83.

64. Praderi L, Cassinelli D. Tránsitos hepatotorácicos de origen hidatídico. Experiencia personal sobre 11 casos. Cir Uruguay. 1970;40 (2):149-57.

65. Súarez H, Victorica A. Tratamiento de los tránsitos hidáticos hepato-pulmonares transdiafragmáticos. Bol Soc Cir Uruguay. 1950;21:245-64.

66. Galarraga J, Soto J, Di Leoni F, Tchekmedyian V, Lorenzelli J, Chifflet J. Complicaciones torácicas de la equinococosis. Cir Uruguay 1994; 64: 241-56.

67. Armand Ugón V, Tomalino D. Tránsitos hidáticos hepatotorácicos. Consideraciones sobre 40 casos personales. El Tórax. 1958;7:188-209.

68. Gómez R, Moreno E, Loinaz C, De la Calle A, Castellon C, Manzanera M, et al. Diaphragmatic or transdiaphragmatic thoracic involvement in hepatic hydatid disease: surgical trends and classification. World J Surg. 1995;19(5):714-9.

69. Tocchi A, Mazzoni G, Miccini M, Drumo A, Cassini D, Colace L, et al. Treatment of hydatid bronchobiliary fistulas: 30 years of experience. Liver Int. 2007;27(2):209-14.

70. Lumsden AB, Colborn GL, Sreeram S, Skandalakis LJ. The surgical anatomy and technique of the thoracoabdominal incision. Surg Clin North Am. 1993;73(4):633-44.

71. Manterola Delgado C, Ávila N, Seco J, Ulloa P, Moraga J. Tránsito hepatotorácico, complicación evolutiva de la hidatidosis hepática. Características clínicas y morbilidad de una serie prospectiva de pacientes intervenidos quirúrgicamente. Rev Chil Cir. 2009;61(4):345-9.

72. Goller, W. A propósito de un quiste hidático de hígado abierto en estómago. Bol Soc Cir Uruguay. 1963;34(12): 19-22.

73. Laviña R, Perrone L, Pamparato M, Venturino W. Fístula duodenal. Complicación de drenaje de cavidad hidatídica hepática. Cir Uruguay. 1980;50:168-9.

74. Suiffet $W$. Consideraciones de terapéutica sobre los quistes hidáticos abiertos en vías digestivas. An Fac Med. Montevideo. 1946;31:409-12.

75. Castanares-Zapatero D, Laterre PF. Ruptured hydatid cyst in a patient with shock. Hepatobiliary Pancreat Dis Int. 2009;8(6):638-9.

76. Lizaso I, Benedictti J. Rotura traumática del quiste hidático de hígado en el niño. Cir Uruguay. 1985;55(6):335-9.

77. Chifflet A. Procesos peritoneales de origen hidatídico. Nomenclatura y definiciones. 11 o Congreso Uruguayo de Cirugía. Tomo II: 200-5.

78. Castiglioni Alonso H. Quiste hidático del hígado abierto en la vena cava inferior. En: Blanco Acevedo E. Práctica quirúrgica: simposio sobre equinococosis. Montevideo:[s.n.];1947.p.317-26.

79. Balik A, Basoglu M, Celebi M, Oren D, Polat Y, Atamanalp S, et al. Surgical treatment of hydatid disease of the liver. Review of 304 cases. Arch Surg. 1999;134:166-69. 
TRATAMIENTO QUIRÚRGICO DEL QUISTE HIDÁTICO HEPÁTICO

80. Bülbüller N, llhan Y, Kirkil C, Yenicerioglu A, Ayten R, Cetinkaya Z. The results of surgical treatment for hepatic hydatid cysts in an endemic area. Turk J Gastroenterol. 2006;17(4):273-78.

81. Adas G, Arikan S, Gurbuz E, Karahan S, Eryasar B, Karatepe O, et al. Comparison of endoscopic therapeutic modalities for postoperative biliary fistula of liver hydatid cyst: a retrospective multicentric study. Surg Laparosc Endosc Percutan Tech. 2010;20(4):223-7.

82. Tekant Y, Bilge O, Acarli K, Alper A, Emre A, Arioðul O. Endoscopic sphincterotomy in the treatment of postoperative biliary fistulas of hepatic hydatid disease. Surg Endosc. 1996;10(9):909-11.

83. Perdomo R, López J, Delbene R, Castro D, Santana C, Bertolini C, et al. Las estenosis biliares posthidáticas y sus consecuencias. Cir Uruguay. 1985;55(2-3):79-97. 


\section{Cirugía laparoscópica}

El tratamiento quirúrgico de la equinococosis hidática hepática mediante abordaje videolaparoscópico lo comunicó por primera vez Katkhouda ${ }^{1}$.

En nuestro país los cirujanos del interior han sido pioneros en esta modalidad terapéutica.

Maglione ${ }^{2}$ en la primer Jornada del Capítulo de Cirujanos del Interior de la Sociedad de Cirugía del Uruguay realizada en el año 1997 en la ciudad de Tacuarembó, presentó un video donde detalló la técnica empleada en un caso tratado en la ciudad de Carmelo.

Posteriormente Oddone ${ }^{3}$ en el XXIII Congreso Mundial de Hidatidología llevado a cabo en la ciudad de Colonia del Sacramento, Uruguay en el año 2009 comunicó 7 casos tratados por esta vía en el departamento de Paysandú. Actualmente su serie es de 11 pacientes.

En la Clínica Quirúrgica 3 del Hospital Maciel, Montevideo se trató un caso en el año 2010.

Sin embargo y a diferencia de otras patologías en que la cirugía laparoscópica a través de la evidencia ha logrado imponerse y consolidarse como patrón oro en su tratamiento, la equinococosis hidática hepática aún no ha alcanzado el consenso necesario para constituirse en el abordaje de elección.

Así lo planteó Ertem ${ }^{4}$ quien sostiene que este abordaje no es el estándar para el tratamiento del quiste hidático hepático.

Los argumentos por los cuales existe reticencia por parte de los cirujanos a indicarla son fundamentalmente dos: la contaminación peritoneal y la anafilaxia.

Yagan ${ }^{5}$ realizó una encuesta a 30 cirujanos del norte de Jordania. Indagó sobre la técnica quirúrgica de elección para el tratamiento del quiste hidático hepático. Tres consideraron la cirugía laparoscópica como técnica de primera línea. La razón esgrimida por 21 de los 27 restantes cirujanos de no indicarla es precisamente el temor a la anafilaxia y la contaminación peritoneal. esta hipótesis.

Sin embargo, las diferentes series comunicadas hasta el momento no han permitido confirmar

Khoury ${ }^{6}$ reportó el primer caso de shock anafiláctico durante la cirugía laparoscópica. Trabajos posteriores no lo incluyen dentro de sus complicaciones.

Yagci ${ }^{7}$ considera que es una técnica segura y eficaz para quistes accesibles y tipo I, II y III de la clasificación de Gharbi. Palanivelu ${ }^{8}$ utilizó como criterio de exclusión en su serie aquellos ubicados en los segmentos I, VII y VIII. Los quistes más favorables son los pequeños, sin relaciones vasculares de importancia, ubicados en los segmentos II, III, IVb, V y VI ${ }^{9,10}$. Sinha ${ }^{11}$ en base a su experiencia planteó que es un buen abordaje para los quistes de segmentos VII y VIII ya que elimina la morbilidad de la toracofrenolaparotomía. La no identificación de un quiste del segmento VII fue el motivo de conversión en la serie de Pinto ${ }^{12}$.

Este abordaje es factible si la realizan cirujanos con experiencia en cirugía laparoscópica, hepática y habituados al tratamiento del quiste hidático por abordaje convencional. Exige respetar todos los principios técnicos de la cirugía convencional. Según Baltar Boilève ${ }^{13}$ todas las técnicas clásicas utilizadas en el tratamiento de los quistes hidáticos hepáticos son reproducibles mediante laparoscopia y por lo tanto, los criterios de tratamiento pueden ser similares. Agrega que esta vía de abordaje no debe descartarse a priori en las localizaciones «no ideales». Al adquirir mayor experiencia ha visto como la adecuada posición del paciente y de los trocares permite acceder en buenas condiciones a los quistes de los segmentos derechos y posteriores ${ }^{14}$. Coincidimos con Ramia ${ }^{15}$ quien afirmó que la cirugía laparoscópica debe cumplir la misma radicalidad que la cirugía abierta. Entendemos 
que la vía de abordaje laparoscópica debe respetar los principios básicos del tratamiento de la hidatidosis hepática ya enunciados en el capítulo correspondiente.

Como ya lo desarrolláramos en el capítulo de tratamiento médico, el albendazol debe ser indicado 30 días previos a la cirugía y continuarse posteriormente por dos meses.

La técnica, americana o francesa es determinada por la preferencia del cirujano. Para los quistes del segmento VI es aconsejable el decúbito lateral izquierdo ya que brinda una mejor exposición. Consideramos muy conveniente la posición para la adrenalectomía derecha ya que se adecua perfectamente a esta situación. Se debe tener presente, de acuerdo a la exploración intraoperatoria la posibilidad de movilizar al paciente con la finalidad de mejorar la exposición.

El neumoperitoneo se puede realizar con técnica cerrada o abierta (Hasson). La presión intraabdominal recomendada es de 12 a $15 \mathrm{~mm}$ de $\mathrm{Hg}{ }^{11}$, 16 . Bickel ${ }^{17}$ demostró que la presión transmembrana generada por el neumoperitoneo no determina mayor riesgo de derrame del líquido hidatídico al momento de la punción.

Berberoðlu ${ }^{18}$ comunicó su experiencia con el tratamiento sin neumoperitoneo. Para ello utilizó un dispositivo de elevación de la pared abdominal en 51 pacientes y lo comparó con un grupo de 26 en que utilizó dióxido de carbono. La única diferencia estadísticamente significativa entre ambos a favor del primer grupo fue el tiempo operatorio, 50 versus 70 minutos.

El emplazamiento de los trocares debe adecuarse a la topografía del quiste. Inicialmente se coloca uno de $10 \mathrm{~mm}$ en la región umbilical para la óptica y luego dos $10 \mathrm{~mm}$, a derecha e izquierda de éste para el cirujano, y un cuarto $5 \mathrm{~mm}$ para la retracción hepática. No se debe dudar en colocar otros trocares de acuerdo a los hallazgos intraoperatorios. Los trocares deben ser seleccionados teniendo en cuenta la posibilidad de cambiar de posición la óptica, de forma de optimizar la visualización del campo quirúrgico de acuerdo a la circunstancia.

Es aconsejable el uso de un cámara de 30․ Luego de realizar la exploración visual y de acuerdo a la valoración imagenológica pre e intraoperatoria (ecografía), de existir riesgos previsibles de sangrado, es aconsejable cargar el pedículo hepático para el control vascular mediante la maniobra de Pringle.

Katkhouda ${ }^{19}$ protege la cavidad peritoneal colocando 2 compresas embebidas en suero hipertónico alrededor del quiste que se introducen a través de los trocares de $10 \mathrm{~mm}$. Pinto ${ }^{12}$ lo hace con agua oxigenada. Estas son marcadas con material radiopaco y se les fija un hilo de nylon para facilitar su extracción ${ }^{19}$.

Con respecto a la evacuación y esterilización del quiste, diversas alternativas se han propuesto.

La punción, evacuación y esterilización por vía percutánea realizada a través del trayecto más corto, transhepático y en lo posible aprovechando la existencia de adherencias parietales del quiste para evitar la siembra peritoneal.

Otra opción es la punción y aspiración percutánea transperitoneal guiada en forma laparoscópica. Para ello la aguja debe poseer una conexión a un sistema de aspiración permanente y otra vía para la instilación de sustancia escolicida. Dos aspiradores - previendo la obstrucción de uno de ellos - deben asegurar la aspiración de líquido hidatídico que pueda fugar en la punción.

Precisamente para minimizar el riesgo de ocurrencia de esta temida complicación múltiples han sido los dispositivos diseñados.

Bickel ${ }^{17}$ en un modelo experimental selló con cianoacrilato el sitio de punción del trócar.

Palanivelu ${ }^{8}$ ideó un trocar de $12 \mathrm{~mm}$ y $29 \mathrm{~cm}$ de longitud que permite a través de una cánula cuyo extremo distal piramidal, la punción y aspiración del contenido del quiste. Consta de dos canales laterales. Uno para la aspiración continua accesoria a la que se realiza a través de la cánula y otro para realizar neumoperitoneo en la cavidad.

Bickel ${ }^{20,21}$ y Aarons ${ }^{22}$ utilizan un aspirador cónico. Mompean ${ }^{23}$ un catéter de 6 Fr. Es criticado ya que no logra el objetivo de evitar la fuga de líquido hidático que ocurre al momento de la inserción. 
Al-Sareef ${ }^{16}$ punciona el quiste con una aguja de Silverman de $12 \mathrm{Fr}$ y la conecta a un equipo de liposucción. Dispone de otro aspirador en la proximidad de sitio de punción para aspirar el líquido que pueda fugar. Inyecta iodopovidona al 10\% que deja actuar por 10 a 15 minutos. Luego a través de un trócar de $10 \mathrm{~mm}$ colocado en el sitio de punción de la aguja de Silverman, pasa un drenaje de tórax de 24 Fr y vuelve a conectar el dispositivo de liposucción para aspirar el contenido y luego vuelve a instilar iodopovidona. aspirarlo.

Avtan ${ }^{24}$ utiliza una cuchilla rotaroria que permite triturar el contenido del quiste y luego

Otras variantes han sido comunicadas por Saðlam, Alpert, Kayaalp, Zengin, y Seven 25-29.

La vasta experiencia nacional con la utilización del trocar de Ochsner y el aspirador de Finochietto, lo transforma en una opción válida para su aplicación al procedimiento laparoscópico. El mismo debe emplearse junto a otro aspirador próximo al sitio de punción del quiste para evitar posibles derrames de líquido hidatídico en la cavidad peritoneal.

Finalizada esta etapa se realiza la apertura de la cavidad, se aspira el contenido remanente y se explora en busca de fugas biliares que pueden evidenciarse espontáneamente o con la instilación de azul de metileno por vía trasncística ${ }^{13}$. Su existencia puede ser resuelta mediante rafia. De no comprobarse se instila solución parasiticida que se deja actuar por 10 a 15 minutos y se aspira.

Con respecto al tratamiento de la adventicia, los procedimientos más utilizados son la resección de la emergente y la periquistectomía parcial ${ }^{16}$.

La periquistectomía total se reserva para quistes pequeños, parcialmente calcificados, periféricos y sobre la cara anterior del hígado. Busić ${ }^{30}$ a pesar de su limitada experiencia (3 casos) la considera una buena opción en pacientes seleccionados. Se recomienda la utilización de bisturí armónico, sellador de vasos o bisturí eléctrico monopolar irrigado con agua ${ }^{31}$. La ligadura de estructuras vasculares y biliares de mayor diámetro es factible realizarlas con clips, suturas mecánicas o puntos de sutura.

La hepatectomía izquierda en quistes de segmentos II y III es una alternativa válida. Este procedimiento representó el 13,7\% (9 casos) de la serie de Palanivelu ${ }^{32}$. Foster ${ }^{8}$ la considera factible si se aplican los mismos criterios técnicos expresados para la periquistectomía total.

En los procedimientos conservadores muchos autores realizan la omentoplastia. Altini ${ }^{33}$ afirma que con ella se disminuyen las complicaciones vinculadas a la cavidad residual y por ello la empleó en forma sistemática.

La utilización de drenajes periquísticos es optativa luego de la omentoplastia. Cuando no se efectuó se puede dejar intracavitario ${ }^{16}$.

Tanto la pieza como las compresas deben retirarse en bolsa de nylon para evitar la siembra en los sitios de abordaje.

Los procedimientos radicales son los que cumplen todos los criterios de tratamiento de la equinococosis hidatídica hepática. Consideramos que la experiencia adquirida en resecciones videoasistidas de tumores benignos, malignos y metástasis hepáticas, deben ser la base sobre la cual se sustente el tratamiento quirúrgico integral - periquistectomías y resecciones hepáticas - de esta zoonosis ${ }^{18,34-37}$.

Como alternativa se ha utilizado la técnica asistida con la mano, ya que en opinión de Bensaadi ${ }^{38}$ brinda mayor seguridad, facilita la intervención y disminuye los riesgos de derrame de líquido hidatídico en cavidad peritoneal. Como hechos a destacar desde el punto de vista técnico, el dispositivo para la mano izquierda del cirujano se coloca a través de una incisión transversa de $6 \mathrm{~cm}$ en hipocondrio derecho que permite la colocación de compresas para protección de la cavidad peritoneal y luego su extracción en bolsa de nylon al igual que los restos parasitarios. Gastaca ${ }^{39}$ considera que es una buena opción para realizar cirugías radicales.

Los buenos resultados de esta cirugía resultan de la correcta selección de pacientes y la táctica quirúrgica. Esta fue la conclusión de Baltar Boilève ${ }^{13} \mathrm{al}$ analizar sus complicaciones. Consideró no adecuado el intento de realizar una periquistectomía total en un quiste grande estrechamente vinculado a la vena cava inferior, que sangró y debió convertir. 
CIRUGÍA LAPAROSCOPICA

Los resultados de las mayores series son las siguientes (Tabla 1):

Tabla 1. Resultados de la cirugía laparoscópica en el tratamiento del quiste hidático hepático.

\begin{tabular}{|c|c|c|c|c|c|c|c|c|}
\hline Autor & $\begin{array}{l}\text { Número } \\
\text { de } \\
\text { pacientes }\end{array}$ & $\begin{array}{l}\text { Complicaciones } \\
(\%)\end{array}$ & $\begin{array}{l}\text { Mortalidad } \\
\text { (\%) }\end{array}$ & \begin{tabular}{|l|} 
Conversiones \\
$(\%)$
\end{tabular} & $\begin{array}{l}\text { Tiempo } \\
\text { operatorio } \\
\text { (minutos) }\end{array}$ & $\begin{array}{l}\text { Dias de } \\
\text { internación }\end{array}$ & $\begin{array}{l}\text { Seguimiento } \\
\text { (meses) }\end{array}$ & $\begin{array}{l}\text { Recurrencia } \\
(\%)\end{array}$ \\
\hline $\begin{array}{l}\text { Berberoglu } \\
1999^{18}\end{array}$ & 87 & 26,4 & - & - & & 3 & $3-36$ & 0 \\
\hline $\begin{array}{l}\text { Khoury } \\
2000^{40}\end{array}$ & 79 & 11 & - & 3 & & 3 & $4-54$ & 3,6 \\
\hline Chen 2007 & 76 & 6,5 & - & - & & 7,6 & $6-38$ & 0 \\
\hline $\begin{array}{l}\text { Palanivelu } \\
2006^{8}\end{array}$ & 75 & 16,5 & - & $=$ & & - & 70 & 0 \\
\hline $\begin{array}{l}\text { Acarli } \\
2004 \text { \&2 }\end{array}$ & 60 & 21,7 & & 13 & & & $42-132$ & 3 \\
\hline $\begin{array}{l}\text { Secchi } \\
2010^{43}\end{array}$ & 47 & 19 & & & & & $12-48$ & 4,2 \\
\hline $\begin{array}{l}\text { Rooh-ul- } \\
\text { Muqim } \\
2011^{44}\end{array}$ & 43 & 7 & & 7 & 46 & & & 4,6 \\
\hline $\begin{array}{l}\text { Sinha } \\
2001^{11}\end{array}$ & 42 & 14 & & 2,3 & & 3,2 & 54 & 0 \\
\hline $\begin{array}{l}\text { Cassone } \\
2007^{45}\end{array}$ & 40 & 22,5 & & & & 4,5 & 36 & 2,5 \\
\hline $\begin{array}{l}\text { Maazoum } \\
2007^{45}\end{array}$ & 34 & 0 & & & & 5 & $12-45$ & 0 \\
\hline $\begin{array}{l}\text { Ertem } \\
2002^{4}\end{array}$ & 33 & 6 & 0 & 4 & 82 & 4,2 & $4-78$ & 0 \\
\hline $\begin{array}{l}\text { Bickel } \\
2001^{21}\end{array}$ & 31 & 19 & 3,2 & 3,3 & & 6 & $9-97$ & 0 \\
\hline $\begin{array}{l}\text { Yagci } \\
2005^{7}\end{array}$ & 30 & 13,3 & & 0 & & 8 & $8-22$ & 3,3 \\
\hline $\begin{array}{l}\text { Seven } \\
2000^{20}\end{array}$ & 30 & 22 & & 23 & & 6 & $3-72$ & 4,3 \\
\hline $\begin{array}{l}\text { Georgescu } \\
2005^{47}\end{array}$ & 24 & 50 & & 25 & & 6 & 0 & \\
\hline${ }_{48}^{\text {Alper } 1995}$ & 22 & 25 & & 27 & & 8 & $2-17$ & 0 \\
\hline $\begin{array}{l}\text { Kayaalp } \\
2002^{27}\end{array}$ & 19 & 0 & & 0 & & & $3-24$ & 0 \\
\hline $\begin{array}{l}\text { Baskaran } \\
2004^{49}\end{array}$ & 18 & 56 & & 11 & & 4 & $12-36$ & 11 \\
\hline $\begin{array}{l}\text { Manterola } \\
2002^{50}\end{array}$ & 8 & 0 & & & & 2 & $23-44$ & 0 \\
\hline $\begin{array}{l}\text { Katkhouda } \\
1999^{19}\end{array}$ & 7 & & & 14 & 179 & & 30 & 0 \\
\hline $\begin{array}{l}\text { Busić } \\
2006^{30}\end{array}$ & 6 & 0 & & & 67,5 & 5 & 0 & \\
\hline $\begin{array}{l}\text { Ramos } \\
\text { Fernández } \\
2011^{51}\end{array}$ & 4 & & 0 & & & & & \\
\hline
\end{tabular}


Morbilidad, osciló entre 0 y 56\%, mortalidad: 0 y 3,2\%, conversiones: 0 y $27 \%$, estadía hospitalaria: 2 y 8 días, tiempo operatorio: 46 y 179 minutos, recidivas: 0 y $11 \%$, con seguimientos entre 2 y 132 meses $4,7,8,18,20,29,40-51$.

En relación a las recurrencias Yagci ${ }^{7}$ comunicó su experiencia de 10 años. La misma fue similar para la cirugía laparoscópica y PAIR 3,3\% y 3,5\% respectivamente, en tanto el de la cirugía convencional ascendió a 16,2\%.

Según Pinto ${ }^{12}$ los costos son similares a los de la cirugía convencional considerando pacientes sin complicaciones postoperatorias. Este autor reportó cifras de 2.107 US\$ para la cirugía laparoscópica y 2.045 para la convencional.

Múltiples trabajos consideran que el abordaje laparoscópico es seguro y factible en casos seleccionados. Sin embargo hacen falta series amplias y controladas para conocer los resultados a largo plazo ${ }^{9,52-53}$.

La revisión sistemática llevada a cabo por Dziri ${ }^{54}$ estableció que el abordaje laparoscópico es seguro con un nivel de evidencia IV y grado de recomendación C.

Manterola ${ }^{55}$ en una nueva revisión sistemática, concluyó en base a trabajos caracterizados por el reducido número de pacientes incluidos y el empleo de diversas técnicas quirúrgicas, que la evidencia sobre la eficacia del tratamiento videolaparoscópico es baja en relación a la cirugía convencional.

\section{Referencias bibliográficas.}

1. Katkhouda N, Fabiani P, Benizri E, Mouiel J. Laser resection of a liver hydatid cyst under videolaparoscopy. Br J Surg. 1992;79(6):560-1.

2. Torres Amorín M. Tratamiento del quiste hidático hepático. Estado actual. Cir Uruguay. 2002;72(2):98-123.

3. Oddone H, Cochi B. Tratamiento de la equinococosis hidatídica en humanos. XXIII Congreso Mundial de Hidatidología. Colonia del Sacramento. Uruguay. 2009;52.

4. Ertem M, Karahasanoglu T, Yavuz N, Erguney S. Laparoscopically treated liver hydatid cysts. Arch Surg. 2002;137(10):1170-3.

5. Yaghan R, Heis H, Bani-Hani K, Matalka I, Shatanawi N, Gharaibeh K, et al. Is fear of anaphylactic shock discouraging surgeons from more widely adopting percutaneous and laparoscopic techniques in the treatment of liver hydatid cyst?. Am J Surg. 2004;187(4):533-7.

6. Khoury G, Jabbour-Khoury S, Soueidi A, Nabbout G, Baraka A. Anaphylactic shock complicating laparoscopic treatment of hydatid cysts of the liver. Surg Endosc. 1998 May;12(5):452-4.

7. Yagci G, Ustunsoz B, Kaymakcioglu N, Bozlar U, Gorgulu S, Simsek A, et al. Results of surgical, laparoscopic, and percutaneous treatment for hydatid disease of the liver: 10 years experience with 355 patients. World J Surg. 2005;29(12):1670-9.

8. Palanivelu C, Senthilkumar R, Jani K, Rajan PS, Sendhilkumar K, Parthasarthi R, et al. Palanivelu hydatid system for safe and efficacious laparoscopic management of hepatic hydatid disease. Surg Endosc. 2006;20:1909-13.

9. Cugat E, Olsina JJ, Rotellar F, Artigas V, Suárez MA, Moreno-Sanz C, et al. Resultados iniciales del Registro Nacional de Cirugía Hepática por Laparoscopía. Cir Esp. 2005;78(3):152-60.

10. Strauss M, Schmidt J, Boedeker H, Zirngibl H, Jauch KW. Laparoscopic partial pericystectomy of Echinococcus granulosus cysts in the liver. Hepatogastroenterology. 1999;46(28):2540-44.

11. Sinha R, Sharma M. Abdominal Hydatids: A Minimally Invasive Approach. JSLS (2001)5:237-40.

12. Pinto P, Vallejos C, Cruces E, Lobos J, Hernández F, Ríos M et al. Tratamiento laparoscópico del quiste hidatídico hepático. Rev Chil Cir. 2011;63(4):361-67. www.scielo.cl/pdf/rchcir/v63n4/art05.pdf.

13. Baltar Boilève J, Baamonde De La Torre I, Concheiro Coello P, García Vallejo LA, Brenlla González J, Escudero Pérez B, et al. Tratamiento laparoscópico de los quistes hidatídicos hepáticos: técnicas y complicaciones postoperatorias. Cir Esp. 2009;86(1):33-7.

14. Baltar Boiléve J, Baamonde de La Torre I, Concheiro Coello P, García Vallejo LA. Respuesta de los autores. Cir Esp. 2010;88(1):61-4.

15. Ramia Angel JM, Figueras Felip J. Hidatidosis hepática: ¿qué cirugía debemos realizar?. Cir Esp. 2010;88(1):1-2. 


\section{CIRUGÍA LAPAROSCOPICA}

16. Al-Shareef Z, Hamour OA, Al-Shlash S, Ahmed I, Mohamed AA, MBBS. Laparoscopic Treatment of Hepatic Hydatid Cysts With a Liposuction Device. JSLS (2002)6:327-30.

17. Bickel A, Daud G, Urbach D, Lefler E, Barasch EF, Eitan A. Laparoscopic approach to hydatid liver cysts. Is it logical? Physical, experimental, and practical aspects. Surg Endosc. $1998 ; 12(8): 1073-7$.

18. Berberoðlu M, Taner S, Dilek ON, Demir A, Sari S. Gasless vs gaseous laparoscopy in the treatment of hepatic hydatid disease. Surg Endosc. 1999;13(12):1195-8.

19. Katkhuda N, Hurwitz M, Gugenheim J, Mavor E, Mason RJ, Waldrep DJ, et al. Laparoscopic management of benign solid and cyst lesions of the liver. Ann Surg. 1999;229(4):460-6.

20. Bickel A, Loberant N, Shtamler B. Laparoscopic treatment of hydatid cyst of the liver: initial experience with a small series of patients. J Laparoendosc Surg. 1994;4(2):127-33.

21. Bickel A, Loberant N, Singer-Jordan J, Goldfeld M, Daud G, Eitan A. The laparoscopic approach to abdominal hydatid cysts: a prospective nonselective study using the isolated hypobaric technique. Arch Surg. 2001;136(7):789-95.

22. Aarons $B$ J. Kune G A. A suction cone to prevent spillage during hydatid surgery. Aust $N Z$ J Surg. 1983;53:471-2.

23. Mompean JAL, Paricio PP, Camprs RR, Ayllowo GG. Laparoscopic treatment of a liver hydatid cyst. Br J Surg. 1993;80:907-8.

24. Avtan L. A new «Perforator Grinder-Aspirator Apparatus (PGAA)» for the minimal access surgery of cystic liver hydatidosis. Hepatogastroenterology. 2005;52(62):339-42.

25. Saðlam A. Laparoscopic treatment of liver hydatid cysts. Surg Laparosc Endosc. 1996;6(1):16-21.

26. Alper A, Emre A, Hazar H, Ozden I, Bilge O, Acarli K, et al. Laparoscopic surgery of hepatic hydatid disease: initial results and early follow-up of 16 patients. World J Surg. 1995;19(5):725-8.

27. Kayaalp C. Evacuation of hydatid liver cysts using laparoscopic trocar. World J Surg. $2002 ; 26(11): 1324-7$.

28. Zengin K, Unal E, Karabicak I, Apaydin B, Taskin M. A new instrument, the «Perfore-Aspirator» for laparoscopic treatment of hydatid cysts of the liver. Surg Laparosc Endosc Percutan Tech. 2003;13(2):80-2.

29. Seven R, Berber E, Mercan S, Eminoglu L, Budak D. Laparoscopic treatment of hepatic hydatid cysts. Surgery. 2000; 128:36-40.

30. Busić Z, Lemac D, Stipanciæ I, Busić V, Cavka M, Martic K. Surgical treatment of liver echinococcosis the role of laparoscopy. Acta Chir Belg. 2006;106(6):688-91 .

31. Takács I, Szerafin T, Kotán R, Kovács J, Sápy P. Laparoscopic resection of intraoperatively diagnosed parasitic cyst of the liver with the use of harmonic scalpel. Magy Seb. 2004;57(4):219-23.

32. Foster EN, Hertz G. Echinococcus of the liver treated with laparoscopic hepatectomy. Perm J. 2010;14(2):45-6.

33. Altinli E, Saribeyoglu K, Pekmezci S, Uras C, Tasçi H, Akçal T. An effective omentoplasty technique in laparoscopic surgery for hydatid disease of the liver. JSLS. 2002;6(4):323-6.

34. Gagner M, Rheault M, Dubuc J. Laparoscopic partial hepatectomy for liver tumor. Surg Endosc. 1992;6:99.

35. Kaneko H, Tsuchiya M, Otsuka Y, Yajima S, Minagawa T, Watanabe M, et al. Laparoscopic hepatectomy for hepatocellular carcinoma in cirrhotic patients. J Hepatobiliary Pancreat Surg. 2009;16(4):433-8.

36. Casaccia M, Famiglietti F, Andorno E, Di Domenico S, Ferrari C, Valente U. Simultaneous laparoscopic anterior resection and left hepatic lobectomy for stage IV rectal cancer. JSLS. 2010;14(3):414-7.

37. Gigot JF, Glineur D, Azagra JA, Goergen M, Ceuterick M. Laparoscopic liver resection form malignant liver tumors preliminary results of a multicenter european study. Ann Surg. 2002;236:90-7

38. Bensaadi H, Champault G. Laparoscopic Hand-Assisted Surgery for Hydatid Cysts of the Liver. Surg Laparosc Endosc Percutan Tech. 2004;14(2):91-2.

39. Gastaca M, Ventoso A, González J, Ortiz De Urbina J. Cirugía laparoscópica del quiste hidatídico hepático. Cir Esp. 2010;88(1):62.

40. Khoury G, Abiad F, Geagea T, Nabout G, Jabbour S. Laparoscopic treatment of hydatid cyst of the liver and spleen. Surg Endosc. 2000;14:243-5.

41. Chen WBA, Xusheng LBA. Laparoscopic surgical techniques in patients with hepatic hydatid cyst. Am J Surg. 2007;194:243-7.

42. Acarli K. Controversies in the laparoscopic treatment of hepatic hydatid disease. HPB. 2004;6:213-21.

43. Secchi M, Pettinari R, Mercapide C, Bracco R, Castilla C, Cassone E, et al. Surgical management of liver hidatidosis: a multicentre series of 1412 patients. Liver Inter. 2010;30:85-93.

44. Rooh-ul-Muqim, Kamran K, Khalil J, Gul T, Farid S. Laparoscopic treatment of hepatic hydatid cyst. J Coll Physicians Surg Pak. 2011;21(8):468-71. 
45. Cassone E, Faccas J, Cassone E, Godoy C, Zambudio M, Riste F. Tratamiento laparoscópico de hidatidosis hepática y esplénica. Rev Arg Cir. 2007;93:235-46.

46. Maazoun K, Mekki M, Chioukh F, Sahnoun L, Ksia A, Jouini R, et al. Laparoscopic treatment of hydatid cyst of the liver in children. A report on 34 cases. J Ped Surg. 2007;42:1683-6.

47. Georgescu S, Dubei L, Tarcoveanu E, Bradea C, Lazescu D. Minimally invasive treatment of hepatic hydatid cysts. Romanian Journal of Gastroenterology 2005;14:249-52.

48. Alper A, Emre A, Hazar H, Ozden I, Bilge O. Laparoscopic surgery of hepatic hydatid disease: Initial results and early follow-up of 16 patients. World J Surg. 1995;19:725-8.

49. Baskaran V, Patnaik P. Feasibilily and safety of laparoscopic management of hydatid disease of the liver. JSLS. 2004;8:359-63.

50. Manterola C, Fernández O, Muñoz S, Vial M, Losada H, Carrasco R, et al. Laparoscopic pericystectomy for liver hydatid cysts. Surg Endosc. 2002;16:521-4.

51. Ramos Fernandez M, Loinaz Segurola C, Fernandez Cebrian JM, Vega Lopez ML. Laparoscopic and hand-assisted liver resection: preliminary results at a mid-sized hospital. Hepatogastroenterology. 2011;58(106):492-6.

52. Chowbey PK, Shah S, Khullar R, Sharma A, Soni V, Baijal M, et al. Minimal access surgery for hydatid cyst disease: laparoscopic, thoracoscopic, and retroperitoneoscopic approach J Laparoendosc Adv Surg Tech A. 2003;13(3):159-65.

53. Gloor B, Ly Q, Candinas D. Role of laparoscopy in hepatic cyst surgery. Dig Surg. 2002;19(6):494-9.

54. Dziri C, Haouet K, Fingerhut A. Treatment of hydatid cyst of the liver: where is the evidence?. World J Surg. 2004 Aug;28(8):731-6.

55. Manterola C, Pineda V, Vial M. Efectividad del tratamiento laparoscópico de quistes y tumores hepáticos. Revisión global de la evidencia. Rev Chil Cir. 2007;59(4):264-71. 


\section{Procedimientos miniinvasivos}

\section{PUNCION, ASPIRACION, INYECCION Y REASPIRACION (PAIR).}

La punción, aspiración, inyección y reaspiración del contenido del quiste es considerada por numerosos autores como un tratamiento alternativo de la equinococosis hidática hepática no complicada. Esta técnica fue introducida por Mueller ${ }^{1}$ en el año 1985 cuando trató a una paciente con una recidiva de un quiste hidático hepático. Utilizó como escolicida nitrato de plata y suero hipertónico y la efectuó bajo guía radiológica A partir de ello la recomienda como alternativa a pacientes que no son candidatos a cirugía.

En 1988 Garavelli $^{2}$ destaca las cualidades de la ecografía como guía para el tratamiento percutáneo de los quistes hidáticos.

Nuestro país no fue ajeno a las experiencias que se comunicaron en la literatura internacional. En el año 1993 Larre Borges aplicó en el Hospital de Clínicas el tratamiento miniinvasivo. Se indicó a pacientes portadores de quistes tipo I y II de la clasificación de Gharbi. La cobertura con derivados benzimidazólicos se realizó en forma previa y posterior al procedimiento. Se utilizó guía ecográfica para la punción y evacuación del contenido del quiste. Luego de haber descartado la fístula biliar mediante quistografía se procedió a la inyección de alcohol al 95\% que se aspiró a los 30 minutos. Finalmente se colocó un drenaje para la realización de lavados y control endoscópico (coledocoscopio) de la cavidad en forma ambulatoria ${ }^{3}$.

Posteriormente Oddone ${ }^{4}$ comunicó en el año 2009, durante el XXIII Congreso Mundial de Hidatidología, Ilevado a cabo en Colonia del Sacramento, Uruguay, la experiencia del tratamiento del quiste hidático hepático en el departamento de Paysandú en el período 2005 - 2008, donde trató dos casos mediante punción percutánea.

Las indicaciones del procedimiento son precisas.

1. Pacientes inoperables o que no aceptan tratamiento quirúrgico.

2. Como alternativa a la recidiva del tratamiento quirúrgico o ante la no respuesta al tratamiento médico.

3. Existe consenso en aplicar la clasificación ecográfica de Gharbi o su modificación propuesta por la Organización Mundial de la Salud para la selección de pacientes. Se benefician de este procedimiento los de tipo I, II y III o CE1, CE2, CE3 ${ }^{5}$. Gupta ${ }^{6}$ en un análisis retrospectivo de una serie de 52 pacientes, afirmó que este procedimiento debe reservase para los casos más favorables, es decir los quistes tipo I y II. Kabaalioðlu ${ }^{7}$ avaló estos conceptos. En su serie reportó resultados favorables en el $100 \%$ de los quistes tipo I y $39 \%$ en los de tipo III. En el metanálisis realizado por Smego ${ }^{8}$ se incluyen quistes tipo IV. Precisamente, una modificación de la técnica PAIR, la punción evacuación (PEVAC) que utiliza un catéter de mayor calibre permite el tratamiento de los quistes tipo III ${ }^{9}$.

4. Quistes múltiples sin son accesibles.

Si bien Ustunsoz ${ }^{10}$ comunicó el tratamiento exitoso de 6 embarazadas mediante PAIR y sin cobertura con albendazol, la experiencia no es suficiente para indicarla en esta población así como en niños menores de 3 años.

Las contraindicaciones surgen de las características de los quistes y el terreno del paciente. Con respecto al primer punto, los quistes que cumplan con alguna de estas condiciones deben ser excluidos de esta modalidad terapéutica: 
1. quistes hepáticos superficiales por el riesgo que significa su rotura y consecuente siembra peritoneal.

2. quiste en topografía inaccesible.

3. quistes que posean contenido heterogéneo.

4. quistes calcificados.

5. quistes con comunicación con la vía biliar. Bajo esta última circunstancia la inyección de cloruro de sodio puede determinar una colangitis esclerosante, por lo que se impone el estudio del líquido hidatídico en busca de bilis previo a la instilación de la sustancia escolicida. El considerable porcentaje de quistes con comunicación biliar llevó a Odriozola ${ }^{11}$ a limitar la técnica a punción, aspiración y colocación catéteres de drenajes. A los 7 días, $90 \%$ de los 18 quistes tratados se abscedaron, habiéndose resuelto la totalidad con lavados y antibioticoterapia. Los resultados fueron comparables con aquellos en los cuales se empleó la técnica PAIR.

Con respecto al terreno del paciente, toda enfermedad que determine trastornos de la crasis (coagulopatías, cirrosis, etc), así como la inmnodepresión excluyen a los pacientes para este procedimiento.

Se recomienda la utilización de benzimidazoles en forma previa y posterior al procedimiento. La revisión bibliográfica permite objetivar la diferencia existente en relación al tiempo de administración. Cuando se trata de albendazol esta varía desde 4 horas a 10 días previos. Para el mebendazol entre 2 y 10 días. Posteriormente al procedimiento el albendazol ha sido administrado desde 15 días a 6 meses, en tanto el mebendazol desde 10 días a 3 meses ${ }^{5,12-16}$.

La Organización Mundial de la Salud recomienda el tratamiento previo por 4 días y luego continuarlo por 1 mes con albendazol o 3 meses con mebendazol.

Como ventajas del procedimiento se citan: menor morbilidad, tiempo de hospitalización y costos en relación a la cirugía ${ }^{17}$.

Al igual que en la cirugía las complicaciones más frecuentes son la anafilaxia, hemorragia, derramamiento del líquido hidatídico en cavidad peritoneal, colangitis escleorsante, súbita despresurización del quiste y consecuente fístula biliar. Filici ${ }^{5}$ sobre 231 quistes tratados reportó una fístula biliar a consecuencia de la proximidad del quiste con la vesícula biliar que requirió resolución quirúrgica.

La morbilidad comunicada en diversos trabajos osciló entre 1,1 y $64 \%$. En referencia a este último valor, cabe aclarar que las mismas fueron consideradas leves, habiendo correspondido el $39 \%$ de ellas a fiebre, y las restantes: $3 \%$ hematoma en el sitio de punción, $3 \%$ urticaria y $19 \%$ hidrotórax ${ }^{18}$ 19. La mortalidad varió entre 0,9 y $1,3 \%{ }^{15,20}$.

Desde el punto de vista técnico, este procedimiento debe ser realizado por cirujanos o en su defecto ser integrante del equipo que lo realiza. Su presencia garantiza la resolución de posibles complicaciones.

Requiere del cumplimiento de las máximas condiciones de asepsia. El sitio de abordaje (intercostal o anterior) se adecua a la topografía del quiste y luego de definirlo se infiltra la zona con anestesia local. Mediante guía ecográfica o tomográfica ${ }^{21}$ se avanza sobre el parénquima hepático hasta alcanzar el quiste. Se toma un tercio de su contenido y se envía a laboratorio para determinar la presencia de bilirrubina - su existencia implica suspender el procedimiento - e identificar protoescólices vivos mediante la observación en microscopio óptico utilizando tinción con rojo neutro al $1 \%$ y protoescólices muertos azul de metileno al 0,03\%.

Posteriormente se inyecta solución escolicida. Diversos productos se han reportado en la literatura. Alcohol al $95 \%{ }^{5}$, suero hipertónico solo o asociado a nitrato de plata ${ }^{16,22,23}$ o alcohol al $95 \%$ ${ }^{15}$, nitrato de plata ${ }^{24}$, mebendazol ${ }^{25}$, polidocanol al $1 \%{ }^{18}$, albendazol. Yetim ${ }^{26}$ en un trabajo experimental 
en conejos comparó resultados de tratamiento con alcohol y albendazol, encontrando mayor efecto escolicida y menos efectos secundarios en la esfera hepatobiliar con el empleo del albendazol.

El escolicida se deja actuar por un plazo de 10 a 15 minutos y luego se reaspira bajo control imagenológico. Se envía este líquido a laboratorio para el estudio de la viabilidad parasitaria.

Se recomienda dejar drenajes en los quistes tipo III y IV ya que permiten el lavado periódico de la cavidad, controlar la viabilidad de los elementos parasitarios y evaluar radiológicamente el tamaño o comunicaciones de la cavidad residual.

El seguimiento debe realizarse mediante controles clínicos, serológicos y ecográficos una vez por semana el primer mes, luego en forma mensual el primer año y finalmente en forma anual por 10 años.

Los resultados se miden de acuerdo a la respuesta clínica, imagenológica y serológica. sintomatología.

Son considerados resultados favorables desde el punto de vista clínico la desaparición de la

Desde el punto de vista imagenológico la tendencia a la degeneración del quiste. Esto se traduce en la reducción gradual de su tamaño, el desprendimiento de la membrana, reducción del número de vesículas hijas, cavidad residual con alto contenido de material ecogénico y finalmente la cicatrización. Este proceso ocurre en un período que oscila entre 6 meses y un año.

Finalmente, títulos menores a 1:160 y protoescólices no viables en el líquido extraído luego de la instilación del líquido hidatídico, indican el éxito terapéutico.

Las recidivas alcanzan al $3,5 \%{ }^{27}$. Crippa ${ }^{28}$ reportó un caso sobre 233 quistes tratados. Ocurrió a los 4 años de seguimiento y se resolvió nuevamente mediante PAIR.

Es de destacar que los resultados varían de acuerdo al número de quistes tratados en un paciente. Zerem ${ }^{29}$ comparó el resultado del tratamiento de quistes hidáticos hepáticos únicos y múltiples (2 y 3 quistes). Constató diferencias estadísticamente significativas en relación a la estadía hospitalaria y desaparición de anticuerpos circulantes a favor de los quistes únicos. No hubo diferencias vinculadas al diámetro final del quiste y su desaparición.

A pesar de las ventajas y buenos resultados comunicados de este procedimiento, la evidencia actual aún no permite confirmarla. Para ello analizaremos las revisiones sistemáticas y metanálisis existentes.

Smego ${ }^{8}$ realizó un metanálisis cuyo objetivo fue comparar la eficacia y seguridad de la técnica PAIR más albendazol o mebendazol versus cirugía radical o conservadora en pacientes portadores de equinococosis hidática. Se incluyeron los trabajos publicados en lengua inglesa desde 1985 a 2002. Excepto dos ensayos clínicos aleatorizados, los restantes trabajos fueron serie de casos.

Fueron incluidos 769 pacientes en el brazo de PAIR más albendazol o mebendazol y 952 en el de cirugía. Los resultados se presentan en la tabla 1.

Concluye que la técnica PAIR es un procedimiento que tiene mayor eficacia clínica y parasitológica, menor morbimortalidad y días de internación que la cirugía. Afirma que es el tratamiento de elección luego del fracaso del tratamiento médico, quedando la cirugía como opción ante el fracaso de la técnica PAIR o en aquellos quistes infectados o con comunicación con la vía biliar.

Este trabajo ha recibido múltiples críticas, fundamentalmente vinculadas a su metodología.

Entre ellas: no se realizó una prueba de heterogeneidad de los estudios en busca de diferencias metodológicas entre los mismos. Este hecho es relevante, ya que su existencia, determina la necesidad de agruparlos y analizarlos en forma independiente.

No se aportaron datos acerca de las características de los pacientes y tipo de quistes que fueron intervenidos quirúrgicamente, y así determinar si los dos brazos del estudio eran comparables. 
Tabla 1. Resultados del tratamiento de la equinococosis hidatídica mediante la técnica PAIR y cirugía.

\begin{tabular}{|c|c|c|c|}
\hline Variable & PAIR & Cirugía & p \\
\hline $\begin{array}{c}\text { Complicaciones } \\
\text { mayores }\end{array}$ & $7,9 \%$ & $25,1 \%$ & $\mathrm{p}<0,0001$ \\
\hline $\begin{array}{c}\text { Absceso } \\
\text { intraabdominal }\end{array}$ & $0,4 \%$ & $3,6 \%$ & $\mathrm{p}<0,0001$ \\
\hline Infección cavidad & $2 \%$ & $6,6 \%$ & $\mathrm{p}<0,0001$ \\
\hline $\begin{array}{c}\text { Fístula biliar } \\
\text { menores }\end{array}$ & $4,4 \%$ & $14,7 \%$ & $\mathrm{p}<0,0001$ \\
\hline $\begin{array}{c}\text { Complicaciones } \\
\text { Fiebre }\end{array}$ & $13,1 \%$ & $33 \%$ & $\mathrm{p}<0,0001$ \\
\hline Reacción alérgica & $4,8 \%$ & $0,1 \%$ & $\mathrm{p}<0,0001$ \\
\hline $\begin{array}{c}\text { Complicaciones } \\
\text { pulmonares }\end{array}$ & $0,1 \%$ & $3,4 \%$ & $\mathrm{p}<0,0001$ \\
\hline Infección herida & - & $6,6 \%$ & $\mathrm{p}<0,0001$ \\
\hline Hemorragia & $0,1 \%$ & $1,3 \%$ & $\mathrm{p}<0,008$ \\
\hline Peritonitis & - & $6,4 \%$ & $\mathrm{p}<0,0001$ \\
\hline Tomado de Smego ${ }^{8}$. & & & \\
\hline
\end{tabular}

Finalmente fueron diversos los procedimientos quirúrgicos empleados.

Estos elementos no permiten determinar con claridad si fueron comparables las poblaciones estudiadas y por tanto concluir sobre la efectividad de un procedimiento sobre otro.

Dziri ${ }^{30}$ realizó una revisión sistemática que dentro de sus diversos objetivos planteó determinar la indicación de la PAIR. Concluye con un nivel de evidencia ll y grado de recomendación B, que ésta asociada a albendazol es segura y eficiente en pacientes seleccionados.

A esta revisión también se le han realizado diversas críticas. En primer lugar haber incluido diversos objetivos, no abordando una cuestión clínica precisa sino varias de gran extensión, constituyendo cada una de ellas un tema para una revisión sistemática particular.

No define claramente las medidas de resultado ni las considera adecuadamente.

No es posible concluir si la revisión fue sistemática ya que no se pudo identificar un protocolo publicado y evaluado por pares.

Estos aspectos han llevado a catalogar este trabajo como una excelente revisión narrativa pero no sistemática.

Finalmente Nasseri Moghaddam ${ }^{31}$ realizó otra revisión sistemática cuyo objetivo fue evaluar los beneficios y daños de la técnica PAIR con o sin cobertura con benzimidazol versus ninguna intervención, técnica de simulación de la técnica PAIR, cirugía o tratamiento médico para pacientes portadores de quistes hidáticos hepáticos no complicados.

Los criterios de selección para el de tipo de trabajos a incluir fueron: ensayos clínicos aleatorizados que comparen la técnica PAIR con las restantes técnicas, independientemente del 
cegamiento, idioma o estadio de la publicación. En base a esto sólo dos ensayos clínicos fueron incluidos.

De ellos, uno comparó la técnica PAIR con o sin albendazol oral $(n=20)$ versus albendazol oral $(n=10){ }^{10}$. El otro, comparó la técnica PAIR $(n=25)$ versus tratamiento quirúrgico $(n=25)^{12}$. Ambos lo hicieron con pacientes portadores de equinococosis hidática hepática no complicada.

El trabajo que comparó la técnica de PAIR con o sin albendazol con albendazol, constó de 3 brazos: PAIR ( $n=10$ quistes), PAIR más albendazol ( $n=12$ quistes) y únicamente albendazol $(n=11$ quistes).

Los síntomas mejoraron en todos los pacientes tratados con PAIR, en tanto en el grupo tratado con albendazol respondió el $20 \%$.

Los cambios ecográficos compatibles con la pérdida de la viabilidad ocurrieron en el $100 \%$ de los casos tratados con la técnica PAIR, en tanto ocurrió esto en el 18,2\% de los tratados con albendazol. La máxima reducción del tamaño de los quistes se observó en los pacientes tratados con PAIR más albendazol.

En estos dos aspectos analizados los resultados mostraron una diferencia estadísticamente significativa a favor de la técnica de PAIR en relación al tratamiento con albendazol.

La mortalidad fue nula en todos los grupos, en tanto las complicaciones para el grupo tratado con PAIR fueron: infección del quiste en 2 casos (10\%), fiebre en $3(15 \%)$, comunicación biliar $1(5 \%)$ y urticaria en 2 (10\%). Tres de los pacientes tratados con albendazol (15\%) presentaron elevación reversible de las enzimas hepáticas.

Los resultados del estudio que comparó la técnica PAIR con cirugía no encuentran diferencias en relación a mortalidad que fue nula en ambos grupos, en el diámetro final del quiste y títulos de anticuerpos parasitarios circulantes en un seguimiento de 17 meses.

Se constataron diferencias estadísticamente significativas en relación a complicaciones, 32\% PAIR versus $84 \%$ cirugía. En este aspecto se debe señalar que 17 de las 21 complicaciones del grupo de cirugía fue fiebre.

Igualmente la estadía hospitalaria fue favorable para la técnica PAIR con 4,2 días versus 12,7 días para la cirugía.

Ninguno de los estudios evaluó el costo efectividad de los diferentes procedimientos.

Diversos aspectos de estos ensayos clínicos han sido criticados, especialmente metodológicos. En este sentido la generación de la secuencia de la asignación y el método de cegamiento fueron inciertos. Se considera que el número de pacientes es insuficiente para llegar a una conclusión válida. El período de seguimiento fue menor a 18 meses en ambos estudios, por lo cual la tasa de recurrencia y complicaciones a largo plazo no fueron evaluadas.

En base a ello, Nasseri Moghaddam ${ }^{31}$ concluye que el tratamiento de los quistes hidáticos hepáticos no complicados mediante la técnica PAIR con o sin cobertura con benzimidazol puede ser equivalente o superior a la cirugía o al tratamiento con benzimidazoles solos, pero los datos no son suficientes para plantear conclusiones definitivas. Por lo tanto no es posible recomendar su uso fuera de los ensayos clínicos aleatorios. Es necesario realizar ensayos clínicos aleatorios adicionales bien diseñados para abordar el tema.

Esta recomendación aún no ha tenido respuesta. Los trabajos publicados posteriormente a la revisión sistemática continúan siendo comunicaciones de serie de casos ${ }^{6,32,33}$.

\section{RADIOFRECUENCIA.}

La radiofrecuencia es un procedimiento miniinvasivo alternativo que se ha empleado en forma percutánea o en el intraoperatorio previo a la quistectomía. Su aplicación produce la destrucción de la membrana germinal o prolígera al igual que el contenido del quiste. A pesar de las ventajas atribuidas 
(no utilización de: escolicida, dilatadores, drenajes e inyección de medio de contraste) y no haberse reportado complicaciones ni recurrencia, el reducido número de casos comunicados con cortos períodos de seguimiento, exige mayor investigación para dilucidar su eficiencia en el tratamiento de la equinococosis hepática ${ }^{34-37}$.

\section{Bibliografía consultada.}

Guidelines for treatment of cystic and alveolar echinococcosis.Informal Working Group on Echinococcosis. Bull World Health Organ 1996;74(3):231-42.

World Health Organization. PAIR: puncture, aspiration, injection, re-aspiration: an option for the treatment of cystic echinococcosis. [En línea]. Ginebra, Suiza: WHO; [2001]. [Acceso 26 de octubre de 2011]. URL: http://www.who.int/csr/en/.

\section{Referencias bibliográficas.}

1. Mueller PR, Dawson SL, Ferrucci JC Jr, Nardi GR. Hepatic echinococcal cyst: successful percutaneous drainage. Radiology. 1985;155(3):627-8.

2. Garavelli PL. Echography in the diagnosis and therapy of hepatic hydatidosis. Minerva Med. 1988;79(4):257-9.

3. Torres Amorín M. Tratamiento del quiste hidático hepático. Estado actual. Cir Uruguay. 2002;72(2):98123.

4. Oddone $\mathrm{H}$, Cochi B. Tratamiento de la equinococosis hidatídica en humanos. En: XXIII Congreso Mundial de Hidatidología. Colonia del Sacramento. Uruguay, 2009. p.52

5. Filice C, Brunetti E. Use of PAIR in human cystic echinococcosis. Acta Trop. 1997;64(1-2):95-107.

6. Gupta N, Javed A, Puri S, Jain S, Singh S, Agarwal AK. Hepatic Hydatid: PAIR, Drain or Resect?. J Gastrointest Surg. 2011;15(10):1829-36.

7. Kabaalioðlu A, Ceken K, Alimoglu E, Apaydin A. Percutaneous imaging-guided treatment of hydatid liver cysts: do long-term results make it a first choice?. Eur J Radiol. 2006;59(1):65-73.

8. Smego RA Jr, Bhatti S, Khaliq AA, Beg MA. Percutaneous aspiration-infection-reaspiration drainage plus albendazole or mebendazole for hepatic cystic echinococcosis: a meta-analysis. Clin Infect Dis. 2003;37(8):1073-83.

9. Schipper HG, Laméris JS, van Delden OM, Rauws EA, Kager PA. Percutaneous evacuation (PEVAC) of multivesicular echinococcal cysts with or without cystobiliary fistulas which contain non-drainable material:first results of a modified PAIR method. Gut. 2002;50(5):718-23.

10. Ustunsoz B, Ugurel MS, Uzar Al, Duru NK. Percutaneous treatment of hepatic hydatid cyst in pregnancy: long-term results. Arch Gynecol Obstet. 2008;277(6):547-50.

11. Odriozola M, Pettinari R. Relato Oficial. Hidatidosis abdominal. 69o Congreso Argentino de Cirugía. Rev Arg Cir. 1998;(No. Extra):9-70

12. Khuroo MS, Dar MY, Yattoo GN, Zargar SA, Javaid G, Khan BA, et al. Percutaneous drainage versus albendazole therapy in hepatic hydatidosis: a prospective, randomized study. Gastroenterology 1993; 104(5):1452-9.

13. Gargouri M, Ben Amor N, Ben Chehida F, Hammou A, Gharbi HA, Ben Cheikh M, et al. Percutaneous treatment of hydatid cysts (Echinococcus granulosus).. Cardiovasc Intervent Radiol.1990; 13(3):169-73.

14. Khuroo MS, Wani NA, Javid G, Khan BA, Yattoo GN, Shah AH, et al. Percutaneous drainage compared with surgery for hepatic hydatid cysts. N Engl J Med. 1997; 337(13):881-7.

15. Men S, Hakimoglu B, Yucesoy C, Arda IS, Baran I. Percutaneous treatment of hepatic hydatid cysts: an alternative to surgery. AJR Am J Roentgenol. 1999; 172(1):83-9.

16. Odev K, Paksoy Y, Arslan A, Aygün E, Sahin M, Karaköse S, et al. Sonographically guided percutaneous treatment of hepatic hydatid cysts: long-term results. J Clin Ultrasound. 2000;28(9):469-78.

17. Salama HM, Ahmed NH, El Deeb N, Ahmed R. Hepatic hydatid cysts: sonographic follow-up after percutaneous sonographically guided aspiration. J Clin Ultrasound. 1998;26(9):455-60.

18. Ormeci N, Soykan I, Bektas A, Sanoðlu M, Palabiyikoðlu M, Hadi Yasa M, et al. A new percutaneous approach for the treatment of hydatid cysts of the liver. Am J Gastroenterol. 2001;96(7):2225-30. 
19. Gavrilin AV, Kuntsevich GI, Vishnevski VA, Ikramov RZ, Zhurenkova TV, Burtseva EA, et al. Ultrasoundassisted puncture method of treatment of hepatic hydatid cysts. Khirurgiia (Mosk). 2002;(8):39-46.

20. Giorgio A, Tarantino L, de Stefano G, Francica G, Mariniello N, Farella N, et al. Hydatid liver cyst: an 11-year experience of treatment with percutaneous aspiration and ethanol injection. J Ultrasound Med. $2001 ; 20(7): 729-38$.

21. Peláez V, Kugler C, del Carpio M, Correa D, López E, Larrieu E, et al. Treatment of hepatic hydatid cysts by percutaneous aspiration and hypertonic saline injection: results of a cooperative work. Bol Chil Parasitol. 1999;54(3-4):63-9.

22. Peláez V, Kugleer C, Correa D, Del Carpio M, Guangiroli M, Molina J, et al. PAIR as percutaneous treatment of hydatid liver cysts. Acta Trop 2000; 75(2):197-202.

23. Tan A, Yakut M, Kaymakcioglu N, Ozerhan IH, Cetiner S, Akdeniz A. The results of surgical treatment and percutaneous drainage of hepatic hydatid disease. Int Surg 1998; 83(4):314-6.

24. Aygün E, Sahin M, Odev K, Vatansev C, Aksoy F, Paksoy Y, et al. The management of liver hydatid cysts by percutaneous drainage. Can J Surg. 2001;44(3):203-9.

25. Erzurumlu K, Sahin M, Selcuk MB, Yildiz C, Kesim M. Intrasytic application of mebendazole solution in the treatment of liver hydatid disease. Preliminary report of two cases. Eur Surg Res 1996;28(6):466-70.

26. Yetim I, Erzurumlu K, Hokelek M, Baris S, Dervisoglu A, Polat C, et al. Results of alcohol and albendazole injections in hepatic hydatidosis: experimental study. J Gastroenterol Hepatol. 2005;20(9):1442-7.

27. Yagci G, Ustunsoz B, Kaymakcioglu N, Bozlar U, Gorgulu S, Simsek A, et al. Results of surgical, laparoscopic, and percutaneous treatment for hydatid disease of the liver: 10 years experience with 355 patients. World J Surg. 2005;29(12):1670-9.

28. Crippa FG, Bruno I, Brunetti E, Filice C. Echinococcal liver cysts: treatment with echo-guided percutaneous puncture PAIR for echinococcal liver cysts. Ital J Gastroenterol Hepatol. 1999;31 (9):884-92.

29. Zerem E, Jusufovic R. Percutaneous treatment of univesicular versus multivesicular hepatic hydatid cysts. Surg Endosc. 2006;20(10):1543-7.

30. Dziri C, Haouet K, Fingerhut A. Treatment of hydatid cyst of the liver: where is the evidence?. World J Surg. 2004;28(8):731-6.

31. Nasseri-Moghaddam S, Abrishami A, Taefi A, Malekzadeh R. Percutaneous needle aspiration, injection, and re-aspiration with or without benzimidazole coverage for uncomplicated hepatic hydatid cysts. Cochrane Database Cochrane Database Syst Rev. 2011;19(1):CD003623.

32. Yasawy MI, Mohammed AE, Bassam S, Karawi MA, Shariq S. Percutaneous aspiration and drainage with adjuvant medical therapy for treatment ofhepatic hydatid cysts. World J Gastroenterol 2011;17(5):646-50

33. El Sheikh A, Al Malki A, El Shiekh MA, Al Robayan A. Non-surgical management in 336 patients of hydatid disease: 23 years experience at Riyadh Military Hospital. Hepatogastroenterology 2011:58(106):336-46.

34. Papaconstantinou I, Kontos M, Prassas E, Karavokyros J, Bakoyiannis C, Pikoulis E, et al. Radio frequency ablation (RFA)-assisted pericystectomy for hepatic echinococcosis: an alternative technique. Surg Laparosc Endosc Percutan Tech. 2006;16(5):338-41.

35. Sahin M, Kartal A, Haykir R, Cakir M. RF-assisted cystectomy and pericystectomy: a new technique in the treatment of liver hydatid disease. Eur Surg Res. 2006;38(2):90-3.

36. Zacharoulis D, Poultsidis A, Roundas C, Tepetes K, Hatzitheofilou C. Liver hydatid disease: radiofrequencyassisted pericystectomy. Ann R Coll Surg Engl. 2006;88(5):499-500.

37. Brunetti E, Filice C. Radiofrequency thermal ablation of echinococcal liver cysts. Lancet $2001 ; 358: 1464$. 


\section{CAPÍTULO 13}

\section{Recidiva o recurrencia}

Manterola ${ }^{1}$ define a la recurrencia como la aparición de hidatidosis abdominal en cualquier localización luego de un año de la cirugía.

Pinto ${ }^{2}$ en el análisis de los factores vinculados con la recidiva, estableció como principales: el empleo de técnicas no radicales, persistencia de cavidades residuales fértiles y la contaminación del sitio quirúrgico con líquido hidatídico. Este autor también hace referencia a aquellos que pasaron inadvertidos en la valoración preoperatoria o durante la intervención quirúrgica. Porras ${ }^{3}$ la plantea entre «signos de interrogación» como causa de reintervención en su casuística. Si bien esta situación es infrecuente en el momento actual dada la resolución de las diferentes técnicas imagenológicas, consideramos no debe ser incluida como recidiva o recurrencia y debe ser catalogada como una persistencia. El término persistencia o falsa recidiva también es empleado para definir a aquellos quistes que aparecen y aumentan de tamaño en los sucesivos controles en el sitio quirúrgico original ${ }^{4}$.

Es preciso aclarar el término de recidiva epidemiológica, el cual hace referencia a la aparición de un quiste en una persona ya operada y libre de enfermedad, que al reintegrarse a su medio contrae nuevamente la enfermedad. También se la conoce como recidiva por reinfestación.

De acuerdo a la literatura la recurrencia oscila entre 0,9\% y 19,2 \% 1, 2, 5-16 (Tabla 1).

Tabla 1. Recurrencia de la equinococosis hidatídica hepática de acuerdo al tiempo de seguimiento.

\begin{tabular}{|c|c|c|}
\hline Autor & Porcentaje de recidiva & $\begin{array}{c}\text { Tiempo de } \\
\text { seguimiento (meses) }\end{array}$ \\
\hline Manterola $^{1}$ & 0,9 & $13-132$ \\
\hline Hidalgo Pascual $^{16}$ & 2 & - \\
\hline Safioleas $^{5}$ & $\overline{44,5}$ & - \\
\hline Kapan $^{6}$ & 4,65 & $25-84$ \\
\hline Perdomo $^{7}$ & 6 & - \\
\hline Prousalidis $^{8}$ & 6,5 & - \\
\hline Silva $^{9}$ & 7 & - \\
\hline Magistrelli ${ }^{10}$ & 9,6 & 36 \\
\hline Wang $^{11}$ & 10 & $12-60$ \\
\hline Aeberhard $^{12}$ & 11 & $8-150$ \\
\hline Pinto $^{2}$ & 11,5 & - \\
\hline Civil $^{13}$ & 12 & 108 \\
\hline Gilevich $^{14}$ & 14,3 & - \\
\hline Coiro $^{15}$ & 18,8 & - \\
\hline Atmatzidis $^{16}$ & 19,2 & 120 \\
\hline
\end{tabular}


Especial mención merece el trabajo de Hidalgo Pascual ${ }^{17}$ que con una casuística de 6834 intervenciones comunicó $2 \%$ de recidivas.

Motivo de controversia, objetivable en las diversas experiencias comunicadas, lo constituyen los factores determinantes de la recidiva.

En relación al tipo de técnica empleada, algunos autores preconizan los procedimientos radicales en virtud del menor porcentaje de recidivas en relación a los procedimientos conservadores. Pinto ${ }^{18}$ comunicó una recurrencia de $1,4 \%$ para los procedimientos radicales y $7,4 \%$ para los conservadores. En las guías clínicas de la Asociación Española de Cirujanos ${ }^{19}$ se establecen recurrencias menores a $2 \%$ para la cirugía radical en relación a 15 y $25 \%$ para la conservadora.

Sin embargo existen trabajos en los cuales no se han reproducido los resultados anteriores. Prousalidis ${ }^{8}$ concluye que la técnica empleada al igual que la administración de albendazol, localización y tamaño del quiste no tiene vinculación con la recidiva. Considera como factor excluyente la rigurosidad y meticulosidad técnica. A igual conclusión arriba Bülbüller ${ }^{20}$. Odriozola ${ }^{4}$ en base a la aplicación de diferentes pruebas estadísticas agrega que no existen diferencias significativas entre el tipo de procedimiento quirúrgico, presentación clínica (asintomático - sintomático) y el regreso a una zona endémica, y la recidiva. Ocurrió lo contrario en relación a: la edad del paciente (aumentó en menores de 40 años), tiempo transcurrido desde la cirugía (aumentó 5,5 veces en pacientes con menos de 10 años de operados), momento en el cual se normalizaron las pruebas serológicas $(29,5 \%$ mayor cuando ocurrió luego de los 24 meses), estado evolutivo del quiste (los complicados tuvieron 1,7 veces más recidivas) y la persistencia de cavidad residual en los controles ecográficos (incrementó las recidivas 1,6 veces). Este último aspecto lo confirmó Wang ${ }^{10}$ al informar en su trabajo que las recidivas ocurrieron en las cavidades residuales. Esto se vincula a la vesiculización intraadventicial o exógena pura a partir de la adventicia remanente, o en su defecto por la persistencia de una cavidad residual fértil a consecuencia de no haber logrado la esterilización completa del quiste.

Con respecto al tiempo de seguimiento así como el intervalo en que es recomendable realizar los controles de los pacientes que han sido tratados, es variable de acuerdo al análisis de la literatura. Sin embargo 5 años parecería ser el tiempo mínimo recomendable haciéndolo a intervalos de 3, 6 o 12 meses. Manterola ${ }^{1}$ realiza un primer control al mes del tratamiento quirúrgico, luego a los 6 y 12 meses, posteriormente en forma anual.

El mismo debe sustentarse en 3 pilares, clínico, serológico e imagenológico. La determinación de inmunoglobulinas IgG4 e lgE mediante la técnica de ELISA, y desde el punto de vista imagenológico ecografía abdominal.

El tratamiento de elección es la cirugía radical. Nardo ${ }^{21}$ trató 33 pacientes que previamente habían recibido un tratamiento conservador. En 53 meses de seguimiento no hubo recurrencia, habiendo sido la mortalidad nula, ascendiendo las complicaciones intraoperatorias a $6 \%$ y las postoperatorias a $12 \%$. Los procedimientos miniinvasivos y la administración de benzimidazólicos deberían ser reservados para aquellos casos en que la cirugía plantee elevados riesgos, ya sea por la topografía del quiste o terreno del paciente. Aeberhard ${ }^{11}$ en la revisión del seguimiento de pacientes operados, comunicó que el único paciente de la serie con una recidiva que operó, falleció a consecuencia de un shock anafiláctico.

\section{Referencias bibliográficas.}

1. Manterola C, Moraga J, Urrutia S. Morbilidad postoperatoria en pacientes con hidatidosis hepática no complicada. Utilización de una propuesta de clasificación de complicaciones. Rev Chil Cir. 2010;62(4):362-68.

2. Pinto P, Redondo J, Rossi E, Bravo G, Silva F, Aguayo C. Recurrencia postoperatoria de la enfermedad hidatídica. Rev Chil Cir. 1989;41(1):74-7.

3. Porras Y. Complicaciones hepatobiliares de la hidatidosis. Cir Uruguay. 1973;43(6):479.

4. Odriozola M, Pettinari R. Relato Oficial. Hidatidosis abdominal. 69 Congreso Argentino de Cirugía. Rev Arg Cir. 1998;(No. Extra):47.

5. Safioleas M, Misiakos E, Manti C, Katsikas D, Skalkeas G. Diagnostic evaluation and surgical management of hydatid disease of the liver. World J Surg. 1994;18(6):859-65. 
6. Kapan M, Kapan S, Goksoy E, Perek S, Kol E. Postoperative recurrence in hepatic hydatid disease. J Gastrointest Surg. 2006;10(5):734-9.

7. Perdomo R, Parada R, Alvarez C, Cattivelli D, Geninazzi H, Barragué A, et al. Estudio epidemiológico de hidatidosis. Detección precoz por ultrasonido en áreas de alto riesgo. Rev Med Urug. 1990;6(1):34-47.

8. Prousalidis J, Kosmidis C, Anthimidis G, Fachantidis E, Harlaftis N, Aletras H. Forty-four years' experience (1963-2006) in the management of primarily infected hydatid cyst of the liver. HPB (Oxford). 2008;10(1):18-24.

9. Silva MA, Mirza DF, Bramhall SR, Mayer AD, McMaster P, Buckels JA. Treatment of hydatid disease of the liver. Evaluation of a UK experience. Dig Surg. 2004;21(3):227-33.

10. Magistrelli P, Masetti R, Coppola R, Messia A, Nuzzo G, Picciocchi A. Surgical treatment of hydatid disease of the liver. A 20-year experience. Arch Surg. 1991;126(4):518-22.

11. Wang Y, Zhang X, Bartholomot B, Liu B, Luo J, Li T, et al. Classification, follow-up and recurrence of hepatic cystic echinococcosis using ultrasound images. Trans R Soc Trop Med Hyg. 2003;97(2):203-11.

12. Aeberhard $P$, Fuhrimann $R$, Strahm $P$, Thommen A. Surgical treatment of hydatid disease of the liver: an experience from outside the endemic area. Hepatogastroenterology. 1996;43(9):627-36.

13. Civil ID, Dempsey EF. Hydatid disease at a peripheral hospital: a review of 25 years' experience. N Z Med J. 1981;94(698):447-8.

14. Gilevich Mlu, Gilevich luS, Porfisenko VN, Tsyrkunov SI, Proskurov AP, Skvortsov AS, et al. Recurrent and residual echinococcosis. Khirurgiia (Mosk). 1990;(12):64-70.

15. Coiro M, Deleón G. Tratamiento de la hidatidosis hepática en Paysandú. Diagnóstico de situación. Cir Uruguay. 1999;69(1-2):82-7.

16. Atmatzidis KS, Pavlidis TE, Papaziogas BT, Mirelis C, Papaziogas TB. Recurrence and long-term outcome after open cystectomy with omentoplasty for hepatic hydatid disease in an endemic. Acta Chir Belg. 2005;105(2):198-202.

17. Hidalgo Pascual M, Barquet Esteve N. Hidatidosis hepática. Estudio de una serie de 7.435 casos. Parte II: Tratamiento quirúrgico, morbimortalidad, tratamiento médico, hospitalizaciones e implicaciones socioeconómicas. Rev Esp Enf Ap Digest. 1987;71(2):103-09.

18. Pinto $P$, Torres $F$, Ríos $M$, Vallejos $C$. Tratamiento quirúrgico de la hidatidosis hepática: evaluación de las diferentes técnicas. Rev Chil Cir. 1994;46(6):637-42.

19. Abscesos y quistes hepáticos. En: Casanova D, Figueras J, Pardo F, editores. Cirugía hepática. Madrid: Arán; 2004. p. 95-123.

20. Bülbüller N, Ilhan YS, Kirkil C, Yeniçerioðlu A, Ayten R, Cetinkaya Z. The results of surgical treatment for hepatic hydatid cysts in an endemic area. Turk J Gastroenterol. 2006;17(4):273-8.

21. Nardo B, Patriti A, Piazzese E, Cavallari G, Montalti R, Beltempo P, et al. Radical surgical treatment of recurrent hepatic hydatidosis. Hepatogastroenterology. 2003;50(53):1478-81. 


\section{CAPÍTULO 14}

\section{Impacto económico y social de la enfermedad}

\section{IMPACTO ECONOMICO.}

El impacto económico producido por la equinococosis hidatídica se vincula a los gastos derivados: 1) del proceso asistencial de las personas afectadas por la enfermedad, 2) los costos por la no producción de dicha persona y 3) pérdidas en la producción nacional en relación al sector agropecuario determinadas por decomiso de vísceras, disminución de la producción de carne, leche, lana y fecundidad de las especies afectadas.

1) Gastos derivados del proceso asistencial. Los mismos se pueden analizar desde diversas perspectivas:

a) Número de días de internación. Purriel ${ }^{1}$ para el período 1962 - 1964 comunicó un promedio de 40 días para pacientes internados en centros asistenciales de la capital y 30 para el interior del país. En total representaron 34.262 días de hospitalización. Estas cifras son similares a las reportadas por Pavletic ${ }^{2}$ en Chile donde oscilaron entre 25 y 45 días. En este mismo país de acuerdo al anuario de egresos hospitalarios del Ministerio de Salud, en los años 1992 y 1993 se utilizaron 22.478 y 22.885 días cama, lo que representó un promedio de 18,4 y 17,7 días cama por paciente respectivamente.

En España, en la mayor serie publicada de casos tratados de equinococosis hidatídica hepática (6834 pacientes) el promedio fue de 40 días, de los cuales 26,4 correspondieron al período postoperatorio 3.

Estos valores son coincidentes con los del Hospital San Juan de Dios de Santiago de Chile, donde en el período 1990 - 1999, el promedio de internación fue de 17 días con un mínimo de 6 y máximo de $71^{4}$.

En Tucumán, Argentina, luego de la implementación de políticas de diagnóstico precoz de la enfermedad, el promedio de días de internación disminuyó de 34,5 a 19,1 días ${ }^{5}$. Esto se vinculó con el tratamiento de formas menos evolucionadas y no complicadas de la enfermedad.

b) Los gastos determinados por la asistencia de estos pacientes representan un importante impacto económico en los sistemas de salud.

En los países integrantes del Proyecto Subregional Cono Sur de Control y Vigilancia de la Hidatidosis, el promedio de gastos en pacientes intervenidos quirúrgicamente fue de US\$4.440, en cambio aquellos que recibieron tratamiento médico fue US\$1.400, considerando cinco ciclos de 30 días de albendazol ${ }^{6}$.

En Chile se determinó que el costo mínimo en la asistencia de un paciente operado de hidatidosis hepática no complicada ascendió a US\$ 880, en comparación con US\$4.483 para un caso complicado. El promedio fue de US\$1465. Dentro de los estudios paraclínicos, los exámenes generales representaron el mayor porcentaje en gastos, seguidos por la TAC y estudios bacteriológicos.

Con respecto a la utilización de medicamentos, los antibióticos representaron un valor promedio de US $\$ 5,3$ y los restantes fármacos US $\$ 3,5^{4}$.

Para el año 1997 se estimó en más de un millón de dólares el costo sólo por el concepto días - camas $^{2}$.

En Perú el costo anual del tratamiento quirúrgico asciende a US\$836.064 ${ }^{6}$.

2) En la experiencia chilena el costo por licencia médica ascendió a US\$127 ${ }^{4}$. Las pérdidas monetarias considerando el costo de diagnóstico y tratamiento de la enfermedad y pérdida de salarios en los países del Cono Sur de América ascendieron a US\$14.900.479 ${ }^{6}$. 
En Perú la pérdida de productividad de los casos que recibieron tratamiento médico ascendió a US\$1.592.764 ${ }^{7}$.

Finalmente en España, en la década del 80 se perdieron 892.200 jornadas laborales vinculadas con el tratamiento de la equinococosis hidática hepática ${ }^{3}$.

3) Es de resaltar que América constituye el primer productor mundial de carne bovina y aviar, tercero de carne de cerdo y productos lácteos ${ }^{6}$. Se estima que las pérdidas en el sector agropecuario - incluyendo decomiso de vísceras, disminución de la producción de carne, leche, lana y fecundidad de las especies afectadas - en los países que conforman el Proyecto Subregional Cono Sur para el Control de la Hidatidosis (Argentina, Brasil, Chile y Uruguay) oscilaron entre 77.583 .576 y US\$ 115.888.134 ${ }^{6}$.

El número de hígados decomisados en el frigorífico Nacional en el período setiembre de 1964 y agosto de 1965 ascendió a 205.122, representando el 76,4\% de las reses faenadas. Esto significó la imposibilidad de comerciar en el mercado internacional $747.556 \mathrm{~kg}$ de hígado ${ }^{1}$.

En Latinoamérica se estima que el número de vísceras bovinas y ovinas decomisadas ascienden a 2.000 .000 y 3.500 .000 respectivamente ${ }^{8}$.

En Chile durante el período comprendido entre julio de 1992 y setiembre de 1993 las pérdidas por decomiso de vísceras y carnes ascendieron a US\$1.682.472, siendo la segunda causa de importancia económica de decomiso de vísceras en bovinos y la primera en ovinos y porcinos ${ }^{8}$.

En Argentina se decomisa un promedio de 25.000 toneladas de vísceras anualmente. En el año 1996 fueron 243.213 vísceras de bovinos y 224.000 de ovinos ${ }^{9}$.

En Perú las pérdidas por decomiso de vísceras ascendieron a US\$196.181, en tanto cuando se consideró las pérdidas totales en la producción fue de US\$3.846.754. Cuando se sumó los gastos de atención hospitalaria la cifra alcanzada fue de US\$6.357.027 7 .

En nuestro país se estimó un costo de US\$22.100.000 al año, considerando los gastos en atención hospitalaria y las pérdidas en la producción agropecuaria ${ }^{10}$.

En España para el año 2005, las pérdidas económicas totales atribuibles a la hidatidosis humana y animal fue de $€ 148.964 .534$, dentro de ellos las de origen humano fueron de $€ 133.416 .601$ y animal $€ 15.532 .242^{11}$.

\section{IMPACTO SOCIAL.}

Todos los trabajos analizados son elocuentes en demostrar el fuerte impacto que representa esta enfermedad en la economía del país en general y en forma particular sobre el paciente, la familia y los servicios de salud. No debemos restar valor a los costos intangibles y que en determinadas circunstancias adquieren igual o mayor peso que el económico, repercutiendo de manera significativa en la esfera sicológica, familiar y social del paciente.

Los costos sociales son difíciles de cuantificar y están definidos por el deterioro en la calidad de vida del paciente y su grupo familiar. Estos están determinados por largas internaciones, el desarraigo del hombre de campo, falta de contacto con sus bienes, desvinculación con los afectos y aislamiento de su contexto natural ${ }^{5}$.

Tomando en cuenta los DALY (Disability Adjusted Life Year) que representa una medida del daño producido por una enfermedad a nivel humano, la pérdida de años en los países integrantes del Proyecto Subregional Cono Sur de Control y Vigilancia de la Hidatidosis es de 1551,8. Mientras que si se suma la estimación de los casos no notificados esta asciende a 1759,9. Este indicador incluye en su fórmula: muerte prematura, morbilidad e incapacidad generada por la enfermedad.

En Perú esta cifra fue de 1139 ?

Guarnera, citado por Irabedra ${ }^{12}$ estimó una pérdida de 47407,43 años de vida saludable (AVISA) en Argentina en el período 1987 - 2005. 
Purriel ${ }^{1}$ en una encuesta sobre 367 pacientes operados, determinó que $60 \%$ eran incapaces de reintegrase a su trabajo o la rutina normal de su hogar antes de los cuatro meses del alta hospitalaria y el $40 \%$ seis meses o más.

A la luz de lo expresado y tal como lo afirma Lorca ${ }^{4}$, la apuesta hacia el refuerzo de políticas de prevención es el instrumento de mayor efectividad para derrotar este flagelo.

\section{MORTALIDAD.}

La hidatidosis, enfermedad «benigna» a la que la gente no teme como a la palabra «cáncer», ha demostrado en reiteradas oportunidades que puede ser tan destructiva como éste y poner en peligro la vida del paciente con hidatidosis complicada ${ }^{13}$.

La mortalidad en el período 1943 - 1964 osciló entre 1,3 y 2,5 / 100.000 habitantes, mostrando un descenso al final del mismo. Purriel ${ }^{14}$ sostiene que este fenómeno se vincula estrechamente con los adelantos en la técnica quirúrgica más que a la disminución del número de casos ${ }^{1}$. Esta tendencia descendente de la mortalidad se estabilizó en el período 1962 - 1971 donde osciló entre 0,9 y 1,5/ 100.000 habitantes. Un nuevo descenso se verificó en el año 2005 donde la tasa alcanzó la cifra de 1,3 $/ 1.000 .000$ de habitantes ${ }^{15}$.

La mortalidad quirúrgica reportada por Delgado ${ }^{16}$ en el año 1991 fue de 5,1\%. Trató 39 pacientes mediante cirugía radical.

González ${ }^{17}$ en 1999 comunicó una mortalidad de 0,76\%. Esta casuística estuvo constituida por 131 pacientes en los que mayoritariamente se les realizó procedimientos conservadores.

En Chile la mortalidad en el período 1989 - 1993 fue de 0,3 / 100.000 habitantes, con un letalidad de 6 a $8 \%{ }^{18}$.

En Tucumán Argentina la letalidad disminuyó de 2,6 a 1,3\% luego de la implementación de diagnóstico precoz ${ }^{5}$.

En el período 1987 - 2001 la tasa de mortalidad específica por hidatidosis en Argentina fue de 4,8 / 100.000 habitantes. La distribución por grupo etario correspondió: 9\% entre 1 y 29 años, 31\% entre 30 y 59 años, y $60 \%$ entre 60 y 89 años. La tasa de letalidad fue de 7,7\%. En tanto los años de vida perdidos prematuramente (AVPP) en el período 1987 - 1996 fueron 8.753. Este indicador permite reflejar el peso de la edad en que fallecen las personas, particularmente cuando las muertes son prematuras, considerando como tal aquellas que ocurren antes de alcanzar la edad promedio de esperanza de vida de la cohorte en ausencia de enfermedad ${ }^{19}$.

\section{Referencias bibliográficas.}

1. Purriel P, Staehle J, Tórtora H, Prantl ML. Hidatidosis en el Uruguay. Radiografía de un problema. El Tórax 1965;14(3):149-62.

2. Pavletic C. Situación de los países. Chile. En: Organización Panamericana de la Salud. Informe del Proyecto Subregional Cono Sur de control y vigilancia de la hidatidosis. Argentina, Chile, Brasil y Uruguay. Primera reunión constitutiva. Montevideo: OPS; 2004. p.34-8.

3. Hidalgo Pascual M, Barquet Esteve N. Hidatidosis hepática. Estudio de una serie de 7.435 casos. Parte II: Tratamiento quirúrgico, morbimortalidad, tratamiento médico, hospitalizaciones e implicaciones socioeconómicas. Rev Esp Enf Ap Digest. 1987;71(2):103-09.

4. Lorca M, Campanella R, Gavrilovics B, Lagos L, Florín C. Estimación de los costos totales y parciales de diagnóstico, tratamiento quirúrgico y seguimiento de la hidatidosis hepática en el Hospital San Juan de Dios, Santiago, Chile 1990-1999. Rev Chil Cir. 2003;55(1):60-4.

5. Remis JA, Guarnera EA, Parra A. Impacto de la hidatidosis. Influencia de factores ambientales y socioculturales en Tucumán, Argentina. RAR 2009;73(3):303-12.

6. Estimación del impacto económico de la equinococosis quística en el Cono Sur (Argentina, Brasil, Chile y Uruguay) 2007 [En línea] Roma, Italia: FAO/RLC; 2007. [Acceso 29 de setiembre de 2011]. URL: http:// ops-oms.org/spanish/ad/dpc/vp/hidatidosis-impacto-econ-07-fao.pdf. 
7. Moro PL, Budke CM, Schantz PM, Vasquez J, Santivañez SJ, Villavicencio J. Economic impact of cystic echinococcosis in Peru. PLoS Negl Trop Dis. 2011;5(5): e1179.

8. Schantz P, Chai J, Craig J, Ecker J, Jenkins DJ. Epidemiology and Control of Hydatid Disease. En:Thompson R, Lymberry A eds. Echinococcus and Hydatid disease. United Kingdom: Cab International; 1995. p. 233302.

9. Echegoyen MC. Situación de los países. Argentina. En: Organización Panamericana de la Salud. Informe del Proyecto Subregional Cono Sur de control y vigilancia de la hidatidosis. Argentina, Chile, Brasil y Uruguay. Primera reunión constitutiva. Montevideo: OPS; 2004. p.28-30

10. Torgerson P, Carmona C, Bonifacino R. Estimating the economic effects of cystic echinococcosis: Uruguay, a developing country with upper-middle income. Ann Trop Med Parasitol. 2004;94(7):703-13.

11. Benner C, Carabin H, Sánchez-Serrano L, Budkec C, Carmenad D. Analysis of the economic impact of cystic echinococcosis in Spain. Bull World Health Organ. 2010;88(1):49-57.

12. Irabedra P, Salvatella R. E Proyecto Subregional Cono Sur de Control y Vigilancia de la Hidatidosis. Rev Peru Med Exp Salud Publica. 2010; 27(4): 598-603.

13. Perdomo R, Parada R, Alvarez C, Cattivelli D, Geninazzi H, Barragué A, et al. Estudio epidemiológico de hidatidosis. Detección precoz por ultrasonido en áreas de alto riesgo. Rev Med Urug 1990;6:34-47.

14. Purriel P, Schantz PM, Beovide H, Mendoza B. Hidatidosis en el Uruguay: comparación de los índices de morbilidad y mortalidad, 1962-1971. Bol Of Sanit Panam. 1975;78(6):519-30.

15. Organización Panamericana de la Salud. Informe del Proyecto Subregional Cono Sur de Control y Vigilancia de la Hidatidosis Argentina, Brasil, Chile y Uruguay. Segunda Reunión. Santiago de Chile, Chile. 17 de marzo de 2005. Santiago de Chile: OPS;2005.p.25.

16. Delgado B. Tratamiento de la hidatidosis hepática por cirugía radical. Nuestra experiencia. Cir Uruguay. $1991 ; 61(1-2) ; 25-8$.

17. González D, Vega A, Monti J, Torres M. Enfermedad hidatídica hepática. Experiencia de los últimos 13 años en Florida. Cir Uruguay. 1999;69(3-4):200-3.

18. Serra I, Araneda J, Araya C, Serra V. Análisis regional de la hidatidosis humana y animal en Chile 19891993. Bol Chil Parasitol 1996;5:3-12.

19. Guarnera E. Hidatidosis humana, su impacto, diagnóstico, manejo y tratamiento. En: Organización Panamericana de la Salud. Informe del Proyecto Subregional Cono Sur de control y vigilancia de la hidatidosis. Argentina, Chile, Brasil y Uruguay. Primera reunión constitutiva. Montevideo: OPS; 2004. p.57-85. 


\section{CAPÍTULO 15}

\section{Control de la enfermedad}

La hidatidosis ha sido incluida por la OPS en el grupo de «enfermedades postergadas en las poblaciones postergadas». Este concepto hace referencia a la escasa trascendencia otorgada por los gobiernos para su prevención y control y por otro a las condiciones de vida de las poblaciones afectadas. Nuestro país ha sido ejemplo en el control de la enfermedad, sin embargo los estilos de vida y las características culturales de ciertas regiones, se erigen en factores primordiales en la perpetuación del ciclo biológico del Echinococcus granulosus. Así lo confirmó Perdomo ${ }^{1}$ estableciendo en base a 6027 encuestas sobre la faena domiciliaria de ovinos, que $19 \%$ las realiza sin poseer un carneadero cerrado. Con respecto al destino de las vísceras, sobre 1955 encuestados, 46,63\% mostró conductas incorrectas (Tabla 1). Posteriormente Equipos Consultores, estableció que $7 \%$ de los poseedores de canes los alimenta con vísceras crudas de ovinos ${ }^{2}$.

Tabla 1. Destino de las vísceras de animales faenados.

\begin{tabular}{|l|l|l|}
\hline Destino & $\mathrm{N}^{\circ}$ & $\%$ \\
\hline $\begin{array}{l}\text { Alimento de perros } \\
\text { (cruda) }\end{array}$ & 442 & 22,6 \\
\hline Se tiran perros & 511 & 16,21 \\
\hline Se entierran de & 317 & 7,82 \\
\hline $\begin{array}{l}\text { Alimento } \\
\text { (cocida) }\end{array}$ & 432 & 26,13 \\
\hline Alimento de cerdos & 100 & 22,09 \\
\hline Se queman & 1955 & 5,11 \\
\hline Total & 100 \\
\hline Tomado de Perdomo ${ }^{1}$. &
\end{tabular}

Otro ejemplo lo constituye la población de la región de Alta Montaña en la Provincia de Tucumán, Argentina, donde los perros se alimentan con achuras crudas, ya que el contexto socio económico determina que esta sea una de las pocas posibilidades que tienen los animales de subsistir. A esto debe sumarse que el hallazgo de quistes en animales faenados, representa en la cultura regional un buen augurio, prediciendo una buena parición de la hacienda ${ }^{3}$.

Otros aspectos vinculados con las costumbres en el medio rural de nuestro país son: que el $37,17 \%$ consume agua de fuentes no proveniente de OSE y sin hervir (Tabla 2 ) y $19 \%$ posee quintas no cercadas ${ }^{1}$.

El control de la enfermedad se remonta a 1864, momento en el cual se inició el primer programa que finalizó con su erradicación en Islandia. Sus pilares fueron el control de perros o su eliminación y el control sanitario de la matanza de animales para consumo cárnico ${ }^{4}$.

Devé, pionero en la detección precoz de la enfermedad, planteó en 1916 la instalación de dispensarios y utilización de unidades móviles en zonas de alta prevalencia. Afirmó que de esta manera, a pesar de que pudieran pasar desapercibidos muchos quistes, otros tantos se diagnosticarían en etapas precoces, aún no complicadas ${ }^{1}$. 
Tabla 2. . Fuente y forma de consumo de agua.

\begin{tabular}{|c|c|c|c|c|}
\cline { 2 - 5 } \multicolumn{1}{c|}{} & \multicolumn{3}{c|}{$\begin{array}{c}\text { Forma de } \\
\text { consumo }\end{array}$} \\
\hline & \multicolumn{3}{c|}{ Sin hervir } & Hervida \\
\hline Fuente & $\mathrm{N}^{\circ}$ & $\%$ & $\mathrm{~N}^{\circ}$ & 3,15 \\
\hline OSE & 3041 & 50,45 & 190 & 0,21 \\
\hline Arroyo & 49 & 0,81 & 13 & 0,61 \\
\hline Cachimba & 231 & 3,83 & 37 & 1,92 \\
\hline Pozo & 1196 & 19,84 & 116 & 2,2 \\
\hline Aljibe & 764 & 12,67 & 133 & 8,11 \\
\hline Total & 5281 & 87,62 & 489 & \\
\hline
\end{tabular}

Tomado de Perdomo ${ }^{1}$.

En América, Argentina y Uruguay fueron pioneros en programas estructurados de control. Durante el período 1970 - 1985 se llevó a cabo el Programa Piloto de Estudio y Lucha contra la Hidatidosis en la Provincia de Neuquén, y a partir de 1973 el Programa Piloto de Control de la Hidatidosis en el Departamento de Flores ${ }^{5}$.

El diseño de los primeros programas fue posible gracias al conocimiento del ciclo de vida del parásito y a la comprensión de la historia natural de la infección. En ellos se aplicó una estrategia vertical. Su objetivo es la eliminación del parásito a través del diagnóstico y tratamiento del huésped definitivo.

En nuestro país se llevó a cabo un plan de control que constó de 5 fases ${ }^{6}$ :

1 - Preparación y organización, efectuada en el año 1990.

2 - Diagnóstico, en 1991.

3 - Ataque, abarcó el período 1992 - 1996.

4 - Consolidación, comprendió el período 1997 - 2004.

5 - Vigilancia epidemiológica a partir de 2004.

Para ello se combinaron 2 estrategias: 1) vertical y 2) horizontal que busca mejorar la condición socioeconómica de la población con la finalidad de modificar los estilos de vida (educación, saneamiento, agua potable, controles de faenas).

Si bien se logró disminuir la prevalencia de la enfermedad en huéspedes intermediarios y definitivos, la evidencia demostró que el control de esta enfermedad, verdadero problema de salud pública, exige un abordaje interdisciplinario, multiprofesional, intersectorial y participativo, donde el empoderamiento de la sociedad es clave para su control. Villar ${ }^{7}$ sostiene que la participación social organizada e informada juega un papel fundamental en el éxito de los programas de control. Paolillo ${ }^{8}$ afirma que la participación de los jóvenes y su efecto multiplicador en la sociedad, es más efectiva que los métodos convencionales, tales como enseñanza curricular y propaganda por medios de difusión. Las acciones en la comunidad deben estar dirigidas a convertir a cada individuo en un agente de cambio ${ }^{9}$.

La actual estrategia de nuestro país incluye las siguientes líneas de acción ${ }^{10}$ : 
- Replanteo epidemiológico con revisión, rediseño e incremento de la cobertura de dosificación canina con praziquantel de acuerdo a la realidad epidemiológica de cada área, priorizando los focos de infección. Según la encuesta de Equipos Consultores ${ }^{2}, 27 \%$ de los encuestados refiere administrar antiparasitario a su perro todos los meses, $18 \%$ cada 2 o 3 meses, $32 \%$ todos los años, $5 \%$ con una frecuencia superior al año, $16 \%$ nunca lo realizó y $2 \%$ no contestó. Estos datos son similares a los reportados por Perdomo ${ }^{1}$ en los cuales el $65 \%$ de los entrevistados refirieron no administrar parasiticida, hacerlo irregularmente, en plazos mayores a los recomendados (45 días) o en dosis insuficientes de acuerdo al peso del animal. Estas cifras difieren sustancialmente con las aportadas por Paolillo ${ }^{8}$, en una investigación llevada a cabo en la ciudad de Sarandí del Yí del departamento de Durazno, donde sobre un total de 392 perros, $282(78 \%)$ recibieron praziquantel en tanto $110(28 \%)$ no se encontraban dosificados adecuadamente de acuerdo a la reglamentación nacional vigente. La baja captura de huéspedes definitivos constituye uno de los mayores problemas identificados a los que se enfrentan los programas. Según se desprende de un estudio efectuado España ${ }^{11}$, una proporción considerable de los perros escapa al tratamiento antihelmíntico, reduciendo la eficiencia del control. Esto se debe fundamentalmente a la numerosa población de perros callejeros existente en áreas endémicas. El costo de la desparasitación sistemática de los canes con praziquantel a una dosis de $5 \mathrm{mg} / \mathrm{kg}$ de peso, entre 8 y 12 desparasitaciones anuales, oscila entre 4.400 .000 y 8.140 .000 US $\$$ para los Programas de Control en el Cono Sur de América ${ }^{12}$.

- Detección de portadores asintomáticos de quistes hidáticos hepático mediante screening ecográfico. En el momento actual la Comisión Nacional Honoraria de Zoonosis lleva realizadas más de 100.000 ecografías ${ }^{13}$.

- Desarrollo y/o promoción de programas de tenencia responsable canina dentro de los cuales uno de los componentes debe ser el control de poblaciones mediante la esterilización quirúrgica de canes, como técnica sustentable en el tiempo, y ampliamente aceptada por la población ${ }^{14,15}$. Esta estrategia sustituyó la anterior de captura y matanza que realizaba la perrera. La Comisión de Zoonosis a través de sus dispensarios móviles ha realizado más de 100.000 castraciones ${ }^{13}$. La población de nuestro país considera como principal estrategia para reducir el número de perros sueltos en la calle, la castración $(77 \%)$, seguido por la captura y posterior sacrificio (8\%). La tenencia responsable de mascotas concebida como el conjunto de normas que los tenedores de animales de compañía deben observar en cumplimiento de una tenencia responsable de los mismos, es la estrategia que permite respetar los derechos de los animales y de las personas, para que las mascotas no les provoquen molestias o perjuicios. Las normas de bienestar animal supone entre otras: Libertad de hambre y sed, por lo cual no debería alimentarse a los animales con achuras crudas; Libertad de dolor, lesiones y enfermedades, para lo cual exige provisión de asistencia sanitaria preventiva, diagnósticos adecuados y tratamiento veterinario cuando sea requerido. Por la misma todos los animales deberían estar correctamente desparasitados. Sin embargo esto no es fácil de concretar y requiere la educación en valores. Hasta el momento, según Púrpura ${ }^{16}$ esto no se ha logrado dado el bajo nivel de confiabilidad y credibilidad de las autoridades sanitarias y de las Protectoras de Animales. En la encuesta de Equipos Consultores se determinó que el $17 \%$ de los entrevistados controlan a su perro con veterinario una vez por mes, $19 \%$ cada dos o tres meses, $24 \%$ una vez al año, $15 \%$ en períodos superiores al año y $25 \%$ nunca realizó una consulta ${ }^{2}$.

- Énfasis en el componente educativo priorizando las intervenciones directas en terreno, junto a las tareas de detección precoz de quistes hidáticos, sin dejar de lado otras estrategia de tipo formativo curricular. En este sentido se orienta la formación de veterinarios especialistas en Salud Pública ${ }^{17}$. Sobre el conocimiento de la hidatidosis, Perdomo ${ }^{1}$ investigó el grado de información y comportamiento de las personas sobre la trasmisión de la enfermedad hidatídica. Estableció que 44,7\% poseía una información suficiente, en tanto el 54,5\% no la tenía o era insuficiente. No existen datos sobre el restante porcentaje. En el año 1989, Paolillo ${ }^{8}$ hizo lo propio con 376 estudiantes del primer ciclo de enseñanza secundaria en Sarandí del Yí. Exploró aspectos generales de la enfermedad: ciclo del Echinococcus granulosus, vías de 
adquisición de la enfermedad en el ser humano, medidas de prevención vinculadas al perro, repercusiones sobre la producción ovina y bovina y repercusiones en la salud humana. Sobre un puntaje total de 30 puntos, el promedio fue de 7 . A esto se agrega que el $61,3 \%$ de los jóvenes consideró insuficiente su información con respecto a esta parasitosis y deseaban recibir mayor información. Se estimó que esta desinformación sería aún superior en la población general ya que un importante porcentaje no accede a la enseñanza secundaria. Años después la empresa Equipos Consultores encuestó a 900 personas. Ante la interrogante: ¿Que es la hidatidosis?, 41\% respondió que es una enfermedad que transmiten los perros, $30 \%$ es una enfermedad que produce quistes, $17 \%$ solo sabe que es una enfermedad, $5 \%$ responde otras cosas y $6 \%$ no sabe ${ }^{2}$.

- Compromiso de la comunidad en todas las etapas de desarrollo del programa. El acuerdo de trabajo firmado entre el Área de Psicología Educacional de la Facultad de Psicología y la Comisión Nacional Honoraria de Zoonosis, tiene como objetivo primordial lograr un cambio cultural en las personas que habitan las zonas de mayor prevalencia de la enfermedad para optimizar resultados en el combate a la hidatidosis ${ }^{18}$.

Irabedra ${ }^{10}$ considera que la cooperación entre países de la región es fundamental como instrumento para mejorar las capacidades institucionales en el logro de metas comunes de desarrollo. Precisamente los países del Cono Sur de América constituyen un ejemplo en este sentido, habiendo concretado en el año 2004 la primera reunión del Proyecto Subregional Cono Sur para el Control y Vigilancia de la Hidatidosis. Argentina, Brasil, Chile y Uruguay ${ }^{19}$. Desde entonces los avances del mismo vienen sido evaluados en sucesivas reuniones anuales ${ }^{20-26}$.

El espectro en el control de la enfermedad ha derivado hacia un enfoque más amplio que incluye entre otros: 1) vacunación de los hospederos intermediarios, 2) simulación de los impactos del control ${ }^{27}$.

1) En 1996 Heath ${ }^{28}$ demostró que una fracción de 25 kDa separada de un extracto antigénico de oncosferas mediante electroforesis en gel de poliacrilamida, inducía inmunidad protectora en el hospedero intermediario. En el mismo año, Lightowlers ${ }^{29}$, obtuvo una proteína recombinante de 16.5 kDa, a la cual denominó EG 95, y mezclándola con un adyuvante (saponina, Quil A o ISA70), logró proteger a ovinos contra el desarrollo de quistes hidáticos.

La vacuna EG95, es una preparación proteica purificada, no infecciosa, no tóxica, no contaminante, producida mediante ingeniería genética. Esta protege a los ovinos contra la primoinfección e infecciones repetitivas, alcanzando con una dosis una protección de $82 \%$, con dos $97 \%$ y tres $100 \%$ 30,31 .

Su efecto persiste por lo menos un año si es suministrada en dos dosis separadas por intervalos de 1 mes $^{32}$. Se transmite pasivamente a los neonatos y protege contra diferentes cepas de Echinococcus granulosus ${ }^{30}$. Tales características la han transformado en un valioso instrumento para el control de la transmisión de la hidatidosis.

Su evaluación en varias regiones de Argentina demostró que su uso permitirá: (a) disminuir el tiempo necesario para controlar la enfermedad en el territorio correspondiente, (b) acentuar la reducción de la oferta de quistes hidáticos a los hospederos definitivos, y (c) reducir la biomasa parasitaria disponible para los hospederos intermediarios, ayudando así a disminuir el riesgo de enfermar del ser humano ${ }^{33}$

2) Torgerson ${ }^{34}$ a través de la aplicación de un modelo de simulación por computadora, sugirió que es posible extender el intervalo habitual de 6 semanas entre cada dosis de antihelmíntico a períodos de tres meses, y reducir aún así a menos del 1\% las tasas de prevalencia en ganado y perros al cabo de 10 a 15 años. Un estudio de campo realizado en nuestro país ${ }^{35}$ determinó que la prolongación de los intervalos de tratamiento más allá del período prepatente no reduce su eficacia porque el tiempo promedio de reinfección supera largamente las seis semanas.

Las variaciones en el tratamiento han sido modeladas por Torgerson ${ }^{34}$ relacionando el uso de antihelmínticos con diferentes intervalos y la asociación de la vacunación de ovinos. Demostró que 
el tratamiento antihelmíntico cada tres meses origina muy buenos resultados a largo plazo, si al menos el $75 \%$ de la población canina (incluyendo los perros callejeros) fue tratada. En cambio con un intervalo a seis meses, es necesario cubrir más del $90 \%$ de la población canina, hecho que resulta imposible en la práctica. Sin embargo si se combina la vacunación con el tratamiento antihelmíntico, el modelo sugiere alta probabilidad de éxito si el tratamiento se efectúa con un intervalo de 6 meses cubriendo el $60 \%$ de los perros y vacunando el $60 \%$ de las ovejas.

Esto demuestra que las intervenciones simultáneas en varios puntos del ciclo de vida del parásito producen un efecto acumulativo, lo que vuelve aconsejable incorporar la vacunación de los ovinos a las estrategias de control, especialmente en los países de bajos ingresos que tienen altas tasas de prevalencia. Con el fin de justificar la puesta en marcha de programas más complejos conviene combinar los modelos de simulación con los de análisis costo/beneficio para determinar las pérdidas causadas por la enfermedad y compararlas con los gastos ocasionados por el control ${ }^{36}$.

Las acciones de control en nuestro país son llevadas a cabo por la Comisión Nacional Honoraria de Zoonosis. En el año 2008 realizó un estudio de situación en 13 pueblos con riesgo epidemiológico, con el objetivo de aplicar estrategias de promoción de salud y prevención de la hidatidosis ${ }^{37}$.

Esta constó de tres etapas: diagnóstico, intervención y evaluación.

En la primera, se recolectó muestra de materias fecales de canes para el diagnóstico de equinococosis con test ELISA y una encuesta sobre conocimiento y prácticas de la población.

En la fase de intervención se realizaron actividades educativas, castración de perros, dosificación canina con parziquantel, screening ecográfico en humanos y relevamiento de problemas sanitarios y ambientales de impacto en la trasmisión de la equinococosis.

La evaluación se llevó a cabo luego de un año. Evidenció una disminución en: 1) el número de perros infectados, 2) número de personas que manifestaron no carnear en domicilio para consumo y 3 ) la no dosificación de canes. Todas ellas con diferencias estadísticamente significativas.

Si bien la experiencia es alentadora, Giacoia ${ }^{38}$ considera que a pesar de haberse logrado disminuir el riesgo de enfermar, los resultados no han sido los esperados, ya que las personas tienen información pero no modifican su conducta, especialmente la de alimentar los canes con achuras. De aquí la necesidad de un promotor de salud especializado en zoonosis que complemente las actividades que ya se aplican en nuestro país.

La precepción de la población en referencia a la Comisión Nacional Honoraria de Zoonosis, fue evaluada a través de una encuesta que exploró diversos aspectos de su gestión y actividades. Ante la interrogante: ¿Ha escuchado hablar de la Comisión de Zoonosis?, las respuestas se dividieron por partes iguales, $50 \%$ respondieron afirmativamente y el restante $50 \%$ desconocen su existencia. La población más informada fue de sexo masculino, con una edad entre 30 y 60 años, residentes en Montevideo y nivel socioeconómico medio y alto.

En relación a la gestión, $87 \%$ respondió buena y muy buena, regular $12 \%$ y mala 1\%. A su vez $80 \%$ considera que la gestión ha mejorado, $17 \%$ que sigue igual y $3 \%$ que ha empeorado.

Con respecto a las actividades desarrolladas, la población identificó las siguientes: castración (80\%), administración de antiparasitarios a perros (78\%), realización de ecografías para diagnóstico de quiste hidático (71\%) captura y sacrificio de perros (15\%).

Finalmente sobre el cobro de patente para financiar las actividades de la Comisión, $75 \%$ lo consideró apropiado y muy apropiado, 3\% respondió como inapropiado o muy inapropiado y $22 \%$ no sabe, no contesta o es neutro.

Ramis ${ }^{3}$ considera que si las diversas estrategias para el control de la enfermedad son aplicadas, las muertes por hidatidosis son evitables. 


\section{Referencias bibliográficas.}

1. Perdomo R, Parada R, Alvarez C, Cattivelli D, Geninazzi H Barragué A, et al. Estudio epidemiológico de hidatidosis. Detección precoz por ultrasonido en áreas de alto riesgo. Rev Med Urug. 1990;6:34-47.

2. Uruguay tiene más de un millón de perros. Zoonosis. 2009;1:10-3

3. Remis JA, Guarnera EA, Parra A. Impacto de la hidatidosis. Influencia de factores ambientales y socioculturales en Tucumán, Argentina. RAR. 2009;73(3):303-12.

4. Turnes A. La hidatidosis como problema de salud pública. Una mirada histórica. Montevideo: Tradinco; 2009. p.96.

5. Larrieu E, Belloto A, Arambulo III P, Tamayo H. Echinococcosis quística: epidemiología y control en América del Sur. Parasitol Latinoam. 2004;59(1-2):82-9.

6. Orlando D. Situación de los países. Uruguay. En: Organización Panamericana de la Salud. Informe del Proyecto Subregional Cono Sur de control y vigilancia de la hidatidosis. Argentina, Chile, Brasil y Uruguay. Primera reunión constitutiva. Montevideo: OPS; 2004. p.39-42

7. Villar H. El inicio de un trabajo conjunto e integrador. Zoonosis. 2009;1:6-7.

8. Paolillo E, Botta B, Cohen H, Dibarboure L, Rodrlguez O, Antoniello L et al. Hidatidosis: un problema de atención primaria en salud. Rev Med Urug. 1991;7:32-7.

9. Giacoia A. Educación: crecimiento, reflexión y acción. Zoonosis. 2009;1:26-8

10. Irabedra P, Ferreira C. Equinococosis quística como un problema de Salud Pública en América Latina. Nuevos enfoques para su control. Zoonosis. 2009;1:33-4

11. Jiménez S, Pérez A, Gil H, Shantz P, Ramalle E, Juste R. Progress in control of cystic echinococcosis in La Rioja, Spain: decline infection prevalences in human and animal hosts and economic costs and benefits. Acta Trop. 2002; 83(3):213-21.

12. Estimación del impacto económico de la equinococosis quística en el Cono Sur (Argentina, Brasil, Chile y Uruguay) 2007 [En línea] Roma, Italia: FAO/RLC; 2007. [Acceso 10 de octubre de 2011]. URL: http://opsoms.org/spanish/ad/dpc/vp/hidatidosis-impacto-econ-07-fao.pdf.

13. Esterilización quirúrgica y desparasitación de canes, ecografías en humanos y educación. Nuestros pilares. Zoonosis. 2011;2:3.

14. Caraballo D. Castración canina. Un proyecto con alta satisfacción de la comunidad. Zoonosis. 2009;1:43

15. Tres pilares fundamentales de la acción de la CNZ. Castración, dosificación y detección precoz. Zoonosis. 2009;1:5.

16. Púrpura R. Tenencia responsable: control zoonótico y protección animal. Zoonosis. 2011;2:10-2.

17. Carballo M. Se instrumentan pasantías de Veterinarios Sanitaristas en Salud Publica. Zoonosis. 2009;1:18-20

18. Comisión de Zoonosis y Facultad de Psicología en acción conjunta para combatir hidatidosis. [En línea] 2009 Montevideo: MSP; 2009. [Acceso 3 de octubre de 2011]. URL: http://www.msp.gub.uy/ ucepidemiologia_2944_1.html

19. Organización Panamericana de la Salud. Informe del Proyecto Subregional Cono Sur de control y vigilancia de la hidatidosis. Argentina, Chile, Brasil y Uruguay. Primera reunión constitutiva. Montevideo: OPS; 2004.

20. Organización Panamericana de la Salud. Informe del Proyecto Subregional Cono Sur de control y vigilancia de la hidatidosis. Argentina, Chile, Brasil y Uruguay. Segunda reunión. Santiago de Chile, Chile: OPS; 2005

21. Organización Panamericana de la Salud. Informe del Proyecto Subregional Cono Sur de control y vigilancia de la hidatidosis. Argentina, Chile, Brasil y Uruguay. Tercera reunión. Porto Alegre, Brasil: OPS; 2006.

22. Organización Panamericana de la Salud. Informe del Proyecto Subregional Cono Sur de control y vigilancia de la hidatidosis. Argentina, Chile, Brasil y Uruguay. Cuarta reunión. San Carlos de Bariloche, Argentina: OPS; 2007 
23. Organización Panamericana de la Salud. Informe del Proyecto Subregional Cono Sur de control y vigilancia de la hidatidosis. Argentina, Chile, Brasil y Uruguay. Quinta reunión. Coyhaique, Chile: OPS; 2008

24. Organización Panamericana de la Salud. Informe del Proyecto Subregional Cono Sur de control y vigilancia de la hidatidosis. Argentina, Chile, Brasil y Uruguay. Sexta reunión. Colonia del Sacramento, Uruguay: OPS; 2009

25. Organización Panamericana de la Salud. Informe del Proyecto Subregional Cono Sur de control y vigilancia de la hidatidosis. Argentina, Chile, Brasil y Uruguay. Séptima reunión. Córdoba, Argentina: OPS; 2010

26. Irabedra P, Salvatella R. El Proyecto Subregional Cono Sur de Control y Vigilancia de la Hidatidosis. Rev Peru Med Exp Salud Publica. 2010;27(4):598-603.

27. Ito A, Urbani C, Jiamin Q, Vuitton DA, Dongchuan $Q$, Heath DD, et al. Control of echinococcosis and cysticercosis: a public health challenge to international cooperation in China. Acta Trop. 2003;86(1):3-17.

28. Heath D, Lawrence S. Antigenic polypeptides of Echinococcus granulosus oncospheres and definition of protective molecules. Parasite Immunol. 1996;18(7):347-57.

29. Lightowlers M, Lawrence S, Gauci C, Young J, Ralston M, Maas D, et al. Vaccination against hydatidosis using a defined recombinant antigen. Parasite Immunol. 1996;18(9):457-62.

30. Lightowlers MW, Jensen O, Fernández E, Iriarte JA, Woollard DJ, Gauci CG, et al. Vaccination trials in Australia and Argentina confirm the effectiveness of the EG95 hydatid vaccine in sheep. Int J Parasitol. 1999;29(4): 531-4.

31. Heath DD, Jensen O, Lightowlers MV. Progress in control of hydatidosis using - a review of formulation and delivery of the vaccine and recommendations for practical use in control programmes. Acta Trop. 2003;85(2):133-43.

32. Heath D, Holcman B, Shaw R. Echinococcus granulosus: the mechanism of oncosphere lysis by sheep complement and antibody. Int J Parasitol. 1994;24(7):929-35.

33. Jensen O, Fernández E, Fernández R, Iriarte J, Sánchez P, Lightowlers M, et al. Inmunización del hospedero intermediario. Su utilización en programas de control. Jornadas Nacionales de Hidatidosis - 2das Jornadas Provinciales de Hidatidosis. Esperanza, Santa Fé, Argentina. 2003.

34. Torgerson P. The use of mathematical models to simulate control options for echinococcosis. Acta Trop. 2003;85(2):211-21.

35. Cabrera P, Lloyd S, Haran G, Pineyro L, Parietti S, Gemmell M, et al. Control of Echinococcus granulosus in Uruguay: evaluation of different treatment intervals for dogs. Vet Parasitol. 2002;103(4):333-40.

36. Torgerson P, Carmona C, Bonifacino R. Estimating the economic effects of echinococcosis: Uruguayan upper middleincome developing country. Ann Trop Med Parasitol. 2000;94(7):703-13.

37. Irabedra P, Elola S. Estrategias para la vigilancia, control y prevención de la equinococosis quística en áreas de riesgo. Zoonosis. 2011;2:13-6.

38. Giacoia A. El promotor de salud en zoonosis. Zoonosis. 2011;2:40-1. 


\section{CAPÍTULO 16}

\section{Marco legal}

Ante la necesidad de actualizar el Código Nacional sobre Enfermedades y Eventos Sanitarios de Notificación Obligatoria, el Poder Ejecutivo promulgó en el año 2004 el Decreto 64/004. En este se establece su lista completa, organizándose en dos grupos A y B de acuerdo a los plazos para su declaración a la Unidad de Vigilancia Epidemiológica del Ministerio de Salud Pública. La hidatidosis se incluye en el lugar número 12 del grupo B, para lo cual el plazo es de una semana a partir de la sospecha de la enfermedad mediante comunicación telefónica, fax, telegrama, correo, correo electrónico o personalmente.

Su artículo 3 establece la responsabilidad de la declaración:

3.1.» Médicos y médicos veterinarios en el ejercicio libre de su profesión o en relación laboral de dependencia.

Directores técnicos de hospitales o instituciones de asistencia públicos, privados o de cualquier tipo. Si el establecimiento o servicio no tuviera director técnico, está obligado a hacer la declaración el funcionario de mayor autoridad del mismo.

Otros técnicos profesionales de la salud y personal sanitario de todas las categorías.

Directores técnicos de laboratorios de análisis y bancos de sangre.

Médicos responsables de internados, comunidades, campamentos y similares.

3.2. Directores de escuelas y liceos y otros establecimientos de enseñanza públicos o privados.

Mandos de establecimientos y dependencias de las fuerzas armadas.

Capitanes de buques y aeronaves.

Cualquier ciudadano que tenga conocimiento o sospecha de la ocurrencia de una enfermedad o circunstancia que pueda significar riesgo para la salud pública».

Con respecto a las sanciones su artículo 13 establece:

«La omisión de la notificación oportuna y de acuerdo a lo dispuesto por el presente Código por parte de las personas que determina el mismo en el artículo $3^{\circ}$ en su numeral 3.1, la autoridad sanitaria deberá radicar la denuncia penal de acuerdo con el artículo 224 del Código Penal. La omisión de la notificación oportuna y de acuerdo a lo dispuesto por el presente Código por parte de las personas que determina el mismo en el artículo $3^{\circ}$ en su numeral 3.2, será pasible de las sanciones administrativas o las que correspondan de acuerdo con las disposiciones legales vigentes».

Su omisión es un delito contra la salud pública, y en tal sentido el Código Penal en su artículo 224 Violación de las disposiciones sanitarias establece: «El que violare las disposiciones publicadas por la autoridad competente para impedir la invasión de una enfermedad epidémica o contagiosa será castigado con tres a veinticuatro meses de prisión. Por lo tanto en estas situaciones no existe violación del secreto médico, ya que existe una justa causa legalmente prescripta».

Berlangieri ${ }^{1}$ cuando aborda la responsabilidad del equipo de salud por incumplimiento de normas y recomendaciones del Ministerio de Salud Pública, lo hace tomando como referencia el artículo 44 de la Constitución de la República. El mismo establece: «El Estado legislará en todas las cuestiones relacionadas con la salud e higiene públicas, procurando el perfeccionamiento físico, moral y social de todos los habitantes del país».

El precitado autor considera que el concepto de legislar debe ser interpretado de una forma muy amplia, no sólo la legislación, llamada ley concretamente, sino también el decreto reglamentario o la ordenanza, deben ser entendidos dentro de este tipo de especificaciones. 
El Estado regula y establece determinado tipo de comportamientos o de noticia que debe dársele al Ministerio de Salud Pública. En este sentido hay dos vertientes en función de las cuales esto se cumple; un área pública y otra privada.

El personal de la salud pública, está sometido desde el punto de vista jurídico-administrativo al estatuto del funcionario público.

El funcionario público comete faltas. La no comunicación por parte del técnico del Ministerio de Salud Pública de la presencia de alguna enfermedad que está específicamente catalogada y dentro de los plazos en los cuales están establecidos, constituyen una falta de tipo administrativo sancionable, como tal, a través de la disposición del decreto 500 de 1991.

Berlangieri ${ }^{1}$ establece con respecto a la falta: «la falta susceptible de sanción disciplinaria es todo acto u omisión del funcionario que intencionalmente oculta o no refiere a su superior la existencia de los deberes funcionales de dar cuenta de la existencia de este tipo de patología».

Este autor considera que la forma de comunicación tiene que ser institucional y jerarquizada. Desde el punto de vista de la jerarquía se tiene que dar la noticia al jerarca más directo del establecimiento, como puede ser el director y, en ese caso, es el director quien comunica.

Con respecto a la actividad privada la situación es diferente. Aquí no se comete una falta, la que sería factible de sanción sería la institución al no dar cuenta de la existencia de esa patología dentro de su establecimiento. Aquí se diluye el aspecto administrativo público para convertirse en un relacionamiento privado entre la Institución de Asistencia Médica Colectiva y el Ministerio de Salud Pública.

En la actividad privada, en la medicina de consultorio, parecería ser que el médico tiene que hacer la denuncia personal. Sería en el único caso en el cual el médico personalmente tiene que hacer este tipo de comunicaciones.

En base a estas apreciaciones, ¿cuál sería la responsabilidad del equipo de salud cuando no se cumplen las normas?

Según Berlangieri ${ }^{1}$ es que en todo equipo sanitario hay un solo responsable que es la cabeza visible. Podrá haber algún tipo de responsabilidad compartida, pero siempre hay alguien que es el responsable.

Por último no existe ningún tipo de responsabilidad civil al no comunicar este tipo de situaciones al Ministerio de Salud Pública, dado que la responsabilidad civil está edificada sobre otros pilares: el daño, la culpa, donde este aspecto, que es eminentemente administrativo, no tiene prácticamente injerencia. se define:

Según el Código Nacional sobre Enfermedades y Eventos Sanitarios de Notificación Obligatoria,

\section{Caso sospechoso:}

Debe sospecharse un caso de Hidatidosis frente al hallazgo de elementos quísticos (únicos ó múltiples) localizados en hígado, pulmón u otros órganos.

Aunque la vinculación del caso con aspectos epidemiológicos (áreas endémicas, trabajador rural, etc.) debe tomarse en cuenta cuando existen, su ausencia no excluye la sospecha diagnóstica.

\section{Caso confirmado:}

Caso sospechoso de Hidatidosis confirmado por:

Serología: prueba de alta sensibilidad (ELISA o HAI) y confirmación con prueba de alta especificidad (DD5)

Visualización de escólex eliminado a partir de un quiste o quiste fistulizado al exterior.

Confirmación post-quirúrgica por radiografía, ecografía o tomografía. 


\section{Bibliografía consultada.}

Código Nacional sobre Enfermedades y Eventos Sanitarios de Notificación Obligatoria. Decreto 64/ 004. [En línea]. [Acceso 3 de octubre de 2011] URL: http//:www.bvsd.paho.org/bvsacd/cd38/Uruguay/ d64-04.pdf.

Código Penal de la República Oriental del Uruguay. [En línea] [Acceso 3 de octubre de 2011] URL: http//:www0.parlamento.guy.uy/codigos/codigopenal/cod-pen.htm

Constitución de la República Oriental del Uruguay. Constitución 1967 con las modificaciones plebiscitadas el 26 de noviembre de 1989, el 26 de noviembre de 1994, el 8 de diciembre de 1996 y el 31 de octubre de 2004. [En línea] [Acceso 3 de octubre de 2011] URL:

http//:www0.parlamento.gub.uy/constituciones/const004.htm.

Decreto 500/91. [En línea] [Acceso 3 de octubre de 2011] URL: http//:www0.parlamento.gub.uy/ decreto500/decr500.htm.

Referencias bibliográficas.

1. Berlangieri CM. Responsabilidad del equipo de salud por incumplimiento de normas y recomendaciones del MSP. [En línea]. Montevideo;2001. [Acceso 18 de setiembre de 2011]: [aprox 1p.]. URL: http://www.elderechodigital.com.uy/smu/doctri/SDMD0014.html. 